\title{
Exploring outcomes of children and young people in kinship care in South Wales
}

\author{
Pratchett, Rebecca
}

How to cite:

Pratchett, Rebecca (2018) Exploring outcomes of children and young people in kinship care in South Wales. Doctoral thesis, Swansea University.

http://cronfa.swan.ac.uk/Record/cronfa45015

Use policy:

This item is brought to you by Swansea University. Any person downloading material is agreeing to abide by the terms of the repository licence: copies of full text items may be used or reproduced in any format or medium, without prior permission for personal research or study, educational or non-commercial purposes only. The copyright for any work remains with the original author unless otherwise specified. The full-text must not be sold in any format or medium without the formal permission of the copyright holder. Permission for multiple reproductions should be obtained from the original author.

Authors are personally responsible for adhering to copyright and publisher restrictions when uploading content to the repository.

Please link to the metadata record in the Swansea University repository, Cronfa (link given in the citation reference above.)

http://www.swansea.ac.uk/library/researchsupport/ris-support/ 
Exploring outcomes of children and young people in kinship care in South Wales.

\author{
Rebecca Pratchett
}

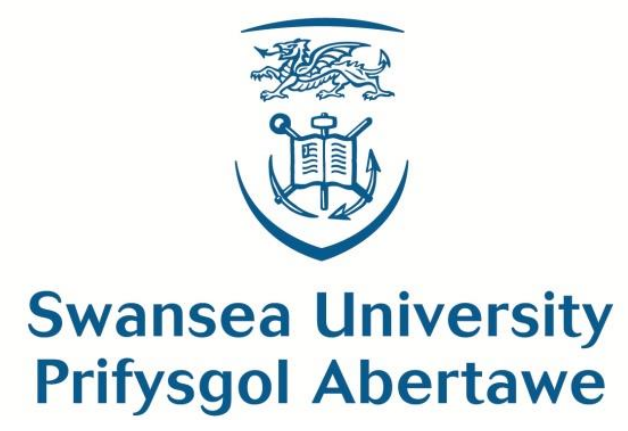

Submitted to Swansea University in fulfilment of the requirements for the programme of Doctor of Philosophy.

Swansea University

2017 


\section{Abstract}

Around 30,000 young people enter care every year, with more than a fifth of those being placed with a relative or close family friend in kinship care. Literature has suggested that kinship care may be a positive avenue for providing alternative out-of-home care to young people in a cost-effective manner. However, some studies have pointed to systematic challenges in formalising kinship care, which threatens to undermine the benefits of a family-based placement. These include permanency options such as Special Guardianship Orders (SGOs). This study will explore some of the outcomes of formal kinship care placements.

The objective of this thesis is to explore the implications of a theoretical shift from formal care toward a kinship model via three study aims: to explore factors affecting stability within kinship care; to assess the relative wellbeing of young people in kinship care who are looked after; and to assess the educational achievement of looked after young people in kinship care.

The study employs a mixed design comprised of two phases. Phase One explores the destination of early care leavers $(n=271)$ of whom 71 were in kinship care and care leavers 'aging out' $(n=48)$ of whom three were in kinship care. The exploration was comprised of a case file audit in two local authorities with followup of medium-term placement outcomes for early care leavers (12 months) and those aging out of care (18 months). Phase two explores the impact of kinship care on young people and kinship carers. Standardised measures explored the mental health, emotional literacy, attachment, cognitive skills, literacy and numeracy of young people. Bespoke questionnaires captured quantitative and qualitative data regarding placement characteristics and viewpoints from young people in kinship care $(n=21)$, their carers $(n=24)$, and their social workers $(n=21)$. These areas were further explored via semi-structured interviews with each participant and a focus group of supervising social workers $(n=4)$.

Results from phase one indicate that pre-leaving care placement type had an effect on the post-care destination of young people leaving care early and that SGOs are stable in the medium-term. Phase two results demonstrated that kinship care is beneficial for the mental health and attachment of young people 
within the care system. The study also found kinship care to be advantageous in maintaining a strong personal and family identity. The study reports novel data on the educational attainment of young people in formal kinship care finding that children are achieving at an appropriate level as predicted by cognitive ability. However, attempts to regulate formal kinship placements from within the current model has created hardship for kinship carers, has led to feelings of intrusion and undermined the concept of family.

This thesis posits that it is crucial that the social work system adapts to incorporate the differing needs of kinship carers rather than attempting to shoehorn a family unit into a professionalised care model. The concept of a dual model of social care, in which foster placements and kinship placements are treated as inherently different, is discussed in relation to modern social work practice. 
"Ohana means family.

Family means nobody gets left behind or forgotten."

(Spencer, Sanders, \& DeBlois, 2002) 


\section{Contents}

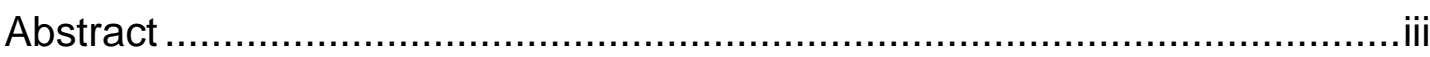

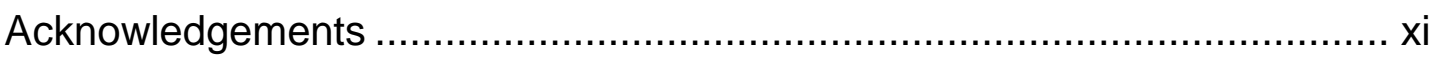

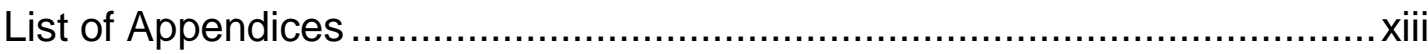

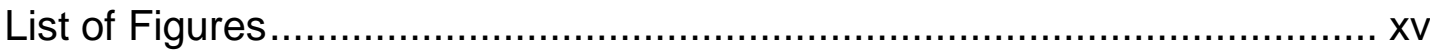

List of Tables ...................................................................................

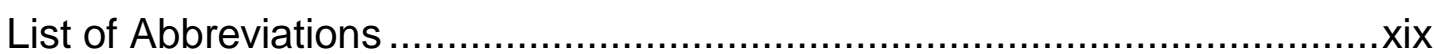

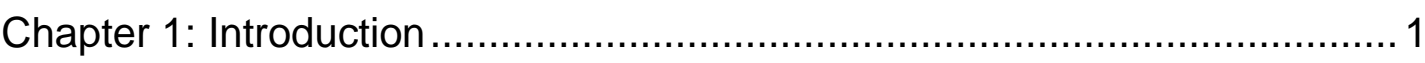

1.1 Thesis objective, aims and research questions. ................................ 8

Chapter 2: Literature review: empirical literature and policy ........................ 12

2.1 Defining kinship care............................................................... 14

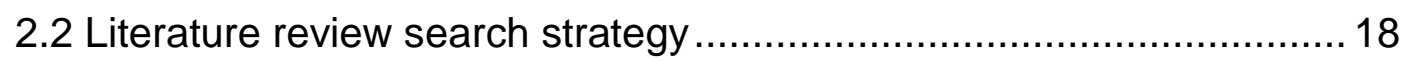

2.3 History of Kinship Care .............................................................. 19

2.3.1 Trends in social work policy, practice \& research....................... 19

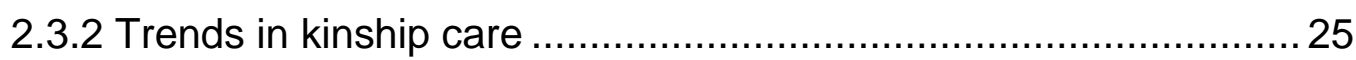

2.3.3 Kinship care in the United Kingdom ...................................... 27

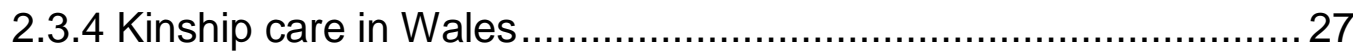

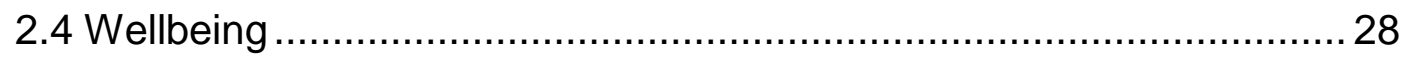

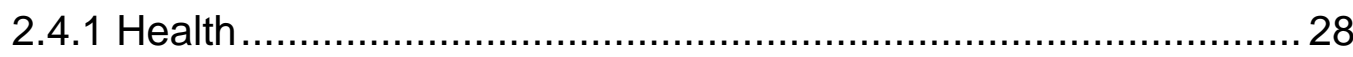

2.4.1.1 Physical health of children and young people in kinship care ...30

2.4.1.2 Physical health of kinship carers ............................................... 36

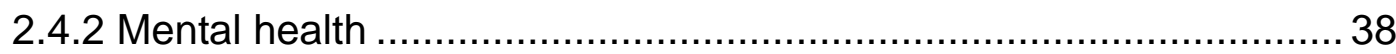

2.4.2.1 Mental ill health and accessing healthcare .............................. 38

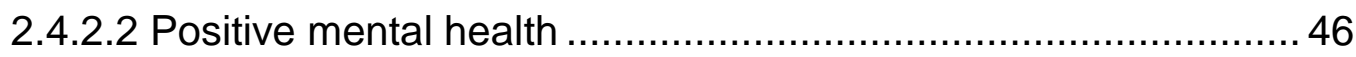

2.4.2.3 Assessing mental health and mental illness ............................ 46

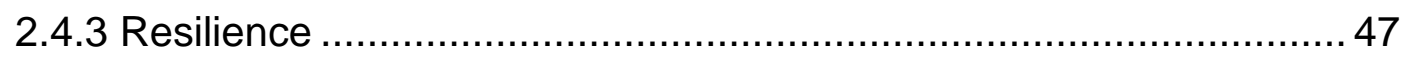

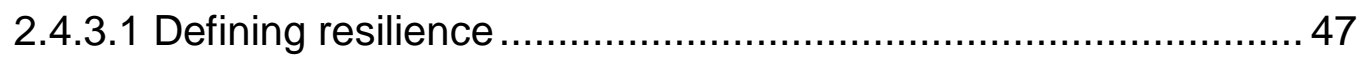

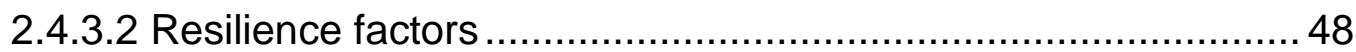

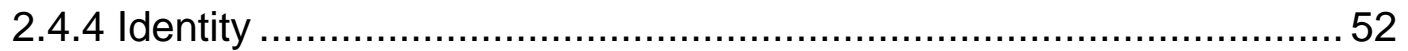

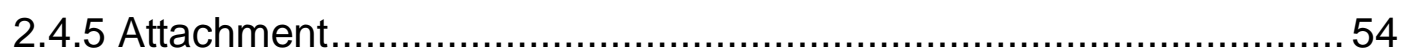

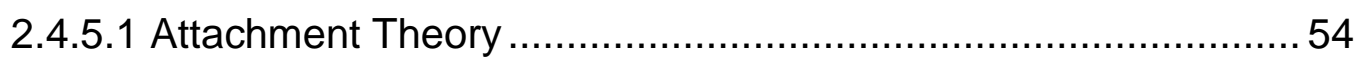

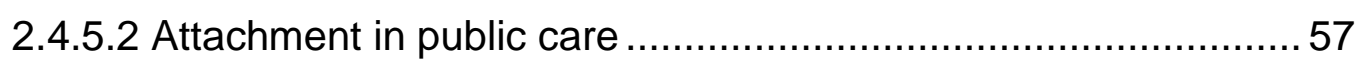

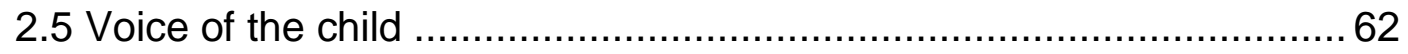

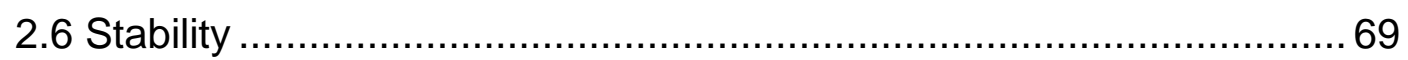




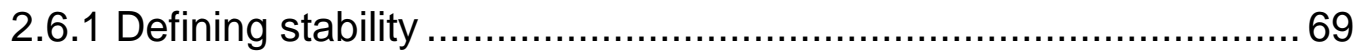

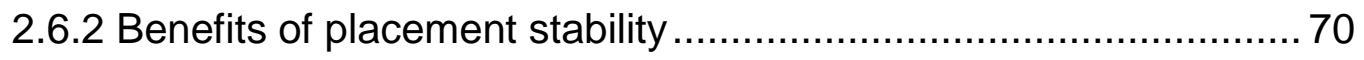

2.6.3 Stability and barriers to stability in kinship care .......................... 72

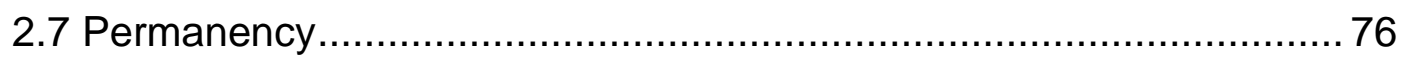

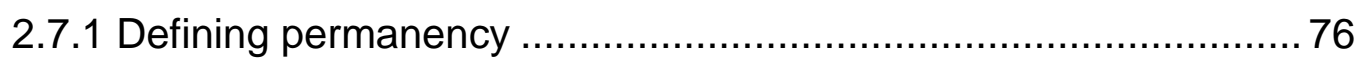

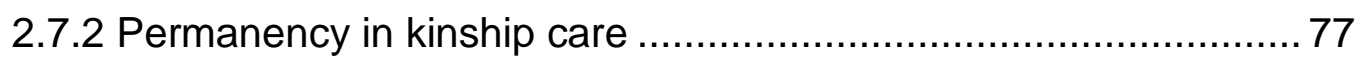

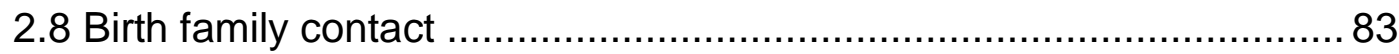

2.8.1 Birth family contact in foster care ........................................... 84

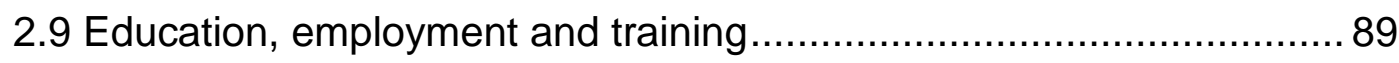

2.9.1 Academic performance ......................................................... 90

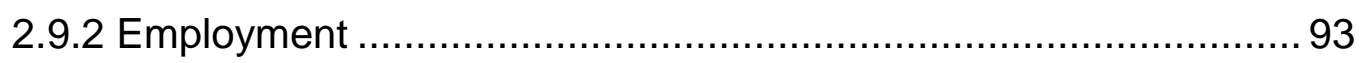

Chapter 3: Literature review: theoretical underpinning of kinship care .........98

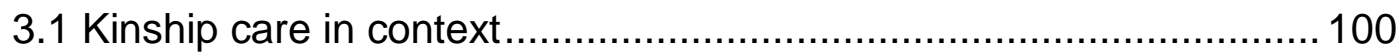

3.2 Structural-functional theory and the evolution of social care work. ... 104

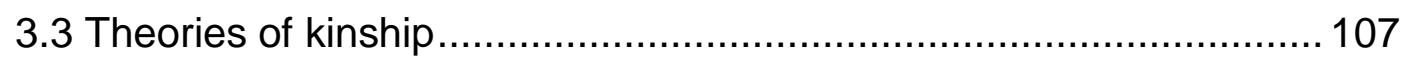

3.4 The interaction of social work and kinship ................................... 112

3.5 Thesis objectives, aims and research questions........................... 117

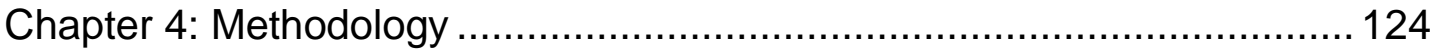

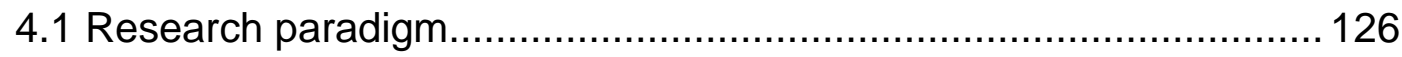

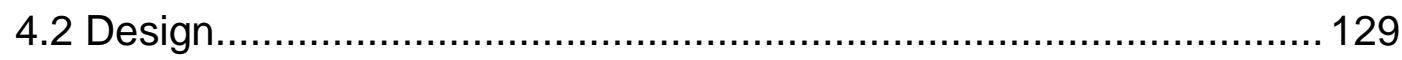

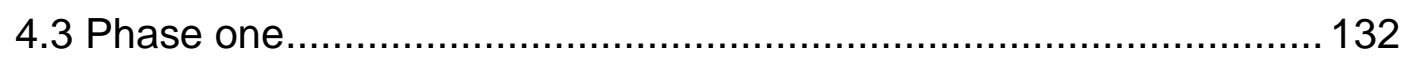

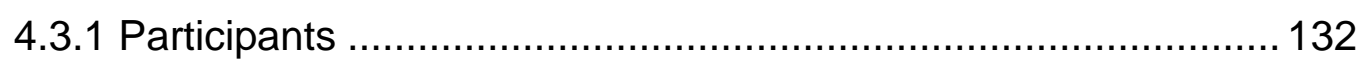

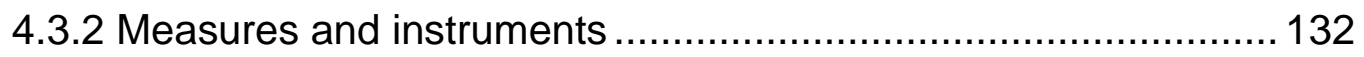

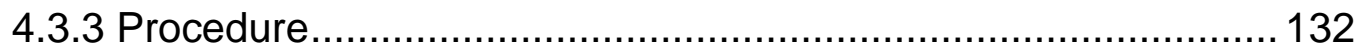

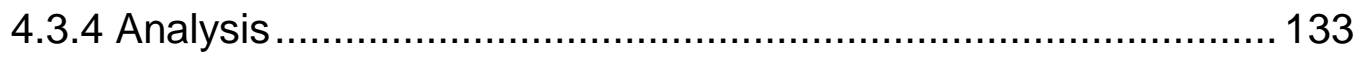

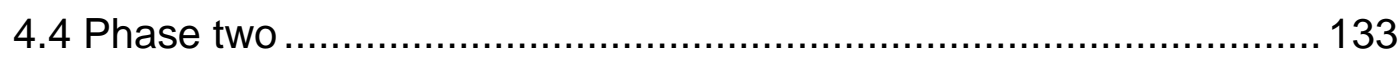

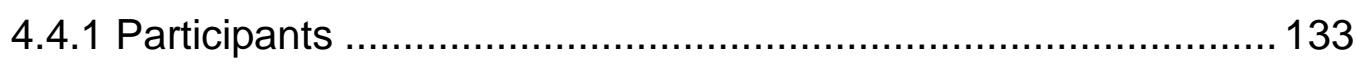

4.4.2 Measures/ instruments (phase two) …..................................... 138

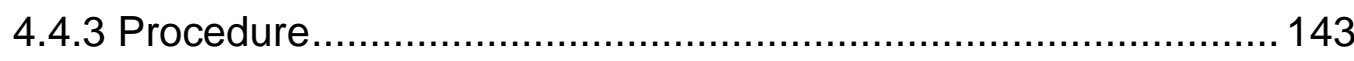

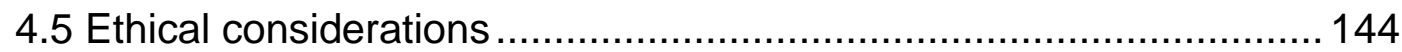

4.6 Access and institutional authorisation......................................... 145

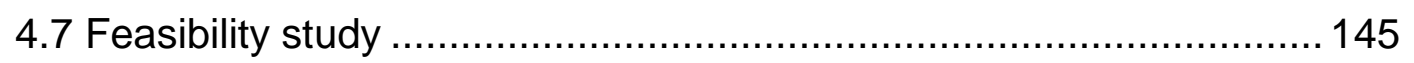

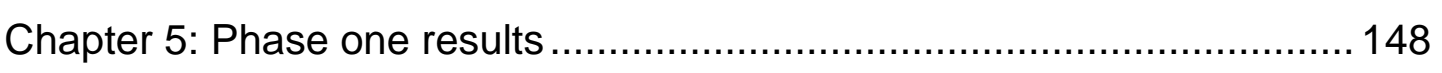




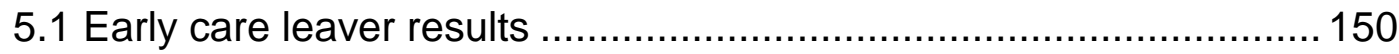

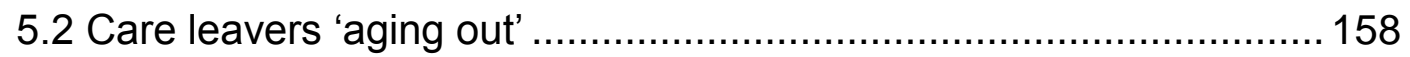

Chapter 6: Phase two quantitative results ............................................... 162

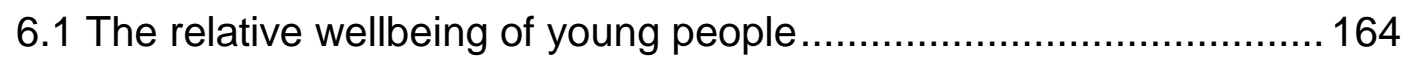

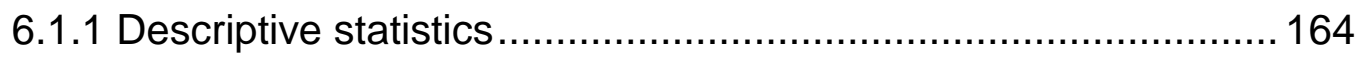

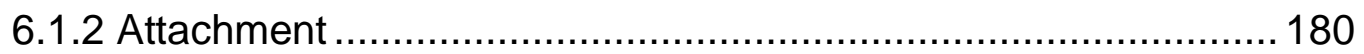

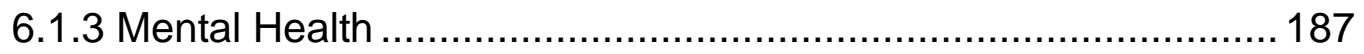

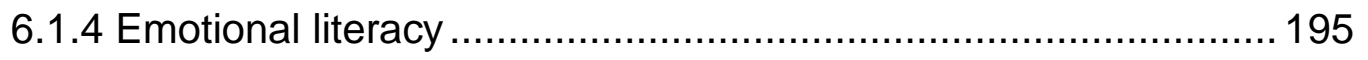

6.2 The educational achievement of young people................................201

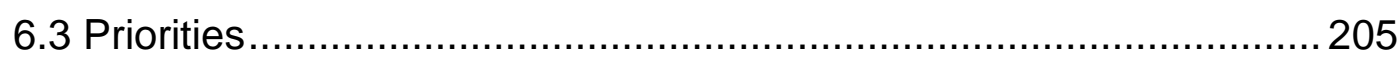

Chapter 7: Phase two qualitative results ................................................206

7.1 Benefits of kinship care .................................................................... 210

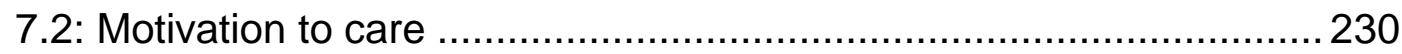

7.3: Mixed advantages and disadvantages .......................................... 240

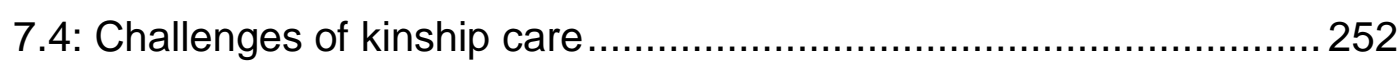

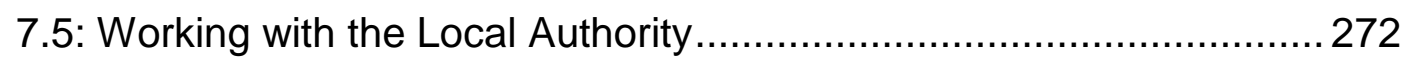

7.6: Special Guardianship Orders.................................................... 286

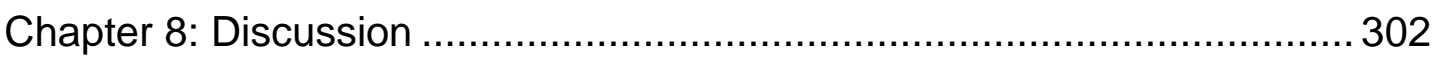

8.1 Stability and permanency in kinship care ....................................... 302

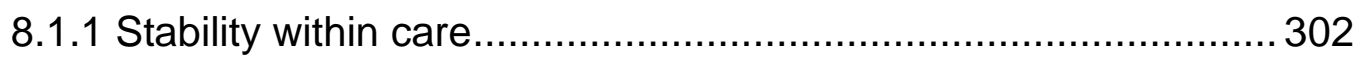

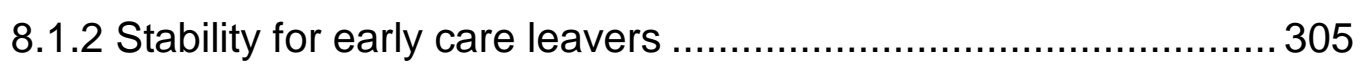

8.1.3 Permanency for early care leavers ........................................... 307

8.1.4 Stability for young people 'aging out' of care .............................. 311

8.2 The relative wellbeing of young people in kinship care ..................... 313

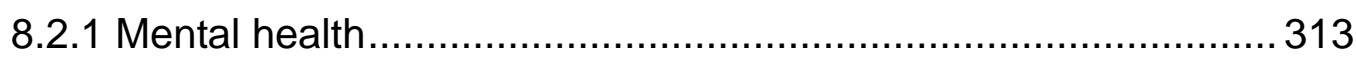

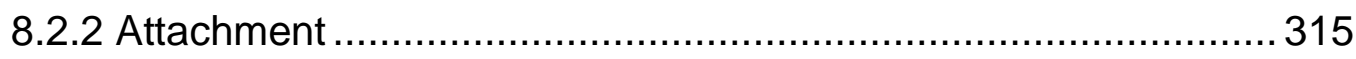

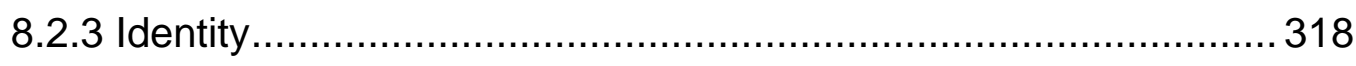

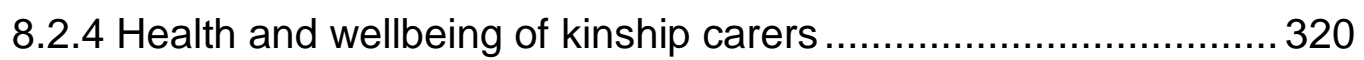

8.3 Educational achievement in kinship care ....................................... 322

8.4 Family, hardship and the professionalisation of kinship care ............ 325

8.4.1 Family \& the acceptance of hardship ...................................... 325

8.4.2 Professionalisation of kinship care ......................................... 328

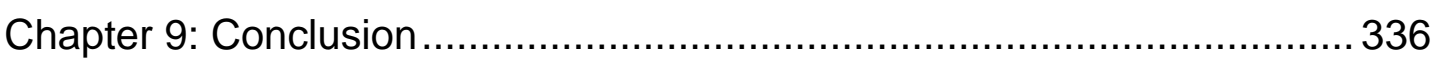




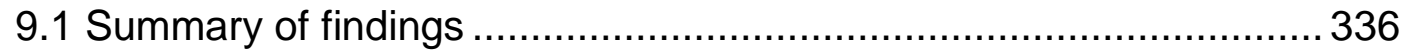

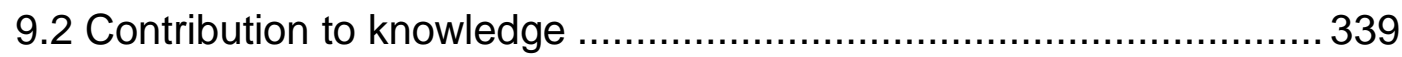

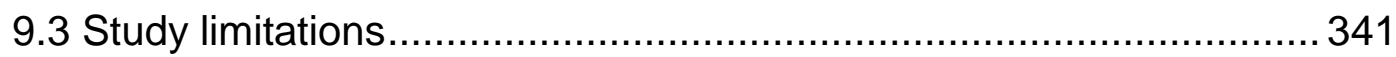

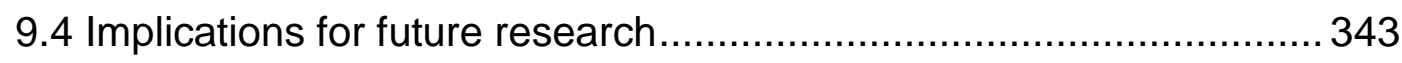

9.5 Implications for policy and practice .............................................. 344

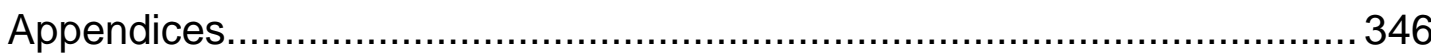

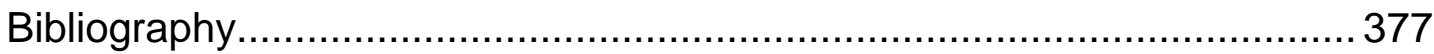




\section{Acknowledgements}

The loneliness of a PhD journey is well documented. In that regard, I feel blessed that I rarely felt lonely as I embarked upon my own journey. Despite the isolation of writing, there was always a cup of tea and company to turn to. For this I have more people to thank than I could mention, but I would like to formally express my gratitude to a select few.

Foremost the project funding partners, the ESRC Wales Doctoral Training Centre, and the two Local Authority Partners, without whom the project would have been impossible.

Thank you to my supervisor, Paul Rees, for keeping me on track and advising, correcting, proofing, and scrutinising my thesis. I feel I have learned a lot whilst preparing and writing my thesis and am grateful for your guidance every step of the way.

I would like to thank the managers and staff of the two Local Authority Partners for answering every question I had (no matter how foolish) and providing support throughout the project. Despite the multiple demands on their time, they always made the time to facilitate this thesis for which I am eternally grateful.

I owe a great deal to the University's administrative staff, namely Maria Davies, who after four years with me around will no doubt be reconsidering her open door policy.

I would like to express my thanks to the kinship carers and young people who participated in this project. Thank you for inviting me to share in your stories and I sincerely wish each and every one of you a bright future.

To my family and friends, old, new, home and abroad and too numerous to name: thank you for your support. Without you all, this truly would have been a lonely journey. 


\section{List of Appendices}

Appendix 1: Interview questions - Children and young people in kinship care Appendix 2: Interview questions - Kinship carers

Appendix 3: Interview questions - Social workers Appendix 4: Ethical approval

Appendix 5: Kinship Carer Questionnaire

Appendix 6: Children and Young People Questionnaire

Appendix 7: Social Worker Questionnaire

Appendix 8: Results of literature database search (Table 39)

Appendix 9: Order of administration of measures (children and young people)

Appendix 10: Order of administration of measures (kinship carers)

Appendix 11: Order of administration of measures (social workers)

Appendix 12: Qualitative data analysis

Appendix 13: Qualitative data analysis

Appendix 14: Young Person Qualitative Themes

Appendix 15: Kinship Carer Qualitative Themes

Appendix 16: Social Worker Qualitative Themes 


\section{List of Figures}

Figure 1: Thematic analysis procedure (as in Braun and Clarke, 2006).... 131

Figure 2: The distribution of early leavers pre-leaving placement type....... 151

Figure 3: The initial destination of early care leavers. ............................. 152

Figure 4: Early care leaver destination by final care placement type $(n=271) .153$

Figure 5: Percentage of special guardians receiving formal support by pre-

leaving placement care order

Figure 6: The post-care destinations over 12-months of care leavers aging out $(\mathrm{n}=48)$. 159

Figure 7: Number of kinship and foster care leavers remaining with carer over a 12-month post-care period. 160

Figure 8: The primary occupation of kinship carers $(n=23)$..................... 165

Figure 9: Percentage of kinship carers whose annual household income is above and below the mean annual salary for a full time worker in Wales $(n=13)$

Figure 10: The relationship status of Kinship Carers $(n=24) \ldots \ldots \ldots \ldots \ldots \ldots . \ldots 167$

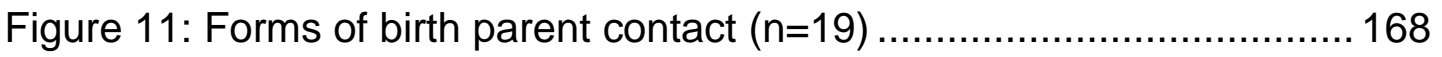

Figure 12: Z score calculation showing the differences between the kinship care group and the general population with regards to attachment to peers, kinship carers and parents. 181

Figure 13: Total attachment scores of young people in kinship care and the general population to primary caregivers and parents. 183

Figure 14: The relationship between placement length (years) and attachment to birth parent. 186

Figure 15: Scatterplot showing the linear relationship between emotional literacy and total difficulties scores. 199

Figure 16: Comparison of achievement on each of the three educational domains. 202 


\section{List of Tables}

Table 1: Participation and attrition rates of eligible young people............... 136

Table 2: Participation and attrition rates of eligible kinship carers.............. 136

Table 3: Reasons for non-participation of young people. ......................... 137

Table 4: Participation and attrition rates of eligible social workers. ............ 137

Table 5: Pre-leaving placement and average age by $L A$....................... 150

Table 6: Types of support offered to Special Guardians of young people leaving

care early by final care placement type.............................................. 156

Table 7: Kinship Carer Demographic Information.................................. 164

Table 8: Average current and historic kinship caseload for social workers $(n=21)$

Table 9: Young peoples' perceptions of control over changes to contact... 169

Table 10: Kinship Carers' perceptions of control over changes to contact 170

Table 11: Social Workers' perceptions of control over changes to contact 170

Table 12: People perceived to have the most influence over changes to contact

171

Table 13: Young people's perceptions of permanency and the future........ 172

Table 14: Kinship carers' perceptions of permanency and the future .......... 172

Table 15: Social Workers' perceptions of permanency and the future ....... 173

Table 16: Kinship carers' weighted priorities in placement ....................... 174

Table 17: Young people's feelings about school ................................... 175

Table 18: The career aspirations of young people in kinship care $(n=21)$.. 176

Table 19: Qualification requirements of career aspirations of young people in

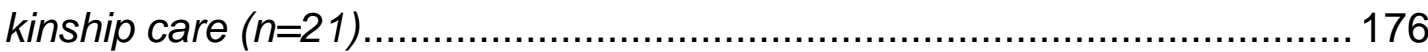

Table 20: Kinship carers' feelings about education ................................ 176

Table 21: The extent to which young people in kinship care feel that they are listened to $(n=21)$........................................................................ 177

Table 22: Free response by young people regarding who listens to them 178 Table 23 : Weighted rank of things that are important to young people in kinship

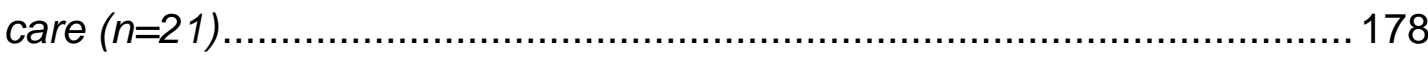

Table 24: Total Attachment scores on the IPPA-R by gender. ................... 180

Table 25 : Kinship Vs. Mainstream foster care: prevalence of clinically significant self-reported difficulty ..................................................... 188

Table 26 : Kinship Vs. Mainstream foster care: prevalence of clinically significant carer-rated difficulty ........................................................ 190 Table 27 : Child self- rated difficulties compared with general population norms.

Table 28: Z scores for child self-rated difficulties compared with general population norms.

Table 29: Kinship carer rated difficulties compared with general population parent norms. 
Table 30: Z scores for carer rated difficulties compared with general population norms. 193

Table 31: Self and kinship carer-rated averages of Emotional Literacy...... 196 Table 32: Comparison of self-reported and carer-reported emotional literacy diagnostic bandings with general population norms.

Table 33 : Literacy and numeracy standardised test scores $(n=21)$ 201

Table 34 : Sample standardised test scores against the wider care population 204

Table 35: Caring priorities: highest three ranked items by group. 205

Table 36: Primary findings, research questions 1-7 297

Table 37: Primary findings, research questions 8-18 298

Table 38: Primary findings, research questions 19-21 299

Table 39: Results of literature database search 366 


\section{List of Abbreviations}

$\begin{array}{ll}\text { AO } & \text { Adoption Order } \\ \text { BAS II } & \text { British Achievement Scale - Second Edition } \\ \text { BFC } & \text { Birth Family Contact } \\ \text { BME } & \text { Black and Minority Ethnic } \\ \text { CAMHS } & \text { Child and Adolescent Mental Health Service } \\ \text { CAO } & \text { Child Arrangement Order } \\ \text { CH } & \text { Care Home } \\ \text { CIN } & \text { Child In Need (register) } \\ \text { CSEW } & \text { Crime Survey for England and Wales } \\ \text { Cus } & \text { Custody } \\ \text { DfES } & \text { Department for Education and Skills } \\ \text { DNA } & \text { Deoxyribonucleic Acid } \\ \text { DV } & \text { Domestic Violence } \\ \text { ECM } & \text { Every Child Matters } \\ \text { EHA } & \text { Event History Analysis } \\ \text { ELA } & \text { Emotional Literacy Assessment } \\ \text { ELAIl } & \text { Emotional Literacy Assessment and Intervention Inventory } \\ \text { ESRC } & \text { Economic and Social Research Council } \\ \text { FCO } & \text { Full Care Order } \\ \text { FSIQ } & \text { Full Scale Intelligence Quotient } \\ \text { GCSE } & \text { General Certificate of Secondary Education } \\ \text { ICO } & \text { Interim Care Order } \\ \text { IL } & \text { Independent Living } \\ \text { IPPA-R } & \text { Inventory of Parent and Peer Attachment- Revised } \\ \text { IQ } & \text { Intelligence Quotient } \\ \text { IRO } & \text { Independent Reviewing Officer } \\ \text { IT } & \text { Information Technology } \\ \text { KC } & \text { Kinship Carer } \\ \text { LA } & \text { Local Authority } \\ \text { LAC } & \text { Looked After Child } \\ \text { NFA } & \text { No Fixed Abode } \\ \text { NHS } & \text { National Health Service } \\ \text { NK } & \text { Not known } \\ \text { NSPCC } & \text { National Society for the Prevention of Cruelty to Children } \\ \text { OAP } & \text { Other Associated Person } \\ \text { ONS } & \text { Office for National Statistics } \\ \text { PARIS } & \text { Public Assistance Reporting Information System } \\ \text { PO } & \text { Principal Officer } \\ \text { PR } & \text { Parental Responsibility } \\ \text { PWP } & \text { Placed with Parents (regulations) } \\ \text { RO } & \text { Residence Order } \\ \text { RQ } & \text { Research Question } \\ \text { RTP } & \text { Return to Parental Home } \\ \text { RWC } & \text { Remain with carer } \\ \text { S2O } & \text { Section 20 Care Order } \\ \text { SDQ } & \text { Strength and Difficulties Questionnaire } \\ \text { SGO } & \text { Special Guardianship Order } \\ \text { SL } & \text { Supported Lodgings } \\ & \\ & \end{array}$




$\begin{array}{ll}\text { SO } & \text { Supervision Order } \\ \text { SSW } & \text { Supervising Social Worker } \\ \text { SW } & \text { Social Worker } \\ \text { UK } & \text { United Kingdom } \\ \text { UNCRC } & \text { United Nations Convention on Rights of the Child } \\ \text { USA } & \text { United States of America } \\ \text { WASI-II } & \text { Wechsler Abbreviated Scale of Intelligence - Second Edition } \\ \text { WHO } & \text { World Health Organisation } \\ \text { WIAT-II-A } & \text { Wechsler Individual Achievement Test - Second Edition - } \\ & \text { Abbreviated } \\ \text { WIMD } & \text { Welsh Index of Multiple Deprivation } \\ \text { WISC-IV } & \text { Wechsler Intelligence Scale for Children - Fourth (UK) Edition } \\ \text { WOS } & \text { Web of Science } \\ \text { YOI } & \text { Young Offenders Institute } \\ \text { YP } & \text { Young Person }\end{array}$


Chapter 1: Introduction 


\section{Chapter 1: Introduction}

At any one time in the United Kingdom (UK), around 90,000 children and young people will be in the care of their Local Authority (LA). This number continues to grow steadily, and has now reached a twenty-year high (Eichler, 2016). The rise in social work cases has risen so rapidly that the President of the Family Division, Sir James Munby, stated "We are facing a crisis and, truth be told, we have no very clear strategy for meeting the crisis" (Munby, 2016). Now with a shortage of foster carers and a vulnerable population requiring out-of-home care, local authorities are seeking alternatives to the mainstream foster care system.

One alternative approach has been to place young people with extended family or close family friends in what is known as kinship care. Theorised to protect the cultural and social identity of the child, it is thought to be an affordable yet effective means of providing care to young people when their parents are unwilling or incapable of doing so. Some international studies have offered empirical evidence to support this theory, although methodological and sampling limitations present challenges when generalising such results to the UK population. With the demand for out-of-home placements ever-present and with local authority budgets being reduced, it is vital that we understand the benefits and risks of a kinship placement. Furthermore, previous research has indicated that the physical and emotional health, and education outcomes of young people in the care system are below that of their peers in the general population. With interventions now being targeted towards vulnerable looked after youth, it is crucial that we consider the effects that the increasing use of kinship placements may have on young people.

Many of the issues surrounding kinship care revert to an age-old debate regarding the extent to which the State should interfere in, or be held responsible for, the private family unit. In Wales, this debate is exacerbated by the requirement for kinship carers to register as foster carers in order to care for a 'Looked After Child'. This generates a duality in which the carer's role is both that of a private family and a professional carer. Distinguishing the two can be problematic. On the one hand they are family, providing care for a vulnerable 
young person due to an emotional, social or cultural connection. On the other they are professional foster carers, registered with a local authority and bound by many of the same restrictions as their mainstream counterparts. Achieving a balance between the two roles is undoubtedly difficult, not only for the carers themselves but also for the LAs. One area where this debate is evident is payment. Kinship carers are eligible to receive discretionary payment from the local authority in order to facilitate the care of the child. Often this takes the form of an allowance which is paid to the carer and based upon the specific age and needs of the child. However, unlike their counterparts in mainstream foster care, kinship carers are generally not provided with a wage or salary in payment for the labour incurred by caring responsibilities.

Whilst it is a contentious issue across the UK as a whole, in Wales, where registering as a foster carer is mandatory, the debate appears to be highly relevant. Some argue that if we expect kinship carers to meet the same standards at assessment, and to provide the same intensity of care to vulnerable young people as mainstream carers, then we should be prepared to pay them to do so. This is the approach that is being rolled-out in Scotland with the Scottish Government pledging £10.1million to local councils in order to facilitate the payment of kinship carers (Scottish Government, 2016). For the charities and Non-Governmental Organisations (NGOs) who have campaigned for equality, this is a significant victory. However, in doing so, there is concern that kinship care, an approach characterised by the emotional and social motivations of kinship carers, will increasingly become a professionalised service. In doing so, the very principles of a kinship placement may be undermined.

Other areas of social care are becoming more professionalised, as evidenced by a recent vote in favour of unionising mainstream foster carers (Coleman, 2016). The unionisation of foster care represents a bold advancement in the way in which social care is understood. Traditional mainstream foster carers are now demanding recognition as employees with the rights and privileges such status affords, such as paid holiday and sick leave. However, it also generates questions for kinship carers and further confounds this debate as to whether they are primarily family or whether they should also be recognised as professional carers. The discussion is not purely financial; there are implications with adopting either 
approach. Registration and financial support of kinship carers theoretically affords them access to the social care system including training, specialised services for the young people and the provision of respite care. Considering the complex needs of the children that they care for, these services may provide an essential lifeline for kinship carers. However, alongside the benefits of registration come disadvantages. These include persistent intrusion from social workers, continuous assessment, and restrictions on providing approval for areas requiring parental responsibility. Such restrictions can also make it difficult to promote and maintain an atmosphere of normality and continuity around a child.

The solution is far from simple, and even local authorities who enact one approach or the other are unclear as to whether it promotes optimal outcomes. The fact that this thesis is part-funded by two local authorities confirms that this discussion has implications that range well beyond the theoretical and academic spheres into the realms of practice and policy. It is encouraging that practitioners and policy-makers are seeking clarification and knowledge on such issues. It is therefore vital that research is conducted that goes some way to filling the gaps in current knowledge and works to provide a basis of literature from which practitioners and policy-makers can work. Given the implications of this debate, and the relatively rapid changes that we are seeing with regards to the professionalisation of care provision, the timely execution of this project is justified.

On a personal note, having grown up with looked after children in the wider and immediate family, I was aware from an early age of the challenges faced by the children and by the professional services that cater for them. Of particular interest were the themes of identity and family, which run through this thesis, and the limitations placed upon each of these by professionalised care services. An aspect I always found peculiar was that one day a young person would be part of our family, treated in every respect like a sibling, the next they would be gone and a new child would be in their place. It is perhaps conflicting to simultaneously professionalise and personalise care in such a way.

These are aspects this thesis seeks to explore; first by examining the quantitative outcomes of kinship care and then by exploring the theoretical and practical 
factors that underpin those outcomes. The overall objective of this thesis is to examine the implications of a shift in the way that social work theory is applied from a professionalised child-rescue model, to a kinship model. This will be explored via three main study aims.

The first aim seeks to establish the stability and permanency of kinship care placements. A particular focus is upon Special Guardianship Orders (SGOs), which remain relatively understudied despite their widespread use as a permanency option. Research questions include "to what extent do Special Guardianship Orders provide permanency for young people?"

The second aim is to explore the relative wellbeing of young people in kinship care. Research questions within the domains of mental health, attachment and emotional literacy will explore this. Key questions include: "how do young people in kinship care compare to those in mainstream foster care on a measure of mental health?"

The third aim seeks to delve deeper into one aspect of wellbeing by exploring the educational achievement of young people in kinship care. The primary research question for this aim, "what is the educational attainment and achievement of young people in kinship care?" seeks to determine whether young people are performing as expected on achievement measures. Further research questions seek to compare children in kinship care with peers in the general population as well as looked after children. Chapter 1.1 on page 8 presents a full overview of the aims and research questions in this thesis.

The three aims are designed to examine the effects of kinship placements within the realm of professionalisation. These aims relate directly to the objective, by studying the implications of a theoretical shift as reflected in the emerging data and their analysis. The multifaceted nature of this enquiry seeks to explore these implications on multiple domains and via a range of approaches.

In order to address the research aims, the study employs a sequential mixedmethodology across two phases of research. Phase one uses a case file audit to examine care leaver destinations in two LAs $(n=312)$. This is further split into two categories: 'early care leavers' who left care before the age of eighteen, usually 
returning to parents or leaving via a permanency order such as adoption; 'aging out' is used to identify young people whose care order lapsed as they reached their eighteen birthday.

The second phase employs a cohort of young people in kinship care who are legally classified as looked after children. Using a mixed-methodology, four groups are defined for inclusion: young people in kinship care $(n=21)$, kinship carers $(n=24)$, social workers (case workers) $(n=21)$ and supervising social workers $(n=4)$. A combination of standardised and bespoke measures are used to examine quantitative outcomes whilst semi-structured interviews and a focus group are used to explore the mechanisms underpinning these outcomes. The study design is broad and exploratory in nature, seeking to identify novel outcome trends but focussing on understanding the social factors that cause these trends to come about.

Chapter two presents a broad overview of empirical literature on kinship care from the UK and further afield. Beginning with the definitional issues of kinship care, the review continues to briefly outline the history of kinship care in practice in the UK. The chapter continues to discuss key areas of concern or debate in kinship care pertaining to physical, behavioural, emotional and social outcomes of kinship placements.

Chapter three forms the second part of the literature review, focussing on the theoretical debates and establishing the theoretical model within which kinship care is situated. Split into three sections, the chapter scrutinises the role of social work in modern society, the role of the family and the ways in which it can be defined, and how the family and social work come together in kinship care. The aims of the project and specific research questions are defined at the end of the chapter three.

In relation to the first aim, it was noted that the stability of kinship care placements lacked relevant, methodologically-sound study. Furthermore, the stability and permanency of SGOs was yet to be explored due to their relatively recent introduction. The literature pertaining to the second study aim revealed that whilst some international studies have examined the relative wellbeing of young people in kinship care, there was a heavy focus on those from Black and Minority Ethnic 
(BME) groups. These studies were found to have limited generalisability to a UK population and, in particular, in the study region of South Wales. Thus, further study of outcomes pertaining to wellbeing is justified in this population. Finally, limitations were identified in previous studies of educational outcomes for the care population. These included inappropriate comparison groups, a heavy focus on attainment rather than achievement, and a lack of data relating to the kinship care population.

Chapter four describes the design and methodology adopted in this study. It identifies the specific methodological approach used in each phase of the study before discussing the ethical considerations and describing the results of the feasibility study.

Chapter five presents the results of the first phase of research and addresses the research questions pertaining to stability and permanency in kinship care. Novel information gathered on the use and permanency of SGOs is also outlined.

Chapter six presents the quantitative results from phase two. These address aims relating to the relative wellbeing of young people in kinship care and their educational achievement. The chapter also presents the results of a bespoke ranking measure, which seeks to ascertain the extent to which young people, their kinship carers and social workers, prioritise key placement characteristics.

Chapter seven presents the qualitative results from interviews and a focus group. Results are split into six themes: the benefits of kinship care, motivation to care, mixed advantages and disadvantages, challenges of kinship care, working with the local authority, and Special Guardianship Orders.

Chapter eight discusses the study's results in relation to previous literature and theory. The chapter is structured around the aims and RQs of the study focussing first on stability and permanency before moving on to the relative wellbeing and then the educational achievement of young people in kinship care. Finally, the theoretical concepts of family, hardship and professionalisation of kinship care are discussed.

Chapter nine summarises the study's conclusions and defines the research conclusions. With regard to the limitations of the methodology used, the 
Chapter 1: Introduction

implications of the findings are discussed with proposals for further research, practice and policy. 
1.1 Thesis objective, aims and research questions.

\section{Objective:}

To examine the implications of a shift in the way that social work theory is applied from a professionalised child-rescue model, to a kinship model.

Aim One: Exploring factors affecting stability within formal kinship care and post-care.

RQ1 What is the initial post-care destination of 'early care leavers'?

RQ2 How does final placement type relate to post-care destination for children and young people and does this differ for those in kinship care?

RQ3 To what extent do Special Guardianship Orders (SGOs) provide permanency for young people?

RQ4 What factors influence whether an application for a SGO is made?

RQ5 What measures do local authorities take to support SGOs of early leavers and are they dependent on pre-leaving placement care order type?

RQ6 To what extent are 'care leavers' who age out already 'staying put'?

RQ7 How does pre-leaving care placement type relate to post-care destination for young people who 'age out' of care and does this differ for those aging out of kinship care? 
Aim Two: Assessing the relative wellbeing of kinship carers and young people in kinship care who are looked after.

RQ8 How are attachments organised for young people in kinship care?

RQ9 How does the strength of attachments of young people in formal kinship care compare to those in the general population and informal kinship care?

RQ10 How does a young person's age relate to the strength and nature of attachments?

RQ11 How does placement stability/permanency relate to the strength and nature of attachments?

RQ12 How does birth parent contact frequency relate to the strength and nature of attachments?

RQ13 How does the mental health of young people in kinship care compare to those of the same age in mainstream foster care, informal kinship care and the general population?

RQ14 How does mental health relate to attachment, contact frequency and placement stability/permanency?

RQ15 How does the emotional literacy of young people in kinship care compare with young people of the same age in mainstream foster care and the general population?

RQ16 How does emotional literacy compare with carer educational status, mental health scores and attachment scores?

RQ17 To what extent do self-rated feelings of control and optimism relate to emotional literacy?

RQ18 How does kinship care affect the health and wellbeing of carers? 
Aim Three: Assessing the educational achievement of looked after young people in kinship care.

RQ19 What is the standard of literacy of young people in formal kinship care?

RQ20 How does educational achievement in kinship care compare with other looked after children and the general population?

RQ21 Which placement objectives and characteristics are prioritised by social workers, young people in kinship care and their carers? 
Chapter 2: Literature review: empirical literature and policy 
2.1 Defining kinship care

The definition of kinship care can vary depending on the country, region, nation, or local authority (LA) in which the term is applied. It was originally understood to incorporate only blood relatives of a young person, such as in the following definition:

"The term used for situations where children live with relatives other than birth parents." ("Quick guide: Kinship Care in Wales," 2012)

This definition required that a kinship carer was related to the child by blood or marriage; a requirement of the Children Act 1989. The Children and Young Person's Act 2008 broadened the definition of kin to incorporate those who were known to the child, but were not directly related to them. This signified a shift in our understanding of kinship from a genetic to a socially organised phenomenon. This was further enshrined in the Social Services and Wellbeing (Wales) Act 2014 and concurrently in England in the Children and Families Act 2014. This broader understanding is clearly defined in the Looked After Children (Scotland) Regulations 2009, where a kinship carer is described as:

"A person who is related to the child; or a person who is known to the child and with whom the child has a pre-existing relationship" (s.10 (2)).

This definition is now used in the UK, Australia, twenty two states in the USA and in the majority of research papers (Broad, 2004). The modern definition emphasises the social and emotional connection rather than the genetic or legal connection with the child.

Whilst the term 'kinship care' is a useful descriptor of placements types, it is often used as an umbrella term incorporating a number of characteristically different placements. These placements can, for example, be separated into two distinct categories. The first is 'formal kinship care', also known as 'kinship foster care', which is used to describe: 
a) A 'Looked After Child' placed with relative/friend who are also approved as a LA foster carer.

b) A 'Looked After Child' placed with a relative/friend awaiting permanency order (e.g. adoption).

The defining characteristic of formal kinship care is that the child is accommodated by the LA as defined by the Children Act 1989. In each case, the carer must be assessed by the LA and approved as a suitable carer in accordance with the Fostering Regulations 2011. If a carer is applying for a permanency order, such as an Adoption Order or a Special Guardianship Order (SGO), this approval can be granted on a temporary basis.

The second category is known as 'informal kinship care'. This incorporates the four distinct types of placement highlighted below.

c) Informal Arrangements (with relative or friend up to 28 days)

d) Informal Arrangements (with 'Close Relative' for longer than 28 days)

e) Private Fostering

f) Private Court Order

Whilst different from one another, each of the four types of placement above share an important feature: the child is not accommodated by the local authority. Types of informal arrangements refer to the unofficial allocation of caring responsibility to a family member or friend. For the most part, informal arrangements lasting for a period of less than 28 days can be considered to be similar, regardless of whether the carer is related to the child or simply known to them. It is only when the carer assumes primary responsibility for a period exceeding 28 days that differences emerge in that those who are not deemed to be a 'Close Relative' of the child must disclose the arrangement to the LA. Meanwhile, 'Close Relatives', defined by the Children Act 1989 as "step-parents, grandparents, siblings, uncles or aunts, by either blood or marriage", are under no such obligation to disclose the arrangement.

Once carers who are not related have disclosed their status as carers to the LA, the placement may be classified as 'Private Fostering'. In such cases, the 
arrangement is voluntary and, whilst the LA should be aware of such circumstances, the child is not considered to be accommodated by the LA. If desired, family members can disclose their circumstances to the LA and become classified as a Private Fostering placement, although they are not required to do so by law. Alternatively, family members or close friends may decide to apply directly to the Family Courts in order to obtain a private court order. These may include Special Guardianship Orders, Residence Orders (now rescinded in favour of 'Child Arrangement Orders' in England following the Children and Families Act 2014) and, less commonly, Adoption Orders. Application for each of these orders can be made directly to the courts and involvement from the LA, whilst sometimes helpful, is not required.

Given the multitude of placement types that are captured by the term 'kinship care', it seems appropriate that a broader definition is used. Whilst this emphasises the social bonds rather than genetic linkage, the differing legal status between family and friend carers can pose challenges for research. As discussed, even within informal care, the requirement to notify the LA is dependent on the degree of relationship with the child. The differences between informal and formal kinship care are greater still. A child who is accommodated by the LA in formal kinship care is subject to the same assessments, care planning procedures, and entitled to the same support as any accommodated child. Furthermore, formal kinship carers are subject to fostering assessment and, in many cases, entitled to support from the LA as foster carers. This contrasts with the rights and responsibilities of informal kinship carers who are not caring for a looked after child. In some respects, the outcomes for such children may be similar, however, those in formal kinship care receive a more structured system of support which may impact upon their outcomes. Furthermore, research examining informal kinship care in the UK has suggested that the informal carers may struggle financially, feel alienated and overwhelmed, and suffer health problems (Selwyn \& Nandy, 2012). As these factors may be mitigated by LA support in formal kinship care, it is imperative that when discussing the outcomes of children in kinship care, a clear distinction is made between formal and informal kinship care arrangements. 
This thesis will focus on the formal kinship care population. In doing so, formal kinship care will be defined as:

"a formal type of care and living arrangement for a child who has to live away from his/her parental home, is known to social services, and is cared for full-time by a member of the child's extended family or a friend." (Broad, 2004)

There are two reasons why this definition will be used. Firstly, the broader definition incorporates friends and is respectful of the unique nature and status of individual kin relationships. Secondly, the broader definition respects the legal distinction between the types of kinship placement and thus the support that each receive. The operational definitions of 'kinship carer' and 'young people in kinship care' are outlined in the next section.

\subsubsection{Operational definition}

In order to meet the criteria of formal kinship carer for the purpose of this thesis, a carer must be:

- A person with whom a 'looked after' young person resides and for whom they provide full time care.

\section{AND}

- A person who is not the birth parent of the young person but to whom they are related by blood or marriage as a close relative (grandparent, aunt, uncle, sibling or step-parent).

OR

- A person who is not the birth parent of the young person but to whom they are known prior to placement commencement (kith). 
A young person shall be deemed to be living in formal kinship care if they are:

- A 'looked after child' residing full time with a close relative (grandparent, aunt, uncle, sibling or step-parent) other than their birth parents to whom they are related by blood or marriage.

OR

- A 'looked after child' residing full time with a carer with whom they have a pre-existing relationship (kith)

This includes young people who are subject to permanent care orders, such as SGOs, who were accommodated by the LA in a kinship placement prior to the private order commencing.

\subsection{Literature review search strategy}

In order to establish gaps in the field, a literature search was undertaken. Seven databases (PubMed, Psycinfo, Web Of Science, Cochrane, Campbell, Social Care Online, Sociological Abstracts) were searched using a range of key phrases and Boolean operators such as "kinship" AND "care" AND "reunification".

To be considered for inclusion, records were required to be either review articles or research studies, published in peer reviewed journals, available in English and relating to human studies.

A total of 1213 titles were identified. Once duplicates were removed, 731 articles remained for screening. Exclusion criteria were applied and 304 articles were excluded either for relating to an elderly care population $(n=106)$ or not relating to kinship care $(n=198)$. Overall, 427 articles remained for review. A table detailing key terms used can be found in the appendix (see page 366, Table 39).

Further articles were identified from keyword searches on Google Scholar, via networking and professional correspondence, and through bibliography searches of identified papers. 
A comprehensive research library was established with identified papers which were read and organised according to theme. These themes provided the structure for the literature review, where key papers in the field are discussed.

\subsection{History of Kinship Care}

\subsubsection{Trends in social work policy, practice \& research}

The phrase "an Englishman's home is his castle" is often used to express the view that the British household is a private domain within which State interference was unwelcome and threatening to the household hierarchy. There has historically been conflict to the extent in which the State should interfere in the private family, with the family being treated as an important entity in law (Fineman, 1998; Olsen, 1984). Historically, the State and the family were considered to exist as separate spheres (Olsen, 1984). Within this model, kinship care has always played a role as family members cared for children who were orphaned or whose parents were unable to care for them. Where kinship care was not available, care of children was often in the hands of charitable or religious organisations who acted without supervision from the State (Pierson, 2011). The 1834 Poor Law Amendment Act was a pivotal moment laying the foundations of social work as we know it today. It created a legal requirement for parishes to create a workhouse to facilitate and regulate poor relief, with commissioners overseeing the Act's implementation (Pierson, 2011). Whilst this early system may not bear much resemblance to the intricacies of the modern day local government, the system introduced by the 1834 Poor Law Amendment Act underpins the roles and responsibilities of the current local governance system.

The Poor Law Amendment Act 1834 remained the primary basis for legislation for more than a century, assisted by charitable organisations such as Barnardo's created in 1867 and the National Society for the Prevention of Cruelty to Children (NSPCC) established in 1889 (Pierson, 2011). The NSPCC, known as the London Society for the Prevention of Cruelty to Children from 1884-1889, were key in campaigning the issues of child protection and for the introduction of the 1889 Prevention of Cruelty to Children Act. The 1889 Act empowered courts to 
give warrants to any person to remove a child deemed to be in danger to a place of safety and for the court to appoint a 'fit person' to take over care of the child. Prior to this, charitable organisations had been removing children with no legal authority and placing them with strangers in an early form of foster care known as 'boarding out'. The child rescue movement was a prevalent approach in the nineteenth century. The approach was underpinned by the idea that a child's environment has a greater influence on the health and success of a child than heredity. Thus, removing a child from an abusive home at the earliest stage was a necessity if their health was to be ensured (Antler \& Antler, 1979; Scott, 2006). Meanwhile, boarding out recognised that the family unit may have an important effect on the child and promote positive outcomes in a way that a large establishment such as a workhouse could not.

Whilst boarding out was widely regarded as a positive measure, a number of controversies, such as the discovery of baby farming, led to the Children and Young Persons Act 1908. Also known as the Children's Charter, it introduced the requirement for foster carers to notify and register with their LA amongst other measures such as the creation of a juvenile court and the prevention of children working in dangerous trades. These heralded a new age for the treatment of children in that they were recognised as inherently different from adults and the responsibility for their protection began to leave the confines of the home and enter the jurisdiction ' of the State (Bradley, Logan, \& Shaw, 2009). Alongside this came a desire to regulate, to at least some degree, adoption which had previously been an informal arrangement without State or local authority involvement. This came to the fore following the First World War when there was an increase in the numbers of orphans and widows unable to care for their children, and led to the 1926 Adoption Act. This Act was key in allowing for the transfer of parental rights and responsibilities from birth parent to an adoptive parent, although with the notable absence of the paramountcy principle which had featured in the 1925 Guardianship of Infants Act. The 1933 Children and Young Persons Act extended the powers of the local authority in making them primarily responsible for bringing a Child In Need before the court. In doing so they also limited the number of people able to do so to three bodies: The local authority, the Police and the NSPCC (Pierson, 2011, p.102). 
Removing children from the home and accommodating them with strangers had become relatively common practice in the emerging field of social work. However it was only during the evacuation of children from major cities during the Second World War that the disparity in the provision of care for children in inner city areas was noticed on a large scale. The behavioural, and to a certain extent cultural, issues that presented, caused difficulties for both the evacuees and their foster families. In response the LAs began to increase the number of visits from local care committees and integrated services to a degree (Pierson, 2011, p.108). It also led to an understanding that the provision for Children In Need at the time was insufficient and laid the groundwork for the 1948 Children's Act.

The 1948 Children's Act required Local Authorities to create children's departments in order to manage the needs of deprived children and families, and to consolidate available services in order to meet those needs. In the three years prior to this Act were two key events that provided the catalyst needed for the changes it proposed. In 1945 Dennis O'Neill died whilst in the care of Newport Borough Council. He suffered cardiac arrest and died following a beating by his foster father who was convicted of his manslaughter. This drew widespread criticism from the public and politicians alike, especially when it transpired at trial that the foster father, Reginald Gough, was known to the police following a domestic incident in 1942. As a result LAs began to assess foster carers more stringently, excluding those with a history of violent conduct. Secondly the Curtis Report, published in 1946, emphasised the importance of working with families as a whole in order to prevent incidences of abuse and neglect. In addition to moving away from purely reactive practice, it also shifted away from the child rescue approach which featured heavily in the late $19^{\text {th }}$ and early $20^{\text {th }}$ centuries and moved towards returning children to their parental home following appropriate intervention. This practice is known as reunification, and is still used as an option when planning the long-term goals of a placement.

Whilst reunification seemed to be an ideal aim following training and rehabilitation for birth parents, it was not always appropriate or successful. Despite investment in the restructuring of the departments and services, in 1973 the Social Care system hit the headlines with the death of Maria Colwell (Stevenson, 1998). At 7 years of age she died from internal injuries following reunification with her mother 
and her mother's new partner. Such events have repeatedly become scandals in media, triggering uproar and leading to calls for change to systems who are deemed to have failed (Butler \& Drakeford, 2003). Following the case, a report was published in order to establish where the system could be improved (Secretary of State for Social Services, 1974). Despite this, and the introduction of Child Protection Registers for children deemed at risk, over the following decade were a number of high profile cases of children who were killed (Colton, 2002). During this period, Social Services were heavily criticised which may have caused an increase in supervision and children entering the care system that followed. In 1987, this was displayed very publicly during the Cleveland child abuse scandal in which 121 children were removed from their homes following a controversial test for sexual abuse. The test was later discredited with 96 of the abuse cases being dismissed from court. Contrary to the previous media outcry for more intervention by authorities, social services were this time heavily criticised for being over-zealous in their approach to child protection (Donaldson \& O'Brien, 1995). This scandal was compounded between 1990 and 1996 when the systematic and widespread abuse of children in a number of care homes in North Wales was investigated following a number of allegations. The extent of the abuse is still not fully known although the Waterhouse report published in 2000 identified "widespread sexual abuse, including buggery" in addition to excessive force and physical abuse (Waterhouse, 2000, p.789). These were just a few of a number of highly publicised scandals, leading to an air of mistrust surrounding social workers and the social care system as a whole (Drakeford \& Butler, 2007).

There was a breakdown in communication between departments involved in caring for children, a lack of information available to parents of children in care, the views of children in care were not heard, and the power struggle between the local authority and parents was seen to favour the local authority (Pierson, 2011, p.182). Following calls for reform for many years prior, legislators attempted to mitigate these factors and address the relationship between parents and authorities via the introduction of the 1989 Children Act. Importantly, the Act reinforced the idea that children should be cared for within the family and stipulated that children should only be removed if they had or would be likely to 
suffer significant harm. It has become the primary basis for the structure and practice of modern social services departments, and is expected to remain so for the foreseeable future. Furthermore, the Act continues to be reinforced by more recent Acts such as the Social Work and Wellbeing (Wales) Act 2014 and its English equivalent, the Children and Families Act 2014.

As a consequence of the 1989 Children Act, social work in the UK took a more holistic approach. Children's views were expected to be taken into account, a move given further precedence in 1991 by the United Nations Convention on the Rights of the Child (UNCRC) which instructed that children have the right to participate in decisions affecting their lives at a level equivalent to their understanding. The wellbeing of children was also brought to the fore with a more holistic approach being idealised. This meant that, rather than reducing a child's success to accomplishing a series of developmental goals, social work looked to expand the impact of intervention to promote positive wellbeing for children and families involved with social services (Pierson, 2011, p.183).

Although the basis was in place, the foundations were shaken again following the death of Victoria Climbié who died in 2000 following a catalogue of abuse inflicted by her aunt and her aunt's boyfriend. A media frenzy ensued and the London Borough of Haringey were challenged when it came to light that authorities had missed twelve opportunities to intervene. Following the inquiry (Laming, 2003) the government responded with a cornerstone Green Paper 'Every Child Matters'. This became the blueprint for the Children Act 2004. In Wales, a similar agenda was simultaneously developed; Rights to Action. Both required local authorities to unify their services beneath a director of children's services and to consolidate data in a central database in order to bridge gaps in communication between departments. Whilst these changes to the system were introduced, the London Borough of Haringey once again came under scrutiny following the death of Peter Connelly (Baby P) in 2007. This is reported to have led to an increase in the number of children being taken into care in Haringey, a figure that may have been replicated elsewhere due to the widespread publicity of the case (Munby, 2016; Sellgren, 2010; Zayed \& Harker, 2015). 
Since its origins, social work has changed dramatically both in the structure it adopts and in its practice. Perhaps beginning with the Poor Law where children who could not be cared for by their parents were placed in workhouses, through an extended period of 'child rescue' and removing children as a preference, the last fifty years have brought a much more community focussed approach to child social work. With an increasing population, the cost of care may have factored in this change. A report by Hannon, Bazalgette \& Wood (2010) estimated the cost of a child's journey through care based on a variety of factors which are thought to affect placement stability including age of entry into care and behavioural and emotional difficulties. They created cost estimates for two 'typical' but contrary care journeys based on previously established correlations between placement characteristics and factors such as behavioural and educational outcomes, age of exit from care and further educational and employment prospects.

The first is the care journey that most local authorities strive for when reunification is not possible and represents $5-10 \%$ of the children currently looked after by their local authority: early entry into care, stable and high-quality placement in longterm foster care and a supported transition from care. The authors estimate that the cost to the local authority for this care journey would be $£ 23,470$ per year until the age of 16 . They then estimate that from the ages of 16-30, assuming good qualifications, good mental health, further education and good employment prospects, the cost to the state as a 'care leaver' would be $£ 7,281$. By defining the young person as a care leaver, the authors account for ongoing support provided to those formally accommodated by their LA. The second care journey, representing the experience of $10 \%$ of the current care population, is considered to be poor with a late entry into care, multiple placement changes, short unstable placements, multiple failed reunifications with birth parents, and an early exit from care with poor mental health and no qualifications. The estimated cost to the local authority in this case would be $£ 56,226$ per year until the age of 16 . Assuming poor employment prospects and poor mental health the authors then estimate the cost from age 16-30 to total $£ 111,923$, more than fifteen times the cost of the first care leaver.

Driving further change in the field of social work are external pressures from media sources and public opinion, often formed following specific events in which 
authorities are deemed to have failed. Relatively recent events such as the death of Peter Connelly have already had an impact at a local level (Macleod, Hart, Jeffes, \& Wilkin, 2010), although the effect that these events may have on the general trends in the field remain to be seen. It certainly seems to be the case that the current social care system has been built upon previous cases and that legislation and policy in this area are mostly reactive.

\subsubsection{Trends in kinship care}

Trends in social work practice have influenced legislation, and the legislation surrounding kinship care is no exception. The Poor Law Amendment Act 1834 stated that grandparents were responsible for the care of their grandchildren should their parents be unable to provide the necessary care. This reinforced the ideology of privacy within the home. This concept of privacy was further perpetuated in the 1870s when proposed legislation surrounding the removal of a child whose parent "had been convicted of bodily harm" was not even debated due to the intrusive nature of the proposal and the threat it posed to the selfregulating household (Pierson, 2011, p.92). This was undermined over the following decades as the child rescue movement grew amongst charitable organisations. Here children were removed from the home and breaking ties with the family altogether was favoured due to the potential for continued abuse. Whilst it is reasonable to expect that kinship care was prevalent on an informal level over the next half century, particularly during the First World War and its aftermath, kinship care itself opposed the principles of formal care which favoured the breaking of birth family ties.

This position was reinforced by the introduction of the 1926 Adoption Act which not only transferred the rights and responsibilities from birth parent to adoptive parent, but also prevented any contact between birth parents and the adopted child. It is not entirely clear when this view changed, although as the Welfare State was introduced following the Second World War, the concept of community based support and whole-family interventions became more popular. Removing children from the home gradually became less popular and an alternative 
approach was advocated with a preventative rather than purely reactive social practice. For those who were removed from the home, the importance of retaining contact with birth family began to be recognised (Aldgate \& Mclntosh, 2006).

In 1982 the Barclay report was published and held great relevance for kinship care. It promoted the retention of family links and endorsed the use of family and friend support networks for those who were struggling to care for their children. Given the turbulent period that followed for social work in the UK, and the widespread mistrust of social workers that ensued, this was a significant turning point for kinship care (Ayre, 2001). When the 1989 Children Act was introduced, it formally embraced kinship care as a positive placement option for children who were removed from the home and instructed that family and friends placements should be explored before any other. The Act also provided for Residence Orders which allow the carer to assume shared parental responsibility for the order's duration. Whilst Residence Orders, now rescinded in favour of Child Arrangement Orders (CAOs), allow kinship carers to make certain decisions, their power to act autonomously is severely limited. By contrast, Special Guardianship Orders (SGOs), which were introduced via the Special Guardianship Regulations 2005, grant Parental Responsibility (PR) to the kinship carer and, although PR is still shared with the birth parents, SGOs allow the carers much more freedom to act without consulting the birth parents. In some respects it recognises the role kinship carers may play in a child's life as the principle carer.

The family is also engrained in the United Nations Convention on Rights of the Child (UNCRC). Understanding the family unit to be the basis of society and the natural environment within which a child should grow, the UNCRC affords some protection to the integrity of the family unit. The convention also decrees that the family is the rightful place for a child to develop their personality and that ties with the family should be retained unless deemed harmful for the child. Furthermore, Article 18 cements the role of the State in providing support to the family in order to fulfil its functions. 


\subsubsection{Kinship care in the United Kingdom}

Kinship care has become a popular placement option in policy and also in practice. In addition to being given primacy in the 1989 Children Act, the position of kinship care for looked after children has been reinforced by the Social Services and Wellbeing (Wales) Act 2014 and the Child and Family Act 2014. Recent studies have examined census returns data to establish the prevalence of kinship care in the UK (Nandy, Selwyn, Farmer, \& Vaisey, 2011). In 1991, more than 69,000 children and young people were being cared for by a relative or friend other than their birth parents. By 2001, this figure had more than doubled to exceed 173,000 children and young people. Of these, the vast majority were informal kinship care arrangements with only $5 \%$ living with a formal kinship foster carer (Selwyn, Farmer, Meakings, \& Vaisey, 2013). Over this period formal kinship placements also rose (Nandy et al., 2011).

This suggests that in $2001,1.3 \%$ of children and young people in the UK were living in kinship care arrangements (Nandy et al., 2011). This was more than twice the number of children and young people being cared for by LAs: $0.52 \%$ of the population.

\subsubsection{Kinship care in Wales}

In wales, care by family or friends other than birth parents described the living arrangements of $1.4 \%$ of children and young people in 2001: more than 9,000 children and young people (Nandy et al., 2011). Comparatively, less than $0.6 \%$ of the population of children and young people in Wales were in the care of the local authority. With a prevalence rate of $1.4 \%$, Wales has the highest proportion of kinship care in the United Kingdom making it an important discussion point for legislators and practitioners alike. Formal kinship care is also widely used in Wales, accounting for $21.1 \%$ of all foster placements in 2016 (StatsWales, 2016a). This figure is up from $19.0 \%$ in 2003.

The rise in formal kinship care in Wales and the rest of the UK may be symptomatic of a more recent theoretical shift from a child-rescue model to a 
family-based model of care. This will be explored further in chapter 3 . It is important that changes in the theoretical basis of social work and working practices are explored. How theory and practice influence one another also needs consideration.

\subsection{Wellbeing}

The following sections will examine literature relating to the wellbeing of young people in kinship care. The concepts of how health is defined will first be explored. Recent literature describing the relative health of young people in kinship care will then be critically reviewed.

\subsubsection{Health}

The concept of health has numerous definitions with varying emphasis. Boorse's (1977) naturalist definition of health and disease defines the latter as a state that impairs the normal biological functioning of an organism. Health would therefore be described as the absence of disease. By contrast, the normativist perspective argues that disease should be defined by the extent to which a state is valued. Here if a state is deemed undesirable it could be deemed disease if it also deviates from statistical norms. Once again, health within this definition would be the absence of disease and would be a desirable state (Ereshefsky, 2009). The normativist definition has come under scrutiny for its lack of emphasis on the role of biological functioning in the understanding of health and disease that is held by both laymen and professionals. A third theory, known as hybrid theory, combines naturalism and normativism. Wakefield (1992) does so to create the following definition:

A condition is a disorder if and only if (a) the condition causes some harm or deprivation of benefit to the person as judged by the standards of the person's culture (the value criterion), and (b) the condition results in the inability of some internal mechanism to perform its natural function, wherein natural function is an effect that is part of the evolutionary 
explanation of the existence and structure of the mechanism (the explanatory criterion). (Wakefield, 1992, p.384).

Whilst it is an ideal compromise in some respects, and may therefore seem to be a more acceptable definition of disease or disorder, it is a very restrictive definition. It requires that both the value and explanatory criterion be met for a condition to be described as a disorder and as such severely narrows the range of states that could be described as disease. Whilst this is not problematic in itself, its contrast with laymen's understanding of disease make it so.

In all three of the definitions presented, there is a notable emphasis on disease which perpetuates the notion that health is simply an absence of disease. By contrast, one could argue that health has a positive range and that lack of disease does not necessarily indicate health in common understanding. Conversely, disease in one domain does not mean that an individual cannot be considered healthy. An example would be an individual who had suffered amputations of the lower limb below the knee. By all three theories of disease above this individual would be described as suffering from disease or disorder and therefore by default be unhealthy. Their inability to walk using their original biological mechanisms is both undesirable (normativist theory) and abnormal for their reference class (naturalist theory). By meeting both criteria, this individual would also meet the threshold for disease or disorder as defined by hybrid theory. If we then suppose that this individual is a professional athlete competing in a high level of their field. In laymen's terms we consider athletes to be the ideal representation of health and this contradicts the notion of health proposed by all three theories of health.

Rather health should be considered in its own right as a state of wellbeing, rather than a state that exists only in the absence of another negative state. By defining as such, we allow for a viewpoint known as individual potential which incorporates a more personal definition of health rather than looking purely at comparison of individuals with species norms. This is a concept that is engrained in the World Health Organisation's (WHO) definition of health: "Health is a state of complete physical, mental and social well-being and not merely the absence of disease or infirmity" (WHO, 1948). 
Whilst it is an important distinction to make in physical health, the difficulties surrounding the definitional debate and the benefits of a positive definition of health become evident when discussing psychological and emotional health. The concept of positive mental health will be discussed later in this chapter, but it is useful illustration of the complexities involved in defining health. The above definition, proposed by the World Health Organisation, will be used in this thesis due to it being widely recognised by both health professionals and organisations, and by laymen.

\subsubsection{Physical health of children and young people in kinship care}

Children and young people entering the social care system are a particularly vulnerable group of individuals. They are at higher risk of having poorer health than the general population on entering care, either due to social deprivation or as a direct result of abuse or neglect (Chernoff, Combs-Orme, Risley-Curtiss, \& Heisler, 1994; Hill \& Watkins, 2003; Rees \& Holding, 2013; Simms, Dubowitz, \& Szilagyi, 2000). In the UK, a report by the Department of Health highlighted areas where LAC were suffering from poor health, including problems with sight, speech delays and bed-wetting (Mooney, 2009). In each of these domains, incidence was higher amongst the LAC population than the general population.

Studies have previously indicated that rather than improve, the health of children and young people in foster care may continue to deteriorate during the placement (Rosenfeld et al., 1997), although this has been contested (Simms et al., 2000). It is not clear whether this is causal or simply a continuation of previous disadvantage, and research into the physical health of children and young people in kinship care is scarce with the majority of existing studies hailing from the United States of America (USA). Whilst there has been a small amount of research conducted in the UK, Australia and even Denmark, the USA remains the primary source of information surrounding healthcare for children in the care of the State, which poses some difficulties. The discrepancies between the UK and the USA on a range of factors including population demographics, system of 
healthcare and differing legal status of children removed from the home make the generalisability of results both challenging and potentially damaging.

It has been argued that the kinship care population may differ from the general care population in some respects. Studies have suggested that more than $90 \%$ of children and young people entering care in the USA may suffer some form of physical health condition or disability, however relatively little is known about the kinship care population in either the UK or USA (Chernoff et al., 1994). A study conducted in the USA in San Diego's only receiving facility (Polinsky) provided an insight into the health factors affecting children and young people on entering the care system and created a comparison by initial placement type (Leslie, Gordon, Meneken, et al., 2005). The study was relatively large with $80 \%$ of those entering the care system in San Diego between the $1^{\text {st }}$ April 1998 and the $30^{\text {th }}$ June 1999 included in the sample $(n=1542)$. The study was retrospective, using records from medical and developmental examinations conducted within two weeks of the child entering the care system. These were studied in order to determine the comparative health status of the children and young people on entry to care. The authors compare the three initial placement types: birth parents, kinship carers and unrelated foster carers. The proportion of children placed with either their biological parents or kinship carers was very similar $28.5 \%$ and $28.4 \%$ of the study sample respectively. The remaining $43.1 \%$ were placed with unrelated foster carers. Only nine children were placed in group homes and were subsequently excluded from the analysis. Group differences were taken into account in analysis. The only difference identified was a higher rate of neglect as the principal form of abuse in those placed with unrelated foster carers compared with the other two groups.

Leslie et al. (2005) found that $86.7 \%$ of the sample were suffering from a physical health problem on entry to care with $31.5 \%$ and $30 \%$ suffering from either one problem or two or more problems respectively. A key finding from this study was that there was no significant difference found in the type of ailment between the children in each placement type. This would indicate that differences found later in the health of children in different placement types may be attributable to the placement itself, rather than as a result of pre-care differences. Developmental delay was measured using the Denver Developmental Screening Test II, with 
$57.9 \%$ of the sample deemed to be at high risk of developmental delay. Once again, no significant differences were found between the placement types. These findings suggest that children entering the care system have similar needs regardless of the type of placement they go on to and are at equally high risk of physical health conditions and developmental delay.

The study by Leslie et al. (2005) is subject to some limitations. Firstly, the participants featured are from a very narrow age range (3 months to 5 years 11 months) which severely limits the generalisability of the results. It is quite possible that the health difficulties and needs of an older population would differ drastically due to a variety of factors such as extended exposure to the socioeconomic deprivation that was reportedly a risk factor, and potential abuse. The type of health problems are also likely to vary with age as the potential for substance abuse and risky sexual behaviour become relevant concerns meaning that age specific assessments would be a necessary tool. Secondly, twelve per cent of the sample had come to the centre for assessment having left previous placements. These placements may have influenced their health in the period between removal from the home and assessment either through direct healthcare intervention or indirect effects from the placement such as increased sensory stimulation from foster carers which may improve developmental outcomes. Whilst the percentage of children from previous placements is small the potential for the introduction of extraneous variables mean that these results should be treated with some caution. That said, the results from this study do build on the results from previous research regarding the prevalence of physical illness in those entering care (Chernoff et al., 1994; Hochstadt, Jaudes, Zimo, \& Schachter, 1987; Mooney, 2009).

Children enter care for a variety of reasons and for those in kinship care in particular, parental substance abuse is often a prominent reason (Cuddeback, 2004). Maternal substance use, especially during pregnancy and whilst breastfeeding, can expose the child to substances that may affect their physical health and development. The proportion of children in kinship care due to maternal substance use is higher than the proportion in mainstream foster care with unrelated carers potentially creating a population that is uniquely vulnerable to poor health outcomes (Kroll, 2007). This is compounded by the financial status 
of many kinship carers. Studies in the past have found a link between poverty and poor physical health (Aber, Bennett, Conley, \& Li, 1997). Numerous papers regarding kinship care report that kinship carers are more likely than unrelated foster carers to be single, unemployed, living in a deprived area and to not be receiving childcare payments at a rate comparable with unrelated foster carers (Nandy et al., 2011; Selwyn et al., 2013). Financial hardship is an important factor when examining health as factors such as malnutrition can have damaging effects for instance restricting growth. This has previously been recognised in both foster care and kinship care (Dubowitz et al., 1992).

Whilst financial hardship may feature heavily in kinship care, it is only one factor that may affect health and this should be considered when looking for ways of making comparisons. Use of a control group from poor economic backgrounds who have not been victims of abuse or care proceedings is a useful way of establishing the extent to which poverty has an effect. By taking this into account, other variables can be examined without interference. Dubowitz and colleagues (1992) used such a control group when investigating the physical health of children in kinship care in the USA. They found that whilst the health of their kinship care sample $(n=407)$ was poorer than the general American population, it was similar to the health status of children in foster care and children from financially disadvantaged backgrounds.

Dubowitz et al. (1992) also found that as many as 44\% of the children and young people in kinship care had received inadequate dental care. In order to establish this they included children aged 3 years and above and adequate care was described as at least one visit to a dentist within the previous 12 months which is half the frequency advised by the National Health Service in the United Kingdom (NHS, 2013). With such a lenient timescale within which dental care could be found adequate, it is quite surprising that just under half of the children failed to meet the required standard. It may be due to the cost of dental treatment in the USA or a cultural difference in the willingness to access healthcare due to the differing healthcare system, and so it would be of great interest to compare this result with a similar study in the UK where dental care is free for children and young people under the age of 19 although no such study currently exists. Dental care in the study by Dubowitz and colleagues (1992) was also measured by 
healthcare professionals who conducted a bank of tests including a dental checkup. They found that as many as $71 \%$ of $0-5$ year olds, $79 \%$ of $6-11$ year olds and $90 \%$ of 12-19 year olds in kinship care were suffering from dental caries to a degree that follow up care was required.

Across the age groups only $10 \%$ of the kinship care sample in the study by Dubowitz et al. (1992) had no physical health problems. The reason for these health problems is unclear, although the authors found a number of risk factors. They found that children with more health problems were more likely to have an unemployed caregiver $(p=.004)$ and have caregivers who were making contact with caseworkers more frequently $(p=.04)$. Contact with caseworkers may be a positive reaction from caregivers who are aware of the health problems of the child, or else it may be that the caseworker was more involved in the supervision of the case due to pre-existing medical complaints. The direction of causality is unclear and would warrant further investigation. Children with more untreated medical complaints were significantly more likely to be older when the placement began $(p=.001)$, have less educated caregivers $(p=.04)$ and have caregivers who were rated as non-compliant with keeping appointments by healthcare providers $(p=.02)$. Interestingly the authors found no significant differences in health based on length of time in kinship care. It is an important consideration due to the interest in the effects of a kinship placement on the health of children and young people. If a kinship care placement is effective in improving the health of children, then better health outcomes may be expected from those who have spent longer in kinship care. The lack of significant findings to this effect suggest may indicate that kinship care is no more effective at improving health outcomes than foster care. Given that child health in foster care has previously been found to be below general population trends, this would be a concerning outcome. Without data comparing the health on care entry and tracking it over time it would be impossible to determine whether kinship care is effective at improving health outcomes over time. However, current literature suggests that, at least in terms of physical health, kinship care may not be the optimal solution to improving outcomes for children and young people looked after by the State.

In addition to the health concerns already noted, health of children and young people in kinship care can be further complicated by adolescence. Whilst their 
health is not separate from the general concerns surrounding kinship care, adolescents in care may have distinct healthcare requirements that differ greatly from the needs of their younger counterparts. The literature has gone some way to addressing this potential disparity and a small number of papers have investigated concerns such as sexual behaviour, substance misuse and risk taking behaviour, all of which can have a detrimental effect on health. Carpenter, Clyman, Davidson and Steiner (2001) studied a sample of young women who had been in foster care $(n=89)$ or kinship care $(n=513)$ and compared them with a control group who had never been in care $(n=9018)$. They found that there were no significant differences between the foster care and kinship care samples in terms of age at first intercourse, conception and the number of sexual partners. When comparing the kinship care sample to the control sample they found that the women who had been in kinship care were significantly younger at first intercourse with an average age of 16.4 years; 6 months younger than the general population control. Furthermore, average age of first conception in the kinship care group was 19.1 years, an average of 8.6 months younger than the control group. This suggests that kinship care may be no better at reducing risky sexual behaviour in young women than foster care. This study was supported and expanded by Taussig and Clyman (2011) who found that living with kin was associated with risky sexual behaviour for both males and females. Interestingly, they linked this with time and found that longer kinship placements were positively associated with high-risk sexual behaviour $(p<0.05)$. Such behaviour leaves young people at risk of unplanned pregnancy and sexually transmitted diseases. The suggestion that young people in kinship care may take higher risks with sexual behaviour is particularly concerning as young people in kinship care are reported to have access to fewer support services (Sakai, Lin, \& Flores, 2011). This means that in addition to suffering from more infections as a result of risky sexual behaviour, for many it may go untreated and lead to further complications although research in this area is severely limited.

Franck (as cited in Cuddeback, 2004) suggested that young people in kinship care may be more vulnerable to substance misuse problems. The study of adolescents in formal kinship care, by Taussig and Clyman (2011), found that longer kinship care placements were positively associated with substance abuse 
$(p<0.05)$, a finding that has been replicated elsewhere (Halfon, Mendonca, \& Berkowitz, 1995). In particular previous research has found that adults who had previously lived in formal kinship care were more likely to use or have used heroin (Benedict, Zuravin, \& Stallings, 1996). The same study also found that those in kinship care were significantly more likely to have traded sex for drugs suggesting that in addition to the health problems associated with substance misuse (Simms, 1989), the drug taking behaviour may be problematic and leave the user vulnerable to secondary health conditions such as infection, disease or pregnancy. Studies in this area are surprisingly few with even fewer focussing solely on substance misuse independently, tending instead to look at its effects on criminality. The studies that do exist tend to be subject to sampling bias due to the difficulty accessing a representative kinship sample retrospectively, and to suffer small sample sizes as a result. These studies must therefore be treated with some degree of caution and be seen only as an indicator of the trends that may be seen for the kinship care population, the behavioural outcomes and the effects this may have on the long-term health of kinship care leavers.

\subsubsection{Physical health of kinship carers}

It is not only the health of children and young people in kinship care that warrants investigation, but also the health of the caregivers. Many studies have noted that kinship carers tend be older which, whilst not a factor of health in itself, has been associated with poorer health (Fisher, 1979; Nandy et al., 2011; Selwyn et al., 2013). A study from the USA $(n=5299)$ found that $26 \%$ of kinship carers had health scores consistent with a serious physical illness (Sands, Goldberg-Glen, \& Shin, 2009). In the UK, the physical health of informal kinship carers was also found to be poor (Selwyn et al., 2013). Of the eighty carers they interviewed, seventy three per cent had a diagnosis for a serious physical illness or disability and more than half suffered from multiple health problems. In particular, chronic pain was found to be a major issue with $37 \%$ of the sample reporting that the pain was restricting their daily lives. The effect this may have on the carer's ability to look after the child may be significant with the authors reporting that more than a quarter of the sample had difficulty climbing a flight of stairs. The study found that 
the health of informal kinship carers is poorer than the general population for all carers except sibling carers who may be protected by factors such as youth and employment which may provide some financial security. Whilst most of the study's participants were older and may therefore be expected to suffer from more illnesses and disabilities, it is a critical finding as the sample demographic is representative of the wider population demographic. Given the extent of kinship care in the United Kingdom, particularly estimates of informal care arrangements, the poor health of carers is a concerning discovery with policy implications.

There are two key points that the literature addresses: firstly, why the health of kinship carers is poorer than the general population; and secondly, what consequences poor health may have for a kinship placement and the welfare of all of those involved. Carers have reported that their time is severely restricted by their caring responsibilities to the point where they are unable to attend to their own healthcare needs (Selwyn et al., 2013). This may be due to multiple caring responsibilities, having restricted mobility as a result of disability or illness (e.g. rheumatoid arthritis) or a combination of such factors.

Poor health in kinship carers, whether formal or informally arranged placements, is a concerning issue for a number of reasons. For the children and young people, their wellbeing may be limited by the health of their carer. Poor maternal health, particularly chronic pain, has previously been linked to poor attachment and social functioning in children and this may be replicated within a kinship care relationship (Barnett \& Vondra, 1999). For the kinship carers, the ability to thrive can be limited and illness exacerbated by the stress and the activities associated with full time care of a child (Jones \& Peters, 1992). Considering the vulnerable state of children entering kinship care and their considerable physical and mental health demands, this is an especially important consideration for carers who may find childcare more challenging. In addition, the multiple caring responsibilities of these carers who may also be caring for other children, elderly relatives and partners, or their adult children means that the toll a kinship care placement may take on a carer may directly affect the welfare of more people than simply the carer and child. Within a welfare state such as the UK it seems not only ethically questionable but also counterintuitive to jeopardise the health and wellbeing of one individual for the sake of another. It may therefore be reasonable for policy 
makers to consider the implications of this when seeking to sustain a safe and non-detrimental kinship care placement for all those involved.

\subsubsection{Mental health}

At the beginning of section 2.4.1, a definition of health was established emphasising the need to treat health as a state in its own right and not merely the absence of infirmity. This definition extends to the domain of mental health, which will be discussed in this section alongside mental illness. This section will address three areas of the mental health literature surrounding kinship care: firstly, the prevalence of mental illness in kinship care across a range of diagnostic axis including depressive or anxiety disorders, psychotic illness and behavioural disorders. This prevalence will be compared with both the general population and children in mainstream foster care and issues such as accessing healthcare will be discussed. Secondly, the concept of positive mental health will be introduced and current literature critically appraised. Finally, the methods for studying and assessing mental health and mental illness will be discussed with regards to future research in the area.

\subsubsection{Mental ill health and accessing healthcare}

Behavioural and emotional difficulties tend to be greater in the foster care population than in the general population (Clausen, Landsverk, Ganger, Chadwick, \& Litrownik, 1998). This remains the case when comparing the foster care sample with children in the general population who have suffered similar socio-economic deprivation (Minnis, Everett, Pelosi, Dunn, \& Knapp, 2006). Estimates of prevalence differ vastly with the lowest around $29 \%$ and the highest estimating that up to $96 \%$ of the care population suffer from some form of behavioural, emotional or developmental disability (Simms et al., 2000).

Emotional and behavioural difficulties, and particularly the latter, do not tend to present in foster placements early on. In a period often referred to in practice as 
the 'honeymoon period' (Szilagyi, 1998; Tucker, Hurl, \& Ford, 1994), children can often seem to be adapting well to their new circumstances, albeit with some emotional upset. It is only after this period that negative behaviours tend to emerge which can cause the placement to breakdown. This honeymoon period can be extended through close supervision from social workers and other professionals, and is essential to encourage positive outcomes and prevent placement breakdown which may further entrench attachment difficulties (Simms et al., 2000; Tucker et al., 1994). However, the existence of a honeymoon period is an important consideration when assessing the mental and behavioural health needs of children in the care system, as assessment on arrival in placement may not be a true representation of a child's needs.

A study by Viner and Taylor (2005) is one of the studies conducted in this area within the United Kingdom. Using the British Cohort Study (BCS70) data, they were able to attain a large sample in order to ascertain the effects of public care on children over a 30 year period. They found that both males $(n=4598)$ and females $(n=4959)$ who had at some point resided in public care were significantly more likely to score highly on the Malaise Inventory, indicating psychological morbidity, than those who had never been in public care. This in itself is not altogether concerning as it is impossible to determine causality from this study alone. It is likely that children entering the care system are in worse emotional health than the general population, not least as a result of the abuse or neglect they may have suffered prior to social care intervention (McAuley \& Young, 2006). They are also more likely to have come from more a deprived background which may leave them vulnerable to emotional and behavioural difficulties (Pilowsky, 1995). It is perhaps therefore not altogether surprising that the emotional and behavioural wellbeing of children within the care system may appear comparatively compromised. Of more interest to a literary debate is the assertion that spending a period of time in public care may itself negatively affect the psychological wellbeing of children (Rosenfeld et al., 1997; Simms et al., 2000; Viner \& Taylor, 2005). Evidence of this is severely limited, although some researchers suggest that a lack of access to healthcare and poor continuity of healthcare provider may mean that the progressing healthcare needs of individuals in public care may be overlooked. This is particularly pertinent to 
mental health services, which suffer from long waiting lists, even with departmental integration between social services and Child and Adolescent Mental Health Services (CAMHS) (Kerfoot, Panayiotopoulos, \& Harrington, 2004). Post-referral to CAMHS, young people in care face challenges in communication between departments, and have a desire for a greater level of LA support (York \& Jones, 2017). Whilst there has been an increase in the past decade of research papers originating in the UK, the more seminal work comes from the USA. Such studies may lack generalisability to the UK due to the differences in healthcare provision and the degree to which services are centralised. Furthermore, the relatively recent introduction of digital case files, enabling widespread dissemination of information amongst relevant professionals, causes difficulty when extrapolating from the larger historical studies.

Given the recent rise in the use of kinship care as a placement option, a number of studies have emerged which examine the psychological benefits and drawbacks of kinship care, often comparing it to foster care with strangers. Before examining the differences in outcomes for different care placements, it is important to consider how the children entering each type of placement differ. A study, mentioned previously, by Leslie and colleagues (2005) examined the medical records of 1542 children entering care via a single assessment centre in the USA. The prevalence rates were relatively low compared with previous estimates, with only $8.7 \%$ having a documented mental health disorder or referral for consultation. A further $7.8 \%$ of the sample were recommended for an additional consultation with a mental health professional. Importantly, no significant differences were found between the prevalence rates by placement type suggesting that on entering care the children in this sample were very similar in terms of their needs.

The disparity between this study and others with regards to reported rate of psychological morbidity may be explained by a number of factors. Primarily, case files were used to identify whether children had a diagnosed mental health disorder. Given the pressures placed by social workers on birth parents to show that they have the capacity to cope, one might expect a degree of under reporting of problems. Secondly, the study failed to use any form of quantifiable screening 
tool. Whilst not a problem in itself, the judgement of the twelve medical professionals who conducted the examination may have been affected by the situational context. All of the children passing through the centre had just been removed from their birth family home and placed into an unfamiliar setting: a process which would be distressing to most children, never mind those who had previously been subjected to abuse or neglect. It is therefore possible that the behavioural baseline for children within this centre may differ from the general population meaning that a degree of emotional distress becomes the norm. Therefore a medical professional working within this centre may have a higher threshold for clinically significant presentation of symptomology than one might expect from a General Practitioner working within wider communities. Without a control group from the general population it is impossible to ascertain whether this is the case, although it is an important consideration.

Some studies suggest that children in kinship care may fare better than their counterparts in non-kinship care with regards to psychological wellbeing. Research suggests that children in a kinship care placement face lower risks of continuing behavioural problems in adulthood, alongside lower rates of mental health therapy use and the use of psychotropic medication (Sakai et al., 2011). A review by Cuddeback (2004) noted that children in kinship care were less likely to have developmental or behavioural problems on their records prior to the placement. There are two possible explanations for this: firstly, that the populations differ in their level of reporting, perhaps because those with family who are able to provide support feel that mental health problems in the child are less concerning. Alternatively, and perhaps more likely, there may exist a placement bias whereby children with behavioural problems are more likely to be placed with non-kinship foster carers who receive additional training and support. It was also reported that children in non-kinship care were more likely to suffer from a serious mental health condition than those in kinship care and that the latter suffered from fewer emotional disturbances and had fewer school problems. It seems, however, that reporting mental and behavioural difficulties, and accessing appropriate support, is greater in non-kinship care. O'Brien (2012) suggests that a lack of reporting in kinship care may in fact be due to the nature of the kinship carers. It is proposed that kinship carers are more positive and less 
problem-focussed than non-kinship carers who, due to the nature of the placement, may have greater supervision. It is also possible that the bond between the kinship carer and the child is greater than that of a non-kinship carer meaning that problems that may affect placement stability are more likely to be hidden by the carer and not reported. This may then lead to the lower rates of mental healthcare use witnessed in many studies (Winokur, Holtan, Batchelder, \& Winokur, 2014).

A study based in Northern Ireland also sought to explore the mental health of young people who are looked after (McSherry et al., 2015). Using the Strength and Difficulties Questionnaire (SDQ) (Goodman, 1997) as a measure of psychological morbidity, the study found that a significantly lower percentage of those in kinship care scored within the abnormal range for total difficulties compared with either the residential or mainstream foster care groups. As a population study within Northern Ireland's public care system, the results from this study provide a reasonable insight into differences in mental health prevalence between different placement types.

There is some limited evidence that children in kinship care suffer fewer behavioural problems than those placed with strangers (Holtan, Ronning, Handegard, \& Sourander, 2005; McSherry et al., 2015). From the Northern Irish study, the difference appears to be high with $41 \%$ of those in foster care having a diagnosed behavioural problem compared with 23\% in kinship care (McSherry et al., 2015). However, a study conducted in Belgium found that the most important predictive factor with regards to behavioural problems was not actually placement type. Rather, the number of previous placements was the best predictor of behavioural wellbeing in children residing in public care (Vanschoonlandt, Vanderfaeillie, Van Holen, De Maeyer, \& Andries, 2012). This is an important point to consider as it the relative stability of kinship care placements reported in previous literature may be key in explaining a disparity in behavioural wellbeing between foster and kinship care.

In addition to behavioural problems, a study from Australia suggested that kinship care was a significant protective factor against attachment problems (TarrenSweeney \& Hazell, 2006). This may be due to the ability of the child to retain a 
relationship that they had prior to removal from the home with their kinship carer (Font, 2014). It may also be due to the relative stability of placements with children in kinship care less likely to have frequent placement changes allowing the child to become attached to a carer over time without as much concern over rejection by their primary caregiver (Angel \& Blekesaune, 2017; López López, del Valle, Montserrat, \& Bravo, 2011; Montserrat, 2014). Furthermore, contact with a wider social network including extended family members, friends from the period prior to placement and birth family may be more frequent for children in kinship care, once again allowing them to retain bonds that facilitate successful attachment behaviour (Kiraly \& Humphreys, 2016). Tarren-Sweeney and Hazel (2006) also suggest that familial attachment, in addition to the child's ability to retain their personal identity, may explain the differences in mental wellbeing between kinship and non-kinship foster care which they report "appear to be clinically meaningful” (Tarren-Sweeney \& Hazell, 2006, pg. 95)

Whilst the research discussed prior to this point indicates that kinship care may lead to better psychological wellbeing in children within public care than stranger foster care placements, a large body of research exists that challenges this assertion. This is particularly true of studies that look at the long-term effects of kinship placements compared with foster placements. Benedict, Zuravin and Stallings (1996) conducted interviews with 214 adult participants who had previously been in public care in the USA of whom forty per cent were placed in kinship care. They looked at a range of factors including mental health, stresses and support, and risk-taking behaviour. The authors found that $18 \%$ of the entire sample had a diagnosis for a mental illness with no significant differences between kinship and non-kinship care. This is lower than previous estimates of mental ill health in the kinship care population and seemingly contradictory to studies which report disparities in mental illness by placement type. Furthermore, the support networks for all participants were very similar with both kinship and non-kinship participants reporting that friends were the biggest source of support rather than family. Life stresses were also not significantly different between the two groups suggesting that the support networks in place were equally effective in minimising the effects of adverse life events. Risk taking behaviour also failed to show many differences between groups, although significantly more 
participants in the kinship care group had traded sex for drugs which may indicate substance dependency rather than casual use. Other studies have also pointed toward higher levels of drug use in adults who have previously been in kinship care compared with those in foster care with strangers (Sakai et al., 2011).

The levels of violence towards partners was surprisingly high for both groups with no significant differences between the kinship and non-kinship care groups (Benedict et al., 1996). Of the 214 participants, 60.7\% had a partner whom they had been with for at least 3 months. Of these, 42\% reported that they had slapped, hit, kicked or beaten up their partner within the 3 months prior to the study. Furthermore, $33 \%$ reported that they had been subjected to violence by their partner within the same timeframe (Benedict et al., 1996). The levels of domestic violence in the general population is incredibly difficult to ascertain due to the secretive nature of both abusers and victims which most likely leads to under-reporting. The Crime Survey for England and Wales (CSEW) estimates that domestic violence rates against men and women for the year ending March 2015 were 4\% and $8.2 \%$ respectively (Office for National Statistics, 2016). Whilst these figures are thought to be lower than the actual prevalence of domestic abuse, the similar approach to data collection between the CSEW and the study by Benedict and colleagues (1996) make these figures a reasonable contextual benchmark.

Whilst the study looked at a longer period of time than those using children as participants, the average participant age was only 23 years meaning that generalising the findings to later stages of life would be questionable. In order to fully understand the effects that a kinship placement may have on an individual in the long term comparative to other placement types, it is important to follow participants over a longer time frame. The study by Benedict et al. (1996) is also limited by the retrospective nature of the sampling technique which may have led to bias. Those who came forward may have had either very positive or very negative experiences of public care, whether placed with or without kin, which led them to participate. The ability to generalise these results to a UK population is also severely limited, especially in areas such as South Wales where the population is predominantly white Caucasian. The sample in the study by Benedict and colleagues was primarily African American (87\%). Whilst racial and 
ethnic differences are not relevant in themselves, the underlying cultural values that may be historically engrained into the identities of carers and the children in their care may lead to differences in variables that may not be predicted.

Studies which examine the long term effects of kinship care are important in establishing which effects are truly beneficial or detrimental, and which are superficial. Despite this, studies investigating longitudinal outcomes in kinship care are scarce, possibly due in part to the relatively recent rise in its use as a widespread placement option. In particular, there are few studies which follow children into adulthood and look at the long term psychological and behavioural outcomes for children in public care in the United Kingdom. Whilst evidence from other nations such as the USA and Australia is useful in indicating the trends that may be found in the United Kingdom, there remains a large gap in the literature regarding UK specific information. Evidence to date, as seen here, is somewhat contradictory which may be due in part to the wide variance in the samples used as a result of internationally differing definitions and social policy. The research to date suggests that although kinship care itself may not be a protective factor, certain factors attributable to kinship care may serve that purpose. Holtan, Rønning, Handegård, \& Sourander (2005), found that the retention of community ties and contact with birth parents were beneficial impacts of a kinship care placement in Norway as children placed with relatives were more likely to remain geographically localised. This is supported by an American study that found that higher levels of birth family contact was related to positive mental health for children in foster care (McWey, Acock, \& Porter, 2010). Whilst this study was not comparative with kinship care, it may be that the maintained links with birth family that are characteristic of kinship care mediate the effects that an out-of-home placement may otherwise have. Within this, the effect of separation anxiety may reportedly be reduced by placing children with their siblings. It has previously been reported that kinship carers were more likely to accept sibling groups than non-kinship carers, although evidence from the UK disputes this suggestion (Farmer \& Moyers, 2005; Paxman, 2006; Sellick, Thoburn, \& Philpot, 2004). Factors such as minimal changes of school and placement stability have also been found to positively affect mental health, although the extent is difficult to determine (Fechter-Leggett \& O'Brien, 2010). If future research is to have any 
impact on policy, it should focus not only on the trends, both short term and long term, of kinship care, but also on potential directions of causality between factors and outcomes.

\subsubsection{Positive mental health}

Benedict and colleagues (1996) studied both the mental illness and mental health of young people in care. Using self-report measures, they found that $76 \%$ of their sample from both kinship and non-kinship care described their mental health as good or excellent. Eighty one per cent reported that they felt good about their mental health. These figures suggest that self-reported positive mental health can be common amongst those in public care and that promoting this may be as important as preventing negative mental health. This has implications for research. Whilst previous studies have focussed on deficiencies in mental health, there is merit in ascertaining the prevalence of positive mental health and factors that have influenced a more positive outcome. This may aid in establishing strategies for not only preventing mental illness, but in promoting positive mental health for looked after young people.

\subsubsection{Assessing mental health and mental illness}

As previously mentioned, it is important to consider both mental illness and mental health when looking at the overall wellbeing of children in public care. The nature of psychological research is such that well tested quantitative measures with internal reliability and consistency are readily available and in many cases can be administered via the internet. These can be completed within short time frames and give a clear snapshot of the wellbeing of a participant by creating and assigning a score to indicate clinical significance. This can then be compared against the general population norms to determine whether an individual deviates from this norm sufficiently for it to be considered clinically significant. Such scoring systems can be a useful indicator of mental health or illness, although they should not be considered, in isolation, to be an adequate means of 
assessing the care population who have complex and often overlapping needs. Within mental health research there is a place for qualitative assessment of factors in order to fully understand the intricate needs of young people in care.

One approach to assessing emotional competence is via the concept of 'emotional literacy'. Emotional literacy relates to the ability of an individual to appraise, express, access and regulate emotion (Roffey, 2008). Emotional literacy is thought to be important in a number of factors with higher literacy found to correspond with lower levels of psychiatric disorder including depression, stress and somatic symptomology (Dawda \& Hart, 2000). Emotional literacy is also considered important in the promotion of meaningful interpersonal relationships (Steiner, 1984) and academic achievement (Bar-On, 1997). There is some evidence, albeit limited, that emotional literacy is lower in young people living in out-of-home care than in the general population. Rees (2013) used the Emotional Literacy Assessment and intervention inventory (ELAII) (Faupel, 2003) to examine the emotional literacy of young people in out-of-home care in Wales ( $n=193)$. Results indicate that emotional literacy, as rated by the young person themselves, their teacher and their carer, was significantly lower than peers in the general population. However, the study did not differentiate between the different placement types meaning that it remains unclear as to whether this pattern would hold within formal kinship care. As emotional literacy has been associated with a number of factors related to wellbeing, further exploration of emotional literacy levels within the formal kinship care population is warranted.

\subsubsection{Resilience}

\subsubsection{Defining resilience}

Rates of mental illness and developmental delay show that although children in public care are at greater risk of developing difficulties, many have some means of circumventing this risk. Rees (2013) found that a number of young people in public care scored positively on mental health measures, whilst further studies have found that reported factors such as physical or sexual abuse, incarceration 
of a parent or neglect do not necessarily result in a child suffering from adjustment disorders or psychological difficulties (Sands et al., 2009). There is a growing body of research that describes this ability to resist life stressors and develop normally as resilience. There are many definitions of resilience, although most definitions focus on the same concept which is that of positive adaptation. This takes the common notion of adaptation, defined as "the process of changing to suit different conditions" (Cambridge Dictionary Online, 2011), and focusses on the attributes of change that result in a positive outcome. Werner (1984) provides the following definition: "the ability to recover from or adjust to misfortune or sustained life stress"(p. 68). In this sense, resilience is an abstract term describing the external factors, personal attributes and individual differences that allow some children to thrive in placements whilst others do not. These factors may originate from the child's environment, for example the child's support network may be a resilience factor. Equally, factors with an internal origin such as intelligence may play a role in protecting an individual from adverse events.

\subsubsection{Resilience factors}

Many factors have been linked with increased resilience in children in public care. One such factor is the child's participation in extracurricular activities such as sports, or artistic pursuits such as writing or playing a musical instrument. Sands, Goldberg-Glen \& Shin (2009) suggest these activities are viewed as strengths as they improve child wellbeing on a number of factors including self-esteem and social interaction. Participating in these activities gives children and young people in public care an opportunity to use their strengths and talents to improve in a given area, and to showcase these in a way that brings them pride, a theme that runs through the relevant literature (Burgess, Rossvoll, Wallace, \& Daniel, 2010). Equally important is receiving recognition for these strengths as positive reinforcement has been shown to enhance self-esteem (Smith \& Smoll, 1990). The children may also find that the activities give them an opportunity to identify themselves with a strength rather than an externally originating label. So rather than being "Jimmy who lives with his Grandma" a child could identify as "Jimmy who plays football well". The concept of self-identity will be explored further in 
section 2.4.4 Identity but should be considered when examining the potential benefits of increasing resilience for children in public care.

Whilst children report reaping benefits from extracurricular activities, and there being some empirical support for this assertion, access to activities may be limited by the type of placement a child experiences (Chapman, Wall, \& Barth, 2004). Financial difficulties are a concern widely reported by kinship carers, particularly those in informal care arrangements or under certain types of care order such as Special Guardianship Orders (Selwyn et al., 2013). Limited financial resources may make it more challenging for children in kinship placements to attend activities requiring investment from carers. A qualitative study by Selwyn, Farmer, Meakings \& Vaisey (2013) investigated this point with informal kinship carers in the United Kingdom. One carer reported "I'm in debt up to my eyeballs. I have about two hours sleep a night 'cos I worry about money. You know that feeling when you go to the cashpoint and you think please, I just need $£ 10$, just to get home” (Selwyn et al., 2013, pg.53). Furthermore, the varying rates of pay granted to kinship carers in combination with the socioeconomic deprivation often featured means that kinship carers are more likely to work whilst caring for a foster child creating large demands on their time (Selwyn et al., 2013). This may make it more challenging for them to transport children to and from sporting or artistic events.

Social support, whilst important in most domains of wellbeing, has become a recurring theme in resilience research. Osterling \& Hines (2006) noted that those with higher resilience tended to have a natural adult mentor to support them. Whilst this sample featured a very restricted age range, the authors argue that social support may play an important role in the development of resilience in children at key developmental stages. The transition into care may be one such transition, although there is currently no evidence available to indicate the role that social support may play. Daining \& DePanfilis (2007) found that having higher social support levels from family, friends and institutions was significantly related to higher resilience levels in care leavers.

It is not only within care populations that the importance of social support has been noted. It has previously been found to mediate a person's ability to cope 
with stress (Cobb, 1976). Metzger (2008) reports that children in kinship care have significantly greater social support than children in foster care. Further evidence has been found to support this claim in kinship care, as stable relationships with relatives, including the extended family, have been found to promote wellbeing (Rink \& Tricker, 2003). The ability to maintain regular contact with extended family is a relatively unique aspect of a placement in kinship care and as such we may expect higher levels of social support and therefore resilience in children and young people placed with kin.

Kinship care is a relatively unique placement type in that it minimises the need for adaptation (Burgess et al., 2010). The child is placed in a setting that, although new from a care planning perspective, is normally physically familiar to them. They are placed with carers who they know and who know them, and are often placed in a home which is nearby their parental home, sometimes even the same street. Whilst this has repercussions in other areas, such as unwanted parental contact, this reduces the child's adaptation requirements. Often they do not need to change schools meaning that their teachers and social circles outside the home are not affected. The retention of the child's ecology, and its potential benefits, will be discussed further in chapter three, however it is highly relevant when discussing resilience in children.

Fearing parental rejection is a common theme in social work research (Selwyn et al., 2013). In kinship care, whilst this is still evident to a certain degree, it may not play as big a role as it does in foster or residential care. Children within the care system often fear that they have been rejected through a fault they possess and that they are therefore to blame for their situation (Biehal \& Wade, 1996; Herrick \& Piccus, 2005). By contrast, being placed in kinship care with family who understand the situation, they may see rejection solely as a fault of their parent rather than generalising it to believe that they are unworthy of care due to their own flaws. There is no evidence as yet to suggest whether kinship care could act as a resilience factor in this sense, although it would be worthy of further investigation.

Whilst a lot of studies focus on the resilience of children in care, some look the broader picture. The concept of family or community resilience has been 
investigated primarily in African American communities in the USA (Scannapieco \& Jackson, 1996). Such studies suggest that kinship care itself is a display of community resilience as the family unite to combat the adversity faced by an individual. There is the suggestion that it may not be enough to promote resilience in the young person who is looked after, but that resilience comes in part from the wider family networks which in turn promotes positive outcomes both for the carer and the young person involved (Metzger, 2008; Scannapieco \& Jackson, 1996). This principle forms the basis of one of the approaches being used in some areas within the UK: the signs of safety model (Turnell, 1998). This is a strengths focussed approach which acknowledges the area of concern faced by each family and explores wider social and familial networks to recruit the necessary support to create a protective environment. This works to attempt to ensure the safety of the child due to both heightened supervision by the wider network and by creating support structures in case of crisis. Most importantly it provides a support structure that can maintain itself autonomously, further ingraining a sense of resilience rather than helplessness. Having a strong family network who are aware of the situation and are able to step in during crisis periods may create a more resilient family structure and enable the family as a whole to progress without the need for formal care orders. It could be argued that resilience should not only be developed for the children, but also for the families as a whole. The signs of safety model are just one means of approaching this proposal.

Research examining the role of caregiver resilience is limited, although there are some indications that it may enhance outcomes for children and young people in public care. In particular the levels of support accessed by carers, including social and instrumental support, seems to have an effect with resilient children tending to reside in placements where the support level is high (Johnson-Garner \& Meyers, 2003). Furthermore, research examining resilience in both young people and carers in formal kinship care in scarce. Given the rise of formal kinship care as a popular placement option, further research in this area is warranted. 


\subsubsection{Identity}

Identity is a vastly debated and highly contentious concept that interests academics from psychology to philosophy. Its various abstractions and conceptualisations come together to model identity from the innermost layers of personal identity to the interactions determined by the multifaceted nature of our social identity. However, despite the differing approaches to the conundrum of identity, one factor that almost all theories share is that understanding our own identities, and the roles that accompany them, is important for our development and mental wellbeing (Suh, 2002). In order to understand the basic underpinnings of identity theory, we must abandon the idea that we have one single identity. Rather, our identity is constructed of layers which define who we are. Which layer is revealed at any one time is determined by the social environment in which we find ourselves. An example from the previous section concerning resilience used a hypothetical child in public care named Jimmy and described him as both a child in kinship care and as a football player. Whilst he is playing football, he does not cease to be in a kinship care placement, but it is not the role that he is primarily filling at that time. In a similar way, he may also be able to speak another language such as French. Unless he is playing with French players, or playing in France then that aspect of his identity would be redundant, although it would still form part of his overall identity. Thus, we adapt at each point in time to fulfil the roles that we are required to fulfil by external social demands.

An important aspect of social identity theory is that of the in-group / out-group contrast. The in-group are people with whom we self-identify as being similar and whom we see favourably comparative to the out-group. Prejudicial social comparison between the in-group and the out-group then leads to increased selfesteem for members of the in-group (Colman, 2003). It is by this mechanism that mental wellbeing may be increased as a consequence of improved self-esteem. The family forms one such in-group, often reinforced by a shared surname.

Previous studies have reported that children entering public care can become distanced from their 'biological identity' and lose their sense of belonging (Laird, 1979). This may seem fairly intuitive, particularly in children who feel rejected by their birth parents. This loss of belonging can lead to adverse effects on a child's 
emotional wellbeing (Dore \& Kennedy, 1981). It is thought that kinship care may be able to mediate these effects to a certain extent. Rather than being removed from the family, they may simply be removed from the home. By residing with kin they may still retain their identity as a part of their family and so have minimal adjustment problems compared with children entering foster care. To date, evidence surrounding this theory is somewhat lacking, although there are several indicators to suggest that kinship care may provide some form of protection for a child's identity (Iglehart, 1994).

Aside from the possible benefits to emotional health, identity is an asset that children in kinship care reportedly value (Broad, 2004; Willis \& Holland, 2009). For many children in foster care, particularly those who enter care at a young age, an understanding of their past and their heritage comes in the form of life story work completed in conjunction with their social worker. This can come in many forms, although it is often presented as a book and details the important figures in a child's life and their journey from residing with birth parents through to their time within the care system. It often contains photographs and can sometimes contain letters from parents and foster carers. For the child it provides clarity with regards to events that may otherwise be confusing for them, such as their entry into care, and gives them a sense of where they have come from (Willis \& Holland, 2009). This is important as identity is an understanding of who we are now through a cohesion of our past selves and who we will be in the future (Perry, 2002). The importance of identity is also recognised at a higher level. The United Nations Convention on the Rights of the Child details the child's right to know their parent and "to preserve his or her identity, including nationality, name and family relations" (UNCRC, Articles 7\&8, 1989).

As with a vast number of US studies which feature identity, Iglehart (1994) hones in on ethnic identity as a major factor for consideration. Whilst the ethnic composition of areas such as South Wales may vary from those featured in foreign projects, the concerns are possibly still valid in relation to national identity. Compared with other areas of the UK, Wales has a unique population where 15\% speak Welsh, with children between the ages of 3 and 15 years accounting for $30 \%$ of that figure (ONS Census returns). Furthermore, with $66 \%$ of the normal residents in Wales describing themselves as primarily Welsh, it would appear that 
a strong national identity is present in a considerable section of Wales. This may have implications when removing children from the home as they may be moving from or to a home with strong national identity. If the national identity of their foster carers contrasts vastly with that of their birth family, it may create friction and confusion in the child's own sense of self. Furthermore, language may be a barrier in areas that have higher proportions of Welsh speakers. Kinship care may help to curb this to a degree. Whilst it is not always the case, families often have shared understandings of national identity and the cultural norms that accompany it (Bennett, Wolin, \& McAvity, 1988). By placing a child in a kinship placement with a culturally analogous carer, the practices and traditions may be shared with the child allowing them a greater understanding of their own heritage (Farmer \& Moyers, 2008). It is for these reasons that studies of ethnically contrasting populations should not be discarded when examining the concept of identity in kinship care. Whilst the validity must be carefully considered in each case, there may be important points raised by such studies that warrant further attention in relation to children in the UK.

\subsubsection{Attachment}

\subsubsection{Attachment Theory}

An area of key interest for those researching public care is that of attachment. Attachment Theory is credited to Ainsworth and Bowlby (1991) who, through a number of studies over some decades, created the framework through which attachment can be viewed today. The theory proposes that children are born with an innate need to form a bond with the primary caregiver that exceeds the behavioural attachment theory that had previously dominated the field (Dollard \& Miller, 1950). Behavioural attachment theory posited that a child's attachment to its mother was based upon the mother's act of feeding the child. Bowlby demonstrated that this theory underestimated the strength of a child's attachment to its mother (Bowlby, Robertson, \& Rosenbluth, 1952). 
It is theorised that the attachment made between a child and their primary caregiver may be the blueprint for a child's future social relationships: a dysfunctional attachment at this stage may lead to dysfunctional social interaction later in life. A secure attachment is such that it also provides comfort to the child, rather than merely providing sustenance. Harlow and Zimmerman (1958) verified the need for nurture in a series of studies with rhesus monkeys where a cloth 'mother' was preferred to a wire version, regardless of which one they were fed from.

Security is the basis of a reasonable proportion of Attachment Theory. When developing theories of attachment styles, Ainsworth proposed that a strong attachment with the primary caregiver creates a secure base from which the child can explore their surroundings (Ainsworth, 1979). It is important that the primary caregiver can be relied upon when needed, but allows and positively encourages independence in order for this to be successful. Possibly the most famous study into infant attachment is Ainsworth \& Bell's (1970) Strange Situation study. Within a laboratory environment, the primary caregiver was instructed to leave the child with a stranger and return at various intervals. The behaviours displayed by the child upon separation from the primary caregiver and upon reunion provided an insight into attachment styles. Consequently, three styles of attachment were proposed: secure attachment, ambivalent-insecure attachment, and avoidantinsecure attachment.

Secure attachment is characterised by distress during periods of separation from the primary caregiver, avoidance of the stranger when alone but no avoidance in the presence of the primary caregiver, and positive behaviour during reunion periods. This attachment style was seen in $70 \%$ of the sample in Ainsworth's study, and is generally deemed to be a positive form of attachment. It suggests that the child is confident that their caregiver will be present when needed, and that they are a secure base from which the child can explore their surroundings. Ambivalent attachment, affecting $15 \%$ of the sample, is also characterised by distress when the primary caregiver leaves, although the infant avoids the stranger even when the caregiver is present, and during the reunion the child will normally look for proximity to the primary caregiver, although resist contact and, on occasion, show signs of anger towards them. The final $15 \%$ of the sample 
displayed avoidant attachment styles where the infant shows no sign of distress when the primary caregiver leaves the room, where the stranger's presence has no bearing on the child's behaviour to the point that the stranger and primary caregiver are equally capable of comforting the infant. During the reunion period, the child shows little interest in the primary caregiver.

In 1951, Bowlby proposed that successful attachment between a child and their primary caregiver was restricted to a critical period, namely within the first two years. After this, the chances of a child forming a secure attachment are thought to be lower. This is a particularly important consideration in public care where children are removed from the home sometime during this critical period. If their care journey is unstable, perhaps residing in multiple short term placements, then it may be more challenging for children to create a secure attachment to a single primary caregiver. Given the higher rates of behavioural difficulties found in the foster care population than the general population (Clausen et al., 1998), and given the link previously suggested between behavioural difficulties and ambivalent and avoidant attachment styles (McCarthy \& Taylor, 1999), it may be that this is the case, although there is currently no directional evidence to support this. Furthermore, caregiver behaviour has been found to correlate with attachment style. Caregivers who smiled more and behaved in a playful manner during face-to-face interactions with their child tended to produce children with secure attachment styles (Blehar, Lieberman, \& Ainsworth, 1977). Equally, the behaviour of the primary caregiver also correlates with their infantile attachment to their own primary caregiver suggesting that the attachment style is relatively constant throughout the lifespan, and that it is passed on from generation to generation (Obegi, Morrison, \& Shaver, 2004). This may have implications in public care, and kinship care in particular, where the child has been removed from a neglectful or abusive caregiver. If caregiver behaviour and attachment style are intergenerational, placing the child within the family unit may compound rather than rectify dysfunctional attachments. That is not to say that it cannot be changed, some studies have proposed the possibility of intervening during the critical periods to support the primary caregiver and promote interactive behaviours that encourage positive attachment outcomes for their infants (Cornell \& Hamrin, 2008). 


\subsubsection{Attachment in public care}

Attachment is a particularly prominent issue in the field of social work and social policy. Whilst in ordinary child development there tends to be consistency in the identity of the primary caregivers, this does not tend to be the case for children entering the care system (Lawrence, Carlson, \& Egeland, 2006). Whether they arrive through child protection, children in need or the juvenile court system, children entering the care of their local authority are removed from their birth home and placed in a new location. For many, this involves moving to a new house with strangers whom they have never met, often staying in an emergency or short-term placement prior to finding a long-term home (Hill \& Aldgate, 1996; Westacott, 1988). There is also often hope of reunification meaning that contact is often encouraged to maintain ties with birth parents (Neil \& Howe, 2004). This means that creating an attachment relationship with foster carers can be challenging, particularly for older children, due to uncertainty in terms of length of stay in each residence and possible return to their birth home. Children who believe the will be reunified with birth parents may be reluctant to form new attachments with foster carers due to concern that it may be emotionally damaging when they leave the placement (Stott \& Gustavsson, 2010).

Fortunately, even infants are capable of forming multiple attachments (Haight, Kagle, \& Black, 2003). This has an evolutionary advantage in cultures that promote community based rearing of children, but may also serve as a protective factor for children in public care. This is important, as these children may have been unable to create strong bonds with birth parents due to abuse or neglect. There are developmental stages of attachment and placement changes within these periods may have differing levels of effect. In particular, separation of a child from their primary caregiver between 6 and 36 months may be especially stressful and affect future relationships with carers and peers. This is due to periods of neural plasticity in child development during which the brain structure changes to form the basis for our understanding of the world (Haight et al., 2003). It has been suggested by a number of studies that if a child fails to form attachments in a constructive way or is exposed to high levels of stress during these key periods, then the brain can potentially develop into a structure that is vulnerable to psychopathology, inappropriate social behaviour and impaired 
emotional and cognitive development (Johnson, Cohen, Brown, Smailes, \& Bernstein, 1999; Kaler \& Freeman, 1994; Weiss, Longhurst, \& Mazure, 1999). Neural plasticity in childhood provides hope for recovery from any negative effects of previous neglect or abuse (Black \& Greenough, 1986). This means that a suitably nurturing fostering placement may have the capacity to not only prevent further attachment difficulties, but to reverse the effects of historic difficulties. If this is the case, the exploration of recovery in public care is justified. Furthermore, studies in the general population have revealed age-related differences in attachment orientation suggesting that age impacts upon the way in which interpersonal relationships exist (Chopik, Edelstein, \& Fraley, 2013; Gorrese \& Ruggieri, 2012). It is arguably worthwhile exploring any age differences in kinship care, where multiple attachments may exist and become stronger or weaker relative to one another.

In addition to the 3 attachment styles proposed by Ainsworth (1979), a further classification of attachment, referred to as Type D, is described by Barnett \& Vondra (1999). Children in this group use disorganised or disorientated behaviours and strategies to cope with separation. Behaviours include contradictory behaviours such as a rapid cycle of seeking proximity and trying to avoid the caregiver, glazed expressions, mistimed movements or stress behaviours such as head banging or huddling on the caregiver's return (Haight et al., 2003). This attachment style has been associated with parental psychopathology such as depression (Martins \& Gaffan, 2000; Teti, Gelfand, Messinger, \& Isabella, 1995). It is thought that the parent's behavioural cues when interacting with the child lead the child to develop such coping strategies. Equally, carers can be placed under high levels of stress leaving them vulnerable to depressive and anxiety disorders. Kinship carers are at particularly high risk due to the low socioeconomic status of many carers, restricted support networks, lower levels of organisational and financial support, multiple caring roles and, in some cases, bereavement (Selwyn et al., 2013). The use of Type D responses to parental behaviour can impact on peer relationships with disorientated attachment being linked to aggressive and hostile behaviour towards peers (Lyons-Ruth, Alpern, \& Repacholi, 1993). It has further been linked to 
psychopathology later in life, poor overall adjustment in school and behavioural problems (Carlson, 1998; Lyons-Ruth, Easterbrooks, \& Cibelli, 1997).

Evidence suggests that children and young people entering kinship care are vulnerable. Examining the reasons for entry to care, Selwyn and colleagues (2013) found that $64 \%$ of the sample had suffered parental indifference whilst $48 \%$ of carers were certain that the child had experienced abuse. Given the associations that have been established between neglect, abuse and disorganised attachment styles, young people in public care are at greater risk of having disorganised attachment (Egeland \& Sroufe, 1981; Finzi, Ram, Har-Even, Shnit, \& Weizman, 2001). However, the ability to form multiple attachments, and a pre-existing relationship with a kinship carer, may enable kinship care to mediate some of the challenges that the child faces regarding attachment. Firstly, the child may have previously formed an attachment with the carer and thus be at lower risk despite prior abuse or neglect. This may serve as a protective factor for the young people. Secondly, as the attachment to kinship carer is pre-existing in many cases, the principle target is to shift the emphasis of attachment from one of secondary to primary caregiver. In some cases this may be more challenging, although it may be simpler for the child than forming a relationship from scratch. The relative ease with which a child can form an attachment to a kinship or mainstream foster carer has not yet been explored, but would be worthy of examination. If kinship relationships are indeed easier to form, it may have implications for practice and policy.

Kinship placements may have further advantages compared with non-kin placements. The relative stability of kinship placements mean that a child has the opportunity to create a strong and lasting bond without the disturbance associated with frequent placement moves (Rubin et al., 2004). Studies have found that foster placements with children who have behavioural difficulties break down more frequently than kinship placements. If children have developed behavioural difficulties as a result of attachment problems, then the stability of a kinship placement may provide the protective environment within which they can develop new behavioural and social strategies (Black \& Greenough, 1986). By contrast, frequent placement changes that are often a feature of non-kin foster placements and residential care may impede this development. Kinship 
placements may also facilitate a continued relationship with the birth parents where it is appropriate to do so, and with wider family and friends due to the geographical locality of a large proportion of kinship placements. Research has suggested that kinship placements tend to be located in the vicinity of the child's pre-placement address meaning that the child can continue to attend the same school and retain pre-existing peer relationships (Selwyn et al., 2013). This may have major implications for children in kinship care as it means that previous attachments are not jeopardised and disturbance is minimised, reducing their risk for attachment problems. For those children who have created attachments to their birth parents, the locality of their placement and the ongoing connections via their primary caregiver enables their attachment to further develop and remain relatively stable. Rather than losing and creating new attachments in the transition from birth parent to foster parent, children in kinship care may be able to enhance their attachments to both parents and kinship carer over time, with the balance of these attachments varying as time goes on.

As with any placement option, kinship care has its drawbacks with regards to attachment. Birth family contact is one such area with higher levels of unplanned contact reported in kinship care (Ehrle \& Geen, 2002; Farmer \& Moyers, 2008). Whilst unsupervised contact may be to some degree beneficial to the parent-child relationship as it enables natural interaction, it can have a negative impact on the child (Macaskill, 2002). Children in kinship care have reported that visits can be upsetting and it is thought that they may evoke painful feelings about separation (Selwyn et al., 2013). This could explain why behaviour can worsen after contact, with foster carers and kinship carers reporting higher levels of behavioural difficulties immediately following a contact session (Macaskill, 2002). An increase in behavioural difficulties may then lead to friction between the child and the kinship caregiver, particularly if the caregiver must become the disciplinarian to counteract the disruptive influence that a birth parent may provide. This friction can interfere with attachment to the kinship caregiver which may extend the attachment difficulties rather than solve them.

Further to problems surrounding contact, the levels of supervision in place from the local authority can sometimes be lower for kinship care than formal foster care, particularly once the placement seems settled (Geen, 2004). Whilst there 
are statutory guidelines surrounding placements, supervision exceeding the minimum may be seen as both unwarranted and undesirable by social workers and kinship carers alike. Furthermore, there is an entire population of children in kinship care who are not known to the LA and as such receive no such supervision. Whilst not an issue in itself due to the relatively successful autonomy of a number of families, it may lead to a failure in detecting problems such as attachment disorders and therefore lead to difficulties in the long-term. One might also expect a degree of under-reporting by kinship carers who may fear that they may be seen by social workers as unable to cope with the caring responsibilities. Carers have reported that many placements are initiated through a fear that the children will be taken into care and that they wished to prevent this (Selwyn et al., 2013). Should they find that they are struggling with the placement due to behavioural issues resulting from attachment difficulties, they may be less inclined to approach formal support services. It has been suggested that underreporting of problems and feelings of duty and loyalty to kin has led some caregivers to continue low quality placements for longer than foster placements (Farmer, 2010).

Whilst Attachment Theory is a prominent issue in the field of social work, it is important that the limitations of this theory are addressed. Of particular note is that the predictive power of attachment and Attachment Theory is very limited. Whilst poor attachment in childhood may be correlated with poor outcomes, the two are not always concomitant. Lewis (1998) argues that many theories surrounding child development are often considered to occur in a gradual manner over a continuous period of time, and in a direction that leads to a specific end point. However, this fatalistic view of human development may misconstrue its true nature. Rather, Lewis (1998) argues, our developmental journey is constantly interjected by randomly determined external factors. Furthermore, as he eloquently states: "the self and its construction of reality interrupts the chain of events between past and present" (Lewis, 1998, p. 106). Therefore, development may be better understood as a journey with many deviations leading to multiple possible outcomes, as opposed to a linear, predictable path. This limits the extent to which we can predict future outcomes, particularly at the individual level, as demonstrated by the incidence of 'positive exceptions' in the study by 
Rees (2013). This limitation is particularly important when discussing Attachment Theory, but is also relevant in other areas that seek to explore the relationship between childhood experience and long-term outcomes.

This section has examined literature regarding the health and wellbeing of young people in kinship care. Given the lack of evidence pertaining to various aspects of wellbeing for young people in kinship care, it is crucial that outcomes are examined further. Aim two of this study will explore multiple domains addressing mental health, attachment and emotional literacy. In addition to establishing the status of young people on each of these domains, research questions will explore the relationship between domains and other outcomes such as placement stability. Given the significance it is given in social work practice, the concept of identity will also be explored with young people and carers.

\subsection{Voice of the child}

\subsubsection{History of voice of the child in policy and legislation}

There is a history of treating children as ontologically different to adults (Qvortrup, Bardy, Sgritta, \& Wintersberger, 1994) and to make decisions on their behalf due to the belief that children are incapable of making appropriate decisions. There is a growing recognition, however, that children wish to be involved in decision making processes (Selwyn et al., 2013) and that participation may be beneficial for their mental wellbeing (Cavet \& Sloper, 2004; Franklin \& Sloper, 2006). Striking the correct balance of encouraging participation to the level of the child's understanding is a challenge that is not easily addressed, although various government reports have attempted to do so. The Green paper 'Every Child Matters' [ECM 2003] led to the introduction of a Children's Commissioner and was the foundation of the 2004 Children's Act [CA 2004]. However, this step was not revolutionary, rather it re-emphasised voice of the child as an aspect of children's care that had been previously established as an area for improvement.

As discussed earlier, the legislative foundation for much of modern day social work was laid down in the 1989 Children's Act. Aside from being the groundwork 
for the structure of social services and the legal framework for social care in Britain, the Welfare Checklist it incorporates provides a legislative basis for the inclusion of children in the decision making process. Section 1(3(a)) of the Children's Act dictates that when making decisions about a child's future, the court must pay regard to "the ascertainable wishes and feelings of the child concerned (considered in the light of his age and understanding)". However, the Act also introduces the paramountcy principle, which states that courts must act in the best interest of the child. Given the historic prejudice of adults with regards to making decisions on behalf of children, it is likely that the paramountcy principle is the primary concern of those who make decisions. The paramountcy principle may itself be described as a measure to reduce the extent to which children are heard in care proceedings as its very existence suggests an underlying mistrust of the children's judgement and understanding.

A child's right to participate has also been ratified more widely in law by the United Nations Convention on the Rights of the Child. Article 12 of this convention stipulates that "when adults are making decisions that affect children, children have the right to say what they think should happen and have their opinions taken into account". Whilst the right of a child to be heard in care proceedings has a strong legal basis, implementing platforms upon which children can voice their opinions and concerns remains a challenge in practice. The current status of voice of the child in practice will be addressed further in the following section and suggests that historically the legislation has not necessarily been put into practice. Roche (1999) suggests that "despite being social actors... children are often rendered silent and invisible by the attitudes and practices of adult society". The introduction of the 2014 Social Services and Wellbeing Act in Wales with its renewed focus on centralising the voice of the individual in care planning may reemphasise the voice of the child in an effective manner, although this remains to be seen. Given the difference between the treatment of children and adults as agents, it will be interesting to see how the Social Services and Wellbeing Act (Wales) will affect the engagement of children in the processes surrounding their care. 


\subsubsection{Legislation in practice}

Despite strong legislative underpinnings, representing the voice of child in care proceedings and key decisions remains a challenge in day to day social work practice. Children continue to report that they do not have enough involvement in the care planning process (Selwyn et al., 2013). The 'children's views digest' (Morgan, 2014) reports on the extent of child inclusion across a range of domains and has consistently found that whilst participation in some areas is growing, children and young people remain on the whole dissatisfied with their levels of participation. A consultation with 2424 children and young people receiving social care services in the UK indicates that $76.3 \%$ of children felt that their right to express their views on things that affect them was being respected (Morgan, 2014 , pg. 8). Within that, children reported that school or college was the primary place where their views were sought with $94 \%$ reporting being asked there, whilst $71 \%$ reported being asked their views by family and $27 \%$ by a hobby organisation of which they were a member. This is an important finding with regards to children in care, as it suggests a further area of support for the child should their needs be unfulfilled by their placement or educational establishment. Involvement in activities and clubs may enable the child to grow individually on aspects such as self-esteem whilst being able to voice their concerns in a non-judgemental environment to adults whom they trust.

Only $10 \%$ of the children surveyed had been asked for their views by the government, $17 \%$ by the local authority and $12 \%$ by a local hospital, although their views may have been passed along by advocacy workers or other third parties without their knowledge (Morgan, 2014). Although concerning on one level that these figures should be so low, with $94 \%$ being able to express their views through their school or college it may be the case that the information is filtering upwards to local authority or even governmental level without necessarily consulting the children and young people directly. Whilst this is a useful mechanism for reaching wider groups efficiently, it may cause some children and young people to feel that they are not being listened to as there is no feedback down the chain to them. 
Of those who had been the subject of a court decision, $29 \%$ of the children and young people felt their views had been taken into account 'a lot'. By contrast, however, $37 \%$ felt that the court had failed to take their views into account at all (Morgan, 2014). The 1989 Children's Act dictates that courts must pay regard to "the ascertainable wishes and feelings of the child concerned" and at first glance these statistics seem to suggest that this may not occurring. However, it is important to consider the influence that other factors may play in this. The paramountcy principle may interfere with enactment of a child's wishes or views. Whist children have the right to have their views heard, if they are not conducive to ensuring the safety of the child, for example if a child wishes to remain in a neglectful or abusive environment, then the paramountcy principle would take precedence. In such cases a child may feel that their voice is not being heard, however it would be an infringement of their right to protection from harm if their views were acted upon. It is undoubtedly a difficult balance to maintain in ensuring that children's voices are heard, and yet they are protected from decisions that may not be in their best interest.

The channels of communication available to children vary depending on their individual circumstances. Whilst schools, colleges, and community projects are pathways open to many young people, for children in care, social workers and case workers tend to play a central role in enabling a child's voice. In addition to listening to the child, they can act as an advocate to feedback a child's concerns to their teams, senior management, committees and courts to ensure that the child's voice is heard. In order to do so effectively, it is important that a child feels able to talk to their social worker about all aspects of their day-to-day life. Of 2305 children in care surveyed in 2013,69\% said that a social worker or caseworker usually or always spoke to them alone (Morgan, 2014 , pg.10). The presence of other adults, such as the child's foster carers or relatives, may influence how much information a child shares, particularly if they feel there are problems in the placement. It is therefore important that children are able to speak to their social worker, a vital communication tool, without coercion or guidance from other adults in their life.

The practice of voice of the child is linked to relationship based practice, a theoretical basis for social work that is rooted in humanistic principles. The 
relationship between social workers and the families they interact with arguably remains central to practice (Howe et al., 2018). The ability to form a positive working relationship with children is a crucial skill for social workers in order to ensure children feel able to express themselves (Sinclair, 2004). Without a positive relationship, children may feel unable to voice their concerns with their social workers, thus removing an avenue through which they can participate in decisions about their care.

Aside from being a right ratified in law, being able to express their views can enhance the wellbeing of young people. The sense of agency gained by listening to children in care can increase a child's self-esteem and help them feel that they exert some control over their own lives (Higgins, Higgins, Bromfield, \& Richardson, 2007). The concept of learned helplessness coined by Seligman and Maier (1967) showed how dogs who had been unable to escape electrocution in one scenario became conditioned to accept that they had no control over their situation. This loss of a sense of agency consequently led to the dogs failing to attempt to avoid electrocution in another setting where they could have avoided it successfully. This study and subsequent studies in the field have found parallels between the behaviour of the dogs and human behaviour in conditions such as depression (Miller \& Seligman, 1975). In such cases humans can become conditioned to stop attempting to help themselves as they feel that nothing they do will affect the outcome. Children who feel that they have no sense of agency, such as those who feel that they are at the mercy of the court, are at risk of becoming conditioned in such a way. Giving children a voice and ensuring that they feel they are being heard is an essential tool in preventing helplessness and instilling that sense of agency in children who may already be at greater risk of mental health and behavioural difficulties.

\subsubsection{Voice of the child in kinship care}

When considering voice of the child, the experience of children and young people in kinship care can differ from that of children and young people who are placed with non-relative foster carers. For those known to social services, children may 
have less contact with the social worker meaning that they have one less channel through which they can regularly voice their concerns (Iglehart, 1994). Given that children in kinship care do not tend to consider themselves looked after in the same sense, this may not pose too much of a problem and they may feel that they are more able than children in non-relative foster care to voice their concerns to their carers (Burgess et al., 2010). In addition to the formal kinship care population, there is a large group of children residing in kinship care informally who are not known to social services. This makes it difficult to determine the extent to which they are heard, although one may assume that as they are residing with family members that they are able to voice their concerns in the same way as a child who resides with their birth parents. From a research perspective, the contrast between the experiences of children in kinship care and children in non-relative foster care is an important area of exploration.

Historically, children's involvement in research has been limited, in part due to ethical restrictions which have long made children a hard to reach population. This is especially the case in social work research due to the vulnerable status of children within the care system (Heptinstall, 2000). Until recently the primary focus of research in the field was the role of kinship care, although current research tends to examine kinship care from the child's perspective (Burgess et al., 2010; Messing, 2006). How effectively researchers have been able to do so is questionable. Most studies have focussed on formal kinship care arrangements where the child is known to social services (Burgess et al., 2010; Messing, 2006). Whilst this may be efficient for sampling purposes, their views may not reflect the experiences of children in informal kinship care. Selwyn et al.'s (2013) recent study was novel in that the carers and children who were interviewed were in an informal kinship placement. Whilst this approach is useful, the sample size $(n=80)$ limits its generalisability. This is particularly pertinent when generalising to Wales as only $6 \%$ of the sample were from Wales. Considering that Wales has the highest estimated proportion of children in kinship care (1.4\%) the group seem to be drastically under-represented. This is especially problematic as there is large variation in socioeconomic factors in Wales (David, Blewitt, Johnston, \& Grazier, 2004). 
Further difficulties lie in recruiting an informal kinship care sample as many within the population may not wish to be known to social services. Whilst $71 \%$ of the sample in the Bristol study (Selwyn et al., 2013) said that they had approached social services for support, it is possible that the sample was biased. Those who are intentionally being discrete regarding their caring arrangements through fear of local authority involvement may not be as likely to come forward to participate in a research study. It should always be a consideration in studies such as that by Selwyn and colleagues (Selwyn et al., 2013) which have the potential to influence government policy as the participants may be taking part due to having a vested interest in the outcomes. Furthermore, there seems to be a sampling bias that is prevalent in studies in this area. Placements that are stable and going well tend to feature more heavily in research studies potentially skewing the results in one direction (Burgess et al., 2010; Holtan, 2008; Messing, 2006).

Research on voice of the child in kinship care is scarce with studies in the field tending to focus on measurable quantitative outcomes such as physical or psychological wellbeing. Where children have participated in research, they report that their experiences of kinship care have tended to be positive with most showing a desire for the placement to continue. Children in Selwyn's (2013) study showed mixed emotions when talking about their experiences of kinship care although most seemed to enjoy the security provided by the kinship placement.

There is currently a dearth of qualitative studies that explore the views of children and young people in kinship care. This is despite discussion that participatory research may be a platform to facilitate the voice of the child (Grover, 2004). It is reasonable to suggest that further qualitative research in this area may throw light on the underlying issues by ascertaining a clear picture from young people. As such the voice of the child becomes not only a legal obligation or factor promoting individual wellbeing, but a strategy for expanding the knowledge base and exploring children's experiences of kinship care.

Consequently, young people will be included in this research as key informers and participants. Research questions will test the relationship between factors such as emotional literacy with young people's perceived control and involvement 
in decision making in order to establish the extent to which children and young people feel involved in the care process to a level of their understanding.

\subsection{Stability}

\subsubsection{Defining stability}

In a broad linguistic sense, stability can be defined as "a situation in which something is not likely to move or change" (Stability, 2014). Within social work, the situation that the definition relates to is commonly thought of as the placement within which a child is placed. A consistent placement where the child resides in a single address with the same primary caregivers is deemed to be stable. By contrast a child who moves from home to home changing carer and address would be considered to be residing in unstable placements. The concept of stability allows a child to feel secure in their placement and to establish clear boundaries which cannot be established if the placement changes frequently. In some respects, stability is linked to permanency in that a stable placement is often a long-term placement, although a clear definitional boundary exists between the two terms. By contrast to stability which relates to the placement, permanency relates to the overall goal for the future which may involve the child eventually returning to their birth parents or being adopted. In this case a child may have either a stable or unstable journey through care, but retain the same permanency goal throughout regardless of stability.

The threshold at which a placement goes from stable to unstable is arbitrary and seems to vary by author. This can cause problems within this field as it creates difficulties in comparing results. An example would be a comparison of two studies examining the stability of kinship care placements in the USA. The first, a study based in California, defined instability as three or more placements within the eight year follow up period (Webster, Barth, \& Needell, 2000). Using this definition they found that $30 \%$ of the children in kinship care had unstable care journeys whilst the sample from non-kinship foster care had instability in $52 \%$ of cases. The second study by Terling-Watt (2001) and using a stricter definition of 
one placement change yielded a result of $49 \%$ of children in kinship care having unstable placements, although the follow-up period was much shorter at three years. Attempting to compare the results of these studies becomes an impossible task due to the differences in both follow-up duration and definition of stability. These differences pose challenges across the field with a lack of standardisation. Despite this, some studies have produced some, albeit limited, evidence regarding the relative stability of kinship placements and the benefits that stability may bring to a child within the public care system.

\subsubsection{Benefits of placement stability}

It is important to note at this point that whilst many studies in this area use stability as a measure of out of home placement outcomes, it is not an aim in itself. Rather it can be described as a process by which the aims of social work can be met, such as improving wellbeing (Harden, 2004). Therefore, when studies measure stability it is usually in reference to the factors that are thought to relate to placement stability. Rubin, O'Reilly, Luan \& Localio (2007) looked at placement stability and its impact on behavioural wellbeing for children and young people in foster care. They identified 3 groups within their sample $(n=729)$ : those who had achieved stability within 45 days of entering care (early stability - 52\%), those who achieved stability after 45 days but within the 18 month follow-up period (late stability - 19\%) and those who never achieved stability (unstable - 28\%). Findings indicated that even after baseline behavioural difficulties were taken into account, those in unstable placements had a much higher probability of displaying behavioural problems. The authors attribute this to placement instability alone and so suggest that the findings "support the development of interventions that promote placement stability" (Rubin et al., 2007). However, the authors fail to demonstrate through this study that stability in placement can improve wellbeing. There was no evidence from the stable groups to suggest that wellbeing was improved by their placements and no significant differences were found between early and late stability with regards to behavioural wellbeing suggesting that the proposed development of interventions may be premature. 
Whilst research looking specifically at behavioural wellbeing is limited at present, other areas of child wellbeing have been examined in more depth.

Given the breadth of factors that come under the title 'wellbeing' it is perhaps overgeneralising to suggest that stability is related to improved wellbeing. However, of the factors found to be affected by stability, many do lead to better outcomes on wellbeing scales. An example would be improved attachment to carers in long-term placements (Schofield, 2002). In section 2.3.5 the notion of attachment styles and the relative benefits of strong attachments were discussed at length with the conclusion that children who form strong attachments to their primary caregiver are less likely to suffer from behavioural problems and difficulties interacting with peers later in life (Black \& Greenough, 1986). Children in kinship care placements, particularly where carers held legal care orders giving them permanent custody, have reported a sense of security that the placements provide (Messing, 2006). The knowledge that they are to remain in a single placement rather than move from home to home is comforting to the children in such placements and allows them to create emotional bonds to their peers and carers without fear of disruption.

Examining placement stability from a developmental perspective allows further insight into its potential benefits. Developmental milestones are markers used by medical and health professionals to determine whether a child is developing linguistic, emotional and social skills at the same rate as their peers. Children within the care system have previously been found to be at higher risk of suffering developmental delays (Hochstadt et al., 1987), in part due to common risk factors found within the population such as prenatal drug exposure and neglect (Azuma \& Chasnoff, 1993; Trickett \& McBride-Chang, 1995). However, it has been suggested by numerous sources that a stable and nurturing environment can go some way to neutralise this risk (Cassidy, 1994; Kochanska, 1995; Turiel, 1998). A stable and nurturing environment has also been found to enhance resilience in children and young people in foster which may help to minimise any negative effects of placements (Harden, 2004).

As previously noted, many children who enter kinship care remain close to their original address. Remaining in a single geographical locality allows children in 
care to not only retain peer relationships and community ties, but also allows for a stable educational environment as the child is not required to change school. This allows teaching staff to create a stable educational programme free from disruption, allows the child to create peer relationships outside of their home, and gives staff and carers an opportunity to flag up concerns that may only appear over the long-term. There is some evidence from studies in the USA which suggests that children and young people in stable long-term placements show significant improvements in their educational achievements (Fanshel \& Shinn, 1978; Simms et al., 2000). Close geographical proximity is also conducive to maintaining contact between a child in care and their birth parent, an important consideration where reunification is the goal. Furthermore, stability may improve contact with birth parents as it allows for the creation of a routine.

\subsubsection{Stability and barriers to stability in kinship care}

Assessing the placement stability of children and young people entering foster care is relatively simple using case files which record every placement the child has had including emergency or respite placements. By comparison, the route into care taken by children in kinship care varies widely. Indeed, the vast majority of children in kinship care in the United Kingdom never formally enter the care system as they reside with relatives in informal kinship care relationships. Therefore it is difficult to gauge the relative stability of kinship or foster placements. For this reason, many studies focus on formal kinship care where the child has been placed with relatives by social services. In such cases, there is evidence to suggest that kinship placements tend to be more stable with children experiencing fewer placement changes (Chamberlain et al., 2006; Farmer, 2010; Farmer, 2009; Iglehart, 1994; Perry, Daly, \& Kotler, 2012). It has also been suggested that this difference in stability only exists for three years, after which kinship and non-kinship foster placements are equally likely to disrupt (Testa, 2001). Whilst stability may be a positive attribute of kinship care, Farmer (2010) found that poorer quality kinship placements tended to last longer than poorer quality non-kinship placements. This was attributed to a higher commitment in kinship carers to the child in their care. If so, this is an interesting 
point to raise as stability should be considered a process to improve wellbeing, not as a goal in itself. If a placement is stable and yet the quality of the placement is poor, the benefits of stability may be undermined.

Whilst kinship care placements tend to be more stable there are some carer and child attributes that feature in kinship care that create unique barriers to stability. Kinship carers are often elderly relatives of the child such as grandparents and the average age of kinship carers is higher than that of non-kin foster carers (Broad, 2004). Whilst the age of the carer is not a barrier in itself, age-related difficulties such as long-term health problems or disability may detrimentally affect the stability of kinship placements. These can disrupt kinship placements for short periods, for example an emergency hospital admission, meaning that the child must be placed in a respite placement either with other relatives or with strangers via social services. Many elderly carers suffer from long term health problems which they report affect their daily living such as diabetes, heart conditions or respiratory conditions (Selwyn et al., 2013). This can mean that children are entering respite care relatively frequently which may undermine the benefits of a stable placement such as feelings of security and ability to form secure attachments.

The mortality of elderly kinship carers is a pressing concern for both the carers and the children they care for (Selwyn et al., 2013). Seventy-eight per cent of the children in this study $(n=80)$ reported worries related to the age, health and caring capacity of their carers. This suggests that even the possibility of placement disruption can cause anxiety for children in kinship care. Furthermore, 49\% of carers reported having made a contingency plan for the child's care should they become too ill to care for them, or they should die. This suggests that it is also a pressing concern for carers, although the plans were rarely shared with the children. These concerns are not unique to the kinship population, although the higher age average and the high rates of physical infirmity may jeopardise placement stability to a higher degree. The elderly carers in the study by Selwyn and colleagues (2013) also reported dual caring responsibilities whether for their elderly spouse or for their adult children who were often the parents of the child in kinship placement. This may add additional emotional, physical and financial strain to the kinship carer which may relate to placement breakdown. 
A study by Farmer (2010) indicated that kinship placements were in part disrupted by difficult behaviour. Given the higher rates of behavioural difficulty reported in kinship care, this factor could be significant (Dubowitz, Zuravin, Jr, Feigelman, \& Harrington, 1993; Tarren-Sweeney \& Hazell, 2006). However, the study also indicates that placements break down due to a lack of carer commitment which is not commonly a characteristic of kinship care. Rather it has been suggested that kinship placements are more likely to continue despite poor quality and behavioural problems compared with non-kinship foster placements.

Some kinship care placements benefit from being geographically local to birth parents and, in cases where there is an existing relationship between the kinship carer and the birth parent, kinship care can lead to increased contact compared with foster care. In particular there is a higher level of informal and unplanned contact with birth parents (Farmer \& Moyers, 2008). Whilst in some cases contact can be a positive experience for children and carers and improve placement stability, in cases where contact is less positive it can have the opposite effect and undermine the stability of a kinship placement. Qualitative studies conducted in the field have produced accounts of how contact impacts the relationship between kinship carer and the child involved. One carer in the study by Selwyn and colleagues (2013) described the child's contact with their mother as disruptive and suggested that the continued contact prevented the children from being able to move on with their lives (pg. 37). An insight into how contact could undermine the stability of a kinship placement can be gained from another carer in the same study who suggested that the child's mother "stirs things up" (pg. 36). Whether by deliberate or inadvertent acts, the qualitative data available would suggest that contact in kinship care may jeopardise the stability of placements. The unique nature of the contact in a large proportion of the kinship care population, with high rates of unsupervised or unplanned contact and the difficult nature of pre-existing familial relationships, makes this area a key concern when discussing stability in kinship care. The majority of evidence to date, however, has come from qualitative studies on a relatively small scale. One study found a relationship between unsupervised contact and placement breakdown in kinship care, although the sample is limited by size and geographical constrictions 
(Farmer, 2010). The evidence base for this relationship remains primarily anecdotal and would benefit from further investigation.

There are some methodological issues presented by studies in this area. The first is a lack of consensus regarding the nature of a stable placement. As previously noted, this varies widely with the number of placement changes differing between studies. There is also very large variation in the duration of study, a factor that would be difficult to overcome. Many children enter and leave the care system in the United Kingdom every year. For some, their entry into care is the beginning of a long journey through foster care until they leave care many years later. For many, their experience of the care system is fleeting as they move on to adoption, a care order such as a Special Guardianship Order, or return to their birth parents. Therefore comparing children who have such widely varying experiences is challenging. After all, a child who is in foster care for six months and changes placement once may be experiencing less stability than a child who is in care for two years and changes placement four times. This also begs the question of how children and young people in kinship care experience stability. If we consider the definition of stability as "a situation in which something is not likely to move or change" (Stability, 2014) then the perception of the children and young people within kinship care is an important consideration for researchers within the field. A perception of placement security may be as important is not more so than actual stability if children are to reap the proposed benefits of a stable placement. Children in kinship care placements have reported that when their carer holds a care order of some kind, they feel more secure in their placement which seemed to bring them comfort (Messing, 2006). In this respect, the case file review approach, which is commonly used when examining placement stability, may be too reductionist. Furthermore, as we consider stability as a process by which other factors, such as improved wellbeing, can be achieved it could be argued that the experiences and perceptions of the children and young people in care are an important measure of placement stability. 


\subsection{Permanency}

\subsubsection{Defining permanency}

An integral part in establishing a secure future for looked after young people is in permanency planning. It is a process which seeks to establish the ideal placement for a child in order to ensure a stable journey through care and beyond. One such permanency route may be long-term foster care, and for many young people such placements can provide a secure and steady home. However, longterm foster care can impact upon a child's sense of identity and security as they remain within the care system (Triseliotis, 1983). A number of permanency options are available aside from long-term foster care. The most common, accounting for $30.3 \%$ of care leavers in 2016 , is reunification where a child returns to live with their parents after a period within the care system (Department for Education, 2016; StatsWales, 2016b). When reunification occurs, it is normally a gradual process with supervision from the local authority. The return may be supervised under Placed With Parents regulations which allows the LA to retain Parental Responsibility (PR) whilst the child and parents adjust to reunification.

A second permanency option, accounting for $14.9 \%$ of all care leavers in England and Wales in 2016, is adoption (Department for Education, 2016; StatsWales, 2016b). An Adoption Order (AO) legally revokes the rights and responsibilities of birth parents and grants $\mathrm{PR}$ to an adoptive parent. An AO is a lifelong order and in the majority of cases, an $\mathrm{AO}$ is successful in providing a permanent home for young people. However, in an estimated $3-4 \%$ of cases the adoption disrupts, the $\mathrm{AO}$ is rescinded, and the child is returned to State care (Selwyn, Wijedasa, \& Meakings, 2014; Triseliotis, 2002).

Whilst Adoption Orders are characterised by a complete separation from birth parents, alternatives such as Child Arrangements Orders (CAOs) and Special guardianship Orders (SGOs) maintain the link between the child and birth parent. Child Arrangement Orders, which replaced Residence Orders and Contact Orders in 2014, and determine where the child will reside and with whom they have contact and when. Carers with a CAO may share PR with birth parents, although may not overrule others with PR. By contrast, carers with a Special 
Guardianship Order hold the majority share of PR and may therefore overrule birth parents on issues such as education and medical treatment for the child. Both CAOs and SGOs will be explored further in this section.

\subsubsection{Permanency in kinship care}

\subsubsection{Reunification and adoption from kinship care}

As with some foster care placements, children's experience of kinship care can be brief. They may be cared for by relatives for a defined period, such as the duration of a parental prison sentence, or simply in the short-term during an emergency such as a lengthy hospital admission. Equally, extended stays in kinship care may result in reunification if the parental home is deemed to have reached an appropriate standard of care provision.

As a permanency planning option, reunification from kinship care is less common. Farmer's (2009) study of young people in kinship care in England $(n=139)$ found that reunification was the aim in only $2 \%$ of placements. Comparatively, the plan for $93 \%$ of the kinship care group was long-term placement in the kinship home until adulthood. Where it does occur, reunification generally takes longer (Testa, 2001). Planning for adoption was also found to be a less common in kinship care, accounting for $1 \%$ compared with $12 \%$ of those in unrelated foster care (Farmer, 2009). Amongst kinship carers, grandparent carers have been found to be less likely than others to pursue adoption (Testa, Shook, Cohen, \& Woods, 1996). The reasons behind this are not necessarily clear, although there is some suggestion that carer age, which tends to be higher in kinship care, may be a factor (Broad, 2004; Selwyn et al., 2013; Testa et al., 1996). Furthermore, Hunt, Waterhouse and Lutman (2008) reported that kinship carers were deterred from an AO by the cost of the application, or were concerned that pursuing an $\mathrm{AO}$ could generate difficulties in their relationship with birth parents.

Whilst studies have identified trends in reunification and adoption in kinship care, they are limited by small sample size and narrow geographical inclusion. Establishing these trends on a national basis, however, is complicated by the way 
in which national data is collected. In both England and Wales, statistical data is collected and analysed in such a way that formal kinship care and unrelated foster care are grouped together. Meanwhile, data regarding informal kinship care is not collected on a national scale. This means that establishing permanency outcomes is challenging, making small-scale studies examining the permanency outcomes of kinship care placements invaluable. Whilst the results must be treated with caution, the studies presented here provide a useful insight into reunification and adoption in kinship care.

\subsubsection{Child Arrangements Orders (CAOs)}

In order to secure a care arrangement in law, kinship carers may look to take out a Child Arrangements Order (CAO). These are not unique to looked after children and can be taken out by birth parents where living situations change such as in the aftermath of a divorce or separation. In this sense, CAOs can be described as a means of settling the living arrangements of a child. CAOs can last for any defined period of time, although they expire when the child reaches sixteen except in exceptional circumstances. Certain people are able to apply for a CAO directly, namely the parent or guardian of a child, the married step parent or civil partner where the child has lived as part of the family, or a person with the consent of another CAO holder. Furthermore applications may come from a relative of the child (grandparent, aunt, uncle, sibling or step parent) with whom the child has lived for a minimum period of one year, or any other person with whom the child has lived for a minimum of three years. Any other person may apply for a CAO, but must attain permission from the court to do so.

In addition to establishing where the child will reside, CAOs can also be useful in kinship and unrelated foster care by grounding contact arrangements in a legally binding structure. This can ensure that the frequency and duration of birth family contact is laid out clearly. In 2016, 3.5\% of all care leavers in England left care via a Child Arrangements Order, whilst Welsh statistics are unavailable (Department for Education, 2016). Once again, establishing the extent of CAOs within kinship care is complicated by the way in which data is collected from LAs, 
however Selwyn and colleagues (2014) report that around $26 \%$ of all Residence Orders (ROs), the precursor to CAOs, are granted to kinship carers. Despite being established as a route to permanency, disruption of ROs/CAOs remains high. Using Event history analysis (EHA), Selwyn et al. (2014) modelled predicted disruption of ROs/CAOs. Results indicate that up to $14.7 \%$ of ROs/CAOs will disrupt over a 5-year period, with factors such as older age at entry to care, higher number of placement moves and the child not being placed with kin increasing the risk of disruption. Given the dearth of research on the impact of placement type on likelihood of pursuing a CAO, further exploration is warranted. Furthermore, with disruption rates high, establishing the use of CAOs for those leaving kinship care in Wales is justified.

\subsubsection{Special Guardianship Orders (SGOs)}

Of all permanency options, Special Guardianship Orders (SGOs) are the most recently introduced. Relating in some respects to the failed custodianship regime featured in the 1975 Children Act (Bainham, 2007) SGOs were incorporated in the Children Act 1989. Since their introduction in 2006, SGOs have become an increasingly popular means of providing permanency for looked after children. SGOs are similar to CAOs in that they maintain a legal bond between the child and their birth parent. However, unlike CAOs, an SGO grants the carer the majority share of PR. This enables carers to overrule birth parents on a number of issues including education and health, whilst providing security for the children within their placement. This is reinforced in SGOs compared with CAOs, as SGOs require parents to apply to the court for permission to challenge an SGO once it is established. SGOs are of particular importance to those in kinship care as one study estimates that $68.4 \%$ of SGOs are granted to kinship carers (Wade, Sinclair, Stuttard, \& Simmonds, 2014).

Aside from providing legal security for children in placements, SGOs may also provide emotional security. Messing (2006) noted that children who were legally tied to their carers in such a way seemed to find it comforting. It may be that it reduces the recurring false hope and disappointment that children in care can 
experience when their expectations of their future fail to come to fruition. For example, many children in kinship care expect to return to their parents care in the future, although in reality this is not a viable aim (Messing, 2006; Selwyn et al., 2013). It may also allow children to form secure attachments to their carers in the knowledge that their placement future is stable.

Disruption rates from SGO are predicted to be between 5.7-6\% over a 5-year period (Selwyn \& Masson, 2014; Wade et al., 2014). Breakdown of kinship placements was established to be much lower with kinship being a protective factor (Wade et al., 2014). This is further supported by Selwyn and Masson (2014) who established that children placed with unrelated foster carers were three times more likely to experience the breakdown of an SGO than those living with kin. However, the methodology of both of these studies limits the reliability of this assertion as both defined breakdown as a return to care of the LA. Wade and colleagues (2014) found that those in kinship care were less likely to return to the care of the LA in cases of SGO breakdown, often moving instead to the care of other relatives. As a result of the definition used in these studies, the estimated rates of SGO breakdown in kinship care may be artificially low. As such, researching exploring the breakdown rates of SGOs granted to formal kinship carers is warranted.

\subsection{Special Guardianship Order (SGO) trends}

Since their introduction in 2006, SGOs have become a popular permanency option accounting for $12.2 \%$ of all care leavers in 2016 (Department for Education, 2016; StatsWales, 2016b). In Wales alone, SGOs have risen from $3.8 \%$ of care leavers in 2008 to $13.9 \%$ in 2016 (StatsWales, 2016b). Most SGOs in Wales are granted to former foster carers, and they accounted for $66 \%$ of SGOs in 2016 (StatsWales, 2016b). What is not clear from currently published data, is the proportion of SGOs taken out by kinship carers. As kinship carers are not treated as a specific group when statistical data is published they, along with informal kinship carers who take out SGOs, are a hidden group who cannot be identified. Therefore establishing the statistical trends of SGOs in the kinship care 
population from current data is challenging. Where studies have looked into kinship carers and permanency, they have suggested that SGOs are a popular choice, with $56 \%$ of informal carers in one study having taken out an SGO (Selwyn et al., 2013). Statistics regarding kinship carers taking out SGOs in South Wales specifically are not in the public domain. With the highest proportion of formal kinship carers in the UK, the permanency destinations of children in Wales is an important area for further research.

\subsection{Demographics of Special Guardians}

There is currently very little known about the factors that lead some kinship carers to pursue SGOs. What little research there is in this field suggests that the emotional security that a permanent option such as an SGO would provide appeals to both children and kinship carers (Messing, 2006; Wade et al., 2014).

Contrary to this, there are certain factors which may become barriers to prevent carers from pursuing them. One such barrier may be financial disadvantage. Less than a third of informal kinship carers in one study reported difficulties in providing basic items on a checklist, such as providing warm winter clothes for the children, or providing a hot meal each day (Selwyn et al., 2013). The levels of poverty suggested by this study were disproportionately high compared with the general population, with $25 \%$ of the kinship carers unable to put on the heating whenever they needed to. Comparatively, only $1 \%$ of the general population report being unable to use the heating when needed. It is not only kinship carers concerned with the loss of support from social services with many Special Guardians citing financial strain as a key issue (Wade et al., 2014). Some formal kinship carers are able to access payments from the local authority, although their status as formal foster carers affects their ability to do so (Nandy et al., 2011). Taking out an SGO can affect the kinship family financially. There is not only the cost of acquiring legal advice privately, but the payments received by the local authority can be discretionary, means-tested, and lead to a reduction in financial support (Nandy et al., 2011; Selwyn et al., 2013). Given the financial difficulty reported by 
some kinship carers, it may be that finances are a barrier to permanency secured through an SGO for children in kinship care.

In kinship care, the carer's relationship with the birth parent may also influence their decision to pursue an SGO. Kinship carers reported anxiety that applying for an $\mathrm{AO}$ would adversely affect their relationship with the birth parent (Nandy et al., 2011). Similarly, Wade et al. (2014) found that less than half of birth parents approved of their children living within Special Guardianship families. Given the high numbers of kinship carers who are grandparents and thus the birth parent's own parent, the risk of alienating their own adult children may prove too large a barrier. Furthermore, having the local authority exercising decision making power may be of comfort to some carers. This is particularly the case around birth parent contact where birth parents may push for extended contact times. From a theoretical standpoint, this fits well with theories pf power and authority. Whilst Special Guardians may possess legitimate power in restricting contact, the expert power and the authority of the social worker may be more influential when dealing with birth parents. It is an example where statutory power alone is insufficient to ensure the desired outcomes, with carers still dependent on social workers to act as the control agent (Beckett \& Horner, 2015). Equally, a challenging relationship with birth parents may motivate carers to secure an SGO by allowing the carer greater control over contact, minimising the need for consultation with both the birth parent and the local authority, and granting them greater levels of legitimate power.

In some studies, carers have expressed a reluctance to pursue permanency routes due to the inherent belief that the child's birth parent would in the future be in a position to resume the care of their child. This is particularly the case for grandparent carers who may feel that exploring an SGO would be a betrayal of their adult child and in some way giving up on the belief that they may one day recover from the problems that are preventing them from caring for their own child (Selwyn et al., 2013; Testa et al., 1996). Some children also seem to believe that they will return to the care of their birth parents at some point in the future (Messing, 2006). It is not certain what effect permanency goals such as SGOs may have on children in such cases. It may remove false hope that enables them to settle into their placement and form strong attachments. Conversely, it may 
trigger feelings of guilt in the children who may feel that they have also betrayed their parent. This could also have the potential to damage a relationship with the carer if the child attributes blame to them for preventing a return to their birth parents.

There is a dearth of research exploring kinship carers' views on SGOs, factors that influence carers' decision making around SGOs and barriers to kinship carers pursuing SGOs. This may be in part due to their relatively new status as a permanency option as they only came into force at the end of 2005 . However, their increasing popularity, particularly amongst the growing kinship care population, makes it a key area for further exploration. Whilst increasingly used in practice, the stability of SGOs is yet to be explored and research that addresses this gap is merited.

Stability and permanency will be explored together in this study and form one of the three study aims. The study aims to explore factors affecting stability in kinship care. A number of research questions will explore the relative stability and permanency of kinship placements for both young people leaving care early and those aging out at eighteen years of age. In doing so, the study will also capture the use of permanency options for early care leavers, and the stability of those transitioning from formal care. This is particularly pertinent following the introduction of the 'When I'm Ready' scheme in Wales [Social Services and Wellbeing (Wales) Act 2014] and its counterpart 'Staying Put' in England [Children and Families Act 2014], both of which extend the provision of accommodation for care leavers until the age of 21. Crucially, research questions will also focus on SGOs and examine factors that motivate and deter kinship carers from applying for guardianship.

\subsection{Birth family contact}

A common feature of State care, birth family contact (BFC) refers to communication between the birth family, often the birth parents, and a child who is residing in a foster care placement (Macaskill, 2002). According to the 1989 Children Act, a child who is accommodated by a local authority in the UK has the right to reasonable contact with their birth parents ("Children Act," 1989). This 
has been further enshrined in UK law by both the Social Services and Wellbeing (Wales) Act 2014 and the Children and Families Act 2014, in addition to being observed in the UNCRC. This right to contact may be contravened if contact may be shown to undermine the paramountcy principle and be against the best interests of the child. The frequency and duration of contact may vary in each case, as does the form the contact takes. Whilst decisions surrounding contact are influenced by social workers involved in supervising the child's case, the decision determining the frequency, duration and form of contact rests with the Family Law Court. In broad terms, contact comes in two forms.

The first of these is direct contact which describes face to face interaction between a birth parent or relative and the child. This contact may be unsupervised, if the child is deemed to be at little risk, or supervised by an authorised person such as a case worker if the child remains at risk. In such cases, contact may take place in a neutral setting such as a local café or restaurant, or may take place in a local contact centre. Secondly, birth family contact may be indirect. Such contact, also known in practice as letterbox contact, may take the form of letters, postcards, birthday and Christmas cards, or photos which are sent to a mediating location to be forwarded to the child. This form of contact is commonly used following adoption, although is also used in foster care when direct contact is inappropriate. This form of contact therefore allows for the location of a placement to remain secret and makes it more difficult for birth parents and the child to arrange contact informally (Macaskill, 2002).

\subsubsection{Birth family contact in foster care}

Birth family contact remains a controversial topic, especially in cases where the child goes on to adoption. More recently the introduction of legislation such as the Children Act 1989 which underpins the child's right to contact has helped to shift viewpoints in practice to a more favourable position ("Children Act," 1989; Macaskill, 2002). This has also been influenced by a number of research studies which report on the benefits of birth family contact for children within the foster care system. McWey Acock \& Porter (2010) suggest that frequent contact with 
birth parents can positively impact the wellbeing of a child in foster care and good quality contact may promote placement stability (Sen \& Broadhurst, 2011). Whilst this is promising, the mechanisms by which contact can be beneficial are difficult to determine. One suggestion is that contact allows the retention of identity that may otherwise be lost (Triseliotis, 2010). As previously discussed in section 2.4.4, identity can be an important factor for children within the care system.

In addition to promoting identity, birth parent contact can allow children who have been subjected to abuse or neglect to gain an understanding of their abuse history. This is particularly pertinent in long term placements where a child is placed at a young age. As they grow they can learn to understand why their circumstances are the way they are. One child in the study by Macaskill (2002) stated, following contact her mother, that "she can't look after herself and she can't look after me" (pg. 57) suggesting a newly discovered understanding of her situation. This child was having contact following adoption, although there is no reason to believe that the experience of a child in long term foster care would differ greatly. Furthermore, birth parent contact allows the child to express their feelings surrounding their abuse history towards those they hold responsible rather than targeting their carer (Macaskill, 2002). This may promote stability by reducing tension between the child and their carer. Around $41 \%$ of children enter kinship care as a result of parental substance misuse (Farmer, 2009). As a result, the health and wellbeing of their birth parent may be jeopardised by addiction which in turn can cause anxiety for children. It has been suggested that maintaining birth family contact can reassure children that their parents are safe and well whilst reducing unrealistic expectations of the future such as beliefs in reunification where this was not a viable option (Macaskill, 2002; Triseliotis, 2010).

Although some studies have suggested that birth family contact can promote wellbeing in children, it can be a source of distress and anxiety in some (Leathers, 2003). In a study of 199 adolescents in unrelated foster care, Leathers (2003) found that having a high level of allegiance to both foster carers and birth parents resulted in greater loyalty conflict. Furthermore, higher loyalty conflict was significantly associated with behavioural and emotional difficulties, although the analytical technique preludes the direction of causation in this relationship. The 
study is limited by the use of indirect data collection methods, such as the use of carer or worker ratings. Consequently, the results must be applied with caution, however, the findings present an interesting alternative to previous assumptions that birth family contact is primarily beneficial (Fanshel \& Shinn, 1978). In addition to the risk of psychological harm, the risk of physical assault whilst supervising contact is a substantiated concern for kinship carers, with carers reporting being victims of violence from the birth parents during contact (Selwyn et al., 2013). Equally, Macaskill (2002) noted instances where children have been known to strike their birth parents in some cases.

\subsubsection{Birth family contact in kinship care}

Research examining birth family contact in kinship care is comparatively scarce with only a few studies featuring it as a main research aim (Vanschoonlandt et al., 2012). Determining the comparative levels of birth family contact in kinship care is challenging. One study found that the proportion of children in kinship care who were not having contact with birth parents was lower in kinship care than foster care (Holtan, Rønning, et al., 2005), a finding that has been replicated in UK samples (Aldgate, 2009; Farmer \& Moyers, 2008). Other studies have found no difference in the levels of contact (Berrick, 1997; Strijker, Zandberg, \& van der Meulen, 2003). Birth family contact in kinship care also has a wider context as children are placed with relatives are more likely to have contact with a broader range of relatives such as aunts and uncles or siblings (Farmer \& Moyers, 2008). This is one of the key benefits that researchers often attribute to kinship care placements when discussing their relative merits.

In kinship care, contact with the wider family is facilitated by both the carer's own relationship with family members, and, commonly, by the placement's proximity to the child's parental home. Furthermore, family events such as weddings or birthdays allow children a degree of normality as they feel part of the family rather than an outsider as they may if they were living in foster care. In addition to the higher levels of wider family contact, kinship care can be beneficial for its flexibility in contact arrangements. Whilst some contact may be strictly scheduled and possibly supervised, for children living in some formal and informal kinship 
arrangements contact can be a more fluid process (Tan, 2000). Birth parents may have unrestricted access to the carer's house, or simply live in the same area leading to unplanned meetings (Selwyn et al., 2013). Whilst this can pose some problems which will be further discussed later in this section, it may prove beneficial as children can interact with their birth parents in a natural setting and without the pressures of supervision (Aldgate \& Mclntosh, 2006). Furthermore, relationships between birth parents and children in kinship care is more likely to be maintained than for children in non-kinship care (Cuddeback, 2004; Flynn, 2002).

Much of the literature in this area focusses on the risks involved in birth family contact. One area of concern in this respect is the nature of the relationship between kinship carers and birth parents. In one study, more than $40 \%$ of cases had a strained parent-carer relationship. In another study of informal kinship carers, only a quarter of carers reported a positive relationship with the child's birth parent (Selwyn et al., 2013). Violence and threats of violence were occasionally a feature of contact in such situations with one carer reporting that they had sustained injuries requiring hospital treatment (Selwyn et al., 2013, pg. 38.). Despite the often turbulent relationships between kinship carers and birth parents, contact is rarely terminated (Farmer \& Moyers, 2008; Hunt, Waterhouse, \& Lutman, 2010). Whilst it is some respects positive that contact is maintained for the sake of the children, a negative relationship between parent and carer can seriously affect both placement stability and child welfare (Hunt et al., 2010; Kiraly \& Humphreys, 2013a). Conflict can create a sense of torn loyalty for children which can lead to anxiety and distress (Hunt et al., 2010). This in turn may affect the stability of a placement. Further evidence has suggested that foster children fare better in placement if their birth mother shows approval for the placement (Vanschoonlandt et al., 2012). Conflict between parent and carer, including accusations that the carer may be "stealing" the child, directly contradict approval and so may affect child wellbeing. The relationship between the birth parents and kinship carers is not simply important for the maintenance of contact, but has a much greater effect on the child's experience of kinship care.

Literature regarding contact in kinship care often features the difficulties posed by supervision, or lack thereof. Despite higher levels of birth family contact, and 
despite reports by a large proportion of kinship carers detailing a poor relationship with the birth parents, supervision of contact in kinship care remains lower than that of foster care (Farmer \& Moyers, 2008). Some kinship carers have also reported that they would like more extensive supervision of contact by the local authority (Kiraly \& Humphreys, 2013a). The reasoning behind the lower levels of supervision in kinship care is unclear, although it has been suggested that kinship carers are simply expected to be able to manage contact with their own relatives on their own (Kiraly \& Humphreys, 2013a).

It may be more difficult for professionals to supervise contact in kinship care. In such placements, contact is often arranged informally (Ehrle \& Geen, 2002) assisted by the geographical proximity of many kinship placements to the birth home and a lack of secrecy surrounding the placement address. In some cases, the kinship carer may be providing care for the child's birth parent such as sending money to support them. This can mean that the birth parent visits frequently and not necessarily with the main purpose of visiting the child. This may lead the child to feel repeatedly rejected by their birth parent. Chance meetings as a result of geographical proximity are also a theme that has been addressed by research. Selwyn et al. (2013) reported a case where birth parents would be in the school playground collecting a child's sibling leaving the child feeling rejected on a daily basis. Another case featured in the same study featured a parent who had no contact with their child who was residing in a kinship placement and who would ignore the child if they saw them on the street. Excessive or unplanned contact is not the only cause of feelings of rejection in children in kinship care. Parents who fail to attend pre-arranged contact can lead to disappointment and distress for children in kinship care (Burgess et al., 2010; Sands et al., 2009).

It has previously been suggested that birth family contact in foster care can improve child wellbeing on a range of factors such as a sense of identity, mediating feelings of rejection and reducing anxiety and guilt (Triseliotis, 2010). However, there is an implicit risk associated with birth family contact which threatens the child's safety, wellbeing and placement stability in cases where contact experiences are negative. With this in mind, it is perhaps pertinent to question the relevance of birth family contact in kinship care. As a placement 
characterised by extended familial association and a sense of identity and belonging, it could be argued that the proposed benefits of contact are already provided by the placement itself. However, studies that have used interview data from children in kinship care have suggested that children value contact with their birth parents and find it an important part of their lives (Hunt et al., 2010; Selwyn et al., 2013).

The pre-existing relationship between parent and carer seems to be a theme that runs through much of this field. Whilst in foster care the care arrangements may tend to remain static for an extended period, the relationship that already exists may mean that responsibility for maintaining and supervising contact may be transferred to kinship carers in a much shorter time frame. Given its importance to children in kinship care, birth family contact seems likely to continue to play a central role in the future. With this in mind it is imperative that the area is examined further in academic literature in order to understand the unique nature of contact in kinship care. Previous literature has suggested that contact in kinship care tends to be informally arranged (Ehrle \& Geen, 2002; Farmer \& Moyers, 2008).

\subsection{Education, employment and training}

Education is an important aspect of any society and a compulsory part of life in the UK for children and young people until the age of sixteen ("Education Act," 1996). A number of previous studies have suggested that children and young people within the social care system suffer from educational underachievement leaving them vulnerable to lower paid employment or unemployment as care leavers (Colton \& Heath, 1994; Gregg \& Machin, 2000; Montgomery, Bartley, Cook, \& Wadsworth, 1996; Rees, 2013). By contrast, Burley and Halpern (2001) found that foster care can have a positive impact on educational attainment. The majority of studies have focussed on the foster care population as a whole, with few focussing on kinship care as a specific group. Those that have found that children and young people in kinship care may face many of the same difficulties as those in foster care (Benedict et al., 1996; Dubowitz \& Sawyer, 1994; Sawyer 
\& Dubowitz, 1994). However, key characteristics differ between kinship and unrelated foster care placements which may influence educational outcomes for young people. Kinship carers have been found to have lower levels of educational attainment than mainstream foster carers and may feel less able to engage with schools (Holtan, Ronning, et al., 2005; Strozier \& et, 2005). Consequently it may be argued that research that examines the educational outcomes of young people in kinship care specifically is warranted. This section will address the challenges of measuring educational achievement, existing literature exploring educational achievement in out-of-home care, and research addressing employment and training in care leavers.

\subsubsection{Academic performance}

Success in education is difficult to quantify. In most formal educational systems, work submitted by a student in the form of coursework or examination is attributed a grade to indicate at what level they are working relative to their peers or the expected national norm. In this respect, educational success is based upon performance in certain situations which can be subject to extraneous variables such as stress caused by the examination process, home life, and motivation. As such, whilst grading systems can be a useful indicator of attainment in the general population, when exploring subsets of the population a more refined measure is required.

Studies exploring educational achievement in out-of-home care have used a number of measures in order to explore outcomes. Self-esteem is well documented as being positively associated with achievement scores: as selfesteem increases, achievement scores also increase and vice versa (Brookover, Thomas, \& Paterson, 1964; Covington, 1989; Holly, 1987; Scheirer \& Kraut, 1979; Walz \& Bleuer, 1992). Equally, factors such as a history of maltreatment, behavioural problems, multiple out-of-home placements and socioeconomic variables have all been shown to be associated with low educational attainment (Pecora et al., 2006; Ryan \& Testa, 2005; Walpole, 2003). However, the extent 
to which these factors inter-relate to influence educational outcomes, is not well researched.

Children and young people within the care system are uniquely vulnerable, often experiencing a number of the risk factors that predict poor educational outcomes. Recent government statistics indicate that $63.5 \%$ of children looked after in Wales have experienced abuse or neglect, whilst 30\% experienced two or more placements in a single year (StatsWales, 2016a). As such, establishing an appropriate group for comparison is challenging. Some studies have attempted to account for these factors, using a socioeconomically matched control group. Such studies argue that the foster care population continue to perform lower than their peers in the general population (Altshuler, 1997; Parrish et al., 2001). However, given the multiple factors that could contribute to these outcomes, and the heterogeneity of young people in care, a socioeconomically matched control may still be insufficient.

Further studies have used proxies as a means of assessing educational outcomes, rather than focus on attainment itself. Scherr (2007) explored the experiences of youth in foster care, using grade retention rates, records of suspensions and expulsions, and eligibility for special education. These proxies allowed for a meta-analysis of outcomes from thirty-one studies, providing a reasonable evidence base to support the theory that youth in foster care perform below their peers. However, whilst each of these factors have been found to associate with educational achievement, they remain an indirect measure.

Research exploring educational achievement is further complicated by difficulties in establishing how foster care relates to achievement. Whilst some studies have suggested that the two relate, it has been argued that foster care actually serves to improve the educational achievement of a vulnerable group (Fanshel \& Shinn, 1978). One of the most frequently cited longitudinal studies, Fanshel and Shinn (1978) noted that foster care provided a stable a functional environment within which children were able to improve academically. This would lend credence to the theory that poor educational attainment may be attributable to pre-existing factors, rather than the care system itself. Forrester, Goodman, Cocker, Binnie, and Jensch (2009) also observed that the way in which attainment data is 
gathered may contribute to the belief that youth in foster care perform poorly in the domain of education. In 2016, over two thousand young people left the care of LAs in Wales of whom $64.7 \%$ were under the age of sixteen (StatsWales, 2016b). Consequently, these early care leavers would be excluded from educational achievement statistics despite comprising a sizeable proportion of the care population.

Recent studies have sought to overcome challenges in establishing suitable controls by employing a within-subject design. Rees (2013) employed a sample of looked after 7-15 year olds $(n=193)$ and used a standardised psychometric measure (British Ability Scales, II) to predict performance in literacy. Performance was then assessed with an attainment test to establish whether young people were achieving in literacy as predicted. Rees (2013) found that, as a group, young people who are looked after are achieving a literacy level that is lower than predicted by cognitive ability. However, the results also found high incidence of positive exception where young people were performing higher than predicted, cautioning against overgeneralisation of results.

A study by Deary, Strand, Smith and Fernandes (2007) sought to assess the realworld efficacy of psychometric measures such as these. In order to do so the authors compared Spearman's $g$ factor to the GCSE results of more than 75,000 children and found that the results of psychometric testing at age 11 was positively correlated (0.81) to performance on GCSE's at age 16 . This suggests that there is a real-world application for psychometric testing. When studying educational achievement in foster care or kinship care, psychometric testing, as employed by Rees (2013) may allow for within-subject evaluation of performance without the drawbacks of longitudinal studies or inappropriate controls.

Despite the benefits of such an approach, there is a dearth of studies that have employed psychometric measures to study educational achievement in the care system. When examining kinship care specifically the availability of such studies narrows further. Of the sample featured in Rees' (2013) study, 17\% were residing in kinship care. However, comparisons between the placement types were not published. Whilst young people in kinship care may share similarities with their mainstream counterparts, there are some factors which could prove to be 
advantageous to those living with relatives. One of the proposed benefits of kinship care is the relative proximity of a kinship placement to the child's previous address and the placement's stability making school changes a less frequent if not obsolete event. A study by Calvin, Fenton, Lee, Pattison, Warner-King and Purbaugh (2000) suggested that changing schools can hinder educational progress by 4-6 months. Therefore, whilst children in kinship are also reported to suffer more behavioural difficulties in school, the stability in school experience may allow for the instigation of a long-term support plan via the school's special educational needs practitioners (Dubowitz \& Sawyer, 1994; Leslie, Gordon, Lambros, et al., 2005; Leslie, Gordon, Meneken, et al., 2005).

In the USA, deficits in educational achievement, cognitive performance and language skills have been found in kinship care samples, alongside higher rates of special educational needs and grade repetition (Sawyer \& Dubowitz, 1994). However, there is a dearth of UK research pertaining to educational outcomes for children and young people who have lived in kinship care. The widespread use of kinship care, the heightened awareness of the need for further research into outcomes and the introduction of IT systems in local authorities to consolidate and record data such as examination results for children in care make it an appropriate time to examine educational outcomes for those in kinship care. Whilst the limitations of the case file approach have been noted, used in combination with psychometric measures they may yield interesting and highly informative results with the potential to influence future educational policy.

\subsubsection{Employment}

Employment is a prominent concern in many Western countries, particularly youth employment (Coenjaerts, Ernst, Fortuny, Rei, \& Pilgrim, 2009). Whilst employment in the population as a whole concerns governments, the outcomes for the less privileged in society, such as those with a history of living in state care, are of particular concern. A number of studies from both the UK and the USA have highlighted these concerns. Such studies have noted that young people who leave the foster care system face difficulties in transitioning into 
independent living including difficulties in finding and retaining paid employment (Reilly, 2003). One study from the USA compares foster care leavers in three states with unaccommodated peers on factors such as employment, progression and income (Goerge et al., 2002). The authors found that not only are employment rates for those in foster care reported to be low, but there is some evidence to suggest that youth with a history of foster care have average earnings below the poverty level (Goerge et al., 2002). The authors suggest that this is more common for youth who have been accommodated than for their peers. Furthermore, the study suggests that fostered youth make slower progress in the labour market and remain on lower incomes for longer than their peers. Whilst the causes for this are unclear, the disparity is concerning.

Compared with research regarding their foster care peers, evidence pertaining to employment outcomes for kinship care leavers is sparse. Some studies have examined employment as part of a wider study of adult functioning such as a US study by Benedict, Zuravin and Stallings (1996). The authors compared 214 youth who had previously been accommodated, forty percent of whom were placed with kin, to establish any differences in functioning on a range of factors such as health, risk-taking behaviours and education and employment rates. They found that those who had been placed with kin had similar difficulties to those who had been placed with unrelated foster carers. There were no significant differences in educational attainment at high-school level or above and employment rates were similar at $49 \%$ for the kinship care sample and $41 \%$ for the foster care sample. This is despite a number of differences in educational factors such as behavioural or attendance problems, or developmental problems, all of which were significantly more prevalent in the unrelated foster care sample. Perhaps important to note when discussing employment, those in unrelated foster care were also significantly more likely to have been in trouble with the law with $27 \%$ compared with $17 \%$ of kinship care leavers. Whilst the degree of criminality is not described, it could explain a barrier to employment or income as certain offences make employment in certain industries such as law enforcement or education, more difficult to obtain.

The difficulties experienced by the foster care population as a whole in the domain of employment are now fairly well documented (Doyle Jr, 2007; Pecora 
et al., 2006; Reilly, 2003). Some training programs and formal support systems have been developed internationally which promote the core skills required for independent living such as money management, interview skills and curriculum vitae writing workshops (Allen, 2003; Stein, Wade, \& Britain, 2000). These can be on a one-to-one basis with case workers or peer tutors, and there is some evidence to suggest that these can be somewhat effective in alleviating problems and breaking down the barriers that care leavers may encounter (Pecora et al., 2006; Stein, 2006). These systems can be seen as a step in the right direction to bridge the transitional gap between looked after youth and their unaccommodated peers. For those residing in kinship care, and in particular those in informal kinship arrangements, accessing such support can be more challenging. Those in informal kinship living arrangements are unable to access the resources that are put aside for care leavers as they are not legally recognised as such. Even those in formal kinship placements who have previously been looked after by their local authority may face challenges in accessing support, especially with the high rate of SGO uptake. It is not clear as to whether such support is needed in cases where a young person is subject to an SGO as their informal support system may be sufficient. However, the similarities between kinship and non-kinship groups found by Benedict and colleagues (1996) in the USA regarding difficulties in the transition to adulthood suggests that it is an avenue warranting further investigation.

Accessing the care leaver population for research purposes can be challenging in itself. In the study by Benedict and colleagues (1996) the sample of 214 came from a potential pool of 322 . Whilst 11 were described as ineligible due to death or incapacity, and nine refused to participate, the vast majority of nonrespondents (88) could not be located. The reasons for this are unknown, however, with $27 \%$ of the participating sample reporting homelessness at some point, it may have been a factor that prevented some from participating. This may mean that the extent of financial hardship are not revealed. Similarly, those in certain professions such as those in the military may not have been easy to locate due to their occupation's mobile nature. This may mean that employment rates are underestimated. Furthermore, previous studies have reported difficulties in accessing care leaver data due to incomplete case files or obstruction form case 
workers (Gilbertson \& Barber, 2002; O'Sullivan \& Westerman, 2007). That is not to say that the studies that have been done to date are unreliable. It is a characteristic of research that participants may be drawn from certain pools with certain traits such as higher altruistic tendencies. Often, those at the extreme ends of the spectrum are inadvertently excluded by unforeseeable and uncontrollable factors such as adverse personal circumstances or professional responsibilities. It is simply worth noting that the studies that exist are not population based and therefore may not reveal the true extent of a problem, rather indicate a general trend.

Whilst there is some evidence that gaining and retaining employment may be more of a challenge for youth who have previously lived with kin, it is constrained by factors such as small scale studies, low participation and poor generalisability. Given these limitations, the field would benefit from further study with a narrower geographical focus which could be applied more effectively to the UK care population.

\section{Section Summary}

Chapter 2 has explored the literature surrounding some of the quantitative and qualitative outcomes for young people in kinship care. Many of the studies that have been conducted with young people and kinship carers to date are confounded by the lack of consistency in the use of the term 'kinship care'. Those that have yielded comparable results seem to indicate that on many factors those in kinship care may fare better than their peers in mainstream foster care. Studies have revealed that placements tend to be more stable for those in kinship care despite formal permanency plans being relatively rare. The stability provided by kinship care seems to also impact upon other wellbeing factors such as health, resilience and education, however the evidence for this is relatively weak with a number of studies contradicting one another and limited by ethnocentricity. However, whilst the placement may be beneficial for the young people, the cost of providing the placement may be high for kinship carers with some studies reporting the loss of gainful employment, financial hardship, and a decline in health as just a few of the issues described. The consequential impact this may 
Chapter 2: Literature review: empirical literature and policy

have on the young people themselves is yet to be clarified, but is worthy of investigation.

In the next chapter, prevailing theories of kinship care will be discussed with reference to both its proposed theoretical benefits to the young people within the care system, and to the wider kinship unit as a whole. The notions of family and kinship will be discussed in relation to its place in wider society, along with the role of social work in supporting the family unit. 
Chapter 3: Literature review: theoretical underpinning of kinship care 
Chapter 3: Literature review: theoretical underpinning of kinship care

Chapter 3: Theoretical underpinning of kinship care

Throughout history, society has been faced with the dilemma of what to do when a child cannot be cared for by their parents. The State has attempted to intervene in such situations with varying results. In this chapter we take a novel look at the theoretical framework underpinning the modern practice of family based care and the relationship between the State and family (Pratchett \& Rees, 2017).

Through the structural-functionalist perspective the crucial role that family plays in society, and the importance of maintaining its stability, can be understood. We look at how social work has evolved from informal charitable to State-funded practices, and the function it fulfils following the breakdown of the nuclear family.

As the State moves increasingly towards family based care, we examine the biological and social underpinnings of kinship and how they can motivate the altruistic actions of carers. In turn we can use this understanding to show how society shapes our perception of kinship.

In the final section we draw together all of these theories to explore the benefits of kinship care to both society and the individual. We argue that kinship care has the potential to be a sound investment, protecting children in need of alternative care and breaking the cycle of care dependency. For the individual, kinship care presents a familiar placement enabling vulnerable young people to develop in safety and without some of the difficulties posed by other forms of care.

\subsection{Kinship care in context}

The question of how to respond to the needs of children who are unable to live with their birth parents presents dilemmas for every society and many have been reluctant to take on responsibility for providing the necessary care (Rees, 2010). Even in industrialised nations such as the UK there is a relatively short history of State intervention and provision of care for children. The concept and practice of 
familial wardship which was embedded in, for example, the Poor Law Amendment Act (1834) meant that grandparents and other close relatives were held legally responsible for providing care to their grandchildren should the child's parents be unable to do so. Despite the immense social, economic and political change that occurred between the time of the Act and the mid- $20^{\text {th }}$ century the primary importance of familial responsibility held firm.

One of the more prominent debates that has emerged in social policy and social work practice surrounds poverty and inequality. Poverty can be broadly defined in two ways: absolute poverty and relative poverty. To live in absolute poverty, a person is living without the financial income needed to support their material needs such as shelter, nutritionally balanced food, weather-appropriate clothing and access to clean drinking water and sanitation. Absolute poverty is relatively simple to define and recognise, with the definition remaining static over time. By contrast, relative poverty is defined by an absence of financial income that is a certain percentage below the average. In the UK, the government define a person as living in relative poverty if their income is less than $60 \%$ of the median (McGuinness, 2015). Unlike absolute poverty, the threshold for relative poverty is constantly changing as the average lifestyle changes with time.

More recently, the issue of social exclusion has become more widely recognised. The idea of social exclusion is not new. As one of the most prominent social theorists in this area, Townsend (1979), recognised that poverty is "less about shortage of income and more about the inability of people on low incomes to participate actively in society" (Ferragina, Tomlinson, \& Walker, 2013, p. 6). This ties in with social class theory in the UK where entire groups of people are denied opportunity and oppressed by systems that are put in place by those in power. In his book entitled "Chavs" liberal author Owen Jones highlights the disdain that the establishment holds for those living in poverty and the way in which they are not only demonised, but also excluded from participating fully in society (Jones, 2012). Jones highlights the way in which those in power attribute poverty as being caused by the feckless, workshy poor rather than being a consequence of systematic oppression. The social commentary he highlights is reminiscent of the Victorian era where the poor were split into the deserving and the underserving. This was embedded into the Poor Law Amendment Act (1834) which required 
those in receipt of benefits to enter a workhouse, the idea being that only those who

In many ways, poverty and inequality remain as pervasive an issue as ever. Whilst the rates of poverty overall have reduced in the past twenty years, poverty rates remain high in groups that have been traditionally at risk, such as pensioners and families with children. Government statistics show that in the year 2016-17, twenty-six per cent of children were living in absolute poverty, whilst thirty per cent lived in relative poverty in the UK (McGuinness, 2015). Meanwhile, in the same year around $15 \%$ of pensioners in the UK were living in absolute poverty and $17 \%$ lived in relative poverty.

In respect to kinship care, poverty is a pertinent subject to consider. Previous research has suggested that many informal kinship carers suffer financial hardship (Selwyn et al., 2013) whilst many of the young people entering the Welsh care system on the whole have come from post codes with high rates of economic and social deprivation (Elliott, 2017). Furthermore, there is some evidence from Selwyn et al. (2013) that financial hardship does impact on the carers and young people's ability to engage in activities that their peers would normally be able to such as sports or afterschool clubs. In the current political climate which is still feeling the impact of austerity measures and controversial tariffs such as the 'bedroom tax', the discourse surrounding poverty is as prominent as ever (Loopstra et al., 2015; Moffatt et al., 2015). The 'bedroom tax' in particular may have impacted on the rate of children entering care as family members face losing the spare bedroom that may have been used to relieve the burden of care on overstretched parents, or else lose out financially. There is currently no research exploring this area specifically, however it is worthy of further exploration.

Despite formalising the legal responsibilities of kin in providing care to orphaned children under the Poor Law, it was not until the Children Act (1989) that the 'State' unequivocally assumed responsibility for these children by requiring local authorities to provide accommodation when no person had parental responsibility, or when the person(s) with parental responsibility was unable to provide, for whatever reason, suitable accommodation or care (Children Act 
1989, Section 20). It is highly significant that these children are referred to in the Children Act (1989) as 'looked after', confirming the State's acceptance of the role of 'care provider'. This role has grown and the 'looked after' population in the UK is now close to 90,000 (Department for Education, 2014; Scottish Government, 2015; Waugh, 2014; Welsh Government, 2015). Although some forms of 'State' care such as foster placements and residential homes have been numerically more popular, formal kinship care has also been a favoured option in a small proportion of cases. The social, health and educational outcomes of 'looked after children' are varied with some performing well in many domains (Rees, 2013), but there is also some evidence to suggest that 'looked after children' in kinship care perform relatively well (Winokur, Crawford, Longobardi, \& Valentine, 2008).

Recently there has been an increase in the number and proportion of children being placed with relatives upon removal from the nuclear family with around $12 \%$ of all 'looked after children' in England now living in formal kinship care (Selwyn, 2009). The underlying reason for this growth is unclear although major care scandals, poor care leaver outcomes, a shortage of mainstream foster carers and decreasing local authority budgets have all been proposed as influencing factors (Biehal, Clayden, Stein, \& Wade, 1995; Broad, 1998; National Foster Care Association, 1997). Interestingly, a similar trend is thought to have occurred in respect of 'informal' kinship care: full-time care provided by kin which has been privately arranged without the State's involvement. Using national census returns Selwyn and Nandy (2009) have estimated the total number of children in the UK being brought up by relative to be around 173,000 which provides an indication of how widespread the practice has become. Given the fact that the State is often unaware of informal kinship care and has no monitoring role it has no means of knowing why the practice is so prevalent. It would seem reasonable to hypothesise that the media's portrayal of some social workers as, at times, unduly interventionist and inept may encourage guarded behaviour by family networks. Similarly, an increase in the necessity for geographically mobility on the part of bread-winners, who also wish to maintain social and educational continuity for their children, would seem to be a plausible explanation for some of the growth 
in private kinship arrangements. Further research which is informed by theory is needed if a clearer picture is to be established.

Here we discuss the assertion that rather than solely being a reaction to such factors, the increase in formal kinship care may also represents an ideological shift towards a strength-based model of care through the fortification of the family unit. Given the historic role of family, it is important to understand the theoretical basis of social care of children in modern society, and the role family continues to play. It is imperative that we understand how the two interact to create the modern social work model of alternative care for children. This chapter will examine the sociological and biological basis of kinship care to provide novel insights into the theoretical underpinnings of modern social work practice and the role of the family within it.

\subsection{Structural-functional theory and the evolution of social care work.}

To begin to understand the theoretical framework of kinship care, it is important to understand the broader social context within which kinship, and even social work as a societal institution, exist. In order to do so, this section will examine social work from a wider, sociological perspective with a particular focus on structural-functionalism. This section aims to assess the role of social work in both traditional Western society and in a modern day context.

Society as a construct is widely debated (Giddens, Duneier, \& Appelbaum, 2003), although it can be understood through the perspective of structural-functionalism. This theory posits that society is a collection of social systems that interact to maintain order within society. Based upon Durkheim's functionalist approach (Pope, 1975), these social systems are groups and institutions of varying size, and share cultural values and norms. They are cohesive in allowing members to identify their own place in society and to relate to others who they deem to be their peers. Structural-functionalism differs from Durkheim's functionalist theory in that the individual is said to be irrelevant and that institutions function to serve the collective rather than benefit the individual. Within a structural-functionalist 
perspective, large institutions such as religions or government are important in sharing and enforcing moral and legal norms. Education also becomes an important structure for socialisation and obedience.

The most common analogy for structural-functionalism, made popular by Herbert Spencer (Macionis \& Plummer, 2009) amongst others, compares the structure of society to the human body. Within this analogy, institutions perform functions in the same way that organs perform functions within the body. The failure or dysfunction of any of the institutions will cause widespread dysfunction amongst others just as the failure of an organ does. Therefore, the overall goal of society is to create an equilibrium where social processes maintain balance and prevent the failure of any institution.

Equilibrium is an important concept in functionalist thought. Functionalists such as Durkheim recognised that society is in a constant state of flux and that as change occurs, society adapts to maintain equilibrium. Parsons described this constant fluctuation as dynamic equilibrium (Parsons, 2013). For example a decrease in employment may lead to higher rates of criminal activity. In functionalism, this adaptation is an implicit action which occurs without any conscious effort or acknowledgement. By contrast, structural-functionalists recognise two types of function. Robert K. Merton (1957) defined these as manifest and latent functions. Manifest functions are the deliberate or anticipated function of a structure, whilst latent functions are the unintended or unanticipated functions. The cycle to work scheme, introduced in the UK in 1999, is a good example to highlight the differences between latent and manifest functions. Cycle to work enables people to buy a bicycle tax-free via their employer. The manifest functions of the scheme were two-fold: to create a healthier workforce who would require lower health spending and less time off work, and to reduce the environmental impact of the work commute. The scheme also has latent functions in that inner congestion was reduced and the cycling sector has a financial boost. However, there were some negative consequences, known as dysfunctions, such as an increase in cycling related death and injury and an increase in bicycle theft (Home Office, 2011). 
For structural-functionalists, the family is an important institution, which represents the building block of society. Referring back to the biological model, the family, or more specifically the nuclear family, performs specific societal functions. Specifically, Murdock (1949) noted four functions fulfilled by the family: catering to sexual needs and limiting sexual access of other members of society; reproductive functions; economic functions with a focus on the division of labour within a family unit to allow prosperity; the education of the young within the family, also known as 'socialisation'. Each of these functions have an important role in the production and maintenance of citizens who can then become active participants in society. By socialising the young, cultural values and norms can be transmitted to a new generation to prevent deviance and maintain equilibrium.

With the erosion of the reality of the single breadwinner family, the nuclear model of family no longer fulfils the four functions outlined in structural-functionalist thought. In families where both parents work, the division of labour has evolved and many of the more domestic duties are often outsourced to third-parties. In some cases services such as childcare, traditionally the role of the mother in a nuclear family, are provided by a formal organisation. However, in around $40 \%$ of families, this role is adopted by a family member such as a grandparent (Huskinson et al., 2014). In such cases the division of labour is not simply between the patriarch and matriarch of the modern family, but may include other family members. A wider understanding of family to include extended kin provides a more representative approach in a modern context whilst encapsulating the four primary functions of family as identified by Murdock (1949).

Whilst the family unit is universally recognised, the composition varies throughout the world. Some societies focus on community-based child rearing as demonstrated by the African proverb "it takes a whole village to raise a child". As such, structural-functionalism has suffered heavy criticism for its emphasis on the nuclear family. Certainly in a modern Western society where single-parenthood is increasingly common and family structure has shifted away from the nuclear model, it is important to consider the relevance of a model based on such a limited definition of family. However, rather than disregard the model, it could be adjusted to incorporate a more modern concept of family. 
While family is recognised as a bedrock of society, it is helpful to understand how social work has evolved to fulfil the functions that it does. Historically, social work may be understood more as an approach than a specific and identifiable structure. With its origins in the work of a variety of religious and charitable organisations, social work served to protect vulnerable children from the dysfunction that resulted from the breakdown of the nuclear family. Over the years it has become a more organised and substantial entity, although to identify it as a structure with its own functions would perhaps be misleading. Rather, social work seems to serve to reinforce the functions of other structures, in particular the family. Originally this was achieved through the child rescue model where a child was removed from a dysfunctional family and placed into a substitute nuclear family who would be able to fulfil the necessary functions and produce a stable citizen. Similarly, the shift in social work practice which emphasised family-based interventions rather than removing the child simply served to reinforce the structure and functions of the family. It could therefore be argued that social work is a sub unit of the nuclear family and serves not only to support the functions of the family in society, but also to maintain its structure.

As the 'building block' of a societal system assembled from inter-reliant structures, the family is a critical institution in the structural-functionalist model. When considered in such a context, the relationship between family and State becomes clearer. Social work, as an institution in its own right, is a vehicle to ensure the stability of the family thus providing a stable bedrock for society to develop.

\subsection{Theories of kinship}

The previous section gave a broad overview of the social context within which social work functions as an institution. This section will examine theories of kinship through biological and sociological perspectives in order to understand the importance of kin relations. Through these theories, we will also consider some of the motivations that lead kinship carers to become the primary carer for young people in the care system. 
According to the Oxford English Dictionary, kinship can be understood by two definitions. The first, a more biological approach, defines kinship as "relationship by descent" (Kinship [Def.1a], 2015). This focuses on genetic lineage and therefore the scientifically quantifiable relationship between individuals. In a more anthropological approach, kinship is also defined as "the recognised ties of relationship by descent, marriage or ritual that form the basis of social organisation" (Kinship [Def.1b], 2015). Whilst it encompasses the genetic element of kinship, this broader definition understands kinship to be the social relations between individuals. These relations, whether formalised through religious rituals such as marriage or through social rituals, become the basis for the organisation of individuals into kinship groups. This may also have grown to include friends of the family who were more traditionally referred to as 'kith'. These differing definitions highlight the ontological conflict in understanding kinship and can be used to examine the proposed theories of kinship relations.

In some respects, kinship appears to conflict with scientific theories of species survival. According to theories of evolution, organisms within a species that have genetic mutations that prove advantageous to their survival will thrive and pass on these genetic benefits. Those who do not are more likely to perish and so fail to reproduce. It would therefore seem contradictory that altruistic traits would continue to be present in both humans and other species. Altruism is best understood as a "behaviour of an animal that benefits one or more others (typically of its own species), but which carries a cost for the individual concerned" (Altruism [Def.2], 2015). In many cases, the cost of altruism is high and can include mortality. Velvet monkeys, for example, have been known to make alarm calls when under attack to warn others within their group of the danger. Whilst this is beneficial for the rest of the group, these cries may also attract the attention of the predator and make the individual more vulnerable to attack (Cheney \& Seyfarth, 1992). Similarly, the financial, lifestyle and time costs associated with becoming a kinship carer make the act of doing so an altruistic one.

How then has altruism survived natural selection? Evolutionary psychologists claim the answer lies in two theories: selfish gene theory and inclusive fitness. Richard Dawkin popularised the concept of the selfish gene in a 1976 book of the same name (Dawkin, 1976). Building upon previous theories of evolution 
proposed by George C. Williams (1966), Dawkin argues that genes have the single purpose of replicating to ensure its continued existence. Whilst the use of the term 'selfish' ascribes a confounding level of anthropomorphism to the innate action of genes, the theory itself provides a solid foundation for the theory of inclusive fitness. This theory posits that our actions are genetically driven by the innate need to replicate. In order to ensure the survival of genes, an individual may sacrifice themselves in order to protect their offspring or other biological relation. This is arguably evidenced by matriphagy; the apparent sacrifice of the maternal spiders to provide nutrients to offspring in some species (Toyama, 2001). Hamilton even proposed that inclusive fitness is a vehicle that promotes altruistic traits and in doing so created a mathematical formula to calculate whether the altruistic gene would pervade through a population (Hamilton, 1964a, 1964b).

Some might be tempted to view inclusive fitness as an explanation for the motivations of kinship carers. Kin, as described in a biological sense, may have a genetic predisposition to behave altruistically in order to preserve the genetic lineage. This is summarised well by J.B.S Haldane who once quipped: "I'd lay down my life for two brothers or eight cousins" (Lewin, 1974). In doing so, Haldane humorously suggests that altruistic behaviour is directly proportional to the degree of genetic relatedness to another. Whilst the biological explanations of kinship present some interesting observations in the animal world, the extent to which they can be applied to human behaviour is, arguably, limited.

One of the main challenges to theories of inclusive fitness is the adoption of unrelated infants and children. Proponents of inclusive fitness argue that adoption of unrelated individuals is an 'off-track' expansion of kin-adoption that has historically prevailed (Barrett, Dunbar, \& Lycett, 2002; Buss, 2015). By describing adoption as 'off-track' these authors seek to dismiss cases of adoption as outliers, or as a phenomenon created by social conditioning. This view is seemingly supported by evidence of adopted individuals being treated less preferentially than genetically related young (Daly \& Wilson, 1980; Eberhard, 1975). Regardless, the adoption of an unrelated individual seems to counter the arguments of inclusive fitness as it removes financial and emotional resources from one's own genetic offspring. It seems counterintuitive that a kinship unit 
would expend resources on those with no genetic linkage to themselves. Wilson, historically a major proponent of kin selection, co-authored a paper which refuted inclusive fitness in favour of group selection (Nowak, Tarnita, \& Wilson, 2010). Here the formation of social groups was recognised as a more important factor in determining the altruistic behaviour of both humans and other species. This would certainly seem to provide a more satisfactory explanation of kith care and adoption although does not fully address the notion of the latter, particularly where there seems to be no identifiable grouping from which the altruistic motivation arises. To understand this further, we must move away from the sociobiological explanations of kinship and turn our attention towards the fields of psychology and sociology.

Social identity theory is one of the most recognised theories to emerge from the field of social psychology. Introduced by Henri Tajfel in the 1970's, social identity theory focuses on how we identify with various groups in society and how we draw our self-esteem from the accomplishments of the groups to which we consider ourselves to belong. These groups are referred to as 'in-groups' and studies have demonstrated a tendency to behave preferentially toward our ingroup when compared with 'out-groups'. In particular, Tajfel and colleagues found that even when assigned to a group arbitrarily, study participants allocated more points to their in-group than their out-group (Tajfel \& Billig, 1974; Tajfel, Billig, Bundy, \& Flament, 1971). It would seem therefore that we require little more than association with a certain group in order to behave favourably towards its members. It is through this that proponents of social identity theory posit that our social identity, as determined by the groups we associate with, can impact upon our behaviour.

Perhaps the most recognised study of social identity comes from the Stanford prison experiment conducted by Zimbardo and colleagues (Haney, Banks, \& Zimbardo, 1973). In this study a mock prison was created and twenty-four students were assigned either the role of prisoner or guard. This role allocation was entirely arbitrary and the participants were given no instruction on how to behave. Originally designed to last for a fortnight, the study was called off after only six days due to the emotional distress of the prisoners who were suffering at the hands of the guards. Despite being given no instruction or training on how to 
fulfil the role of a guard, the participants allocated to the role behaved in a similar way to real prison guards, using both physical and psychological punishments to maintain order and authority. This phenomenon was eloquently described by Abrams and Hogg (Abrams \& Hogg, 1990, p. 297) who stated that "group behaviour arises from a shared sense of social category membership". In the Stanford prison experiment this was demonstrated by the guards who identified as a part of that group and so behaved as they believed a guard should.

Numerous studies have informed us that we will behave preferentially to a group to which we are assigned in a laboratory setting. What is interesting, however, is how this can be applied to enhance our understanding of natural group dynamics in everyday life. A single person is normally a part of numerous in-groups, whether it be a small group such as a sports team, or part of a large group such as a religion or nation. The different groups to which we are affiliated are ones with which we may share certain values or beliefs and to which we identify as being a part of. In the words of Emerson "the simplest statement that can be made about a nation is that it is a body of people who feel that they are a nation" (Emerson, 1960). Simply, in order to be a part of a group one must only feel a part of that group.

In the first section we identified the structural-functionalist perspective of the family as the base unit of society. Through this model, the concept of family has been reinforced for centuries. The biological models explored earlier in this section went some way to explaining how the kinship group came to form in nature, however kin selection could not sufficiently account for kith relations and adoption. By contrast, social identity theory may go some way to explain kith relations and their role in the social group. Social identity theory posits that a family group is defined by each individual's understanding of themselves within the social group. Therefore an individual who considers himself to be part of a family group may be so in spite of a lack of biological relatedness. This may also be indicative of an innate and implicit understanding of the relationship between nature and nurture. This may widen the traditional understanding of kin to encapsulate kith and go some way to explaining the motivations of kith carers. 
Importantly, social identity theory provides a further explanation of the factors that motivate kinship carers to undertake caring duties despite negative consequences for their own wellbeing. In a study of informal kinship carers, researchers found that carers often described a sense of ownership and family obligation (Selwyn et al., 2013, p. 13). This sense of obligation may come from the internal identity of the carers who see it as part of the role they should play. This concept is supported by the number of female kinship carers. Traditionally caring roles were the responsibility of females within the nuclear family. Despite decades of social change leading to the sharing of such roles, females still account for more than $55 \%$ of kinship carers in the UK (Nandy et al., 2011). As such the figures would suggest that the roles in which we identify within the family unit may not have changed as much as we may wish to imagine. Equally, the function of the family unit as a protective factor seems to be engrained in our perceptions of kinship relations.

One of the major strengths of social identity theory is that it does not seek to override the social, political and biological explanations of intergroup relations, but rather to complement theories in these areas. In doing so we can see how social identity theory enhances our understanding of group dynamics to supplement our comprehension of group selection. In the final section of this chapter, we will explore how social work and kinship relations interact to fulfil the functions of the family.

\subsection{The interaction of social work and kinship}

In the previous sections we examined the roles of both social work and family in society and explored the theoretical basis of kinship. In this section we will explore how social work, as we have come to understand it, interacts with families to form kinship care placements. In order to do so, we shall discuss ecological systems theory and how it is integrated into the modern day social work model.

Ecological systems theory was formulated by Urie Bronfenbrenner, an American psychologist working in the field of child development (Bronfenbrenner, 1979, 1992). This theory was founded on the view that children do not develop within a 
'vacuum' but rather develop within the social, economic and political climates that surround them. It followed, therefore, that the external environments at the various levels of interaction would impact upon the child's development. Whereas previously child development had focussed on the immediate environment of the child, Bronfenbrenner introduced to the field a wider perspective within which developmental psychologists should work (Bronfenbrenner, 1977).

The ecological model can be understood as five embedded structures resting inside one another "like a set of Russian dolls" (Bronfenbrenner, 1994, p. 39). The microsystem consists of the child's immediate environment and includes the physical, social and interpersonal interactions that the child faces on a day-to-day basis. Within the microsystem may be the immediate family relations, friends, and school interactions such as with peers and teachers. The mesosystem consists of the "linkages and processes between two or more settings containing the developing person" (Bronfenbrenner, 1994, p. 40). Essentially the mesosystem is a series of microsystems interacting with one another such as the parent and teacher.

The next layer, the exosystem, contains the links and processes between a setting where the developing person has no active role and the individual's immediate context. An example would be a parent acquiring a new job which requires them to work longer hours and so reducing the amount of time the parent could spend at home with the developing person. The macrosystem refers to the cultural context within which the developing person lives. This can be, for example, ethnicity or socioeconomic status. Finally there is the chronosystem which is understood as the effects of the passage of time on development, not merely in a chronological sense, but in the sense of transitional events over the life course and historically. For example, one could expect the development of a child to differ in the wartime and post-war eras due to environmental differences brought about over time.

Social work practice has developed over time and the strategies used to protect vulnerable young people have adapted accordingly. Using the ecological model, we can examine how the approach to social work has changed. The original child rescue model, favoured by charitable and religious organisations in the $19^{\text {th }}$ 
Century, focused on removing a child from harm. In order to do so, the child was removed from their microsystems and placed into new systems which were presumed to be better. To a certain extent this has continued into more recent history with removal for adoption still being prevalent amongst young children in the care system (Barth \& Berry, 1988; Department for Education, 2014). Displacing a child into an entirely new system was seen by many as a fresh start, although research has indicated that there may be some adverse effects in doing so (Lindholm \& Touliatos, 1980). In particular, young people adopted from preschool age were more likely to suffer from conduct disorders and personality problems than their non-adopted peers. Furthermore, adopted children in a study in the USA were more likely to suffer poorer school adjustment between fourth and eighth grade than their peers (Ternay, Wilborn, \& Day, 1985).

Perhaps the natural development for social work then was for the child to remain within the family unit for as long as possible. Where this was not possible, the child would be encouraged to retain contact with birth parents with an eventual aim towards reunification. The 1946 Curtis Report emphasised the importance of working with families in order to prevent abuse and neglect. This encouraged a shift in social work practice from a reactive force that displaced young people to a preventative force that acted to improve the nuclear family unit and strengthen the microsystems of the developing person. There are some advantages to this approach in that the systems are familiar and consistent for the young person. However, for many young people the risk of harm is too great for them to remain at home during the period of intervention with birth parents. It is for this reason that placements outside of the parental home still play a key role in social work practice.

Kinship care can perhaps be described as the middle ground for social work practitioners seeking to protect young people from harm. Placement with relatives enables practitioners to remove children from the potential dangers of the parental home whilst minimising the changes to their ecology. There are many elements and systems within a kinship placement that remain the same: continuity of educational establishment and peer groups, consistency in family relations and in many cases, due to the geographical proximity of placement to parental home, stability in neighbourhood (Ehrle \& Geen, 2002). As such, rather 
than displace the child, kinship care placements simply change the dynamics of the linkages between the microsystems. By doing so social work practitioners can work with the family to maintain the functional aspects of the child's ecology whilst reinforcing or adapting the dysfunctional aspects. Through this we would expect that kinship care, where appropriate and where there is suitable involvement from public services, would be superior to mainstream foster care.

A problem that is now recognised by the State is that of the intergenerational cycle of abuse (Buchanan, 1998). This is a self-perpetuating cycle of care dependency in which parents who were in the care system themselves are more likely to re-enact abuse they suffered with their own children. For the State, kinship care may pose a partial solution to this problem. This is summed up in the proverb: "give a man a fish, and you feed him for a day. Teach a man to fish, and you feed him for a lifetime." The child rescue model can be compared to the first part of this proverb in that it displaces a single child and fails to address the social issues that endangered that child in the first instance. This means that should another child be born, the same problems would present and the next child would also need to be rescued. Kinship care, however, offers an alternative solution. By investing resources into strengthening the ecology surrounding a vulnerable child, social work can create a self-sustaining and protective family unit. Essentially kinship care is about altering the dysfunctional elements to enable a family unit to be self-sufficient without the need for further intervention from the State. In terms of cost-effectiveness it is better to teach a family to care for itself in this way than to "give them a fish". By initiating these kinship support networks where appropriate, social work has the potential to break the selfperpetuating cycles of care dependency and in doing so reduce the number of children within the care system.

In some respects the prominence of formal kinship care placements within the care system is a fresh approach to out of home placements for young people. Despite a long anthropological and sociological basis for kinship networks and informal care relationships, the rise of kinship care in professional social work is relatively modern phenomenon. However, it could be argued that the theoretical underpinnings of kinship care are anything but novel. Social work practice has undergone many changes with various trends in the approaches it has taken to 
child protection, but the sociological aim has always remained the same. At its core, the function of social work has always been to reinforce and support the family unit. From the child rescue model where the child's ecology was replaced in its entirety to the kinship model where the dysfunctional elements of the ecology are simply adjusted, the family has remained a central tenet of social work.

\section{Section summary}

This chapter has explored a number of theories in order to understand how kinship care fits within the common understanding of contemporary society. Various papers outlined in chapter two noted that hardship is a frequent consequence for kinship carers once they agree to provide full-time care for the young people. Given that hardship, it is important to understand why kinship carers are motivated to take on the additional responsibility and how the social work system supports them as they do so.

Through the facet of structural-functionalism, section 3.2 identified the function of the family unit and how it has changed over time from the nuclear family to a wider understanding of family and kinship that is inclusive of extended family and close friends. Due to the importance of the family as the foundation of industrial society, this section outlined a number of structures that are in place to support and enforce its stability. These can come in many forms, from the prescriptive regulation of the Poor Law Amendment Act (1834) to the more modern social work system which seeks to support families in addition to its regulatory enforcement powers. These extrinsic motivators go some way to explaining why kinship carers may be willing to disadvantage themselves in order to care for kin, but seem woefully insufficient in isolation.

Section 3.3 explored some of the more intrinsic motivators that may influence a kinship carer when deciding whether or not to provide care for a child in need. Social identity theory was identified as being a key theoretical component of kinship care relations. It suggests a more intrinsic motivator to kinship care such as group preservation and increased esteem within the group. The combination 
of these theories provides some insight into the underpinning of kinship care from the perspective of society and the family. However, it is also essential to understand the impact that any care intervention will have on a young person who is recovering from abuse or neglect.

The final section sought to explore this through the lens of ecological systems theory. The principal of mainstream foster care is that children who are residing in harmful environments need to be removed from their current ecological system and placed into a more positive ecology. Whilst beneficial in removing harmful influence, this approach has led to a number of difficulties as outlined in chapter 2. The use of kinship care, meanwhile, reduces the extent to which the child's ecology is altered and thus requires less adaptation. Essentially the theoretical position on kinship care is this: kinship care should provide better outcomes for young people who are looked after than mainstream foster care. In addition to providing better outcomes, kinship care promotes group resilience through support and intervention at the family level with the aim of reducing intergenerational cycles of abuse. This is then beneficial at a societal level as the family unit is preserved and strengthened.

\subsection{Thesis objectives, aims and research questions}

The literature review has outlined a number of areas where further research is required. The research questions for this project will be presented here, alongside a brief outline of the gap this research seeks to fill in the field.

The first aim seeks to establish the stability and permanency of kinship care placements. The literature highlights the benefits of stable placements in ensuring positive outcomes for young people within the care system. Whilst there is some evidence to suggest that kinship care placements promote stable longterm placements, the extent to which this leads to permanency is, as yet, undetermined. Furthermore, with the introduction of SGOs as a proposed permanency option and post-care placements for young people aging out of care, research is required to understand the effect of new policy on the care population. Thus, the following research questions are proposed. 
RQ1: Research exploring the outcomes of care leavers has tended to focus on those aging out of care. Government statistics highlight that more than $83 \%$ of Welsh care leavers in 2016 left care before the age of sixteen (StatsWales, 2017b). However, despite amounting to a large proportion of care leavers, the impact of placement type on the route by which young people leave are is unexplored. Consequently, this study poses the question: what is the initial postcare destination of 'early care leavers'?

RQ2: Again exploring early care leavers, the second research question seeks to establish how final placement type impacts upon post-care destination. The relationship between final placement and post-care destination is not clearly defined in the literature, in particular whether there are differences between kinship care and other placement types.

RQ3: There is a dearth of research exploring the permanency of SGOs. Preliminary research has predicted a breakdown rate of $5.7-6 \%$ over five years, (Selwyn \& Masson, 2014; Wade et al., 2014) however, due to the relatively recent introduction of SGOs to practice, accurate breakdown rates within kinship care are undetermined. Given their growing use as a permanency option, exploration is warranted thus the third research question: to what extent do Special Guardianship Orders (SGOs) provide permanency for young people?

RQ4: Whilst SGOs are becoming a common route by which children leave the care system early, little is known about the factors which motivate or deter kinship carers in pursuing an SGO. There is some evidence that informal kinship carers may be influenced by financial hardship and an inherent belief that the children will eventually return to their birth parents. The extent to which this relates to the formal kinship care population is yet to be established.

RQ5: Previous literature has indicated that informal kinship carers experience concern that pursuing an SGO will lead to the withdrawal of LA support. There is a dearth of literature pertaining to the extent to with these beliefs are founded. Exploring the measures taken by LAs to support SGO placements is therefore warranted. 
RQ6: Existing literature documents poor outcomes for young people aging out of care, however, the extent to which post-care placements pre-date the introduction of the 'when I'm ready' and 'staying put' schemes is poorly documented. The sixth research question seeks to establish the extent to which care leavers who age out are already 'staying put'.

RQ7: The previous research question seeks to explore the number of young people 'staying put', however the effect of final placement type on other post-care destinations is equally undetermined. RQ7 seeks to understand the relationship between final placement type and the post-care destination of care leavers aging out.

The second aim if this thesis is to explore the wellbeing of young people in formal kinship care. The wellbeing of young people in foster care and group homes is well documented. Studies indicate that the population are characterised by disorganised attachments, poor mental health, and lower levels of emotional literacy when compared with the general population. However, the extent to which these challenges are also experienced by their looked after peers in kinship care is yet to be established. The second aim of this study is to determine the relative wellbeing of young people in formal kinship care compared with young people in mainstream foster care and the general population.

$R Q$ 8: Previous literature has noted a number of placement characteristics that may serve to promote attachments between young people in formal kinship care and both their birth parents and carers. Factors such as remaining geographically local to their parent's address and informal contact may aid in promoting attachment to birth parents, but may equally cause disruption to the placement. This research question aims to fill the gap in knowledge and aid in understanding how young people in formal kinship care organise their interpersonal relationships.

$R Q$ 9: Furthermore, previous literature has proposed that children can form multiple attachments and that relationships with birth parents may be better preserved in kinship care. However, it is unclear whether this occurs in formal 
kinship care. Establishing the relative strength of attachments to caregiver and birth parents will provide an insight into the way in which young people feel about their relationship with their carer and birth parents. Comparing these to mainstream foster care and the general population also serves to establish whether these attachments are stronger, weaker, or the same as their peers.

$R Q$ 10: Literature has established that attachment style and strength change over the life course. This may be particularly pertinent to formal kinship care where multiple attachments are encouraged for many young people with both birth parents and kinship carers. Despite this, there have been no studies exploring the relationship between age and attachment in formal kinship care. Thus, the tenth research question seeks to investigate how children's attachments change with age in kinship care.

RQ11: Previous research into kinship care has determined that kinship placements tend to be more stable. Furthermore, there is evidence that kinship carers are more committed to the young people in their care than mainstream foster carers and therefore more likely to persevere despite difficulties. The way in which stability may relate to the child's attachment to carers and birth parents has not yet been researched. Research question eleven seeks to fill this gap by establishing whether attachment strength and placement length are related to one another.

RQ12: The literature has highlighted differences between kinship care and mainstream foster care in the way in which birth parent contact is scheduled and conducted. In particular the informal nature of contact in informal kinship care is thought to be beneficial in maintaining a strong attachment relationship between the child and their parent. However, it is unclear whether the benefits are retained in formal kinship care where care arrangements are more rigid, and how contact can impact upon a child's attachment to their carer, given previous concerns that birth parent contact may trigger conflict.

RQ13: Difficulties with mental health is a well-established characteristic of those in out-of-home care. Studies have identified difficulties both within care and beyond into adulthood. However, methodological problems along with inappropriate control groups may have over-estimated the extent of the problems. 
This may be especially true for those in formal kinship care whose in-care experience may differ markedly from their mainstream peers. Comparison with young people in informal care may yield an insight into the effectiveness of formal interventions as a looked after child, whilst general population norms continue to provide an aspirational baseline.

RQ14: The relationship between mental health and factors such as attachment, birth parent contact and placement stability is not well established in literature. There is some indication that children with behavioural problems are more likely to experience placement breakdown with those in mainstream care likely to breakdown faster than those residing with kin. However, it is not clear whether this remains the case in formal kinship care where a greater level of support may be available to carers than would be for informal kinship carers. Given the causal relationship proposed by Attachment Theory, whereby disorganised attachment may cause mental health difficulties, it is important to establish how each domain of attachment (carer, parent and peers) relates to mental health. Furthermore, previous literature has failed to establish whether mental health problems are related to birth family contact.

RQ15: The importance of emotional literacy has been evidenced across a variety of domains. Research has found that emotional literacy is lower in the care population than the general population, however there is no research on the relationship between placement type and emotional literacy levels. Therefore, this study aims to establish whether differences exist in the level of emotional literacy between young people in formal kinship care, the care population as a whole and the general population.

RQ16: In addition to establishing whether differences exist between placements, this study aims to assess whether emotional literacy level correlates to other factors such as mental health, attachment, and contact frequency.

RQ17: The voice of the child is a well-established concept when working with children and young people. Research has indicated that young people experience a number of benefits as a result of feeling listened to and included in decision making. For those in out-of-home care, their ability to participate is determined by their perceived level of understanding and maturity. Despite 
increasing inclusion, young people continue to report that they are not listened to. It is unclear whether this is the case. Research question seventeen seeks to understand how emotional literacy is related to a child's sense of control and optimism. Doing so may provide insights into how young people can be given a greater sense of control.

RQ18: Poor physical and psychological health is a common characteristic of informal kinship carers. However, little research has been conducted to explore the health and wellbeing of formal kinship carers. This study seeks to fill this gap in knowledge.

The final aim of this thesis seeks to further explore wellbeing by focussing on the educational achievement of looked after young people in kinship care. Low educational attainment is a well-documented feature of out-of-home care. Research has suggested that kinship carers tend to have a lower level of formal education and to feel less able to communicate effectively with schools. As such, it is unclear whether young people in kinship care share the risk of low attainment with their peers in mainstream foster care.

RQ19: Assessment of literacy levels has been plagued by problematic methodological design and inappropriate control groups. Studies that have used a within-subjects design have found that whilst young people in care tend to perform lower than the general population, the rate of positive exception had previously been underestimated. Research question nineteen seeks to establish the standard of literacy of young people in formal kinship care and the degree to which they are achieving as expected on the domain of literacy.

RQ20: Furthermore, studies to date have failed to distinguish between placement types meaning that it is unclear whether literacy is higher, lower or equal in kinship care or mainstream care placements. Research question 20 seeks to compare literacy levels of those in kinship care to the general population and their peers in other placement types.

RQ21: Despite having documented low levels of literacy in the care population, research has shown that educational aspirations remain high. However, given the characteristic differences that kinship carers have been shown to display, such 
Chapter 3: Literature review: theoretical underpinning of kinship care

as lower levels of formal education, the extent to which education is prioritised as a placement outcome is yet to be determined. The extent to which priority for placement outcomes is shared between young people, kinship carers and social workers is also unknown. The final research question seeks to explore the factors that are prioritised by young people, kinship carers and their social workers. 
Chapter 4: Methodology 


\subsection{Research paradigm}

Whilst social work legislation may be indirectly informed by research findings, the practice of social work is arguably based upon its own history and experience. Radical shifts in practice also seem to follow media-highlighted events. It is perhaps one of many reasons that formulating a research paradigm for the study of social work is challenging as researchers attempt to apply a research framework that does not necessarily reflect the nature of social work practice. This has resulted in a long-standing debate within the academic community. On one side are academics who support the application of a positivist epistemology in the field in order to achieve standardised protocols with minimal bias (McNeece \& Thyer, 2004; Teater, Devaney, Forrester, Scourfield, \& Carpenter, 2016). This had become embroiled within the wider debate of evidence-based practice and the role that research plays in the field (Dill, 2016; Fischer, 1973; Mullen \& Dumpson, 1972). Perhaps more familiar in the context of natural science, positivism is seen by its proponents to be a strong alternative to a more normativist approach. Positivism undoubtedly has its advantages, with objectivity and standardised practice to name but a few. However, serious questions have been raised regarding its ability to study a field as steeped in human emotion and experience as social work (Heineman, 1981; Webb, 2001). In particular, there is concern that quantitative research is not accessible to practitioners and is difficult to translate into practice (Gambrill, 1999; Howard, McMillen, \& Pollio, 2003). In some respects, the debate reflects the early dilemma of social work practice which itself had difficulty determining whether it could be more appropriately described as a science or an art form (Peile, 1988).

The normativist paradigm is perhaps grounded in more forgiving epistemology. Rather than dismiss abstract concepts, it incorporates them into the design in order to create, arguably, a more ontologically valid result. In social work studies, many of which are applied research with direct practical applications, this is an important factor to include. However, to shift the paradigm dramatically in the direction of normativism may create as many problems as it is deemed to solve. If nothing else, descriptive statistics of populations are a good way to establish the extent of a societal issue. By contrast, research methods such as those supported by normativist researchers, seek to understand the route by which this 
comes about. Whilst useful in a sociological context, without a firm and reliable quantitative platform to build upon, the opportunities to generalise the information gathered and to affect political or legislative change are limited. Furthermore, more complex empirical research can examine factors in a reliable way. Regression analyses may, for example, reveal the groups within the general population who are most at risk of entering the care system. By using a predictive model in such a way, the findings of empirical research can inform policy and practice in a meaningful way.

Epistemologically speaking, the two approaches may seem oxymoronic, although this is contestable. Whilst the normative approach acknowledges the limitations of a pure empirical approach, it also recognises that it may have some uses in social work research. There are some aspects of social work knowledge that can be confined to the scientific approach of empiricism and yield important and relevant information about the current state of affairs in the field. However, the field is also highly subjective and there are simply some areas where it would be inappropriate to attempt to fit the scientific model. By its very nature, the field of social work is based upon human interaction, not in quantifiable terms, but in more emotional and abstract terms such as love. To attempt to apply an empirical scientific research model to such research questions could be compared to attempting to fit a square peg into a round hole. Simply, the epistemology of social work incorporates knowledge that positivism cannot wholly accommodate. It is in this sense that a mixed methodology (Tashakkori \& Teddlie, 2010) becomes a viable research option, combining the generalisability and objectivity of positivism with the subjective and experiential elements of the normativist paradigm. This goes in hand with the demands of social work practice which requires standardised protocols for practice whilst acknowledging and incorporating the subjective human experience in order to adapt practice to various situations.

Within the field of social work, studies have varied methodology. Many, particularly those relating to medical or psychological factors, have focussed on a more empirical approach. Some have used data already available in the public domain to look at relationships between key variables such as time in public care and health (Viner \& Taylor, 2005). Others have used standardised measures to assess outcomes (Leslie, Gordon, Meneken, et al., 2005). On the opposite end 
of the research spectrum are those using purely qualitative methods, or qualitative with very limited descriptive statistics (Selwyn et al., 2013). This would generally relate to areas traditionally considered to have evolved from sociological areas such as the relevance of voice of the child or the emotional effects of birth family contact in kinship care. One such study by Kiraly and Humphreys (2013b) used focus groups and interviews to establish the views of young people regarding birth family contact and provided strong support for the view that many children feel excluded from the decision making process despite displaying a comprehensive understanding of their situation. Further studies have successfully integrated both positivist and normativist paradigms in a mixed methods approach (Allen-Meares \& Lane, 1990). One such study, summarised in a paper by Broad (2004) used case file data regarding variables such as placement length, combined with qualitative data from focus groups and interviews (Broad, Hayes, \& Rushforth, 2001). This combination allowed for results with direct practical implications for public policy with both empirically valid and ontologically relevant discussion.

The way in which positivist and normitivist research paradigms are used concordantly has triggered a philosophical debate amongst researchers (Shannon-Baker, 2016). A pragmatic approach is one response to this debate, focussing on research questions and research outcomes (Tashakkori \& Teddlie, 2010). Pragmatism integrates the normitivist and positivist paradigms into a single approach, triangulating qualitative and quantitative data to gain shared meanings (Arnon \& Reichel, 2009; Shannon-Baker, 2016). Conversely, critical realism acknowledges the dissonance of the two paradigms and seeks to "facilitate dialogue and compatibility between quantitative and qualitative approaches" (Shannon-Baker, 2016, p. 323). Embedded within constructivism, critical realism proposes that knowledge is constructed in the mind of the observer. However, this is within the context of realism whereby reality also exists outside of human observation (Bhaskar, 2013; Creswell \& Clark, 2007; Maxwell \& Mittapalli, 2010).

The UK court and social services systems deal with the measurable and the probable in determining the best interests of a child in care. This can be demonstrated by the use of the Welfare Checklist, an objective set of statutory 
criteria to guide the courts in their decision making process. This thesis employs the paradigm of pragmatism as this appears well suited to the research topic, and mirrors the practice of the courts and social services as they attempt to measure the human experience.

\subsection{Design}

The design is comprised of two sections. Phase One employs a longitudinal case file audit in order to gather quantitative trend data. This data focussed on research questions relating to stability and permanency. Case file auditing was chosen due to its efficiency in compiling large amounts of data for analysis. Equally, the indirect nature of data collection diminished concerns of disrupting unstable placements. There are some limitations to case file auditing as a means of data collection, not least concerns related to the data accuracy. Where data was obviously missing, this limitation could be mitigated through consultation with relevant case workers in order to establish accurate data.

Phase Two employed a cross-sectional mixed-methods approach. Quantitative methods included the use of standardised and bespoke measures. These allowed in some cases for within and between-subject comparisons. Phase Two also incorporated qualitative interviewing in order to understand how each group experience the shift towards professionalisation of kinship care. Semi-structured interviews were used with kinship carers, young people and case social workers. Interviews were selected to allow for in-depth responses whilst preserving confidentiality amongst the participants. It was also deemed to be more convenient due to the large geographical spread of participants which would have made focus groups difficult to arrange. With supervising social workers, where confidentiality and geographical proximity posed no challenges, a focus group was arranged in order to provide an efficient means of extracting meaningful data from the participants.

The overall objective of the thesis, examining the implications of social work's theoretical shift, lent itself to a phenomenological design for the qualitative elements. This design emphasises the way in which participants experience the 
phenomenon, in this case formal kinship care. Given the exploratory nature of the semi-structured interviews, an inductive thematic approach was deemed to be the most appropriate method of analysing qualitative data. Data was transcribed and common themes identified. Transcripts were then coded according to these themes. Each participant category was analysed independently with crossover of themes incidental rather than a deliberate approach. A full outline of the analysis process can be seen in Braun and Clarke's procedural paper (2006) whilst an overview is presented in Figure 1. An obvious limitation of thematic analysis is the introduction of bias by the researcher. Attempts were made to minimise this by using the standardised thematic process outlined by Braun and Clarke (2006). Nonetheless, by its very nature qualitative coding is open to subjectivity and it is a limitation that must be recognised.

Data was triangulated by research aim. Each data type tended to be used independently in response to a research question, however some triangulation was required. In such cases, quantitative data was normally used in order to group participants and establish any statistically significant correlational or causational effects. Qualitative data was then used to provide depth of meaning to the quantitative data and attempted to explore the reasons for, or the implications of, the quantified effects. 
1. Familiarisation with data.

Process whereby the researcher is immersed in repeated reading of the data. Can also be undertaken during data collection and transcription.

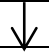

2. Generation of initial codes.

Generation of codes through systematic reading of data and identification of repeated or important patterns within the data.<smiles>[AlH]</smiles>

3. Search for themes.

The organisation of codes into overarching themes that accurately reflect the data.

\section{Review themes.}

Review of how the themes support data and theoretical perspectives. Revisit data if analysis seems incomplete.

5. Define and name themes.

Researcher defines the themes, the data that the themes capture and reasons for inclusion.

6. Prodduce report.

An analytic narrative of the data. Provides and analyses the data for publication.

Figure 1: Thematic analysis procedure (as in Braun and Clarke, 2006). 


\subsection{Phase one}

\subsubsection{Participants}

Two Local Authorities (LAs) in South Wales were selected to take part in this study. They were selected for participation as they were both co-funders of the project.

Local Authority A (LA A) is a rural county with a population density of around 75 people per $\mathrm{km}^{2}$. On the Welsh Index of Multiple Deprivation (2014) $8 \%$ and $17 \%$ of the wards are ranked in the bottom and top quartiles respectively. Ninety young people left the care of LA A during the 12 months preceding $3^{\text {rd }}$ October 2014, of whom seventy one left care early.

Local Authority B (LA B) is an urban county with a population density of more than 600 people per $\mathrm{km}^{2}$. On the Welsh Index of Multiple Deprivation (2014) $35.1 \%$ and $26.4 \%$ of the wards are ranked in the bottom and top quartile respectively. $A$ total of 231 children and young people left the care of LA B in the 12 months preceding $30^{\text {th }}$ September 2014, of whom 200 left care early.

\subsubsection{Measures and instruments}

Commercial databases were used by the LAs. These were: PARIS (Public Assistance Reporting Information System) and CareFirst. The databases allow data matching to create a single case file for each service user in order to centralise key information in an accessible format. The system was accessed via a networked computer terminal within each local authority.

\subsubsection{Procedure}

A case file audit of both local authorities (LAs) was undertaken. Each LA provided a report containing details of all cases where children had ceased to be 'looked after' by the local authority between 30/09/2013 and 30/09/2014. Each child's placement prior to leaving care and their destination in the 7 days after leaving care was established through case file audit. This process involved analysis of case notes, registered addresses of both the young person and known associates, and consultation with case workers. Pre-leaving placement groups 
were coded using the discrete categories adopted by the Welsh Government Department for Education and Skills (Welsh Government, 2014). Where LA coding differed from these discrete categories, the information was gained from case notes and manually classified. The care leaver destination of all cases was identified and categorised into the following: 'SGO' (Special Guardianship Orders), 'Return to parents', 'Aged out', 'Adoption', and 'Care home' and 'Custody'. Data was recorded at three month intervals for twelve months from the date of leaving care for those who 'aged out' of care. Young people subject to SGOs were followed for 18 months.

\subsubsection{Analysis}

Initially, descriptive statistics for each local authority were compiled for both the care leaver population of all ages, and the sub-population of care leavers 'aging out'. Data from both LAs was then pooled to examine comparative trends. Nominal data was analysed using a chi-square test whilst an independent samples t-test was used to examine interval level data.

\subsection{Phase two}

\subsubsection{Participants}

Participants in Phase Two of this study can be broadly split into three groups based on their role: kinship carers $(n=24)$, children and young people $(n=21)$, and social work practitioners $(n=21)$. Supervising social workers were also included $(n=5)$. The recruitment process for kinship carers and for children and young people was the same and so participants from these groups are described together (see "kinship carers and children and young people in kinship care"). As the recruitment process for social work practitioners differed, participants from this group are described separately (see "social work practitioners"). 
Kinship carers and children and young people in kinship care

Participants were drawn from two local authority areas in South Wales. In order to be eligible for participation, each participant was required to meet the inclusion criteria for their respective role.

\section{Kinship carer:}

A person with whom a child resides and for whom they provide full time care.

\section{$A N D$}

A person who is not the birth parent of the child but to whom they are related by blood or marriage such as a close relative (grandparent, aunt, uncle, sibling or step-parent).

\section{OR}

A person who is not the birth parent of the child but to whom they are known prior to placement commencement (kith).

Participants with a minimum age of 18 years were included in this study. No maximum age limit was applied.

At the time the study was taking place, the carer was required to be residing within the boundaries of the two local authorities

\section{Children and young people in kinship care:}

A child who at the time of the study was residing full time with a close relative (grandparent, aunt, uncle, sibling or step-parent) other than their birth parents to whom they are related by blood or marriage.

$O R$

Residing full time with a carer with whom they have a pre-existing relationship (kith) 
This included children who were subject to care orders, such as residence orders, special guardianship orders and adoption orders.

Participants aged between 8-18 years were eligible for inclusion in this study. The study included children and young people in formal kinship care who were residing in a kinship placement and legally considered 'looked after' by the local authority. Children and young people living in informal kinship care were not included in this study.

At the time of the study the child was required to reside within the boundaries of the two local authorities.

Eligible kinship carers and children and young people were selected from case file information provided by each local authority. Social workers of those who met the inclusion criteria were contacted regarding suitability to participate. Social workers declined permission to approach 7 young people and 6 kinship carers. Those for whom permission was granted and who met the above criteria were contacted by telephone and invited to participate.

In total, 33 kinship carers and 45 children and young people were contacted, of whom 24 (5 male) and 21 (8 male) agreed to be contacted further. Contact failed to be established with 2 kinship carers and 2 young people. An appointment was arranged with each participant to visit in their home at a convenient time. The participation rates of young people and kinship carers are shown in Table 1 and Table 2 respectively. The reasons for non-participation were recorded and are presented in Table 3.

The age of the participating kinship carers ranged from 33 to 81 years with a mean age of 58.3 years.

The mean age of participating children and young people ( 9 male) was 13.1 years with a range of 9.4 to 17.1 years. 
Table 1: Participation and attrition rates of eligible young people.

\begin{tabular}{lcccccc}
\hline & \multicolumn{2}{c}{ LA B } & & \multicolumn{2}{c}{ LA A } & \multicolumn{2}{c}{ Total } \\
\hline & $\underline{n}$ & $\underline{\%}$ & $\underline{n}$ & $\underline{\%}$ & $\underline{n}$ & $\underline{\%}$ \\
Meeting Eligibility Criteria & 35 & & 19 & & 54 & 100 \\
Access permitted by LA & 29 & 82.86 & 18 & 94.74 & 47 & 87.0 \\
Access declined by carer & 9 & & 8 & & 17 & \\
Part. declined by YP & 6 & & 3 & & 9 & \\
Participation & 14 & 48.28 & 7 & 38.89 & $\mathbf{2 1}$ & $\mathbf{4 4 . 6 8}$ \\
\hline
\end{tabular}

Table 2: Participation and attrition rates of eligible kinship carers.

\begin{tabular}{lcccccc}
\hline & \multicolumn{2}{c}{ LA B } & \multicolumn{2}{c}{ LA A } & \multicolumn{2}{c}{ Total } \\
\hline & $\underline{n}$ & $\underline{0}$ & $\underline{n}$ & $\underline{\%}$ & $\underline{n}$ & $\underline{\%}$ \\
Meeting Eligibility Criteria & 26 & & 15 & & 41 & \\
Access permitted by LA & 21 & 80.77 & 14 & 93.33 & 35 & 85.37 \\
Part. declined by carer & 5 & & 6 & & 11 & \\
Participation & 16 & 76.19 & 8 & 57.14 & $\mathbf{2 4}$ & $\mathbf{6 8 . 5 7}$ \\
\hline
\end{tabular}

\section{Social work practitioners}

Participants in this group were drawn from LA A and LA B. In order to be eligible for participation, each participant was required to meet the following inclusion criteria.

They were required to be fully qualified social work practitioners and at the time of the study be employed by one of the two participating local authorities.

They were required to have a participating young person assigned to their caseload. 
Table 3: Reasons for non-participation of young people.

$\underline{L A B}$

Access declined by LA

Placement too unsettled

Contact failed to be established

Access declined by carer

Placement too unsettled

Aspiring to normality

Time restrictions

Fear of reprisal from LA

No reason given

YP declined participation

Experiencing difficulties

No reason given
LA A

$\underline{\text { Total }}$

9

6

1

7

2

77.8

22.2

13

4

4

30.8

7.7

1

15.4

. 1

7.7

3

4

53.8

Prospective participants were identified by team managers or kinship care case files from each local authority and approached via email, telephone or face to face interaction in the local authority offices. In total, 21 eligible participants were approached all of whom agreed to be contacted further. The participation rates of social worker in each local authority are shown in Table 4.

Table 4: Participation and attrition rates of eligible social workers.

\begin{tabular}{|c|c|c|c|c|c|c|}
\hline & \multicolumn{2}{|c|}{ LA B } & \multicolumn{2}{|c|}{ LA A } & \multicolumn{2}{|c|}{ Total } \\
\hline & $\underline{n}$ & $\underline{\%}$ & $\underline{n}$ & $\underline{\%}$ & $\underline{n}$ & $\underline{\%}$ \\
\hline Meeting Eligibility Criteria & 13 & & 8 & & 21 & \\
\hline Refusal & 0 & & 0 & & 0 & \\
\hline Participation & 13 & 100 & 8 & 100 & 21 & 100 \\
\hline
\end{tabular}


Estimated number of current kinship care cases for each worker ranged from 1 to 10 with a median of 3.5 cases. The median estimated number of historic cases was 6 ranging from 1 to 30 .

Four supervising social workers were recruited for a focus group. They were recruited via a convenience sampling method and invited to attend.

\subsubsection{Measures/ instruments (phase two)}

\section{Bespoke questionnaires}

A bespoke questionnaire was developed for each of the three participant groups (see Appendices 5-7). Each consisted of a series of open ended questions and a number of statements with Likert scales. Likert scales consist of a statement followed by a five point scale upon which participants can record the extent of their agreement with the statement. The items on each questionnaire relate to subjective experience and opinion. In order to reflect this, an odd number of response categories was selected to prevent forced choice (DeVellis, 2012). A five point scale was used to provide participants with a range of responses reflecting the intensity of their opinion (Jacoby \& Matell, 1971). Consideration was also given to the limits of participants' power of discrimination which restricted the response scale to 5 items (Garner \& Hake, 1951; Guilford, 1954). Data from Likert scales was intended to be analysed as descriptive statistics.

The Likert scale was used on the questionnaire for the child and youth group due to its preference amongst youth of all ages (Laerhoven, Zaag-Loonen, \& Derkx, 2004). Given the wide age range in the child and youth group (8-18 years), and to allow for variance in literacy levels, images were used in place of numerical or written response items (see Appendix 6). Images of ticks and crosses of varying quantity were used in their place with an ' $O$ ' marking the neutral response option. These were coloured in a traffic light sequence: red (cross marks), amber (neutral 'O'), green (tick marks). Written cues were also presented at the top of each column (totally disagree and totally agree) to further indicate the direction of agreement. Children and young people were asked to circle the appropriate 
response as previous studies have shown a preference for circling response items (Rebok et al., 2001). .

The carers' questionnaire (see Appendix 5) followed a similar format in the use of Likert scales, although images were not used. Response items were marked with both numerical and written items: strongly disagree (1), disagree (2), neutral (3), agree (4), strongly agree (5). Participants in the carer group were also asked to circle the appropriate response. Studies have shown that $12 \%$ of the working age population in Wales lack basic literacy skills (Miller \& Lewis, 2011). As a result the carer questionnaire was assessed for readability and given a FleschKinkaid Reading Ease score of 74.7.

In addition to closed-response items, each questionnaire featured open-ended questions. Some questions required ranking of self-determined items based on importance. In the carer and social worker questionnaires, there were 2 such questions. In each there was also a ranking task where 12 items were provided and participants asked to number them from most important (1) to least important (12). A similar ranking task, with 13 items, was constructed for the children and young people, although to assist with this the items were presented on flashcards. The young people were presented with two flashcards; a green card titled 'most important' and a red card titled 'least important'. A third card represented the 'bin' where young people could place items that were not important to them at all. This was designed to prevent a forced response. The thirteen values could then be placed between the two coloured cards and the order changed as much as the young person wished during the task. This ranking task was conducted as a separate activity with the children and young people. The response items used for the adult and young person ranking tasks were based upon the 'Good Enough Parenting' framework, the NSPCC's parenting capacity guidelines and the Green Paper 'Every Child Matters' (DfES, 2003; NSPCC, 2014; Winnicott, 1969).

In order to address research questions relating to the demographics of kinship carers, additional questions were added to the questionnaire. They sought the carer's age, marital status, household income, profession, highest academic qualification and number of dependents. All questions were open ended with the exception of marital status and household income. These questions used closed- 
ended categories taken from the Office of National Statistics (Statistics, 2010). Questionnaires can be found in Appendix 5-7.

Inventory of Parent and Peer Attachment - Revised (IPPA-R)

The Inventory of Parent and Peer Attachment - Revised (IPPA-R) is a standardised self-report measure consisting of 28 items (Armsden \& Greenberg, 1987; Gullone \& Robinson, 2005). The tool uses a statement followed by a 3point response scale with the headings: 'always true' (1), 'sometimes true' (2), and 'never true' (3). There are multiple versions of the IPPA-R each measuring attachment to a specific person or group. This study used three versions of the IPPA-R: the Peer Questionnaire the Parent Questionnaire and, as discussed below, the Carer Questionnaire. Previous studies support the reliability (Cronbach's coefficients between 0.86 and 0.93 ) and validity of both the original and revised parental attachment measure (Armsden \& Greenberg, 1987; Gullone \& Robinson, 2005). There is no version available to measure attachment to a carer as a primary caregiver. Gullone, via private correspondence, expressed the view that changing the word 'parent' to 'carer' was unlikely affect the validity or reliability of the tool. The internal consistency across the three subscales (trust, communication and alienation) of the tool is good on both versions (Cronbach's alpha coefficients of 0.69 to 0.87 ).

The IPPA-R was selected for this study as there was comparative data available for both general population norms (Gullone \& Robinson, 2005) and an informal kinship care sample (Farmer, Selwyn, \& Meakings, 2013).

Strength and Difficulties Questionnaire (SDQ)

The Strength and Difficulties Questionnaire is a standardised measure using 25 items to explore psychological attributes. Two versions will be used in this study: a self-report questionnaire for youths aged between 11-17 years, and a carer version for children and young people aged 4-17 years. The items on each 
version are the same, although the wording is slightly changed for the adolescent measure (Goodman, Meltzer, \& Bailey, 1998). The participant is presented with 25 statements, some positive and some negative, regarding their functioning. Response is measured on a 3-point scale with the headings: 'not true', 'somewhat true' and 'certainly true'. On the rear of the assessment sheet is a supplement to examine the impact of difficulties or distress experienced by the young person (Goodman, 1999). The SDQ has been found to have high concurrent validity with other well-established and lengthier measures such as the Rutter questionnaires (Goodman, 1997). It has also been found to be a reliable measure of strengths and difficulties with a reported internal reliability quotient of 0.73 (Goodman, 2001; Goodman \& Scott, 1999).

The SDQ was selected for use in this study as there is comparative data available for general population norms (Meltzer, Gatward, Goodman, \& Ford, 2003), and mainstream foster care samples (Goodman \& Goodman, 2012; Minnis et al., 2006; Mount, Lister, \& Bennun, 2004).

\section{Emotional Literacy Assessment (ELA)}

The ELA is a standardised inventory of emotional literacy. There are two versions: the primary version (7-11 years), and the secondary (11-16 years). For each there is a parallel parent/carer version and a teacher version. The checklist consists of 25 statements relating to five areas of emotional literacy: self-awareness, selfregulation, motivation, empathy and social skills. Four response options are available ranging from 'very like me' to 'not like me at all'. An 'Overall' score can be calculated and norms are available for each inventory. Internal consistency reliability quotients for parallel inventories are reported to be 0.76-0.94 (Faupel, 2003; Rees, 2013).

The ELA was selected for this study as comparative data is available for general population norms and a mainstream foster care sample (Rees, 2013). 
Wechsler Abbreviated Scale of Intelligence, second edition (WASI-II)

The WASI-II is an established standardised measure of general intellectual function for children and adults aged 6 years to 90 years. Four subtests are used to generate a Full Scale Intelligence Quotient (FSIQ): Block design, vocabulary, matrix reasoning and similarities. The FSIQ is said to represent an individual's cognitive capacity and is considered to be a good predictor of scholastic achievement (Hrabok, Brooks, Fay-McClymont, \& Sherman, 2014; Spreen \& Strauss, 1991 , p. 63).

Where an estimate of $I Q$ is required, a short-form of an established test is commonly used. A number of abbreviated versions exist using various combinations of WISC-IV (Weschler Intelligence Scale for Children, fourth edition) subtests. The WASI-II uses only four subtests reducing administration time to around 30 minutes. Split half reliability coefficients have been found to be high with .96 (child) and .97 (adult) for FSIQ, whilst test-retest reliability has a coefficient of more than .90 (Irby \& Floyd, 2013). The WASI-II also has high validity, correlating with the WISC-IV FSIQ (.91) and the Weschler Adult Intelligence Scale, fourth edition (0.92) (Irby \& Floyd, 2013). Norms are available for FSIQ based on a USA sample of 2,300 participants aged 6-90 years.

The WASI-II was selected for use in this study as it is standardised to general population norms, it correlates well with the WIAT-II-A, and comparative data is available for a mainstream foster care sample (Rees, 2013).

Wechsler Individual Achievement Test, second edition - Abbreviated (WIAT-II-A) The WIAT-II-A is a standardised abbreviated test of academic achievement for children, young people and adults aged 6-85 years (Wechsler, 2005). The abbreviated form is comprised of three subtests: Spelling, Word Reading and Numerical Operations. The scores from these subtests combine to create a composite score indicating general academic achievement. Test-retest reliability and internal consistency for Total Composite means were high, each with a coefficient of .98 for the 6-19 years age range (Lichtenberger \& Smith, 2005). 
Construct, content and criterion-related validity is also reported to be high for the WIAT-II-A.

\section{Bespoke Interview schedule}

Bespoke interview schedules were developed for each of the three participant groups; kinship carers, social workers and young people. The interviews were semi-structured to allow participants freedom to discuss their views whilst retaining comparable qualitative data between participants. The questions, developed from key themes within the literature review, were all open-ended with a series of prompts for each question. The interviews explored themes of permanency (via discussion about the future), birth parent contact, voice of the child, and education. The full schedules can be found in appendix 1-3. At the end of each interview schedule, participants were asked if there was anything not included that they wished to discuss.

Analysis of qualitative interview data was undertaken in three consecutive stages. The primary stage of immersion within the data was achieved through the transcription of audio by the researcher ad repeatedly listening to audio files and reading transcripts. At this stage, broad themes were identified and noted. The secondary stage of analysis involved the coding of the data using NVivo as a tool to organise the emerging themes and subthemes. Once these themes and subthemes were identified, the final stage of analysis employed the use of whiteboards to allow for flexibility as the researcher organised and grouped the themes and subthemes across the three participant groups.

\subsubsection{Procedure}

Participants were contacted by telephone and invited to participate. Those who chose to do so were visited at home (or in the local authority building in the case of social workers) by the researcher and asked to complete a bespoke questionnaire and a series of standardised measures specific to their role (see 
Appendices 9-11). Once completed, the participant was interviewed according to the schedule laid out in appendix 1-3.

\subsection{Ethical considerations}

The project complied with the Economic and Social Research Council's framework for research ethics (ESRC, 2015). In accordance with this framework, the project proposal was submitted to the College of Human and Health Science Ethics Committee and approved (see appendix 4) Ethical considerations are outlined below.

It was recognised that participants may have suffered a history of abuse or neglect and find the topic emotive. Whilst there were no questions relating directly to their past, participation had the potential to trigger traumatic memories. Equally, questions relating to the future or to the topic of birth parent contact had the potential to cause upset. Protocols were established should participants become upset including pausing of the interview, the opportunity to postpone or withdraw participation and signposting to support services. These support services were third sector organisations such as the National Society for Prevention of Cruelty to Children (NSPCC), National Domestic Violence Helpline, ManKind (for male victims of domestic abuse) and Childline. Website addresses and phone numbers for each of the above third sector bodies were made available.

In the briefing the researcher clearly outlined the conditions of the confidentiality agreement. This stated that disclosure of information that led the researcher to believe that there was reasonable risk of harm to a person would be relayed to the caseworker. Given the project's topic, there was a risk of disclosure of abuse to the researcher. In such cases the participant would be reminded of the process that the researcher must undertake. The researcher would then contact the research supervisor and then the relevant social worker if necessary. Support would be offered in the form of contact information for the relevant third sector organization such as those outlined above. 
There was a small risk that participation may cause conflict for kinship carers with other relatives, in particular the birth parents. This conflict is particularly problematic if there are ongoing legal disputes surrounding custody of the children. To ameliorate this risk, a number of steps were taken. Firstly, the case worker was approached prior to inviting participation from carers or children in order to establish whether any conflicts of interest were likely to arise. Secondly, it was clearly stated to all involved that participation would in no way affect the care planning process of a child in care. Finally, data was anonymised to ensure that the origin of any statements made by participants cannot be identified.

Ethical approval was granted by Swansea University's College of Human and Health Sciences Ethics Committee on 20 th January 2015 (see appendix 4).

\subsection{Access and institutional authorisation}

Both LAs provided staff level access to casefile storage systems, local authority offices and local authority staff. Concerning access to kinship care social workers at each stage of the research, workers for one LA were geographically centralised with all team members working from a single council building. In the other LA, social workers with kinship care cases were spread across four separate teams in different geographical locations. However, with access to the central telephone and email systems in each local authority, contacting team members was simple. When in each local authority, the relevant staff identification badge was worn to provide a level of familiarity for participants.

Once the project proposal was finalised, it was submitted to the Director of Social Services in each LA for approval. This was granted in each case.

\subsection{Feasibility study}

This section briefly outlines the feasibility testing undertaken as part of this project. The aim of the feasibility test was to establish whether there would be any difficulties in recruiting or testing young people for phase two of this study. 
The need for a feasibility study was deemed particularly pertinent due to the relatively small target population. Any minor problems may have had a substantial effect on the number of participants whose results would be valid for analysis.

In total, seven participants completed elements of the protocol. Participants for the feasibility study were recruited from mainstream foster care and were approached via social workers in one of the participating local authorities.

Five young people completed the bespoke measures as part of a focus group. The group was predominantly female $(n=4)$. The average age of participants was 13.8 years with a range of 5 years. All participants were residing in mainstream foster care placements and were known to one another but not currently cohabiting.

Two young people were invited to complete all of the study measures on an individual basis. These participants were both female and aged 11 and 12 years old.

The feasibility testing resulted in the following outcomes:

- An average completion time was calculated to be 1 hour and 30 minutes for all components.

- Interactive tasks should be interspersed within the standardised questionnaires to relieve fatigue and re-engage the young person.

- Young people displayed a desire to participate without the need for reward. Assistance from the LA was high providing a positive indication that strong co-operation can be anticipated in the main phase of testing.

- Clear guidelines need to be provided to case workers and carers who wish to remain present for the administration of test items. This includes: remaining silent during test administration and leaving the room during verbal tasks.

The feasibility study led to a number of adjustments to the testing protocols and led to the formulation of measures to preserve confidentiality by preventing the presence of other people during the verbalised stages of testing. The bespoke measures provided useful information and proved to be popular and accessible to the young people. No difficulties were raised during the recruitment phases of 
Chapter 4: Methodology

the study indicating that accessing the population in the main study should not pose any problems. In conclusion, the outcomes of the feasibility study suggest that the main study is a feasible proposal. 
Chapter 5: Phase one results 
Chapter 5: Phase one results

\subsection{Early care leaver results}

This chapter presents the results of the first phase of data analysis. Section 5.1 addresses the outcomes of 'early care leavers' defined as those who leave care before reaching the age of eighteen.

A total of 271 young people left care early in the year ending $30^{\text {th }}$ Sept $2014 ; 71$ from LA A (29 Male) and 200 from LA B (110 Male). Table 5 presents the breakdown of these figures by LA and final placement type. A total of 71 young people were in kinship care placements prior to leaving care early.

Table 5: Pre-leaving placement and average age by $L A$.

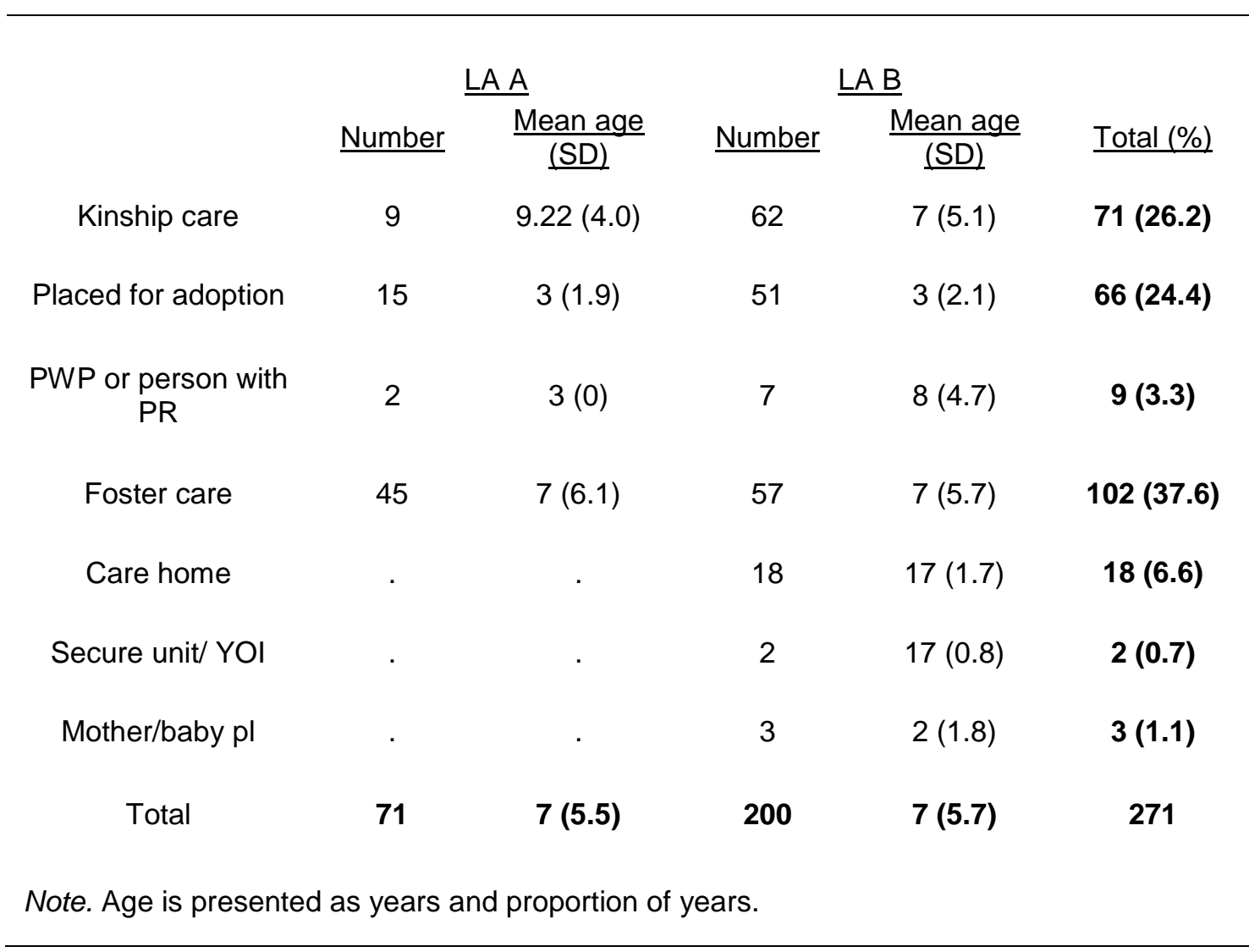




\section{RQ1: What is the initial post-care destination of 'early care leavers'?}

Participants were resident in seven different placement types prior to leaving care. The distribution of early care leavers $(n=271)$ across these placements are shown in Figure 2.

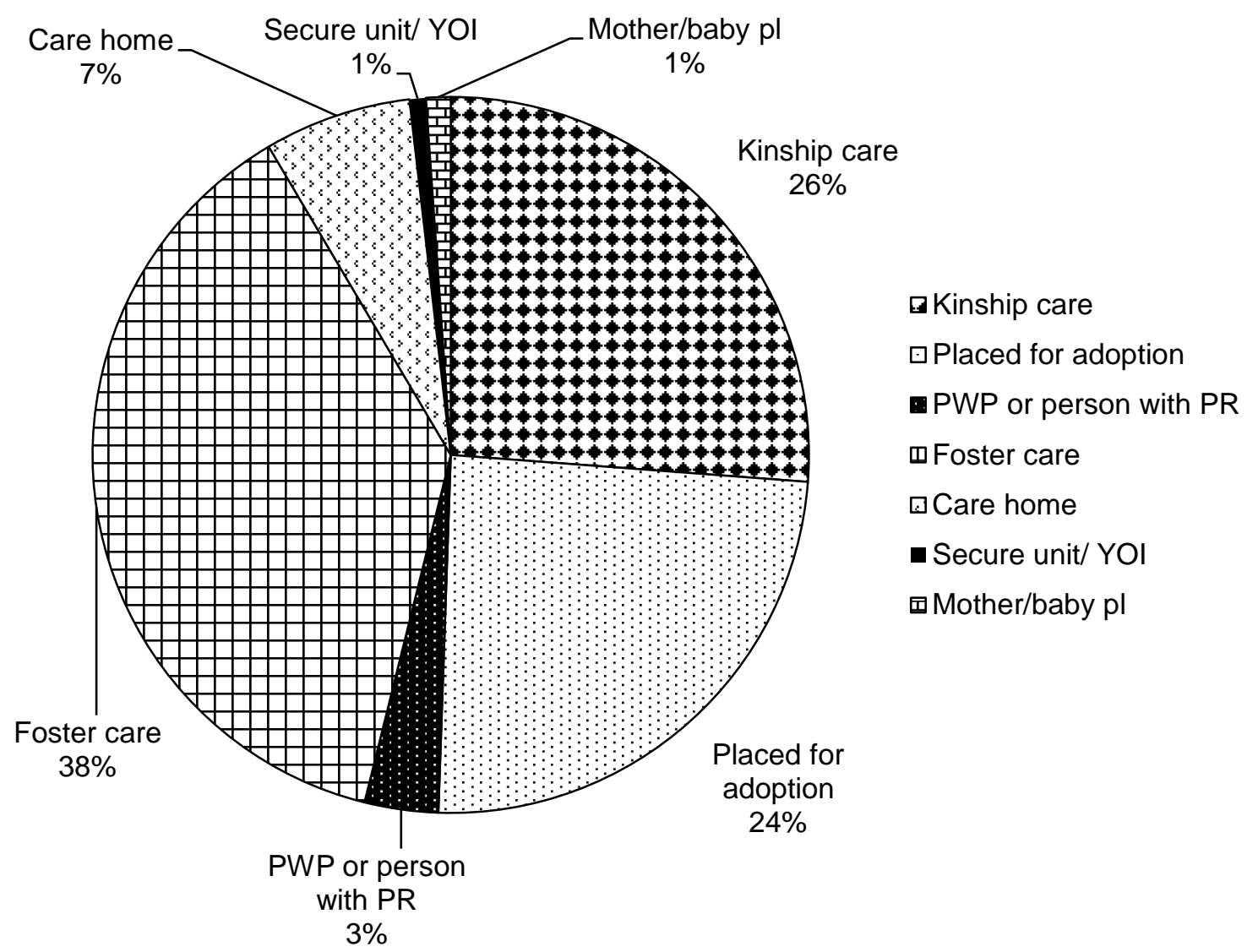

Figure 2: The distribution of early leavers pre-leaving placement type.

The most common placement seen was mainstream foster care followed by kinship care and placed for adoption. Figure 3 shows that the most common destination for early care leavers was return to parents followed by adoption and SGO. 


\section{Initial destination of Early Care Leavers \\ $(n=271)$}

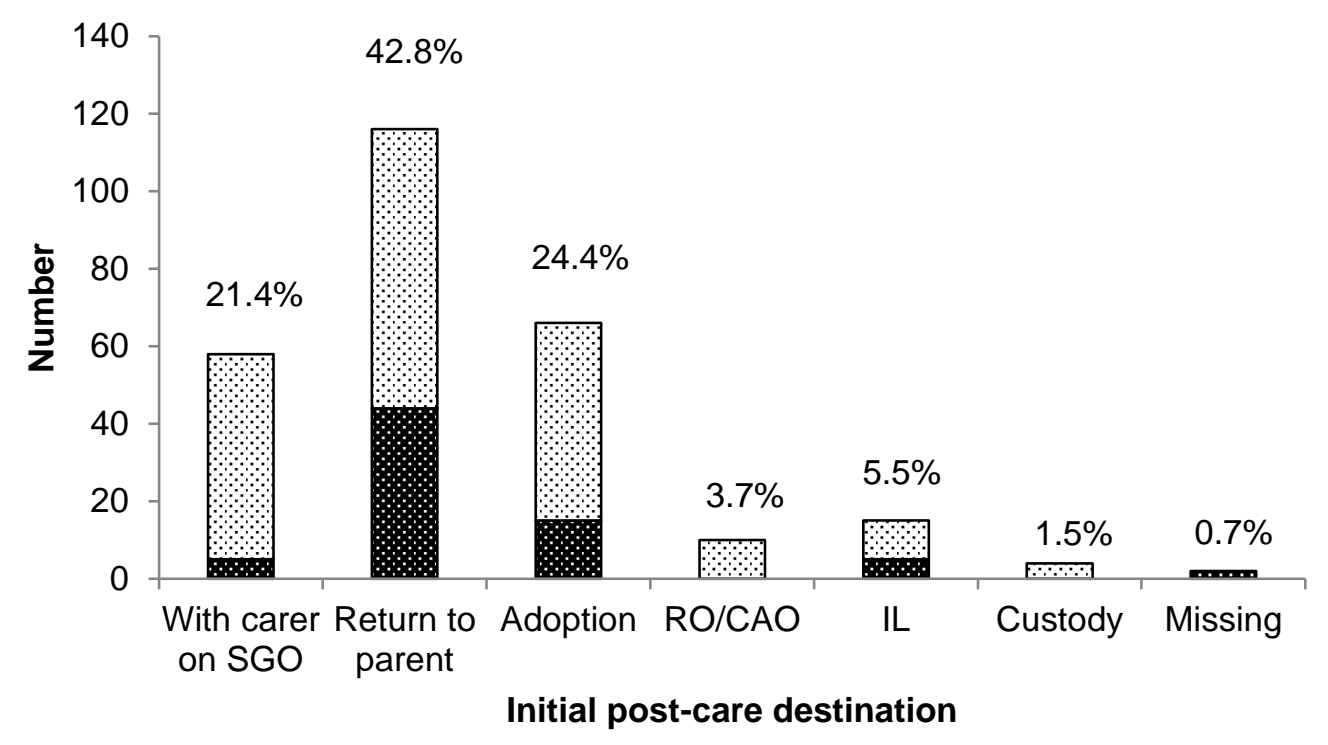

Q $\mathrm{LAB}$ 는 $\mathrm{LA}$

Figure 3: The initial destination of early care leavers.

RQ2: How does final placement type relate to post-care destination for children and young people and does this differ for those in kinship care?

The relationship between final care placement and post-care destination is depicted in Figure 4.

Children and young people in kinship care are significantly more likely to leave care with an SGO than those leaving early from mainstream foster care: $\chi^{2}(1$, $\mathrm{N}=173)=45.92, p=0.01$. 


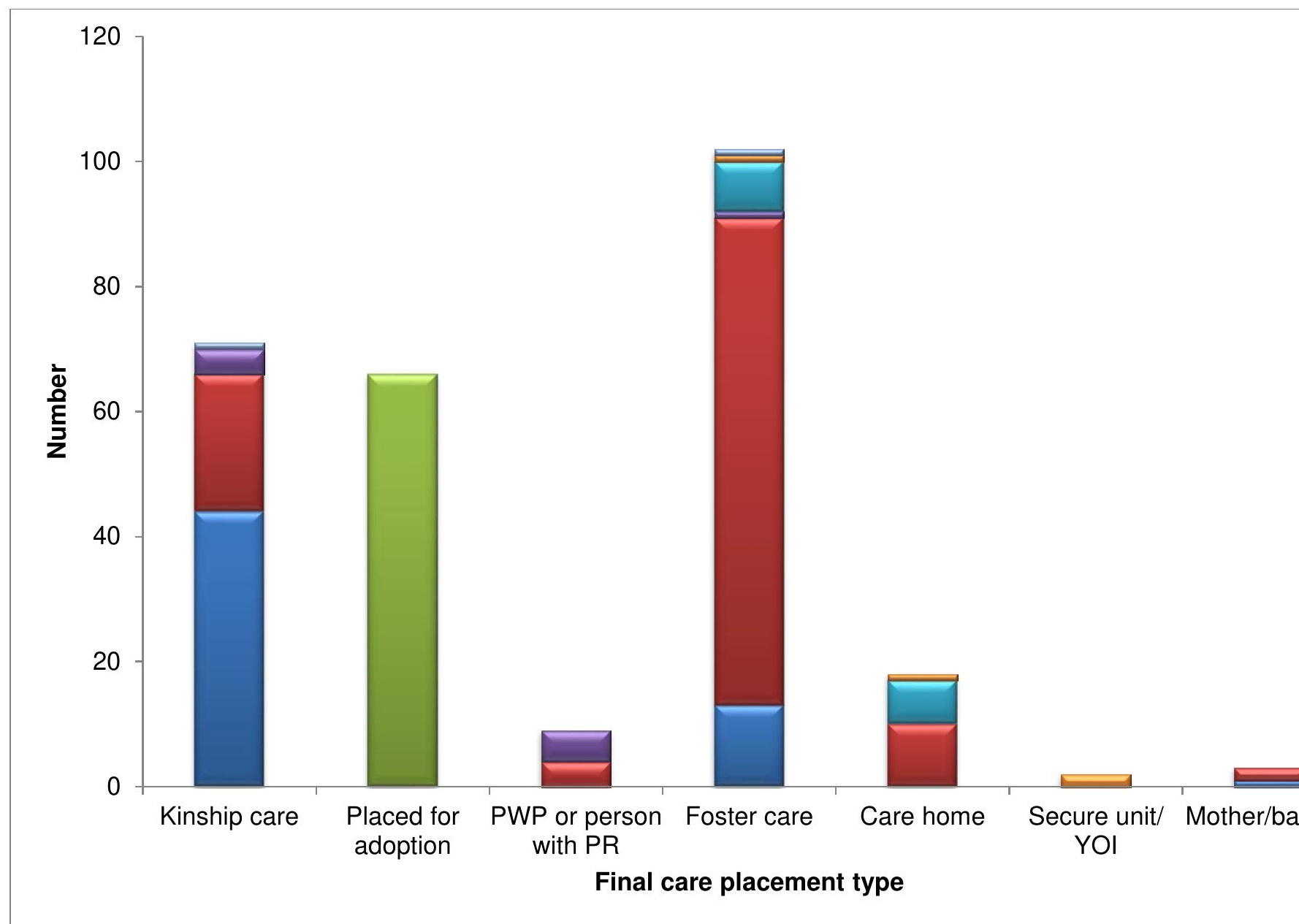

Figure 4: Early care leaver destination by final care placement type $(n=271)$. 
Conversely, those leaving mainstream foster care were significantly more likely to return to live with birth parents than those leaving early from kinship care: $\chi$ ${ }^{2}(1, N=173)=35.51, p=0.01$.

No significant differences were found in the post-care destination of any other placement group.

\section{RQ3: To what extent do Special Guardianship Orders (SGOs) provide permanency for young people?}

All young people in Phase one who left care early due to the initiation of an SGO were followed-up at 18-months. All 58 of the young people had remained with their carers for the duration of the follow-up period. These data indicate a very high level of placement permanency for those leaving early with an SGO.

\section{RQ4: What factors influence whether an application for a SGO is made?}

Of the 58 cases that became SGOs, the majority featured at least one blood relation to the young person $(n=40)$. The coefficient of relationship (the degree of genetic linkage) in these 40 cases was $25 \%$, most commonly a grandparent and on occasion an aunt or uncle.

Whilst the majority $(n=37)$ of applications were submitted by couples (each consisting of one male and one female), a further 21 were submitted by single female carers. None of the applicants were single male carers. Significantly more kinship carers are single applicants than unrelated applicants $\left(\chi^{2}(1, n=58)=7.12\right.$, $\mathrm{p}=0.01)$.

Those leaving care early via an SGO to a kinship carer were significantly more likely to have been in care through Section 20 (S.20) than a Full Care Order (FCO) $\left(\chi^{2}(1, n=43)=10.87, p=0.00\right)$. Those leaving from an S.20 order to an SGO are significantly more likely to be related to their carer than those leaving an Interim Care Order $(I C O)\left(\chi^{2}(1, n=34)=16.90, p<0.00\right)$. The results show that the 
degree of relatedness between an SGO applicant and the young person is significantly associated with care order type.

These data indicate that the degree of genetic relatedness affects the decision to apply for an SGO. Single females are more likely to apply for an SGO if they are related to the young person by blood. Furthermore, young people in kinship care looked after under S.20 are more likely to leave early via an SGO than other types of care order.

RQ5: What measures do local authorities take to support SGOs of early leavers and are they dependent on pre-leaving placement care order type?

All of the 58 early care leavers who were placed on an SGO received financial support from the LAs. The details of financial agreements were not available for comparison. Thirty-three also continued to receive formal support or supervision. Formal involvement is defined as support, involvement or services (aside from financial) granted by the LA and pledged via a court order such as a Child Arrangements Order (CAO), a Supervision Order (SO) or by the child remaining on the Child In Need (CIN) register. The types of support are presented in Table 6.

There was a significant difference found between the age of the carer and the likelihood of receiving further formal involvement $(t(44)=-3.32, p=0.00)$. Those receiving further formal involvement from the $L A$ were significantly younger $(M=50.99, S D=6.44)$ than those who received none $(M=58.02, S D=7.96)$.

Type of final care order prior to SGO was found to have an impact on whether the LA supplied formal involvement after the SGO was granted. Significant differences were found between FCOs and $\operatorname{ICOS}\left(X^{2}(1, n=35)=21.90, p=0.00\right)$, FCOs and S.20s $\left(X^{2}(1, n=43)=12.352, p=0.00\right)$ and ICOs and S.20s $\left(X^{2}(1\right.$, $n=34)=4.51 . p=0.03)$. These data show that those in care on an ICO were most likely to receive formal involvement from the LA once discharged on an SGO, whilst those leaving an FCO early via SGO were least likely to receive formal involvement. These trends are depicted in 
Table 6: Types of support offered to Special Guardians of young people leaving care early by final care placement type.

\section{Involvement alongside SGO}

\begin{tabular}{|c|c|c|c|c|}
\hline$\frac{\text { Final LAC care }}{\text { order }}$ & $\frac{\text { CIN }}{\text { register }}$ & $\frac{\underline{\text { Child }}}{\text { Arrangements }}$ & $\frac{\text { Supervision }}{\text { Order }}$ & 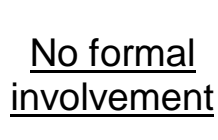 \\
\hline Full Care Order & 4 & 0 & 0 & 18 \\
\hline $\begin{array}{c}\text { Interim Care } \\
\text { Order }\end{array}$ & 10 & 1 & 2 & 0 \\
\hline Section 20 & 9 & 2 & 4 & 6 \\
\hline $\begin{array}{c}\text { Supervision } \\
\text { Order }\end{array}$ & 0 & 0 & 1 & 0 \\
\hline $\begin{array}{l}\text {-ull Care Order \& } \\
\text { Placement Order }\end{array}$ & 0 & 0 & 0 & 1 \\
\hline Total & 23 & 3 & 7 & 25 \\
\hline
\end{tabular}




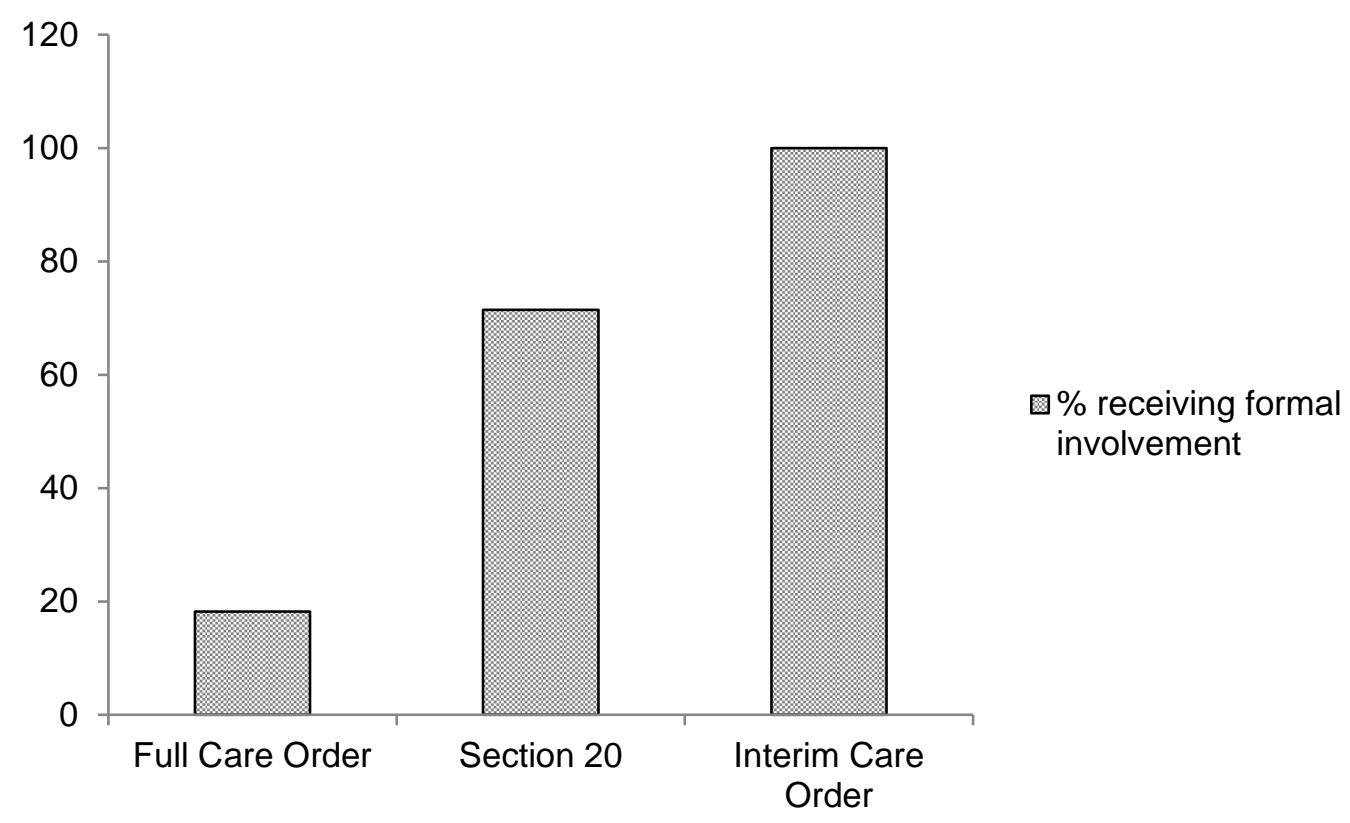

Figure 5: Percentage of special guardians receiving formal support by preleaving placement care order

No significant differences were found in levels of formal involvement when grouped by the age of the young person, levels of relatedness, or number of children named on SGO application. Furthermore, single applicants were no more likely than couples to receive further support. 


\subsection{Care leavers 'aging out'}

Section 5.2 addresses the outcomes of those who 'age out' of care, defined as young people who reach the age of eighteen causing the care order to lapse. In the year ending $30^{\text {th }}$ September 2014, 50 young people aged out of care. Data for the full 12 month follow-up period was unavailable for two young people. Casefiles for these two young people were unavailable due to the client being deceased $(n=1)$ or being under police protection $(n=1)$. Of the remaining 48 young people, 17 were from LA A (12 Male) and 31 were from LA B (17 Male). Three young people aged out of kinship care.

\section{RQ6: To what extent are 'care leavers' who age out already 'staying put'?}

The following post-care destinations were identified: 'Remain With Carer' (RWC), 'Return to Parental Home' (RTP), 'Other associated person' (OAP) 'Independent Living' (IL), 'Supported Lodgings' (SL), 'Care home' (CH), 'Custody' (Cus), 'No Fixed Abode' (NFA) and 'Unknown' (NK).

The post-care destination of those aging out of care is depicted at three month intervals in Figure 6. At the 7 day point, the most common destinations for care leavers aging out was RWC ( $n=20,41.7 \%)$ followed by SL ( $n=10,20.8 \%)$, RTP $(n=8,16.7 \%)$ and $I L(n=4,8.3 \%)$.

At 12 month follow up, RWC was still the most common at $31.3 \%(n=15)$ followed by IL at $25 \%(n=12)$. This was a drop of $10.4 \%$ for the group remaining with carer and a rise of $16.7 \%$ for those living independently.

Whilst the RTP group fluctuated over time, the overall figure remained at $16.7 \%$ between the 7 day and 12 month follow up periods. This shows that whilst almost a third of care leavers aging out are already 'staying put' with their carers, the majority leave their care placement within 12-months of the care order lapsing. 
5.2 Care leavers aging out

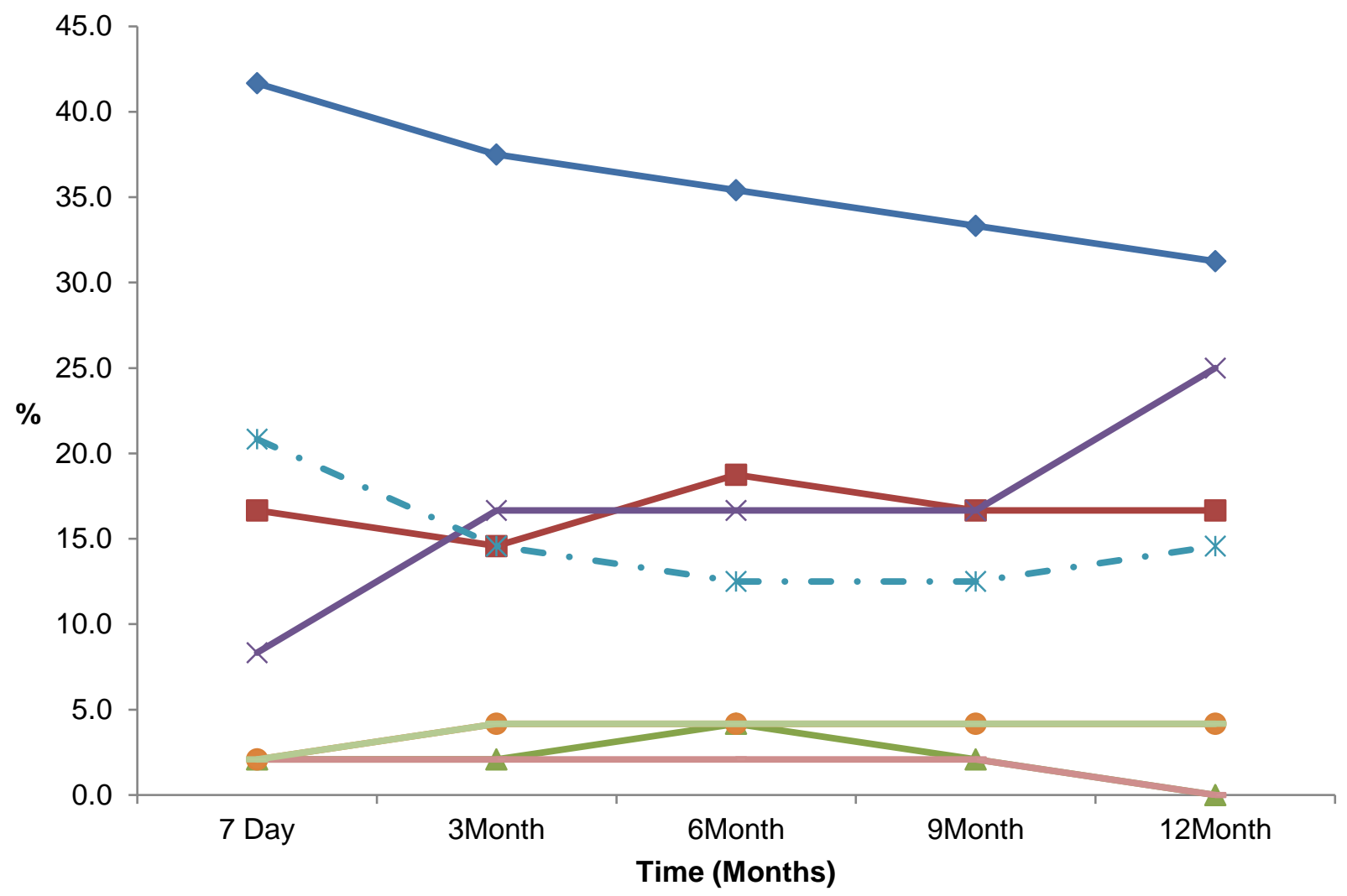

Figure 6: The post-care destinations over 12-months of care leavers aging out $(n=48)$. 
RQ7: How does pre-leaving care placement type relate to post-care destination for young people who 'age out' of care and does this differ for those aging out of kinship care?

Only those in kinship and mainstream foster care remained with the carer after aging out of care. A total of three young people aged out of kinship care in the two LAs and all three remained with their carer for the duration of the 12 month follow up period. Of those aging out of mainstream foster care, $68 \%$ remained with their carer for at least seven days after aging out $(n=17)$.

Figure 7 examines those who had remained with their carer at the 7-day point and shows how the number remaining with their carer declined gradually over the 12 month follow up period. Overall $48 \%$ of young people aging out of mainstream foster care remained with their carer for the entirety of the follow up period $(n=12)$. Of the five who moved on from their foster care placement during the follow up period, three moved into independent living, one into supported lodgings and one moved on to an adult care facility.

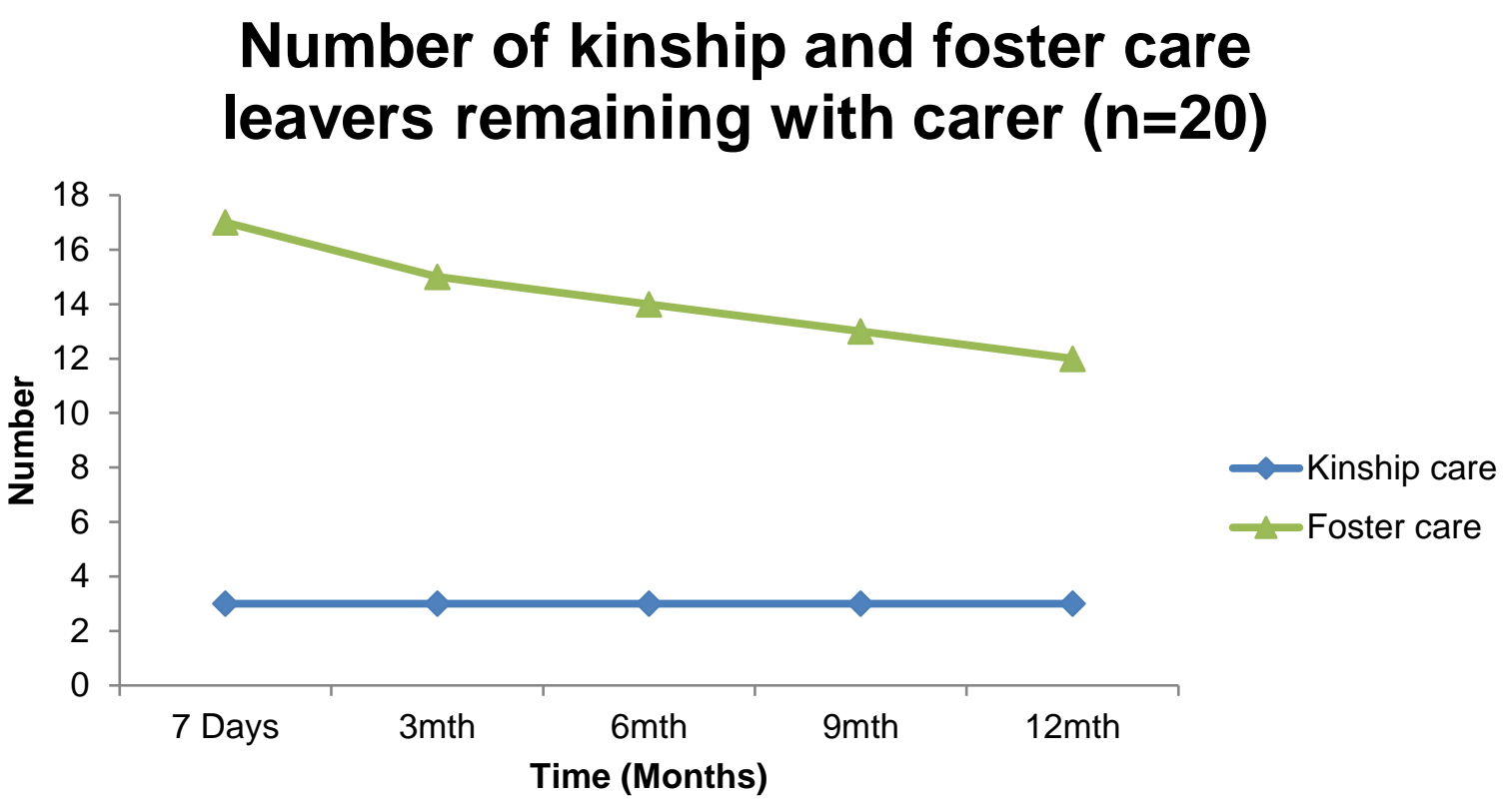

Figure 7: Number of kinship and foster care leavers remaining with carer over a 12-month post-care period. 
Chapter 6: Phase two quantitative results 


\subsection{The relative wellbeing of young people}

This chapter presents the results for the quantitative elements of Phase Two. Participants in Phase Two consisted of young people currently residing in kinship care $(n=21)$, their kinship carers $(n=24)$ and social workers $(n=21)$. Data on the relative wellbeing and educational achievement of young people in kinship care is presented.

\subsubsection{Descriptive statistics}

\subsubsection{The Kinship Carers}

Table 7 shows the quantitative demographic information relating to kinship carers in the study sample. Carer and young person ages and placement length were treated as continuous variables and are presented in years and proportion of years. Number of dependents is inclusive of adult dependants and the young people in placement. Contact frequency is calculated and presented as contact occasions per year. Academic qualification was noted as qualitative data (e.g. GCSEs) and adapted to a numeric scale using UK standard qualification framework levels (DfE, 2017). The response rate for the question relating to academic attainment in carers was lower than other questions within the section.

Table 7: Kinship Carer Demographic Information

\begin{tabular}{|c|c|c|c|c|}
\hline & $\underline{\text { Response Rate }}$ & $\underline{\text { Mean }}$ & $\underline{\mathrm{SD}}$ & Median \\
\hline Kinship Carer Age & $91.67 \%$ & 58.50 & 12.15 & 61 \\
\hline Length of placement & $96.55 \%$ & 6.93 & 4.51 & 7 \\
\hline Age of children in your care & $96.55 \%$ & 12.86 & 2.43 & 13 \\
\hline Number of dependants & $96.55 \%$ & 2.29 & 1.56 & 2 \\
\hline Contact Frequency & $96.55 \%$ & 28.71 & 47.86 & 12 \\
\hline Highest Academic Qualification & $79.31 \%$ & 2.35 & 2.08 & 2 \\
\hline
\end{tabular}

Employment Status 
Employment status was established via an open-ended question. The response rate for this question was $95.83 \%(n=23)$. Responses were then grouped by employment sector to establish trends in fields of employment. As seen in Figure 8 , the most common occupation was care/healthcare $(26.08 \%, n=6)$ alongside those in retirement $(26.08 \%, n=6)$. Three kinship carers described their main profession as 'foster carer' (13.04\%).

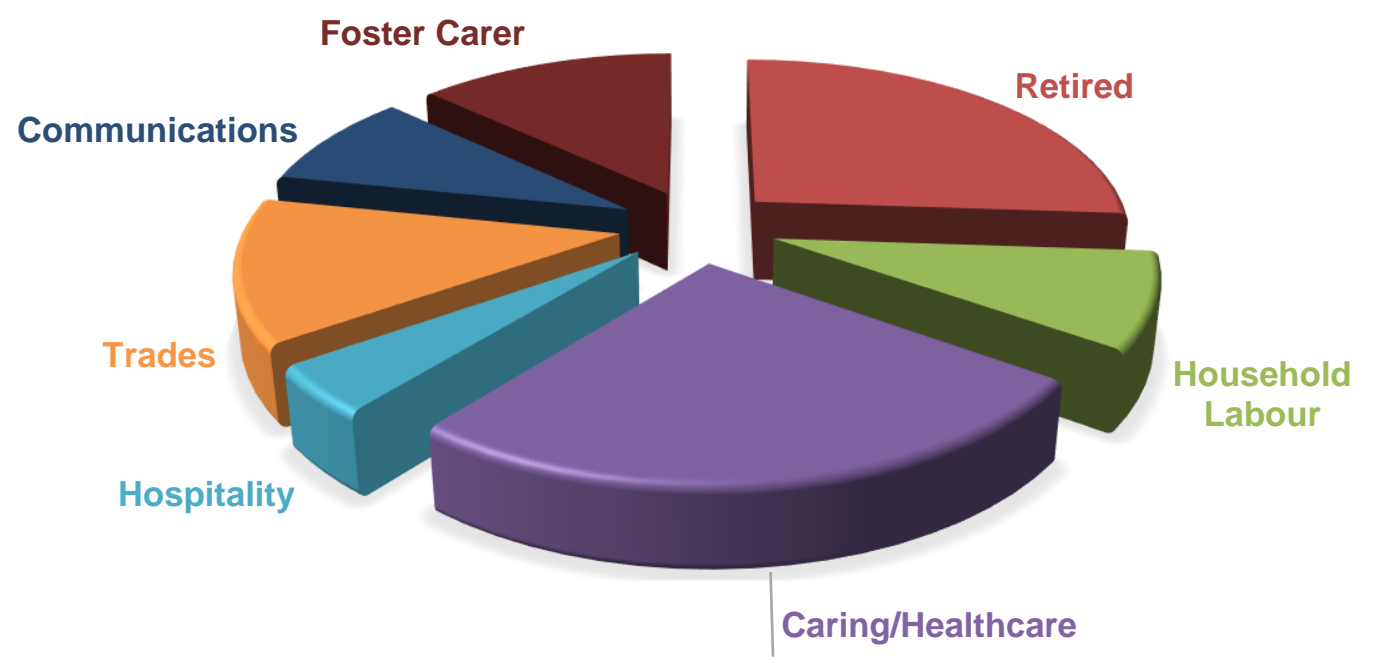

Figure 8: The primary occupation of kinship carers $(n=23)$

Household Income

A question relating to household income was completed by $54.17 \%(n=13)$ of kinship carers. The banded response was compared to the national average annual salary of a single full-time worker in Wales which was £29,432 in 2016 (StatsWales, 2017a). Figure 9 depicts the percentage of kinship carers whose annual household income falls above and below the average national salary. 


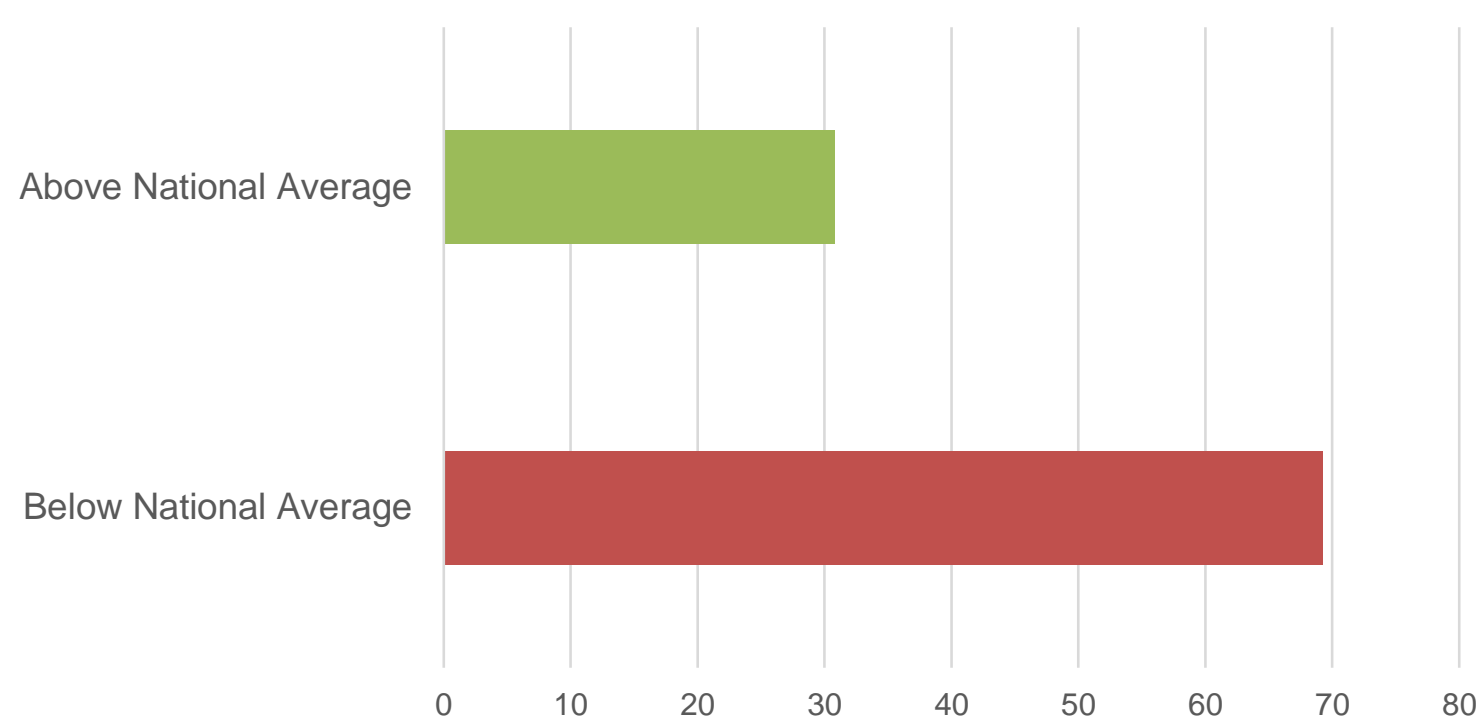

Figure 9: Percentage of kinship carers whose annual household income is above and below the mean annual salary for a full time worker in Wales $(n=13)$

Relationship Status

The relationship status of kinship carers was established via questionnaire with a response rate of $100 \%(n=24)$. Figure 10 shows how relationship status was split across the sample. Half of the sample were married with a further $8.3 \%$ cohabiting. The remaining $41.7 \%$ were sole carers for the young people in their care, reporting their relationship status to be single $(4.2 \%)$, separated $(4.2 \%)$, widowed (12.5\%), or divorced $(20.8 \%)$. 
6.1 The Relative Wellbeing of young people

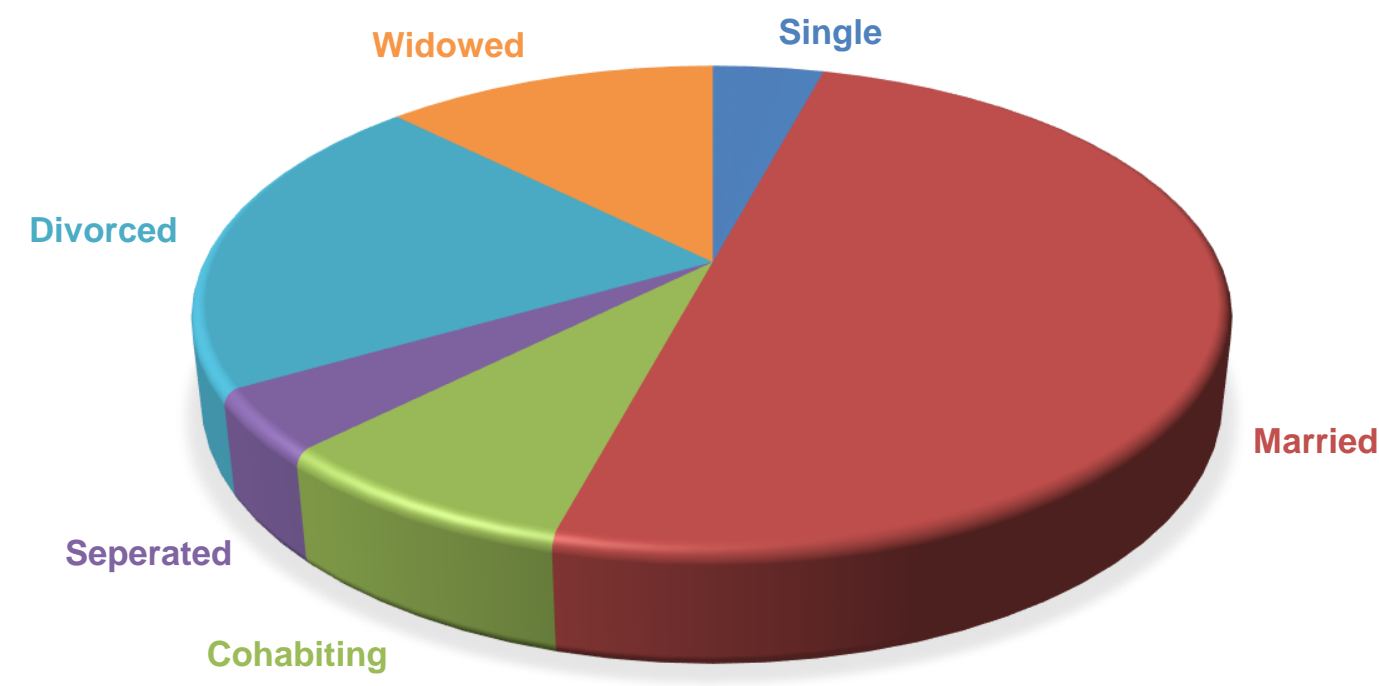

Figure 10: The relationship status of Kinship Carers $(n=24)$

\subsubsection{The Social Workers}

The number of current and total historic kinship cases that each social worker had been involved in was established. The results are shown in Table 8.

Table 8: Average current and historic kinship caseload for social workers $(n=21)$

\begin{tabular}{|c|c|c|c|}
\hline & Mean & $\underline{\mathrm{SD}}$ & Median \\
\hline Current kinship cases (estimate) & 3.8 & 2.66 & 3.5 \\
\hline Total kinship cases historically (estimate) & 6.7 & 5.85 & 6 \\
\hline
\end{tabular}

\subsubsection{Birth Family Contact}

Contact type

Kinship Carers were asked to indicate how often the young person had contact with their birth parents. The response was used to calculate the number times the young person had contact each year. Young people in kinship care have birth parent contact, on average, 28.71 times per year $(S D=47.86)$ with a median of 
12 contact occasions. The form that this contact took varied across the sample. For the majority of young people, contact with birth parents was in the form of a supervised visit, often supervised by kinship carers. Figure 11 shows the proportion of young people experiencing the different forms of contact.

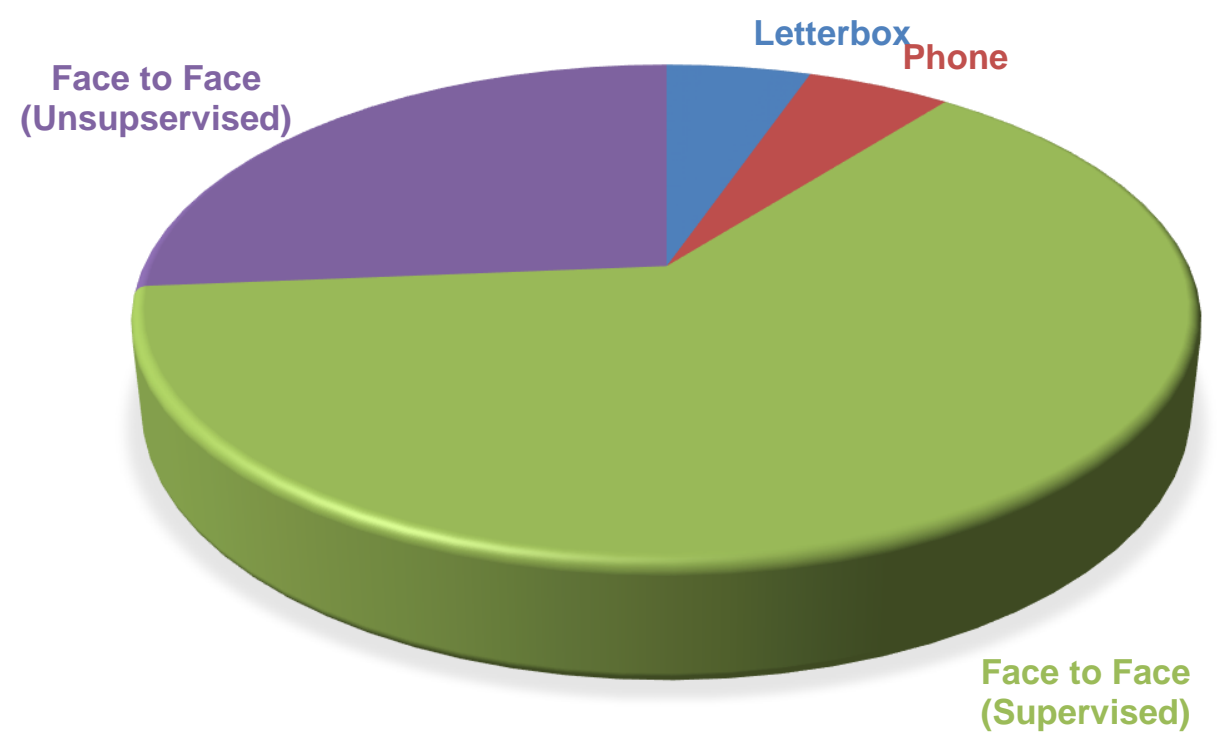

Figure 11: Forms of birth parent contact $(n=19)$

Distance from birth family home

Using postcode data extracted from case files, the distance between the birth parent's home and the placement address was calculated. This was calculated for all of the young people who were eligible to participate $(n=54)$ with a mean distance of 4.23 miles $(S D=6.48)$. This was almost identical for those who chose to participate in the second phase of the study $(n=21)$ with an average distance of 4.20 miles $(S D=4.54)$. 
6.1 The Relative Wellbeing of young people

Decisions over contact

Young people, kinship carers and social workers were all asked a series of questions to establish the extent to which they felt control over decision making relating to birth parent contact. Statements were scored on a five item Likert scale with a score of five indicating strong agreement. The results from each group are presented in Table 9, Table 10, and Table 11.

The results indicate that young people feel able to talk to their kinship carers, social workers, and birth parents about changes to contact. When the do discuss contact, they feel listened to.

All agree that the young person has a strong influence on changes to contact and agree that the level of contact is appropriate.

\begin{tabular}{|c|c|c|c|}
\hline \multicolumn{4}{|c|}{ Table 9: Young peoples' perceptions of control over changes to contact } \\
\hline & $\underline{\text { Median }}$ & Mean & $\underline{\mathrm{SD}}$ \\
\hline I see my birth parent as much as I would like & 4 & 3.80 & 1.40 \\
\hline I can choose how much I see my birth parent & 4 & 3.48 & 1.72 \\
\hline $\begin{array}{l}\text { If I wanted to change how much I see my birth } \\
\text { parent, I could speak to my carer }\end{array}$ & 5 & 4.57 & 0.68 \\
\hline $\begin{array}{l}\text { If I wanted to change how much I see my birth } \\
\text { parent, I could speak to my social worker }\end{array}$ & 5 & 4.43 & 0.87 \\
\hline $\begin{array}{l}\text { If I wanted to change how much I see my birth } \\
\text { parent, I could speak to my birth parent }\end{array}$ & 5 & 3.90 & 1.48 \\
\hline $\begin{array}{l}\text { My social worker always listens to how I feel about } \\
\text { seeing my parent }\end{array}$ & 5 & 4.33 & 1.02 \\
\hline $\begin{array}{l}\text { My carer always listens to how I feel about seeing } \\
\text { my parent }\end{array}$ & 5 & 4.62 & 0.59 \\
\hline
\end{tabular}




\begin{tabular}{|c|c|c|c|}
\hline & Median & Mean & $\underline{\mathrm{SD}}$ \\
\hline I feel that the level of contact is appropriate & 4 & 3.93 & 0.94 \\
\hline I feel that the child would benefit from more contact & 2 & 2.28 & 1.11 \\
\hline I feel that the child would benefit from less contact & 3 & 3.00 & 1.26 \\
\hline I am happy with how contact is managed & 4 & 3.72 & 1.01 \\
\hline $\begin{array}{l}\text { I would prefer to have more social services support for } \\
\text { contact }\end{array}$ & 3 & 2.76 & 1.22 \\
\hline $\begin{array}{l}\text { I have a strong influence on changes to contact } \\
\text { arrangements }\end{array}$ & 4 & 3.21 & 1.14 \\
\hline $\begin{array}{l}\text { Social workers have a strong influence on changes to } \\
\text { contact arrangements }\end{array}$ & 4 & 3.89 & 0.77 \\
\hline $\begin{array}{l}\text { The birth parent has a strong influence on changes to } \\
\text { contact arrangements }\end{array}$ & 2 & 2.81 & 1.28 \\
\hline $\begin{array}{l}\text { The child has a strong influence on changes to } \\
\text { contact arrangements }\end{array}$ & 4 & 3.41 & 1.25 \\
\hline
\end{tabular}

Table 11: Social Workers' perceptions of control over changes to contact

\begin{tabular}{|c|c|c|c|}
\hline & Median & Mean & $\underline{\mathrm{SD}}$ \\
\hline I feel that the level of contact is appropriate & 4 & 3.80 & 1.16 \\
\hline I feel that the child would benefit from more contact & 3 & 2.80 & 1.16 \\
\hline I feel that the child would benefit from less contact & 2 & 2.37 & 0.67 \\
\hline I am happy with how contact is managed & 4 & 3.80 & 0.89 \\
\hline I would prefer to have more involvement in contact & 2 & 2.39 & 0.83 \\
\hline $\begin{array}{l}\text { I have a strong influence on changes to contact } \\
\text { arrangements }\end{array}$ & 4 & 3.77 & 0.63 \\
\hline $\begin{array}{l}\text { The birth parent has a strong influence on changes to } \\
\text { contact arrangements }\end{array}$ & 3 & 2.79 & 1.18 \\
\hline $\begin{array}{l}\text { The child has a strong influence on changes to contact } \\
\text { arrangements }\end{array}$ & 4.5 & 4.33 & 0.84 \\
\hline
\end{tabular}


Kinship carers are happy with how contact is managed but responded neutrally to the statement "I would prefer to have more social services support for contact". By contrast, social workers indicated disagreement to a parallel statement, indicating that they did not wish to have more involvement in contact.

Each of the three groups were asked to indicate who had the most influence on changes to contact arrangements on a free-response task. Responses were weighted and averaged across each group. The results are presented in Table 12.

Young people and kinship carers both felt that social workers had the most influence over changes to contact. By contrast, social workers ranked themselves fourth for influence.

\begin{tabular}{cccc}
\hline \multicolumn{3}{c}{ Table 12: People perceived to have the } & most influence over changes to contact \\
\cline { 1 - 2 }$\frac{\text { Weighted }}{\frac{\text { Rank }}{1}}$ & Young People & Kinship Carers & Social Workers \\
2 & Social worker & Social worker & Young person \\
3 & Self & Carer & Birth parent \\
4 & Carer & Young person & Carer \\
5 & Birth parent & Birth parent & Social worker \\
6 & Universe & Other family & Local Authority \\
& Other family & Court & Independent Reviewing \\
& members & & Officer \\
\hline
\end{tabular}

\subsubsection{Permanency and Placement Priorities}

The concept of permanency was explored through a questionnaire section entitled "thinking about the future". Young people, kinship carers and social workers indicated on a five-item Likert scale the extent to which they agreed with statements relating to permanency with five indicating total agreement. The results are presented in Table 13, Table 14, and Table 15. 
6.1 The Relative Wellbeing of young people

\begin{tabular}{llll}
\hline Table 13: Young people's perceptions of permanency and the future \\
\hline & Median & $\underline{\text { Mean }}$ & $\underline{\text { SD }}$ \\
I think about the future a lot & 4 & 4.19 & 1.08 \\
I know where I will be living in the future & 4 & 3.62 & 1.24 \\
I think that I will stay with my carer & 5 & 3.81 & 1.36 \\
I think that I will move back to my parent's & 2 & 2.24 & 1.30 \\
I think that I will go somewhere new & 3 & 3.00 & 1.45 \\
I talk about the future with my carer & 3 & 3.29 & 1.38 \\
I talk about the future with my parent & 3 & 2.95 & 1.36 \\
I talk about the future with my social worker & 3 & 2.86 & 1.35 \\
I talk about the future with my friends & 4 & 3.48 & 1.47 \\
I feel good about the future & 4 & 4.05 & 0.92 \\
I sometimes worry about the future & 3 & 2.95 & 1.28 \\
\hline
\end{tabular}

Table 14: Kinship carers' perceptions of permanency and the future

\begin{tabular}{|c|c|c|c|}
\hline & Median & Mean & SD \\
\hline $\begin{array}{l}\text { I expect that the child will live with me until they } \\
\text { are } 18\end{array}$ & 5 & 4.59 & 0.67 \\
\hline $\begin{array}{l}\text { I expect that the child will move back to live with } \\
\text { their birth parent }\end{array}$ & 1 & 1.75 & 1.13 \\
\hline $\begin{array}{l}\text { I expect that another person will take over the } \\
\text { care of the child }\end{array}$ & 1 & 1.28 & 0.45 \\
\hline I often think about the future & 4 & 4.39 & 0.62 \\
\hline I have made plans for the future & 4 & 4.00 & 0.91 \\
\hline I often worry about the future & 4 & 3.72 & 1.14 \\
\hline $\begin{array}{l}\text { I discuss the future often with the child in my } \\
\text { care }\end{array}$ & 4 & 4.19 & 0.94 \\
\hline $\begin{array}{l}\text { I have accessed information about Special } \\
\text { Guardianship Orders }\end{array}$ & 4 & 3.66 & 1.09 \\
\hline $\begin{array}{l}\text { I have considered applying for a Special } \\
\text { Guardianship Order }\end{array}$ & 3.5 & 3.32 & 1.36 \\
\hline
\end{tabular}




\begin{tabular}{|c|c|c|c|}
\hline \multicolumn{4}{|c|}{ Table 15: Social Workers' perceptions of permanency and the future } \\
\hline & Median & Mean & $\underline{\mathrm{SD}}$ \\
\hline $\begin{array}{l}\text { I expect that the child will live with their current } \\
\text { carer until they are } 18\end{array}$ & 5 & 4.30 & 1.15 \\
\hline $\begin{array}{l}\text { I expect that the child will move back to live with } \\
\text { their birth parent }\end{array}$ & 2 & 2.03 & 1.10 \\
\hline $\begin{array}{l}\text { I expect that another person will take over the } \\
\text { care of the child }\end{array}$ & 2 & 1.77 & 0.86 \\
\hline I discuss the future often with the child & 4 & 3.97 & 0.72 \\
\hline $\begin{array}{l}\text { I have discussed applying for a Special } \\
\text { Guardianship Order with the carer }\end{array}$ & 4 & 3.67 & 1.30 \\
\hline I believe this placement is stable & 5 & 4.50 & 0.82 \\
\hline $\begin{array}{l}\text { I would support the carer if they applied for a } \\
\text { Special Guardianship Order }\end{array}$ & 4 & 4.03 & 1.10 \\
\hline $\begin{array}{l}\text { I believe that this placement is the best long- } \\
\text { term option }\end{array}$ & 5 & 4.57 & 0.63 \\
\hline $\begin{array}{l}\text { The primary objective for any placement is } \\
\text { permanency }\end{array}$ & 5 & 4.57 & 0.63 \\
\hline
\end{tabular}

Kinship carers and social workers strongly agreed that the young people would likely remain with their carer until at least the age of eighteen. Social workers agreed that they would support the carer if they applied for an SGO. However, kinship carers were, on average, ambivalent to SGOs when asked to rate out of ten (where ten is extremely likely) the likelihood that they would apply for an SGO $(\mathrm{M}=5.05, \mathrm{SD}=3.97)$.

Young people also agreed that the placement was likely to be permanent. When it came to discussing the future with other people, the young people responded neutrally to discussions with carers, social workers and birth parents. However, the young people agreed that they sometimes discussed the future with their friends. The young people also agreed with the statement "I feel good about the future".

Kinship carers and social workers were asked to identify the main priorities of a kinship placement. This was a free response task with space for five responses. Not all participants used all five lines. The results from the kinship care group were weighted and are presented in Table 16. 


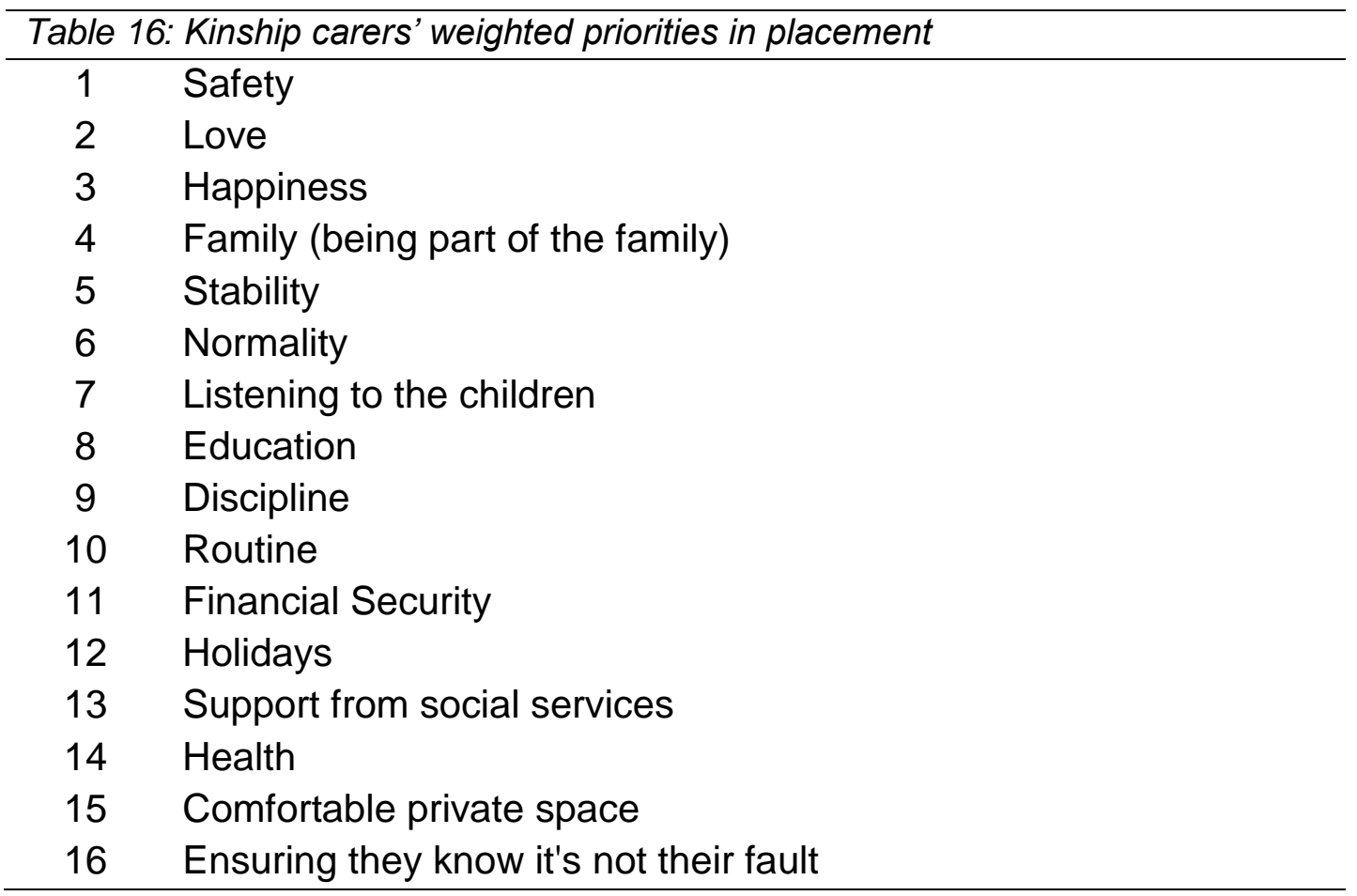

Kinship carers indicated that safety is paramount in placement followed by love and happiness. Family was identified as highly prioritised whilst education and discipline were deemed to be less of a priority.

A similar task for social workers resulted in longer responses with multiple facets, therefore a more thematic approach was deemed to be more appropriate in presented these results. Social workers highlighted permanency and family identity as core priorities of a kinship placement, along with safety, secure attachment and emotional warmth. Social workers also noted concern for the stigma associated with being a 'looked after' child and saw minimising that stigma as one of the goals of kinship placements.

\subsubsection{Education and Employment}

Young people were asked to respond to a series of statements relating to their feelings about school and education. Responses were recorded on a five-item Likert scale with five indication strong agreement. The results are presented in Table 17. 


\begin{tabular}{lcccc}
\hline \multicolumn{4}{l}{ Table 17: Young people's feelings about school } & \\
\hline & Median & & Mean & $\underline{\text { SD }}$ \\
School is important to me & 5 & 4.76 & 0.54 \\
I like school & 4 & 3.90 & 0.89 \\
I have friends at school & 5 & 5.00 & 0.00 \\
Getting an education is important to me & 5 & 4.81 & 0.40 \\
The teachers like me & 4 & 4.24 & 0.77 \\
The teachers tell me that I do well & 4 & 4.29 & 0.56 \\
I am a good student & 4 & 4.14 & 0.65 \\
I know what I want to do when I grow up & 4 & 3.95 & 1.16 \\
I know what I have to do to get there & 4 & 4.05 & 1.02 \\
\hline
\end{tabular}

Young people rated school and getting an education as important to them and, on average, agreed that they liked school. All of the young people strongly agreed to having friends at school and rated themselves as good students.

Young people were given a free response task in which they were asked to report things that they liked and disliked about school. Young people reported that they liked seeing friends $(n=9)$ and highlighted specific academic subjects that they enjoyed $(n=13)$. Their dislikes were broader, indicating that disagreements with peers $(n=3)$ and bullying $(n=1)$ posed problems for the young people, along with travelling to school $(n=1)$ and the length of the school day $(n=1)$.

Young people were asked to indicate their career aspirations on a free-response task. The responses were grouped to protect anonymity and to explore trends. The results are presented in Table 18.

Responses from the same free-response task were regrouped to establish the level of qualification required for each career aspiration. The majority of young people will be required to pursue further or higher education in order to fulfil their career aspirations (61.9\%). The results are presented in Table 19. 
Table 18: The career aspirations of young people in kinship care $(n=21)$

\begin{tabular}{lc}
\hline & Percentage \\
Armed forces & 9.52 \\
Uniformed Emergency Services & 9.52 \\
Skilled Trade & 28.57 \\
Sport (player/coaching) & 9.52 \\
Teaching or academia & 19.05 \\
Agriculture & 4.76 \\
"Don't know" & 19.05 \\
\hline
\end{tabular}

Table 19: Qualification requirements of career aspirations of young people in kinship care $(n=21)$

\begin{tabular}{lcc}
\hline & Number & Percentage \\
\cline { 2 - 3 } No career identified & 4 & 19.05 \\
No further qualification required & 4 & 19.05 \\
Aspirations requiring Further Education & 9 & 42.85 \\
Aspirations requiring Higher Education & 4 & 19.05 \\
\hline
\end{tabular}

Kinship carers were asked a series of questions to establish the importance of education in their home. Statements were scored on a five item Likert scale with a score of five indicating strong agreement. The results are presented in Table 20.

\begin{tabular}{lcccc}
\hline Table 20: Kinship carers' feelings about education & & & \\
\hline $\begin{array}{l}\text { Education is the most important thing in our } \\
\text { home }\end{array}$ & $\frac{\text { Mean }}{4.04}$ & $\frac{\mathrm{SD}}{1.12}$ & $\frac{\text { Median }}{4}$ \\
$\begin{array}{l}\text { School attendance is extremely important in our } \\
\text { home }\end{array}$ & 4.69 & 0.47 & 5 \\
$\begin{array}{l}\text { There is a designated time for the child to do their } \\
\text { homework }\end{array}$ & 4.10 & 0.76 & 4 \\
$\begin{array}{l}\text { I always assist with homework } \\
\text { I enjoyed school when I was younger }\end{array}$ & 4.03 & 0.72 & 4 \\
\hline
\end{tabular}


Deprivation prior to placement

The birth parent's postcode prior to the child's removal from the home was extracted from case files. These were compared against the Welsh Index of Multiple Deprivation (WIMD) to estimate the degree of deprivation the young people may have been subject to.

Of the study sample $(n=21), 61.9 \%$ came from postcodes that fell within the lowest quartile on the ranked composite WIMD.

In all, 33.33\% came from postcodes that fell within the lowest decile on the ranked composite WIMD.

\subsubsection{The Voice of the Child}

Young people were asked a series of questions to establish the extent to which they felt they were listened to by key people in their life. Statements were scored on a five item Likert scale with a score of five indicating strong agreement. The results are presented in Table 21.

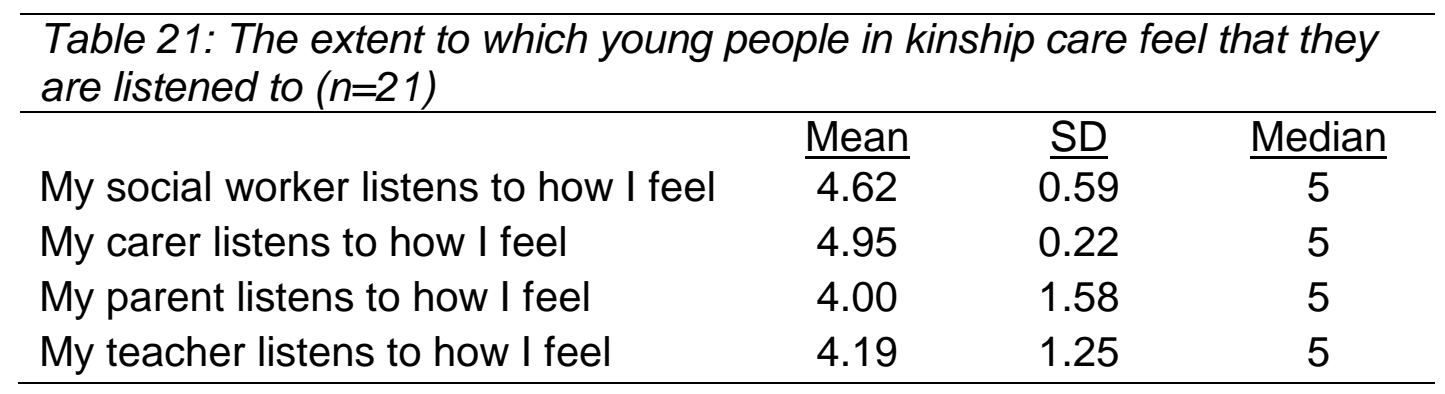

Young people were given a free response task in which they were asked to identify those who listened to them the most. The results were weighted and the rank order is presented in Table 22.

Young people were given a free response task in which they were asked to identify what is important to them. Space was provided for five responses, 
6.1 The Relative Wellbeing of young people

although around half used all available spaces $(n=11)$. Responses were weighted and placed into rank order. The results are shown in Table 23.

\begin{tabular}{cc}
\hline Table 22: Free response by young people regarding who listens to them \\
\hline Weighted Rank & $\frac{\text { Person }}{\text { Carer }}$ \\
2 & Birth Parent \\
3 & Social worker \\
4 & Other family \\
5 & Friends \\
6 & Teacher \\
7 & Strangers
\end{tabular}

Most frequently identified as important were relationships, such as those with friends, family and pets. Education was also ranked highly.

Table 23 : Weighted rank of things that are important to young people in kinship care $(n=21)$

Weighted rank number

1

2

3

4

5

6

7

8

9

10

11

12

13

14

15

16

17

18
Friends

Family

Education

Contact with birth parents

Pets

Contact with wider family

Future

Phone

iPad

Play (including video games)

Driving

Love

Country

Work

Social worker

Music

Health

Being listened to 


\section{Section Summary}

The descriptive data provides an overview of the views of young people in kinship care and the status of their carers. The mean birth parent contact levels appear initially to be relatively high at 28 occasions per year, although there is a very large variance on this figure suggesting that for many young people in the sample, this figure is rather different to their own experience of contact frequency. It is also interesting to note the high levels of supervision which will explored further in the qualitative chapter.

Kinship carers reported that the mean number of dependents is two which concurs with previous literature suggesting that kinship carers are providing care on multiple fronts. It was interesting to note, however, that three of the carers defined their occupation as 'foster carer' given that all of the young people in the home were classed as being in kinship care. Given previous literature on the importance of employment as an aspect of identity, it was interesting to see that some of the carers see their provision of care as a form of formal labour and identified that labour as making them a part of the workforce.

Household income varied widely, however almost seventy per cent of those who responded were below the national average. Given that the national average used was based on a single worker's salary, this should have taken into account that almost half of the carers were either single, divorced, separated or widowed. However, the number who remain below the threshold is alarming and concurs with prior research indicating that poverty may be an issue for kinship carers. The only challenge to asserting this is that it is not possible from the descriptive data to calculate differences in housing costs. Given the average age of the carers in this study was fifty-eight years, it is possible that many are homeowners in which case costs will be lower compared with national trends which cover all adult age groups.

With regards to contact arrangements, all parties feel that the level of contact is appropriate, however there is disagreement regarding who influences changes the most. The carer and young person both felt that they were overruled by the social worker who, in turn, ranked themselves as the fourth most influential person on changes to contact. The relationships between the parties will be 
discussed further in the qualitative analysis and discussion, however it is worth noting at this point that a discord exists.

\subsubsection{Attachment}

\section{RQ8: How are attachments organised for young people in kinship care?}

Table 24 gives young people's total attachment scores to peers, kinship carers and birth parents, as measured on the IPPA-R. The differences between males and females are also shown. Whilst variance in scores given for kinship carers was low, the scores given for birth parents showed a large variance.

Table 24: Total Attachment scores on the IPPA-R by gender.

$\frac{\text { Peers }}{(\mathrm{M}: S D)} \quad \frac{\text { Kinship carer }}{(\mathrm{M}: S D)} \quad \frac{\text { Birth Parent }}{(\mathrm{M}: S D)}$

$\begin{array}{cccc}\text { Male } & 24.4(6.1) & 23.8(5.7) & 16.7(10.0) \\ \text { Female } & 28.8(5.0) & 21(1.9) & 15(11.2) \\ \text { All } & 27(5.8) & 22.2(4.1) & 15.8(10.5)\end{array}$

Norm data $24.6(8.4) \quad 23(8.2)$

Z scores were calculated to establish the extent to which the mean attachment to each target (parent, carer and peers) deviated from the general population means. Figure 12 depicts this trend, with attachment to peers appearing to be higher than the general population whilst attachment to birth parents appears to be lower. These descriptive statistics indicate that differences may be observed between the kinship care sample and the general population in the average attachment to each target. 


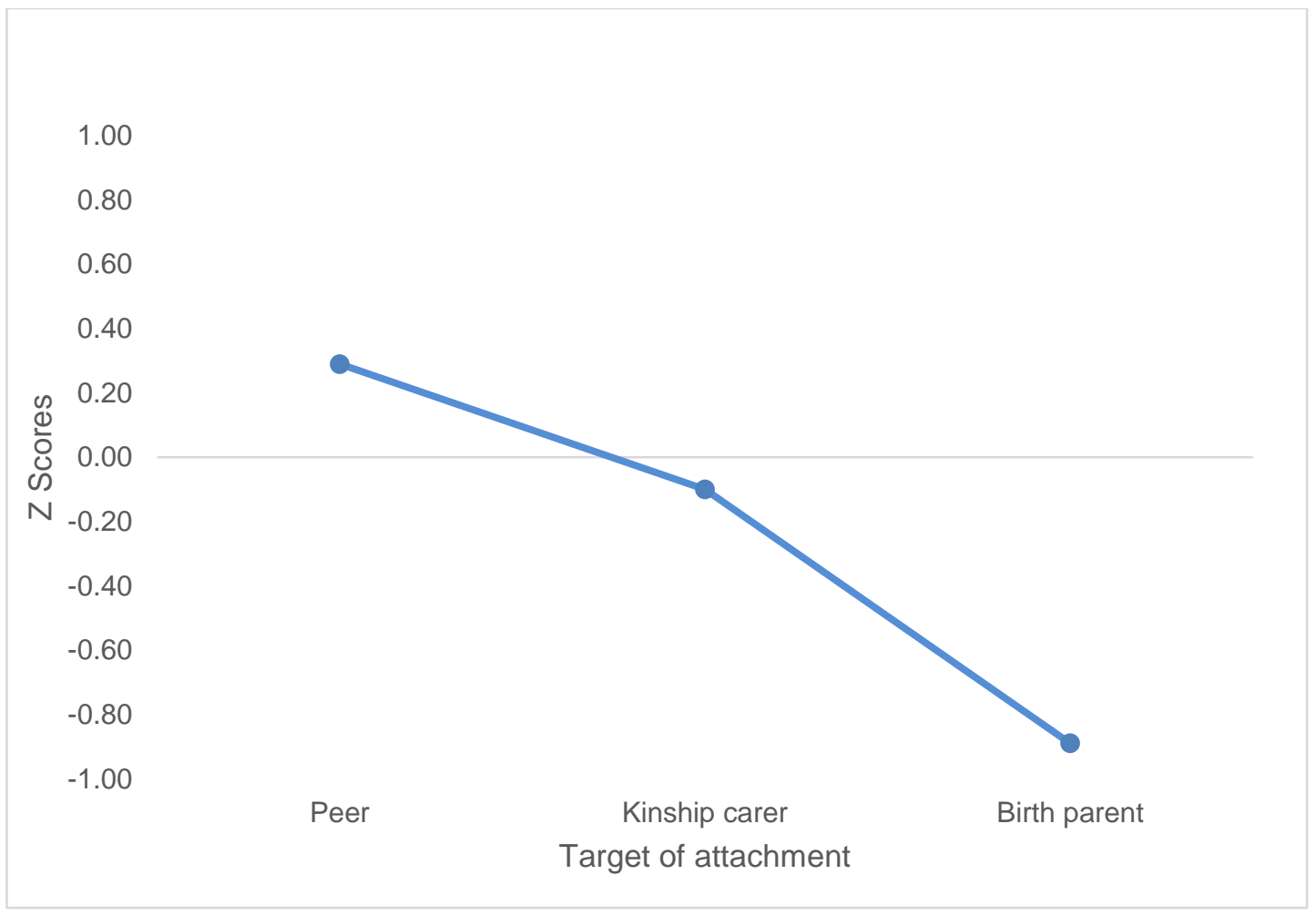

Figure 12: Z score calculation showing the differences between the kinship care group and the general population with regards to attachment to peers, kinship carers and parents.

RQ9: How does the strength of attachment of young people in formal kinship care compare to those in the general population and informal kinship care?

Total attachment results were compared with population norm data using a onesample $Z$ test. The norm data was extracted from Gullone \& Robinson (2005). The results showed that young people in kinship care were significantly less attached to their birth parent $(M=15.75, S D=10.46)$ than the general population, $Z=-11.32, p<0.00$.

The young people's attachment scores on each of the sub-domains from the IPPA- $R$ were compared to norm data using a one-sample $Z$ test on each domain. The results showed that young people in kinship care rated their birth parents as significantly higher on the trust $(M=20.1, S D=5.62)$ subdomain than their peers in the population, $Z=16.70, p<0.00$. Similarly, young people in kinship care reported higher levels of communication $(M=16.4, S D=5.39)$ than the general population, 
$Z=7.05, p<0.00$. However, young people in kinship care reported significantly higher alienation scores with respect to birth parents $(M=20.75, S D=3.71)$ than their peers in the general population with regard to their parents, $Z=38.75$, $\mathrm{p}<0.00$.

The total attachment to kinship carers in the kinship sample were compared with attachment to parents in the general population. The mean total attachment scores to kinship carer $(M=22.19, S D=4.12)$ were compared with the norm data total attachment scores to parent (Gullone \& Robinson, 2005). The results showed no significant difference between the means, $Z=-1.35, p=0.09$. The total attachment scores to kinship carer and birth parent, and the general population scores are shown in Figure 13. The results show that young people in kinship care are equally attached to their carer as the general population are to parents. This would indicate that the attachment relationship of young people and kinship carers as a primary caregiver is no different than the general population.

The total peer attachment scores for the study sample $(n=21)$ and the norm data were compared using a one sample $Z$ test. The results showed a small but significant difference with those in kinship care reporting higher attachment to peers $(M=26.95, S D=5.78)$ than the general population, $Z=3.79, p<0.00$.

Gendered differences were explored. When compared with the norm data males were found to have higher attachment to peers $(M=24.44, S D=6.12)$ than males in the general population, $Z=4.39, p<0.00$. Further analysis on the sub-domains revealed significantly higher ratings of peer trust within the male kinship care sample $(M=23, S D=3.16)$ than the general population, $Z=15.51, p<0.00$. Equally, males in kinship care rated higher on the peer communication domain ( $M=18.44$, $S D=4.59$ ) than males in the general population, $Z=12.38, p<0.00$. However, males in kinship care also scored higher on the alienation sub-domain for peers $(M=17, S D=2.4)$ than males in the general population, $Z=24.45, p<0.00$. 


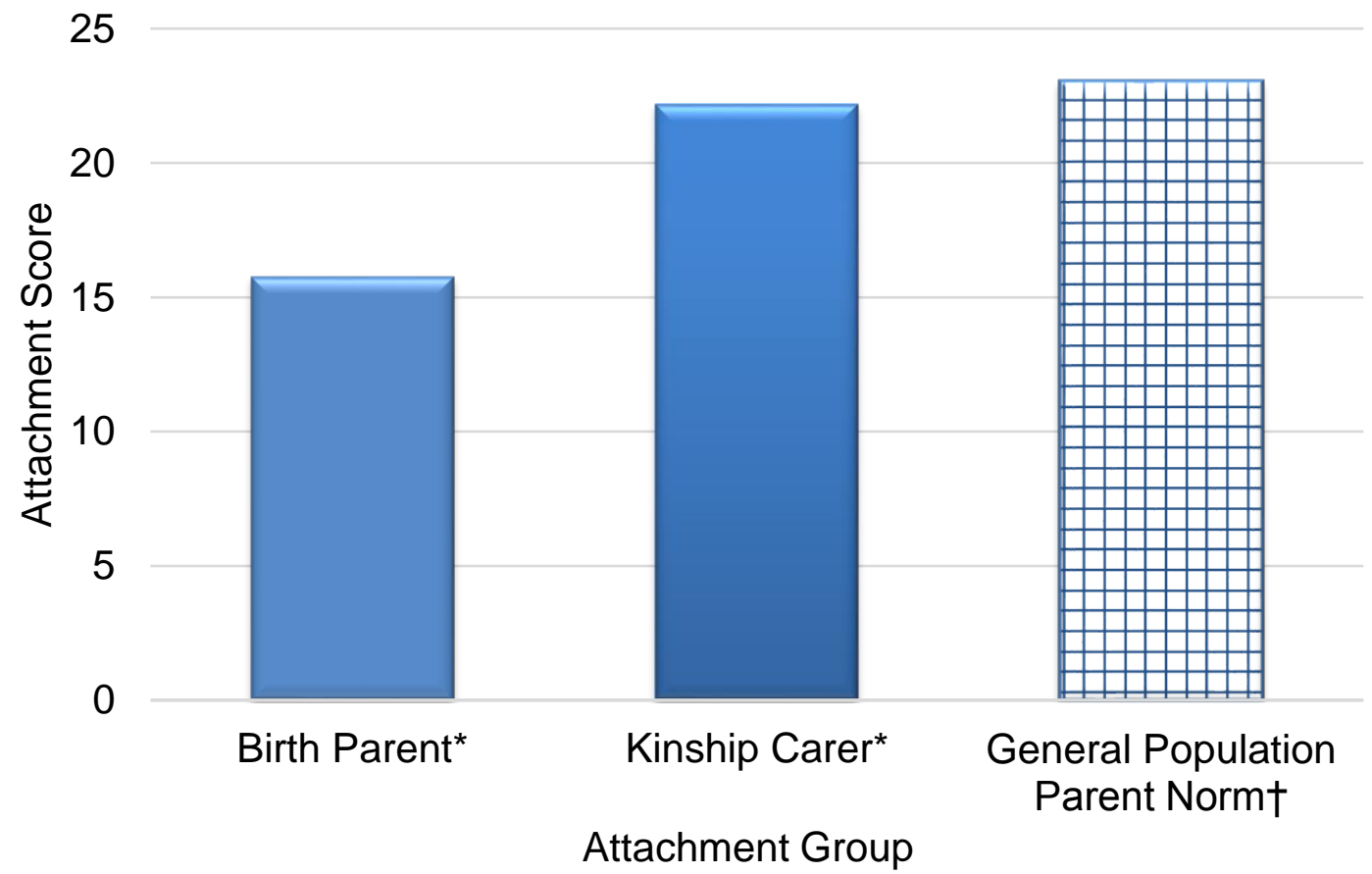

Figure 13: Total attachment scores of young people in kinship care and the general population to primary caregivers and parents.

*Young people in kinship care

†General Population norm (Gullone \& Robinson, 2015)

Exploration of the total peer attachment for females revealed that those in the kinship care sample $(M=28.83, p=0.04)$ were more attached to peers than females in the general population. Analysis of the sub-domains revealed a similar trend to the males, with females in kinship care scoring higher on peer trust $(M=25.17, S D=3.54)$ than general population norms, $Z=18.89, p<0.00$. Similarly, the kinship care sample rated peer communication as higher $(M=21.58, S D=2.97)$ than females in the general population, $Z=13.14, p<0.00$. Finally, females in kinship reported significantly higher levels of alienation $(M=17.92, S D=2.19)$ than females in the general population, $Z=33.3, p<0.00$.

These results show that whilst young people in kinship care are less attached to their parents, their attachment to their kinship carer is comparable to the general population. Regarding birth parents, young people in kinship care rate their parents higher on trust than the general population, although report higher levels 
of alienation. Total attachment to peers is higher in kinship care than the general population, with differences present across the subdomains. Of particular note are the high peer alienation scores present for both males and females in the kinship care sample.

Total attachment to carer was compared between young people in informal kinship care (Farmer, Selwyn \& Meakings, 2013) and 'looked after children' in kinship care. The results indicate no significant difference in attachment to carer between the two groups $(\mathrm{t}(99)=0.27, \mathrm{p}=0.79)$. The two groups were split by gender to establish whether any gender differences in attachment existed. When compared with informal kinship care, neither looked after males $(\mathrm{t}(40)=1.55$, $p=0.13$ ) nor females $(t(57)=1.15, p=0.25)$ from formal kinship care were found to differ significantly in their ability to form an attachment to their carer.

The results indicate that looked after status does not affect a child's ability to form an attachment to their kinship carer.

\section{RQ10: How does a young person's age relate to the strength and nature of attachments?}

In order to test whether there any linear relationship exists between a young person's age, calculated in years and proportion of years, and their attachment to birth parent, a Pearson's correlation coefficient was calculated $(r(20)=-$ $0.27, p=0.13)$. This showed a weak negative relationship in which older participants displayed weaker attachment to birth parents.

The analysis was repeated with regards to each of the sub-domains. No significant correlations were found between age and any of the subscales with the exception of the communication subscale which showed a weak but statistically significant negative relationship $(r(20)=-0.38, p=0.048)$ with communication reducing as age increased.

A Pearson's correlation coefficient was calculated to establish whether the strength of the child's attachment to kinship carer would change as young people grow older. The results showed no relationship between young person's age and 
their total attachment to carer $(r(21)=0.01, p=0.49)$. Age was also not found to be significantly correlated with any of the subscale scores.

\section{RQ11: How does placement stability/permanency relate to the strength and nature of interpersonal relationships?}

Placement length was explored to establish whether it relates to attachment scores. Length of placement was not found to be significantly correlated with either total attachment to carer $(r(20)=0.16, p=0.49)$ or any subscale. Equally no relationship was found between attachment to peers and length of placement. However, a Pearson's correlation coefficient revealed that length of placement was negatively correlated with total attachment to birth parent $(r(20)=-0.49$, $p=0.01$ ). This relationship can be observed in Figure 14. This indicates that as placement length increases, attachment to birth parent weakens.

Furthermore, moderate negative correlations were found between placement length and scores on the parent 'communication' $(r(20)=-0.59, p=0.00)$ and 'trust' $(r(20)=-0.50, p=0.01)$. This indicates that longer placement length is related to lower levels of trust and communication with birth parents.

Young people were asked to indicate on a five-item Likert scale how much they agreed with the statement "I believe that I will stay with my carer" (C\&YPV1, see Appendix 6). Those who 'totally agreed' with the statement by selecting option five $(n=11)$ were compared with those who selected the remaining options $(n=10)$. No significant differences in attachment scores relating to parent, carer or peers were found between the groups. Furthermore, no differences were found on any subscale item.

These results suggest that the young people's attachment to their kinship carer is not related to placement length, however longer placements relate to weaker attachment to birth parents. Furthermore, longer placements are related to weaker reported levels of parental trust and communication. The results also suggest that there was no relationship between children's perception of placement permanency and their attachment to others. 


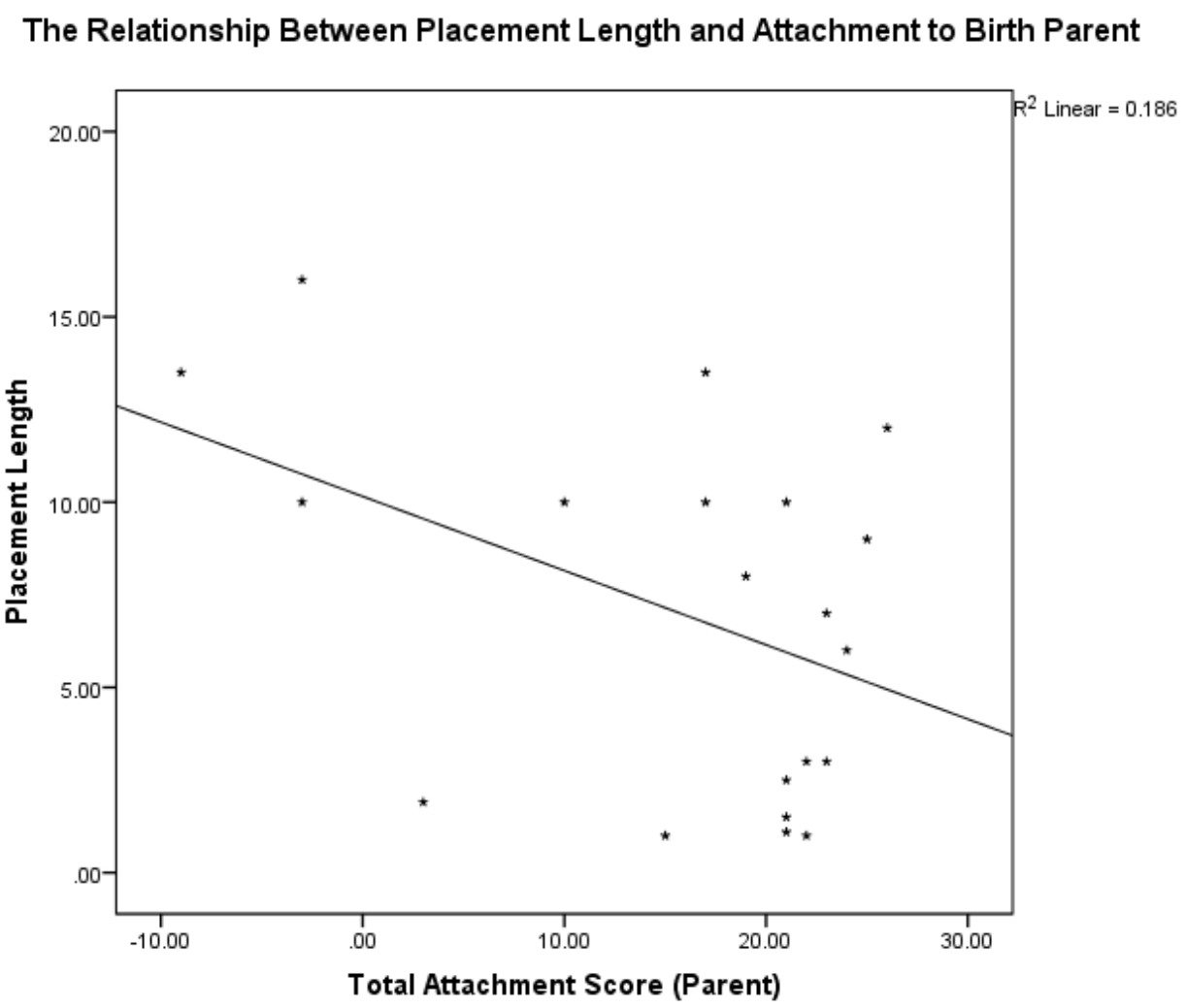

Figure 14: The relationship between placement length (years) and attachment to birth parent.

RQ12: How does birth parent contact frequency relate to the strength and nature of attachment?

A Pearson's correlation coefficient was calculated to establish whether any linear relationship exists between contact frequency, recorded as a continuous variable, and total carer attachment scores. The results showed a reasonable, negative correlation that did not reach significance $(r(21)=-.31, p=0.23)$.

Whilst no relationship was found between contact frequency and carer attachment, analysis revealed a moderate positive correlation between contact frequency and parent attachment total with a coefficient of $0.45 \operatorname{sr}(20)=0.45$, $p=0.02$ ). Given the sample size, this correlation may be considered strong as reflected in the significant $p$ value. Further linear relationships were found between contact frequency and parent subscale scores for trust $(r(20)=0.47$, $\mathrm{p}=0.02)$ and communication $(\mathrm{r}(20)=0.46, \mathrm{p}=0.02)$. 
These results would indicate that birth parent contact and attachment to birth parent are positively related whilst contact with birth parents has no significant relationship to carer attachment.

\subsubsection{Mental Health}

RQ13: How does the mental health of young people in kinship care compare to those of the same age in mainstream foster care, informal kinship care and the general population?

When compared with young people in mainstream foster care (Mount et al., 2004) young people in kinship care rated themselves as having significantly lower total difficulties on the SDQ $(t(70)=2.186, p=0.032)$. These results indicate that young people in kinship care report less difficulty than those in mainstream foster care. The means for each of the kinship care, mainstream foster care and general population norm groups are shown in Table 25.

Furthermore, young people's self-report scores on the SDQ total difficulties scale were positively correlated with carers' scores showing a degree of agreement between the two $(r(21)=0.388, p=0.041)$.

Kinship carer's SDQ ratings of the young people they were caring for were compared with data from mainstream foster care published by Goodman and Goodman (2012). The average carer-rated scores are presented in Table 26. Comparison of total difficulties score revealed a significant difference between the two groups with mainstream foster carers scoring young people's difficulties higher than kinship carers $(\mathrm{t}(808)=2.00, \mathrm{p}=0.05)$. This would suggest that young people in mainstream foster care suffer from higher rates of psychological difficulties than young people in kinship care.

Clinical cut offs were applied to the sample data to establish the proportion reaching clinical significance. Prevalence of clinical disorder was compared to mainstream foster care data published in (Minnis et al., 2006). 
Table 25 : Kinship Vs. Mainstream foster care: prevalence of clinically significant self-reported difficulty

\section{Mean $(S D)$}

\begin{tabular}{|c|c|c|c|}
\hline SDQ subscale & $\frac{\text { Kinship Care }}{(\mathrm{n}=21)}$ & $\frac{\frac{\text { Mainstream }}{\text { Foster Care }}}{(n=50)}$ & 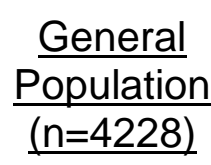 \\
\hline Total Difficulties & $12.62(6.55)$ & $15.84(5.26)$ & $10.3(5.2)$ \\
\hline Emotional problems & 3.29 (2.51) & Not reported & $2.8(2.1)$ \\
\hline $\begin{array}{c}\text { Conduct Problems } \\
\text { Hvneractivity }\end{array}$ & $2.71(2.24)$ & Not reported & $2.2(1.7)$ \\
\hline Problems & $5.10(2.68)$ & Not reported & $3.8(2.2)$ \\
\hline Peer Problems & $1.52(1.57)$ & Not reported & $1.5(1.4)$ \\
\hline Prosocial & $8.19(1.57)$ & Not reported & $8.0(1.7)$ \\
\hline
\end{tabular}

Error! Reference source not found.Table 26 shows that prevalence of carerreported difficulties in kinship care was found to be lower on total difficulties score and across all subdomains. In the case of total difficulties, conduct problems and peer problems, differences between the two groups were found to be significant at the 0.01 level. The results indicate that young people in kinship care suffer lower levels of difficulties than their peers in mainstream foster care, although the direction of causality cannot be determined.

Self-scored total difficulties scores from the study sample were compared with UK normative data published by Meltzer et al. (2003). Table 27 displays the selfscored mean and standard deviation for each SDQ sub-scale. These scores were compared with population norm data with significant differences were found on the 'total difficulties', 'conduct' and 'hyperactivity' scales. In each case, young people in kinship care rated themselves as higher than their general population counterparts. The $z$ scores and $p$ values for each subscale can be found in Table 28. 
6.1 The Relative Wellbeing of young people

The results indicate that whilst young people in kinship care may fare better than their peers in mainstream foster care, self-reported difficulties are still higher than the general population. 
Table 26 : Kinship Vs. Mainstream foster care: prevalence of clinically significant carer-rated di $\underline{\text { SDQ subscale } \quad \text { Mainstream Foster Care }}{ }^{+}$ $(n=175)$

Kinship Care Sample $(n=21)$

Prosocial behaviour

*Differences in prevalence significant at the 0.01 level compared with mainstream foster care $g$ ¥ Kinship carers where the young person also completed a SDQ (available for triangulation). $\S$ Kinship carers including data where the young person did not also complete a SDQ (not avail + Data extracted from Minnis et al. (2006) 


\section{Table 27 : Child self- rated difficulties compared with general population}

norms.

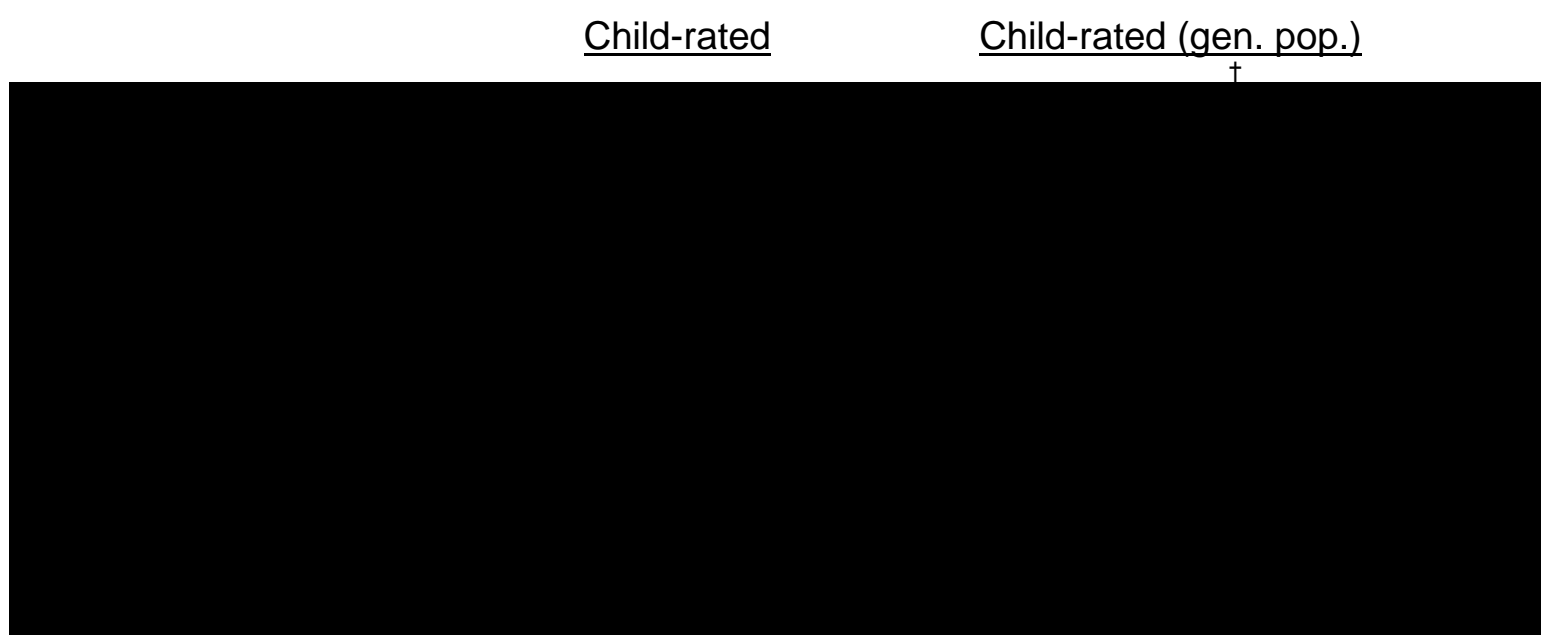

Prosocial

$8.2(1.6)^{N S}$

$8.0(1.7)$

*Significant at the 0.05 level

${ }^{* *}$ Significant at the 0.01 level

${ }^{\dagger}$ Norm data source: Meltzer, Gatward, Goodman, and Ford (2003)

Table 28: Z scores for child self-rated difficulties compared with general population norms.

$\begin{array}{cc} & \frac{\text { Z score }}{4.66^{* * *}} \\ \text { Total Difficulties } & 1.55^{N S} \\ \text { Emotional problems } & 1.79^{*} \\ \text { Conduct problems } & 4.02^{* * *} \\ \text { Hyperactivity } & 0.08^{N S} \\ \text { Peer problems } & 0.67^{N S} \\ \text { Prosocial } & \end{array}$

*Significant at the 0.05 level

${ }^{* *}$ Significant at the 0.01 level

${ }^{* \star *}$ Significant at the 0.001 level 
Carer-rated total difficulty scores were compared with parent scores from the norm dataset. The results revealed that kinship carers rated young people as having significantly higher difficulties than the general population on all subscales with the exception of prosocial behaviour where the kinship care sample scored lower. These results can be seen in Table 29. Results from the onesample $\mathrm{Z}$ tests can be found in Table 30 .

Table 29: Kinship carer rated difficulties compared with general population parent norms.

$\frac{\text { Kinship carer-rated }}{\underline{(n=29)}}$

$\mathrm{M}(S D)$
Parent-rated (gen. pop.)

$\underline{\left(n=10,298^{+}\right)}$

$\mathrm{M}(S D)$

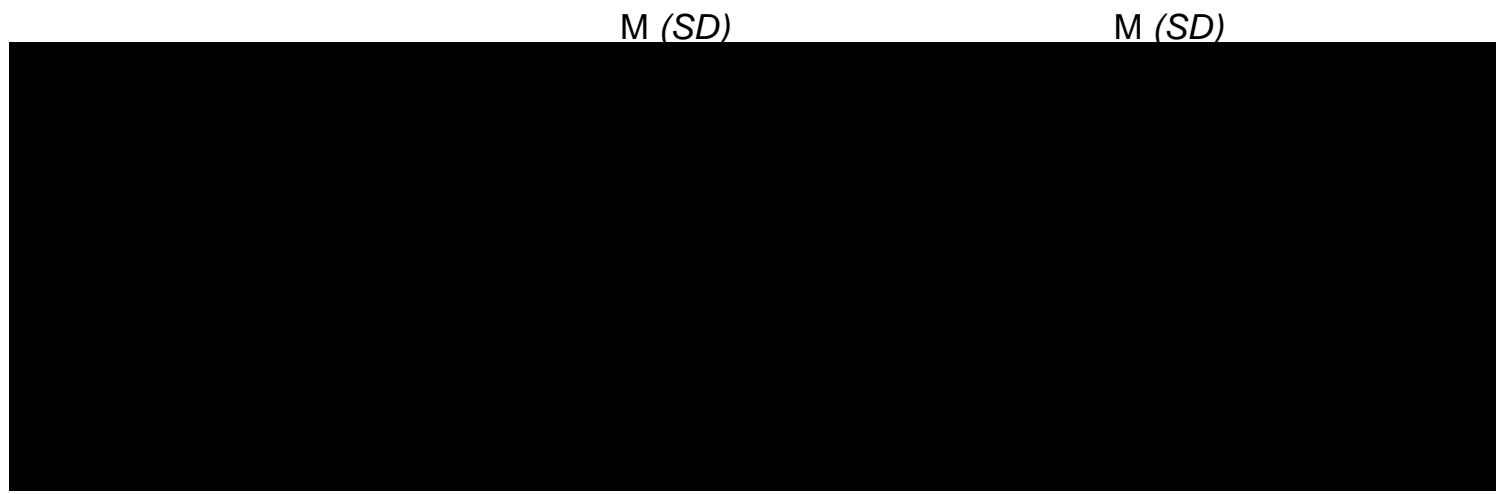

Prosocial

$8.0(1.8)^{* *}$

$8.6(1.6)$

*Significant at the 0.05 level

**Significant at the 0.01 level

${ }^{\dagger}$ Norm data source: Meltzer, Gatward, Goodman, and Ford (2003)

The results indicate that the young people in kinship care experience higher levels of emotional difficulty then the general population when rated by their carer.

Clinical cut-offs were applied to self-reported total difficulties scores as dictated in the SDQ scoring manual. The prevalence of young people in the study sample reaching the cut-off for 'Abnormal' was compared with peers in informal kinship care published in Selwyn, Farmer, Meakings \& Vaisey (2013). No significant difference was found between the proportions of young people in the 
formal kinship care sample (24\%) and informal kinship care (34\%) who fell within the 'abnormal' classification on total difficulties $\left(X^{2}(1,200)=2.43, p=0.12\right)$.

The results indicate that the mental health of young people in formal kinship care is similar to young people in informal kinship care.

Table 30: Z scores for carer rated difficulties compared with general population norms.

\section{$\underline{\text { Zscore }}$}

$\begin{array}{cl}\text { Total Difficulties } & 8.81^{\star * *} \\ \text { Emotional problems } & 4.72^{\star * *} \\ \text { Conduct problems } & 2.89^{\star} \\ \text { Hyperactivity } & 4.54^{\star * *} \\ \text { Peer problems } & 2.19^{\star} \\ \text { Prosocial } & -2.43^{*}\end{array}$

*Significant at the 0.05 level

${ }^{* *}$ Significant at the 0.01 level

${ }^{* * *}$ Significant at the 0.001 level

\section{RQ14: How does mental health relate to attachment, contact frequency} and placement stability/permanency?

A Pearson's correlation coefficient was calculated to establish whether a linear relationship exists between total difficulties score and attachment to carer. The results indicate that no significant correlation exists between the two factors $(r(21)=0.18, p=0.22)$. Furthermore when compared to each of the subscales on the Strengths and Difficulties Questionnaire, no statistically significant correlations were found between any domain and carer attachment.

Further correlational analysis found no significant linear relationship between total difficulties score and birth parent attachment $(r(21)=0.05, p=0.42)$. 
Furthermore when compared to each of the sub scores on the SDQ, no correlations were found between any domain and birthparent attachment.

A Pearson's correlation coefficient revealed a small but not significant linear relationship between total difficulties score and attachment to peers $(r(21)=$ $0.193, p=0.201)$. Furthermore when compared to each of the sub scores on the $S D Q$, no correlations were found between any domain and peer attachment.

Self-rated total difficulties score was compared with contact frequency to examine whether any linear relationship exists. A Pearson's correlation coefficient showed a weak positive correlation between the two variables although this did not reach significance $(r(21)=0.273, p=0.115)$.

Further analyses were carried out comparing contact frequency with self-reported difficulties scores on each of the sub-scales. Only difficulties on the 'peer' domain were found to be significantly correlated with contact frequency showing a moderate negative relationship $(r(21)=-0.409, p=0.033)$. The results indicate that whilst contact frequency is not related to difficulties on most of the subscales, a negative relationship exists between contact frequency and difficulties with peer relations. Due to the nature of the analysis, the direction of causality cannot be determined.

Young people were asked to indicate on a five-item Likert scale how much they agreed with the statement "I can choose how much I see my birth parent" (see CYPQV1, Appendix 6). Those who totally agreed with the statement by scoring five $(n=10)$ were compared with those who scored the item lower $(n=11)$. No significant differences were found between the groups on self-rated total difficulties $(t(19)=0.1176, p=0.9076)$, nor on any subscale.

A Pearson's correlation coefficient was calculated to establish whether any linear relationship exists between placement length and carer-reported total difficulty scores. The results revealed no significant correlation between the two variables on either the total difficulties score $(r(28)=0.126, p=0.261)$, nor any subscale item.

Young people were asked to indicate on a five-item Likert scale how much they agreed with the statement "I think that I will stay with my carer" (see CYPQV1, 
Appendix 6). Those who totally agreed with the statement by scoring five $(n=11)$ were compared with those who scored the item lower $(n=10)$. No significant differences were found between the groups on self-rated total difficulties $(\mathrm{t}(19)=0.987, \mathrm{p}=0.336)$, nor on any subscale.

Kinship carers were asked to indicate on a five-item Likert scale how much they agreed with the statement "I expect that the child will live with me until they are 18" (see KCQV1, Appendix 5). Those who totally agreed with the statement by scoring five $(n=19)$ were compared with those who rated the item lower $(n=10)$.Total difficulties score was not found to be significantly different between the two groups, nor on any subscale item.

The results reveal that the mental health of young people in kinship care is not related to carer or birth parent attachment, placement length, the child's sense of control or expectations of permanency from either the child or their carer. Peer attachment showed a small but not significant negative relationship with mental health. Furthermore, a weak relationship was found between mental health and contact frequency whereby mental health decreased as contact frequency increased.

\subsubsection{Emotional literacy}

RQ15: How does the emotional literacy of young people in kinship care compare with young people of the same age in mainstream foster care and the general population?

Composite emotional literacy scores from each of the self-rated and kinship carer-rated scales are presented in Table 31. 


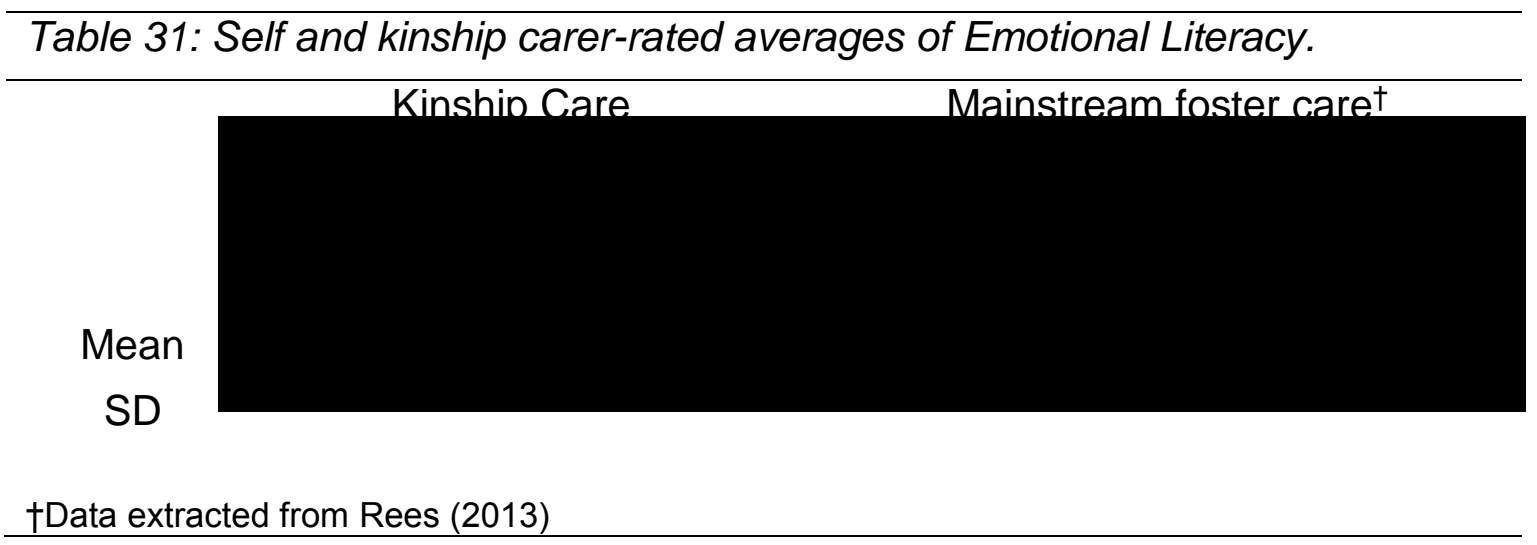

The mean composite score for each of the self-rated and carer-rated total was compared to a mainstream foster care sample (see Rees, 2013). The average self-rated ELA score in the kinship care group was not significantly different from those in mainstream foster care $(\mathrm{t}(203)=0.32, \mathrm{p}=0.75)$. However, the carer-rated scores revealed a significant difference in the average scores between the two groups $(\mathrm{t}(215)=4.02, \mathrm{p}=0.00)$.

Scores were grouped based on clinical cut-offs defined by the scoring manual. These results are presented in Table 32. The results from the study sample were compared with data from a sample of children in mainstream foster care in Rees (2013). The proportions of young people in kinship care whose self-rated score ranged within the 'average' range was significantly higher in kinship care than mainstream foster care $\left(\chi^{2}(1,205)=4.92, p=0.03\right)$. No other significant differences were found in the distribution of young people falling into each qualitative category between those in kinship care and mainstream foster care. Carer-rated groups were also compared between mainstream foster care and kinship care. Those in mainstream foster care were significantly more likely to be classified as 'well below average' than those in kinship care when rated by carers $\left(\chi^{2}(1\right.$, $217)=4.58, p=0.03$ ). Conversely, those in mainstream foster care were significantly less likely to be classified as 'well above average' than those in kinship care $\left(\chi^{2}(1,217)=23.04, p=0.00\right)$. 
Table 32: Comparison of self-reported and carer-reported emotional literacy diagnostic ba

\section{Kinship Care}

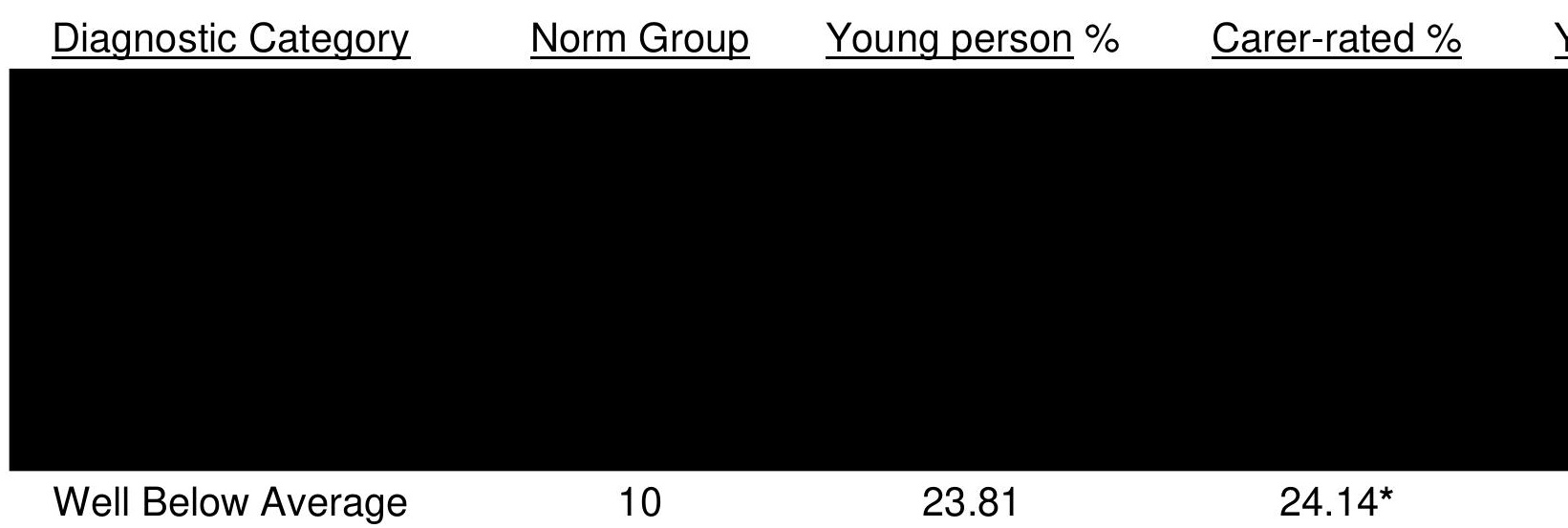

*Indicates significant result at the 0.05 level when compared with general population norms. \&Indicates significant result at the 0.05 level when compared with the kinship care data.

† Data extracted from Rees (2013) 
The proportion of young people in kinship care that were self-ranked in each band was compared with the population norm groups. The results can be seen in Table 32. No significant differences were found between young people in kinship care and the general population in the proportions of young people in each scoring band. Furthermore the average ELA score in the kinship care group was found not to be significantly different from that of the general population $(t(1716)=1.094$, $\mathrm{p}=0.274)$.

When compared with the general population norms, no significant differences were found in the proportions of kinship carers rating young people as 'well above average', 'above average' or 'below average'. Significantly less kinship carers ranked the young person as 'average' than the general population $\left(X^{2}(1,71)=\right.$ 4.564, $\mathrm{p}=0.033)$. Conversely, significantly more kinship carers rated the young person as 'well below average' than the general population $\left(X^{2}(1,129)=3.927\right.$, $p=0.048$ ). The distribution of scores across the diagnostic groups can be seen in Table 32.

The average carer-rated ELA score was not significantly different from the general population $(t(595)=0.467, p=0.924)$. This indicates that young people in kinship care may be performing as well on emotional literacy as their non-LAC peers.

The results indicate that the emotional literacy of young people in kinship care is at a level commensurate with the general population. High levels of emotional literacy are more common in those in kinship care than their mainstream foster care counterparts. Furthermore, when rated by carers, the emotional literacy of young people in kinship care is higher than mainstream foster care.

\section{RQ16: How does emotional literacy compare with carer educational status, mental health scores and attachment scores?}

Self-reported total difficulties scores were compared with emotional literacy scores to establish whether any linear relationship exists. Pearson's correlation analysis revealed a strong negative relationship between total difficulties score on the SDQ and emotional literacy score with a coefficient of $r(21)=-0.79, p=0.00$ 
(see Figure 15). This would indicate that those with lower emotional literacy scores suffer with poorer mental health.

Emotional literacy score was found to have a moderate positive correlation with young people's attachment to peers $(r(21)=0.50, p=0.01)$. Emotional literacy score was not found to be correlated to parental or carer attachment scores. The results indicate that a linear relationship exists between emotional literacy and peer relations with higher emotional literacy correlated with stronger peer attachment.

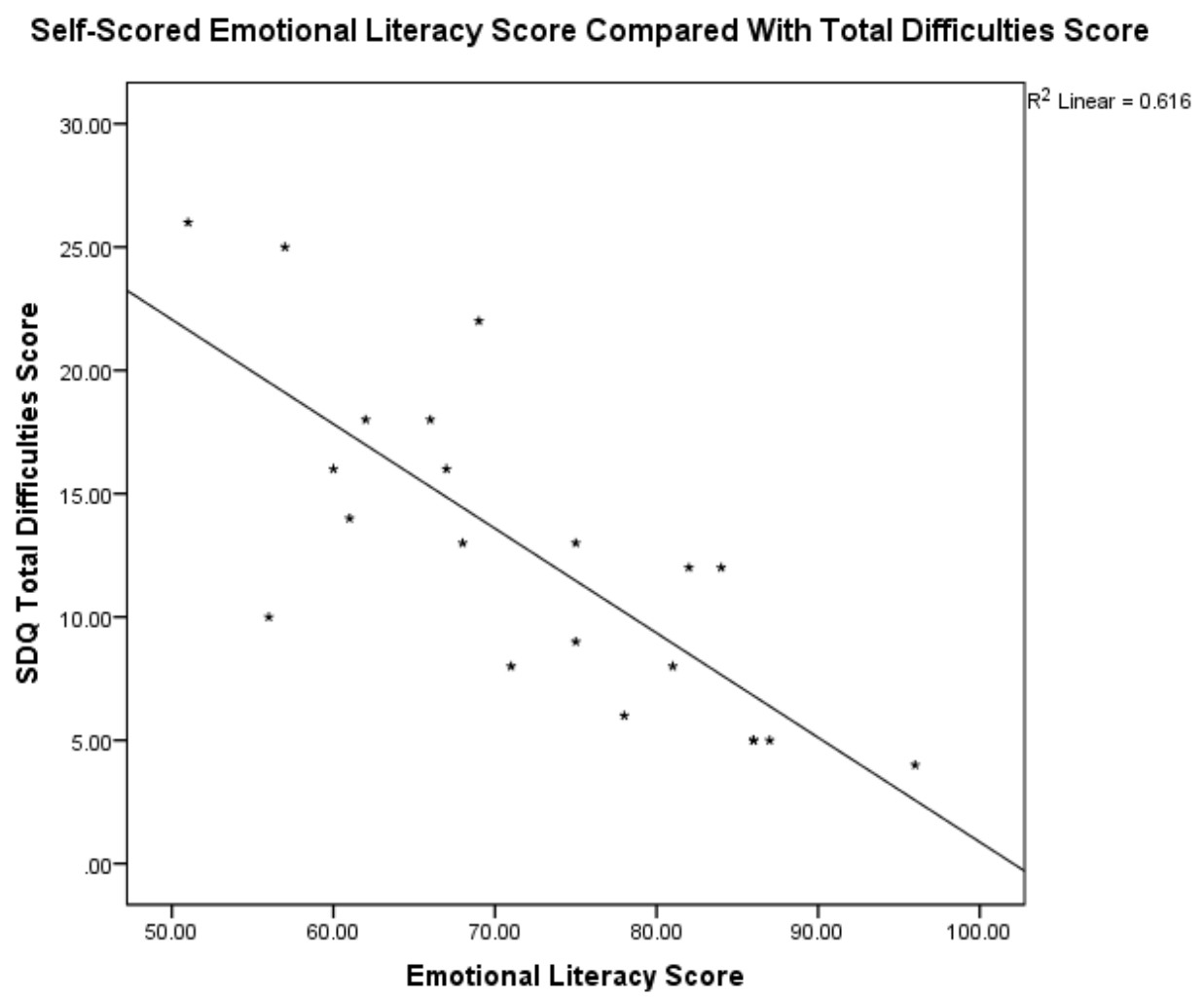

Figure 15: Scatterplot showing the linear relationship between emotional literacy and total difficulties scores.

A Spearman's Rho test revealed no significant correlation between the educational attainment of kinship carers and the emotional literacy scores of young people $(r(16)=-0.22, p=0.42)$. This indicates that the educational level of kinship carers has no effect on the emotional literacy of young people in their care. 
The results show that lower levels of emotional literacy is associated with poorer mental health. There is also evidence of a relationship between low emotional literacy and low attachment to peers.

\section{RQ17: To what extent do self-rated feelings of control and optimism relate to emotional literacy?}

Young people were asked to indicate on a five-item Likert scale how much they agreed with the statement "I can choose how much I see my birth parent". Those who totally agreed with the statement by scoring five $(n=10)$ were compared with those who scored the item lower $(n=11)$. No significant differences were found in the emotional literacy level between the two groups $(t(19)=0.08, p=0.94)$.

Kinship carers were asked to indicate on a 5-item Likert scale the extent to which they agreed with the statement "The child has a strong influence on changes to contact arrangements". When compared to children's emotional literacy score using a Spearman's Rho test, no significant correlation was found $(r(21)=-0.22$, $p=0.34)$

Young people were asked to indicate on a five-item Likert scale how much they agreed with the statement "I feel good about the future". A Spearman's Rho test revealed a significant positive correlation with those feeling positive about the future having higher levels of emotional literacy $(r(21)=0.53, p=0.01)$.

Young people were asked to indicate on a five-item Likert scale how much they agreed with the statement "I sometimes worry about the future". Those who selected a response of four or five, indicating agreement $(n=8)$, were compared with those who had selected one or two, indicating disagreement $(n=7)$. Emotional literacy scores were significantly lower amongst those who agreed with the statement than those who did not $(t(19)=3.87, p=0.00)$.

The results indicate that lower levels of emotional literacy is related to worrying about the future and lower levels of optimism. However, emotional literacy is not related to feeling in control over contact arrangements. 
6.2 The educational achievement of young people

This section focusses on research questions relating to the educational achievement and attainment of the kinship care sample. These results are also featured in a book chapter by Pratchett and Rees (In Press).

RQ19: What is the standard of literacy of young people in formal kinship care?

Table 33 shows the average standard scores on each subscale of the WIAT-II. The average scores for reading and spelling are very similar, both within the low average range. The mean numeracy score fell within the 'Below average' category.

Table 33 : Literacy and numeracy standardised test scores $(n=21)$

Mean (Standard Deviation). $\quad$ Qualitative descriptor

Reading

$87.86(17.07)$

Low average range

Spelling

$87.62(15.86)$

Low average range

Numeracy

$83.14(12.38)$

Below average range

It is possible to directly compare attainment on the WIAT-II and cognitive performance (FSIQ) standardised scores to gain a basic insight into of the extent to which a child is achieving. Generally speaking a child who obtains the same score or higher on the attainment measure can be said to achieving. A more complex model that takes into account the norm sample discrepancy distributions was also used. This allowed for consideration of the magnitude of the discrepancies, observed in the context of the frequency with which they occurred in the norm sample. 
Figure 16 shows the percentages of young people who achieved as expected in each domain along with those who underachieved and positive exceptions. Equal numbers of young people achieved as expected on each of the three subscales.

\section{Percentages of educational achievement on each domain $(n=21)$}

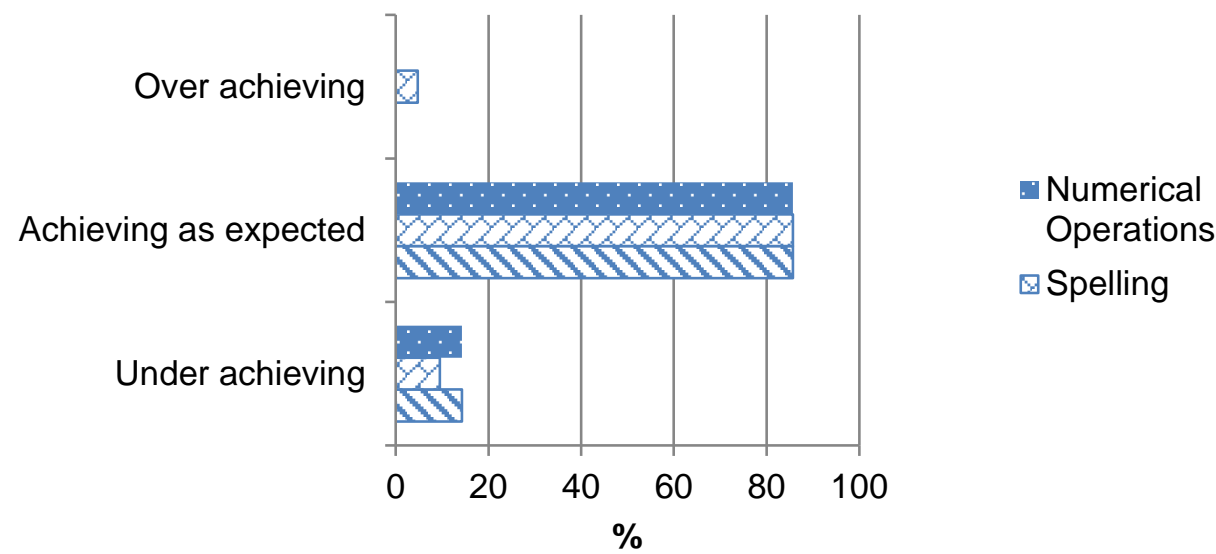

Figure 16: Comparison of achievement on each of the three educational domains.

\section{Positive exceptions}

Positive exception criteria was defined as a discrepancy between the predicted and observed standard score (WASI, FSIQ) of more than 20 points. This figure was chosen as this discrepancy is found in $<5 \%$ of the norm population.

Incidence of over achievement was low with only one individual meeting the criteria on spelling (4.8\%). None of the young people met the criteria on either the reading or numeracy subscales.

\section{Literacy}

Analysis revealed that $85.7 \%$ of those tested were achieving as expected relative to cognitive ability on Word Reading $(n=18)$. The remaining $14.3 \%$ were underachieving relative to cognitive ability $(n=3)$. 
Similarly, $85.7 \%$ of young people were achieving within the expected range relative to cognitive ability $(n=18)$ on Spelling with $9.5 \%$ deemed to be underachieving $(n=2)$.

\section{Numeracy}

In numeracy, $85.7 \%$ of young people achieved scores within the expected range based on cognitive ability $(n=18)$. The remaining $14.3 \%$, who consisted entirely of females, were found to be underachieving relative to cognitive ability $(n=3)$.

\section{RQ20: How does educational achievement in kinship care compare with other looked after children and the general population?}

When compared with general population norms, the children's mean score was significantly lower in Reading ( $z=-3.71, p=0.00$, Cohen's $d=-.8)$, Spelling $(z=-3.78$, $p=0.00$, Cohen's $d=-.8)$, and Numeracy $(z=-5.15, p=0.00$, Cohen's $d=-1.1)$.

Average results for Reading and Spelling were compared with a looked after sample published in Rees (2013). Children in 'formal kinship care' in the wider sample were not included in this analysis to avoid like-with-like comparison. The data suggests that the average level of literacy of children in 'formal kinship care' is very similar to that of the wider population of children in care. The differences are not statistically significant: Reading $(z=0.37 \mathrm{p}=0.72)$ and Spelling $(z=0.39$ $\mathrm{p}=0.85)$.

A further analysis was undertaken to establish how discrepancies in relative achievement of the kinship care sample compared to discrepancies in the wider care population. Chi square analysis revealed a significant difference in the proportion of young people achieving on target or above for both word reading $\left(X^{2}(1,213)=21.96, p=0.00\right)$ and spelling $\left(X^{2}(1,211)=26.75, p=0.00\right)$. In both instances, the proportions achieving where expected or above were higher in kinship care than the overall looked after sample. 


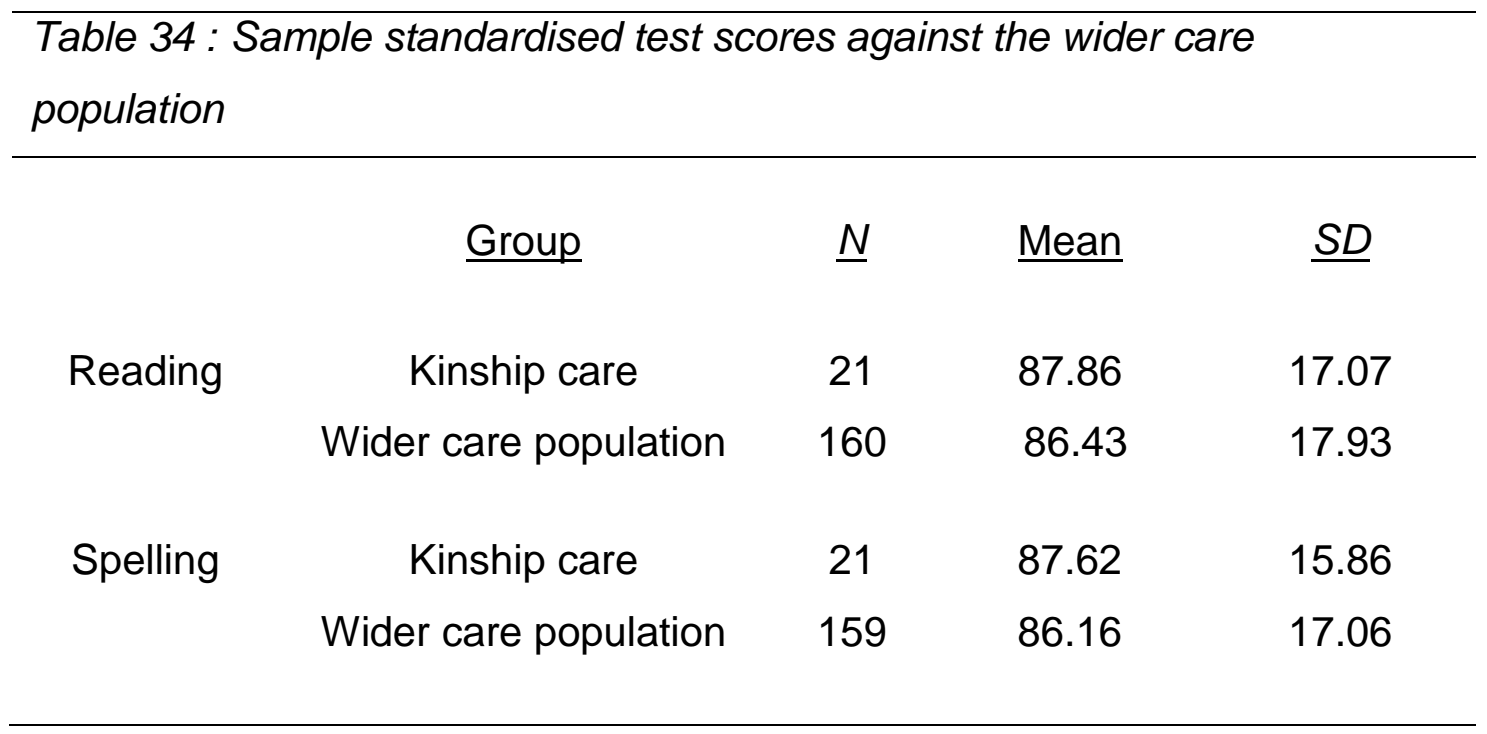

The results show that young people in kinship care achieve lower on both literacy and numeracy than the general population. Furthermore, there are no differences between the formal kinship care sample and the wider care population in the average literacy scores. However, when literacy scores are compared with cognitive ability young people in kinship care achieve as expected with significantly higher frequency than their 'looked after' peers in other placements. 


\subsection{Priorities}

\section{RQ21: Which placement objectives and characteristics are prioritised by} social workers, young people in kinship care and their carers?

Ranked items were allocated a score based on their rank position. The highest ranked item was granted a score of 1 whilst the lowest ranked item was given a score of 13. The average score of each item was calculated with lower scores indicating higher preference.

Table 35 shows the three highest ranked items and the average rank score given to each. The same three priorities were ranked highest by each group, with young people prioritising love marginally higher than their carers or social workers.

Table 35: Caring priorities: highest three ranked items by group.

\begin{tabular}{|c|c|c|c|}
\hline Ranking & $\frac{\text { Kinship Carers }}{\text { (Average rank score) }}$ & $\frac{\text { Social Workers }}{(\text { Average rank score) }}$ & $\frac{\text { Young people }}{\text { (Average rank score) }}$ \\
\hline 1 & Safety (2.63) & Safety (2.43) & $\begin{array}{c}\text { Knowing Love } \\
(4.14)\end{array}$ \\
\hline 2 & Feeling Safe (3.00) & Feeling Safe (2.43) & Feeling Safe (4.32) \\
\hline 3 & $\begin{array}{c}\text { Knowing Love } \\
(3.25)\end{array}$ & $\begin{array}{c}\text { Knowing Love } \\
\text { (3.90) }\end{array}$ & Safety (4.75) \\
\hline
\end{tabular}

The results indicate that safety and the perception of safety were the main priorities for kinship carers and social workers, whilst young people expressed that knowing they are loved is the highest priority. However, the placement priorities are shared by all three parties. 
Chapter 7: Phase two qualitative results 
Chapter seven presents the results of semi-structured interviews conducted separately with kinship carers $(n=24)$, young people in kinship care $(n=21)$ and social workers $(n=21)$. The results of a focus group with supervising social workers $(n=4)$ are also presented. Interview and focus data was recorded and transcribed. Thematic analysis was conducted in accordance with the procedure outlined by Braun and Clarke (2006) (see Chapter 4.2). Analysis was exploratory, employing an inductive, data-driven approach.

The stages involved in the thematic analysis are briefly outlined in chapter 4.4.2. The initial transcription and immersion phase took approximately three months due to the volume and length of audio files. In total, 26.9 hours of interview data was recorded, transcribed and analysed. During this period, broad themes were identified and noted for future analysis as audio files and transcripts were repeatedly read/listened to in order to be fully immersed in the data.

Despite efforts being made to allow the young people to participate fully in the interview process, relatively little data was yielded from this participant group. The average audio time for young people was 11.7 minutes compared to 36.6 minutes for kinship carers and 23.4 minutes for social workers. Whilst disappointing from a researcher's perspective, the lack of direct commentary from the young people may not be as much of a limitation due to the nature of the roles of the social workers and kinship carers. Both of these groups regularly advocate for the young people and, according to the data in the previous chapter, see it as a part of their role. Many of the comments in the coming chapter reflect this and seem to take into account the experience of young people.

Transcription of the data was an arduous process, but an ideal opportunity for immersion into the data. Repeatedly listening to the audio recordings and rereading the transcripts provided intimate knowledge of the themes that arose early on in analysis. The analysis was undertaken using NVivo. Themes and subthemes were manually coded, however NVivo proved useful in organising these themes and providing visual outputs to indicate their frequency. These are provided for reference in Appendices 14-16. Once the data was thematically coded, the themes and subthemes were written out onto 'post-it' notes and placed on a table. This allowed for themes to be organised in a flexible manner with the 
ability to move the themes around as much as needed to provide clarity. A whiteboard was also used to facilitate this and highlight the connections between the themes (see Appendix 12). Following this process, a thematic map was developed and is available in Appendix 13.

A number of codes were identified which cluster around six themes.

Section 7.1 reports on themes surrounding the reported benefits of kinship care, including positive identity and attachment.

Section 7.2 explores the theme of 'motivation to care'. This includes factors such as love of family, the desire to provide stability and the notion of family as an identity for kinship carers.

In section 7.3, the data highlights the mixed advantages and disadvantages of kinship care. Within this theme, areas such as birth family contact, the fear of repeating patterns and the impact on wider family are presented.

Section 7.4 focuses on the challenges of kinship care. These pertain mostly to kinship carers, including a lack of preparation time, changes to the carer's lifestyle and the impact of becoming a kinship carer on their identity.

Section 7.5 presents results within the theme of working with the local authority. This section presents findings on the way in which kinship carers and the LA work together in pursuit of positive outcomes.

Finally, section 7.6 focusses on the theme of Special Guardianship Orders (SGOs). Here, the experience of the permanency planning process for kinship carers, social workers and the young people is reported. Furthermore, factors that motivate and deter carers in pursuing an SGO are presented. 


\subsection{Benefits of kinship care}

Introduction

Analysis of interview and focus group transcripts uncovered a number of perceived benefits attributed to kinship placements. The majority of these relate to the relative wellbeing of young people in kinship care including the positive sense of identity and the socially reinforced attachments that kinship care may afford. Mainstream foster care was naturally the main point of comparison for carers, young people and social workers alike. This proved helpful in identifying where the strengths and weaknesses of kinship care may lie.

The nature of kinship care meant that the history between a young person and a carer was often shared. This section will begin by examining how the transmission of family history via anecdotes within the confines of a family-based placement compares to the narrative of life-story work prevalent in mainstream placements. It will also look at how this shared history shapes a young person's identity and the implications of being LAC in a kinship placement on the child's wellbeing and peer interaction and attachment.

The family was identified as a key subtheme for all participant groups. This section seeks to understand how family is defined in the context of kinship care and how this interacts with identity and thus the wellbeing of young people. It will evaluate the seemingly conflicting views that emphasise either genetic or social ties as the basis for family.

Finally, the subthemes of normality and equality will be discussed in relation to kinship placements. These were deemed by kinship carers and social workers to be important factors in ensuring a kinship placement was successful. The extent to which these outcomes are achievable and the limitations of doing so for LAC young people will be examined. 
Identity: Shared history

Social workers commonly identified the benefits of shared history between kinship carers and the young people in their care.

"The kinship carer [is] a family friend, so she actually knows what YP's gone through rather than reading it [from case notes]... she knows the history of the family, she's got first-hand experience" (SW121)

"It's just knowing the family, it's just knowing the background more, you know, actually living through the background, not just writing on a bit of paper... she knows the family, she knows the background of what YP's been through without even reading it on paper." (SW121)

Mainstream foster carers are provided with some limited information about the background of the child and family. This, alongside life story work with a social worker, provides the basis for a looked after child's understanding of their family history. By contrast, social workers identified that in kinship care, the carer has a broader understanding of the child's history and need not refer to a document in order to uncover information.

The benefits of shared ties with the young person are not limited to a historical context. Kinship carers are privy to information that may benefit the young people and which may not necessarily be available to mainstream foster carers. One social worker discussed this knowledge and its advantages for young people in kinship care.

"They might have an estranged relationship with his dad, and with his mum, but they know what's happened all these years, they know where mum is, what's happening with dad because they hear it through friends, families, they know what's happening and I think mainstream foster carers wouldn't know that, so for YP just knowing who he is, where he comes from, about his mum, his dad, I think for any child that's nice to know about you know, their families and them." (SW116)

In addition to the higher levels of knowledge that kinship carers have about the children's past, social workers also noted a difference in regards to the way in which this knowledge is passed on. Specifically, some social workers felt there was less need to perform specific life story work with the children as they 
understood their background through day-to-day interaction and narrative from their carer.

"She knows so much about her background, I haven't had to do any official life story work with her, she knows it all" (SW127)

Furthermore, even when life story work is undertaken in kinship care there are advantages to carers' knowledge and ability to participate in the work.

"They've been there though the journey and I think mainstream foster carers wouldn't be able to provide that life story when it needs to be done you know, as he grows older you're going to have to clarify things a lot more based on things that he will be able to understand and mainstream foster carers can be told about it by Social Services... but... mainstream foster carers wouldn't know the details and that's part of their identity, and I think kinship carers they know all of that." (SW116)

Kinship carers also noted that this shared history may be advantageous to looked after children. Some discussed the ways in which they passed on the child's history and identity through anecdotes. This was seen to be a more natural way of passing down the child's family history. Rather than a formal in-care process, it was deemed to be more similar to the experience of children who live with their birth parents.

"At one time we took a lot of photos and we're showing them the photos of when [their dad] was young and things like that... what school he went to and things like that 'cos he went to the same school up by here, same school." (KC 113)

"They're just with people who... look like them, or they look like you don't they? They do thinks like you, you know, they... the photographs around, the history around the house, the fact that they're in the home with you and they learn about their family... We talk about my mother and father, we talk about my husband's mother and father, you know, they've still got a little history there haven't they? That's what I think." (KC117)

Shared history with kinship carers was also identified as an advantage over mainstream foster care by some young people. The knowledge that kinship carers have about the child's history proved beneficial to the young people on two levels. Firstly, they felt that they needed to explain the history less, as the carers knew the historical narrative of the children's past. 
"Because you get the love from family members you can... they know what's happened" (YP125)

Secondly, the young people felt that the carers would have a greater understanding of their problems due to the historical knowledge that kinship carers have. This would provide a greater level of empathy with any difficulties that the young person may have.

"If I was trying to say problems... they wouldn't really understand because my family would know more but [foster carers] would just know that I've had to come live with them maybe. (YP125)

Identity: Peer relations

Young people did not only value a shared history with carers but also found that similarities between their own history and peers' proved advantageous for peer relationships.

"Some people who have parents who are together or they live with parents they, they don't really know what it's like to have a trouble with parents so they won't know what it's like not to live with parents perhaps? And I feel somebody... who doesn't live with their parents or their parents have split up, they will understand my problems better." (YP125)

One of the key aspects of a child's life story is the impact that their understanding can have on the development of identity. By being brought up by kin rather than strangers, the children were thought to be able to develop a positive sense of self and construct an identity. In contrast with children and young people in mainstream foster care, this identity often does not include identifying as a looked after child. This was recognised by a number of social workers.

"That's the other thing you hear from our kinship carers and children that are there that they don't feel like they're looked after children, "I'm not a Looked After Child, I just live with my nan," (focus group)

"As far as their identity's concerned their narrative is not one of a looked after child, they don't see themselves as looked after children, they see themselves as living in the family and they're being brought up the same 
as any other child. So their identity has not been affected because they're in that family context." (SW103)

Social workers identify this sense of normality as being important for the children and relatively unique to kinship care placements. In a similar way, kinship carers do not identify as foster carers to the children, but see their role and attachment to be one of family. When asked whether the carer identified as family or a foster carer, the unanimous response was the former.

"I mean, I don't look upon myself as a carer for him, it's just our grandson living with us." (KC131)

Those who do identify as LAC, such as those in mainstream foster care, are often stigmatised for being LAC. Social workers identified the impact that being stigmatised for their LAC status can have on young people in care.

"It's the stigma that sits with LAC children isn't it, you know? No matter what we do to try and make it better for Looked After Children, the fact is, is that they're in care, you know, and there is a stigma that's carried with that and I don't think, no matter what we do, I don't think you can really shake that." (SW110)

"The children struggle with being looked-after, they don't want to be different to anybody else in their class, they don't want to have social services visiting so I think it's in terms of the stability for them and not having to engage with any workers coming in and out, it provides them with normality really." (SW113)

In this way, kinship care is a protective factor for young people who are looked after. There seems to be a sense of inherent 'normality' about the arrangement that is not achievable in a foster care placement. However, whilst the young people themselves may not have identified themselves as looked after, their interaction with social workers and the limitations of their legal status still impacted on their day-to-day living.

"When I'm with my friends I can't... like go over theirs or... go places cos I need the social worker's permission, but then if they so no... [for example] I wanted to go camping with my friends but we had to say no because we're young and social workers would probably say no because it's... young kids camping alone. But then all of my friends got to go because 
they don't like have social workers so they only have to ask their parents. But... then I couldn't go." (YP105)

Whilst some found being looked after limiting, for the most part, carers and young people did not find that their status affected the way that they lived. This was in part due to the relatively high levels of autonomy afforded to kinship carers, particularly those in a long-term placement. However, for many of the young people, social workers had long been a part of their lives and so the system within which they operated was the only one they knew.

"The youngest thought everybody had a social worker. Cos they'd been in her life since she's been born and she thought... and nobody had thought to explain it to her. So they did do it, not so long ago." (KC107)

Whilst for the most part the young people may not have internalised being LAC as a part of their identity, they showed an awareness of how being looked after may make them different from their peers. Some were fairly open about being looked after, especially with regards to teachers.

"No I think in two lessons, my Welsh lesson and my English lesson we had to write a self-portrait and in them I said that I didn't live with my parents and why and I was quite happy to let the teachers know." (YP125)

Even where they were fairly open about their living situation, young people tended to restrict sharing details of their past to a few close friends. These friends acted as confidantes for the young people and sharing information with them became a source of comfort.

"I don't want to share with everyone. Like, what has happened in my past but I will with really close friends and people I'm close to." (YP127)

"I quite like it because like, if I'm worried then she knows what's happened and stuff. And [when] I see my mum then she knows straight away that I'm crying about my mum." (YP123)

However, carers expressed concern over the level of intrusion inflicted on the children in school by social workers. Some felt that by visiting the young people during school hours, social workers were removing the young person's choice as to whether they disclosed being looked after to their peers. As such they felt that the young people were having the identity of being looked after forced upon them. 
"It's not only that, it's the stigma. You know? Like they go into school and it's intrusive for the kids and they got to explain to their friends why have you gotta do that then" (KC103)

"He's like being pulled out of class isn't he to go to these prep meetings with social workers and things like that, he doesn't like it, he's craving to be a normal child." (KC116)

For some young people, living in kinship care was accepted by peers and they did not feel any different from them. In these cases, even the LAC status was not an issue as they did not identify as such.

"They say it's fine cos it's just the same as them really. They're living in a street like me. So yeah it's just the same and they don't say anything about it." (YP117)

Equally, whilst most of the young people stated that being LAC had not caused them any trouble with peers, a few identified how their LAC status had impacted upon their social life. In some cases they were targeted by peers leading to emotional distress, in others such targeting led to anger and violent responses which in turn led to the young person being disciplined.

"She do come home from school sometimes saying she's been bullied in school and said er why are you with your granny, your mother and father don't love you. [I said] you go back and tell them, erm, tell them they do love you, but things haven't worked out like they should. You know, there's no need to say what's happened or nothing." (KC105)

"Somebody said... go be a tramp like him... I said I'm not a tramp I live in a house and he said no you don't you live up the park in a bush and you have to check on your mother every two hours. And I got upset and I pushed him and I hit him." (YP125)

Carers themselves showed an awareness of the stigmatising nature of being LAC and played a part in minimising the disruption for the young person. This could often mean trying to avoid interacting with social workers except when absolutely necessary. This provided a sense of normality in day-to-day living.

"I very rare bother them, erm... if there's something wrong I would bother them, but if I can do it myself I do. Because I find the less, although they're in social, the less they get involved with the social [the less] they feel they're different to other children" (KC105) 
Identity: Family Identity

Rather than promote the identity of being a looked after child, kinship carers seemed to prefer to focus on the child's identity within the family. For many, it was about being a part of something bigger and part of a unit. In some cases, even the physical likeness between the young person and other family members was felt as a positive factor for promoting identity.

"I think he identifies with them, you know, he's part of something you know what I mean he looks like his cousin which is quite freaky actually, and they're half-cousins as well but actually l'll be damned if, they look like each other, and yeah they go to the same school, they're in the same community, it works and it's nice." (SW101)

Whilst kinship care has the advantage of providing the context within which a child can develop their identity, this is not always a positive influence. One social worker identified a case where they felt the young person's identity was being damaged by the carer. In this case there was a history of domestic violence and the carer was found to be comparing the characteristics of the young person with the negative characteristics of family members.

"But gran was a victim [of domestic violence] from [two of YP's relatives], now gran is telling YP he's turning out the same way which is the worst bloody thing you could possibly do, but to gran she thinks it's genetics... I don't know what the research suggests or indicates in relationships but I do know it's not giving him a positive identity, he knows his [relatives] ...of that family... so association with that to YP is just going to reinforce that he's a waste of space, that he is becoming what he should never have, that they are ostracising him and this is a problem... just because of what gran is doing, she's conjuring up this negative image which I just don't think it helps." (SW101)

This case highlights that whilst kinship care and the knowledge of a kinship carer can promote a positive sense of identity, where the carer has suffered a history of trauma the identity promoted can be negative.

In spite of this, the conceptual identity of family endured in all of the placements. Social workers in particular focussed on why the concept of family is so important in social work practice. Some reflected on how family and kinship was important 
at an individual developmental level and how it functions as the basis of our identity and support network.

"In general in society, well I think for most of us it's kind of, it's just the foundation of everything isn't it... what we place value on and how we regard ourselves and it's just so linked to who we are in early childhood [and] as we... grow up really, it's just massively important." (SW127)

Some carers also discussed family as a sociological concept rather than a biologically driven need. For many, the values of community and kinship seemed to trigger nostalgia and were a source of pride as they spoke about the patterns of behaviour that they had been brought up to believe in.

"I used to live in another part of town and it was a community and the people they were like big families, 12, 15 in the family and they all lived in these terraced houses. But they all lived together; they all looked out for each other." (KC130)

Such values were seen as historic and decaying from a morally superior past. They often described their belief in caring for family as unusual in contemporary society. As such it gave a sense of pride that their own belief system had protected their family unit from the erosion of social norms that existed in the modern world.

"It's old fashioned values. As I tried to say before, it's very old fashioned values. In years gone by family looked after family. Well we have been brought up with families who still believe in that." (KC130)

"It's always been important to me... whatever's gone on in my life it's always family first. You know, always. You know I looked after my mother... for ten years. It's just always been the natural thing to do isn't it? For me... I couldn't have seen her go into a home or I couldn't have seen these two go into a home, I just couldn't." (KC107)

But whilst some felt that kinship was based on social and emotional ties, others focused on a genetic or biological need for family. They reflected more on family and kinship as an innate altruism specific to family. The need to connect was attributed more to an instinctive pattern than to a socialised behaviour.

"Human beings, we just naturally want to be part of... you know, it's like a pack instinct. We want to be part of a family so whether that be your own 
birth family or just to fit into somewhere. That's a part of human nature I think." (SW111)

This was reinforced by anecdotal evidence from a case where one young person had experienced kinship care with both a genetic and non-genetic carer. In this case, the blood connection to carer was identified as an important factor in the young person being able to settle in placement.

"For YP, it's being with her family, with the biological family [that] is very important for her, you know. Although she was very well looked after with her sister's gran, she wasn't biologically connected... She found that hard... I think, and that's why she walked." (SW110)

The biological identification of kin was not restricted to carers and young people. Social workers spoke about cases where family and friend carers often had no emotional tie to the young people. In these cases the biological tie was deemed to be sufficient to classify a carer as kin. In one extreme example, a kinship carer was granted an SGO on a family and friends basis despite never having met the children in question. Instead, identification of kinship came through a DNA test that established paternity.

"So if you talk about bonding, what we were talking about earlier about this nature thing, nature, that isn't natural 'cos she didn't even know she was gran, the kids didn't even know she was gran, there's no nature there, so you're placing within the family but equally... Why is she family? Because DNA has proved it." (Supervising social worker)

Whilst it was relatively uncommon for the carers to not know of the young person at all, many reported having no relationship with them prior to them moving in. In some cases this gap was bridged in supervised contact sessions allowing the carer and young person to establish some form of rapport. In such cases this period tended to be short with only a few brief meetings.

"We met him in the March and then he came to live with us in the August." (KC131)

In other cases, however, the first time they met the child was as they arrived on their doorstep following a crisis.

"We hadn't met him before and they brought him here." (KC116) 
Where a pre-existing relationship did not exist, carers reported some resentment towards their treatment from social services. Kinship care was perceived as being beneficial for the service whilst being detrimental for both the carer and the young person. This included not receiving allowances that would be afforded to young people in mainstream foster care.

"I said yes, but they would only do it on friends and family, I said but I'm not friends and family... you know, I said, I didn't even know them before. But they said, well... that's the only basis we're prepared to do it on and I said fine. Whatever. And erm... so they did but I then didn't realise that that meant that she would actually be at a disadvantage, because of the classification. So, the plan now is to make me into a mainstream carer... at which point she will get the additional allowances that all the other children get..." (KC109)

\section{Attachment in kinship care}

In many of the cases where the carer was a family friend rather than a blood relative, the social relationship was the foundation of a strong placement. In one case the emotional ties to the children led to the carer being asked to step forward for caring responsibilities.

"I used to be their next door neighbour and they were neglected so the school phoned social services and social services got involved and I agreed to keep the four for two weeks until they found somewhere else because they were going to split them all up. Basically then the social worker kept asking me if I'd keep the girls because they already knew me and I had a good relationship with them. And I ended up being assessed for the girls and my friend was assessed for the boys and we lived on the same street." (KC121)

Carers' emotional tie to the child was often cited as a motivating factor for taking on the caring responsibilities. In particular, carers' empathy with the child stood out and their ability to visualise the effect it would have on them.

"As I said I could have walked. But the thought of him in that school and social workers gonna pick him up and take him, "ooft", dreadful thought. It would have finished him, most definitely." (KC111) 
In some cases there was a sense that prior to formal care, the carer had already played a key role in the child's upbringing. This had the dual effect of motivating a desire to continue caring and of a strong emotional attachment already being formed.

"I had gotten really close to both of them and we'd had them. I mean, you know, we'd really brought them up." (KC117)

This familial bond that carers felt with the young people seemed to be advantageous for the young people. Even where there was no genetic link, there was a sense of ownership from the carers. They spoke about their connection with the young person as a familial connection and demonstrated a desire to provide a good childhood for the young person.

"He does tend to have a bit more than he should have but he's family isn't it and you'll do it for your family." (KC129)

In most cases this commitment was not planned as a short-term intervention; rather carers talked of an on-going commitment to the young person into independence and beyond. There was a sense of permanency to the placements that extended beyond legal definitions and processes.

"Well she's mine isn't she? No l'm hoping, you know l'm going to be the one that's there when she has her first child, when she gets married, when she sets up home, I'm always going to be there. But I don't know if that would be the same if it wasn't a friends and family carer, do you know what I mean? Cos obviously other foster carers have children coming and going, don't they? And some see it as just a job, I couldn't do that. Like when the kids are eighteen they're on their own? I couldn't do that." (KC121)

Both carers and social workers also identified the lack of transition for young people as an advantage of kinship care. Whilst some young people moved in with carers during a crisis, in many cases the carers had already been providing a level of support to the birth parents including childcare. One grandmother carer had lived with the children and birth mother for a year prior to becoming a formal carer.

"I lived with them for about a year, I didn't know how... to try and... get her back on track. It obviously didn't work. And then... one Christmas, she just... I think it was... the day we started back after the Christmas holidays, 
she just upped and went. And we didn't see her. So then it was decided to take... the children came to live with me." (KC107)

Whilst the children were required to move house in order to enter placement, their familiarity with the carer and the boundaries that were put in place made the transition less traumatic. Similarly, the carer's familiarity with the children's preferences and routine made the adjustments less stressful. Similarly, social workers recognised the value of this pre-existing relationship in establishing a secure placement.

"I think the attachment, if you've got the attachment there already, you know, why would we disrupt that to start everything all over again with, you know, they're strangers, foster carers are going to be strangers and these are people that have been familiar to them from birth." (SW105)

Social workers often compared this attachment to cases where family members had not come forward and the impact that it had on the young people involved. In such cases, the emotional effects were evident and seemed to have a powerful impact upon the young person and their sense of self. These cases highlighted the importance of the family unit both as a physical representation and as a social construct. In particular there was the sense of belonging to something and feeling wanted. Social workers found that in kinship care those feelings were present in a way that they were not in mainstream foster care, particularly where family seemed to reject them.

"The two younger boys, their fathers took them. The youngest daughter, no one in the family came forward, and she was so angry that she wasn't with a family member, you know, the fact that she ended up in a foster placement just broke her heart... But she carried that, and she will probably carry it for life, the fact that her younger two brothers, family members came forward and no one came forward for her." (SW109)

"It's the feeling, I think, that, I know I've got a few of my care leavers now, a feeling that no one wanted them, no one cared. I've got one girl I can think of, she's 18, she is so angry, absolutely, and she carries this anger with her everywhere, every conversation I have with her, it will come up, the fact that no one wanted her, and that's when, she'd gone, I think, and I think Mother used to just leave her with various people before this department became aware of her, and when she came into care, the fact that no one contacted, no one asked for contact with her, no one sent a birthday present, say from her family, no one rang to see how she was, 
there were no Christmas cards, no birthday cards, no letters, nothing, and that is so hurtful." (SW109)

Identifying as family had further implications. Carers were eager to promote equality in their treatment of the young people and made no differentiation between the LAC and non-LAC children in their home. Interestingly, equality did not feature as a theme in interviews with the young people. In some respects, this may be seen as a measure of the carers' success. Carers seemed to feel that their ability to achieve equality was partially due to the type of placement. Comparing to mainstream care, one carer said:

"If they're also living in mainstream carers with other children with issues, they're going from a similar situation where they're fighting for attention. Whereas they come into ours, our two don't have any issues or trauma so they don't, so they've been able to come in and be part of the family and feel exactly the same as my two. There's no differentiation. You're all the same. You get the same for your birthdays and everything, you know." (KC112)

For this carer, as with many, treating all of the children in placement equally was a key factor in promoting a positive attachment. This was particularly key as the carers had their own children living with them and for the most part they felt that they were successful in achieving this integration. For others, particularly grandparent carers, achieving equality for the young people became a balancing act. In some cases, carers felt they were able to treat the young people in their care and other grandchildren equally.

"I've got seven grandchildren as well, besides these but they're all, you know, we care for them all the same way. Yeah." (KC114)

In other cases carers found that their involvement and attachment with the young people differed from their other grandchildren who were not in placement and created a role confusion.

"Sometimes you feel as if it has [affected my relationships] because... like my granddaughter who I took away this year because YP wasn't going [with us]. And you feel like you're more distant to her than what I am to [the grandchildren who are] living here. And I think there is a bit of a distance. I don't know why I felt that, I dunno." (KC113) 
This sometimes led to young people themselves promoting an agenda of inequality, albeit in favour of themselves. One young person in particular seemed to feel a greater sense of ownership and entitlement than his cousins who lived with birth parents.

"He'll tell my other grandchildren that this is his house and I say no, well really, when you think about it they've got the same right to be here as you... but he's says no because I live here, it's my house. There is that little bit of a difference and I think the other grandchildren have seen a bit of difference that he gets more... than they do. Because he's living here you know, and he just does what he likes. And as he says this is his home and that's the end of it." (KC129)

Whilst the young people may find this distinction beneficial, for carers and other family members it can cause conflict. Younger family members may be left confused as to why a young person is being treated preferentially by grandparents. Carers themselves may feel conflicted in their loyalty to the young person as their primary caregiver whilst maintaining the role of grandparent in the eyes of relatives. Despite these difficulties, carers aspire to create an environment of equality for young people in their care and for the most part seem to achieve the balance well.

Wellbeing: Normality

On a par with equality was the desire for normal family life. Normality for the young people was discussed by a number of carers as a placement goal.

"I don't let it impact on our family life. They er... we're a family and we do what other families do. And I think the social services knows that now." (KC103)

“You know what it's like, you can't make them aware... you don't make them aware... it's not their fault is it? So you've got to try and be as normal as possible with them." (KC120) 
Carers seemed keen to ensure that children did not feel looked after, but rather felt as though they were part of normal family life. Children themselves noted that they had a sense of normality in kinship care such as the young person below.

"I feel normal with my family. Cos they're they ol- they're the weird ones out of us, me. So, I feel much like, it would be weird in the middle of town I'd know I'm not the other weird one. There's more of me." (YP101)

But whilst normality was aspired to, carers identified a number of factors limiting their ability to provide a normal environment. One of the barriers to achieving normality was social services intervention, particularly in schools. Deferring to social workers for decisions or attending meetings was deemed by carers as a barrier to the normal family life that the children wished for.

"I did have an issue with a few of the rules because I felt that, you know like I had to have permission for him to do certain things in school and he would say to me, oh god you haven't got to ask for permission for this again now have you? Because he was feeling different to everybody else in the school." (KC129)

"He's like being pulled out of class isn't he to go to these prep meetings with social workers and things like that, he doesn't like it, he's craving to be a normal child." (KC116)

For some carers, social services intervention seemed nonsensical in the context of family and friends. Training, often administered to both mainstream and kinship carers simultaneously, had elements that carers felt were overreaching. One such element related to physical contact with the child. Carers are encouraged to avoid physical contact with young people as a self-protective measure, however where there was a pre-existing relationship, carers found this challenging. For the most part, however, carers seemed to ignore the stringent nature of the rules and continue to care for the children as they had prior to formal care. They felt that this provided an element of normality for the young people.

"You're given the T\&Cs and whatnot, but ultimately you can't suddenly stop hugging them when you've hugged them for all their lives and they're used to it. And how can you hug... how can I hug my two and not hug them, so yeah. It is quite scary the stringent things that are out there, and I understand, however it is quite scary the difference. And I couldn't imagine not being able to give them a hug. So knowing that, I don't think I could be 
a mainstream carer for that reason because I'm quite nurture and tactile and so I know that I would struggle with that, with that aspect." (KC112)

"He's our grandchild and that is it. If we want to give him a cuddle, we'd give him a cuddle. Simple as that." (KC131)

It was not simply the desire to continue hugging the child that was marked as different to mainstream. In two cases carers mentioned the child in their care sleeping in the carer's bed. The history in these cases was of substance misuse and neglect and so the children found a great deal of comfort in being close to the carer and being able to check on their wellbeing during the night. In a mainstream placement this would have been forbidden but, whilst discouraged, it was permitted in kinship care. The children had their own beds available and carers stated that they were encouraging the children to sleep alone under guidance of their social workers. In the meantime the ability of a kinship carer to provide a nurturing environment in line with the child's need was seen as important for the child's development and wellbeing.

Whilst ignoring guidance tended to be in the best interests of the child, such as providing a more tactile style of care, this could extend out to less beneficial behaviours.

\section{Summary}

The shared history of kinship carers and looked after young people was identified as a positive aspect by all participant groups. Whilst there was some risk that carers could use their knowledge of the family history to reinforce a negative identity for the young person, this risk was deemed minimal. The methods of transmitting the child's history was deemed to be a more natural route with social workers placing an emphasis on the benefits of anecdotal history. Furthermore, young people placed value on their carer's innate knowledge and the lessened need, therefore, to describe their past to carers in order to gain understanding. 
Being part of a kinship unit was perceived to be beneficial in developing a positive sense of identity. The young people expressed that they do not identify as LAC, a sentiment echoed by social workers and kinship carers. This seemed to provide an element of protection from the stigma of being LAC, although in a small number of cases young people cited being victimised by peers. Moreover, whilst not a dominant aspect of their identity, the continued interaction with social services meant that young people could not escape the identity of LAC entirely.

Interviews with social workers and carers in particular seem to suggest that the family as a structure still plays an important function in society. In this respect, identity extended beyond individuals and identity as a family group was important. However, there seems to be disparity in how family is defined; not only between the groups, but also on an individual level. Whilst some unrelated carers took on young people that they knew and cared for as their own, others defined their relationship by genetic affiliation. This variation in the definition of kinship may have implications in its applications with some limited evidence to indicate that placements are occasionally classified as kinship inappropriately and to the detriment of carers and young people. In general, however, the family unit was regarded in a positive light and beneficial for the wellbeing of young people.

Kinship carers aspired to equality in placement. This was especially the case if other young people, such as their own biological children, were still residing in the family home. However, whilst treating all of the young people equally was simple in principle, it posed a number of challenges for some carers. This was especially the case for grandparent carers who wished to treat all of their grandchildren equally whilst also providing a parenting role for the young people who resided with them.

Carers aspire to provide a normal family environment for children and are relatively successful in doing so. Children report feeling normal when living with family carers. Crucially, through carers aspiring to normality, the young people described good attachments to both carers and to their peers whom they felt treated them without prejudice. However, in order to provide this normality, kinship carers are allowed a greater degree of leniency regarding guidelines than mainstream carers. Whilst this leniency tends to be in the interests of the child 
7.1 Benefits of kinship care

and provide some benefit, it may also lead to behaviours that can be detrimental to the young people. Furthermore, a discourse between the normality of family life and the nature of being 'looked after' pervades. 
7.2 Motivation to care 
7.2: Motivation to care

Introduction

During interviews, kinship carers spoke about their motivations for providing care. This section will address these motivations, first addressing the perceptions of mainstream carers and how these perceptions drove kinship carers to action in order to protect the wellbeing of the young people. In doing so, kinship carers' perceptions of themselves will also be discussed.

Secondly, the concepts of stability and permanency will be examined including the value placed upon each by carers and social workers. This section will also look at the qualitative evidence supporting the positive impact that stability has on young people and their sense of self.

Finally, the notion of family will be explored in relation to how carers and young people identify, how they are identified by others, and the effect that this identity has on their decision to provide care. 
Love of family: professional care

The professionalisation of mainstream foster care led to kinship carers identifying as quite different to their mainstream counterparts. In particular kinship carers felt that the motivations for caring for children differed.

"I think [foster carers] do it for the money, not for love." (KC121)

"They're loved and we do it, not for money or anything, we do it for them. And the money does help for us to give them a bit of a better life but we do care and l'd say l've known people who have fostered and when they're 18 they're gone. And I know that has happened-we wouldn't do that. And we do care about them there's a difference." (KC114)

Some carers noted that unlike mainstream foster carers, kinship carers did not choose to become carers autonomously but rather through necessity.

"A mainstream foster carer is a short term care for a child or a baby. It's a job for them. This isn't a job; we've done this because he's family. You know, let's be honest about it. I think we wouldn't look at fostering or adoption or anything else unless we had to and we had to. We're family." (KC131)

Such comments were not uncommon and kinship carers seemed to feel as though their motivations for caring were purer than mainstream foster care. There seemed to be an element of resentment towards professional carers, although such statements were often qualified with comments regarding the good care that some mainstream carers provide. For example, the carer below drew a distinction between the care that mainstream and kinship carers provide and, whilst respectful, seem to believe that kinship care can provide a level of commitment that mainstream carers cannot.

"I mean foster carers, they do an amazing job in the mainstream, they really do. But it's not like being with your own family is it?" (KC131) 
It was not just kinship carers who had felt the differentiation between mainstream carers and kinship carers. Social workers noted the difference in motivations and in the way in which the role is marketed by local authorities.

'in foster carers' defence it clearly is a job and we in our own way we sort of tie it around, band it around as a job, you know, just take a respite, just give it all I can, if there's a problem l'll take respite the trouble is whilst it might be great for them it might not be good for the child" (SW101)

There was some concern that the professionalisation of mainstream foster care may impact upon the child's sense of purpose and wellbeing. One of the supervising social workers noted that children in mainstream care recognise that carers are professionals fulfilling the requirements of a job.

"When you talk to kids that are in mainstream care, they turn around and they'll tell you, "He's paid, he or she is doing it 'cos they're paid, they don't have to." (Supervising social worker)

Of course, mainstream foster carers may have motivations to becoming a carer aside from financial gain. Whilst they are financially compensated for their duties, the emotional and physical toll of becoming a full time foster carer would suggest that money is not the sole reason that carers pursue that career. Some social workers discussed anecdotes which also seemed to suggest that mainstream carers do create strong and lasting emotional bonds with the children in their care. Despite this, finances were seen by kinship carers as the principal motivator for mainstream carers. It was not necessarily through a lack of contact with mainstream carers that these views were formed. One carer had been in foster care herself many years previously and spoke of how her experience had shaped her views.

"Well, I went to a foster home when I was sixteen and erm... my mother was very ill and we all went, my brother and sisters as well. Cos I was looking after them all but I couldn't keep up with it. And I found, they've got children and, and you're, well it's only natural their children come first. Some homes are very good, but others, I could see it straight away." (KC105) 
Love of family: attachment

The difference between kinship and mainstream carers was attributed to the emotional connection formed between the child and carer. Kinship carers simply did not believe that mainstream foster carers could form the same relationship with the children if they were not related to them. There was a sense that with family, the investment was higher and so the motivation to care for them was also higher.

“You're under no emotional obligation to keep them then are you? You go offer a roof to someone, and if they don't fit in with you, you get somebody else in. You know, it's like renting out the room. With family and friends, it's not renting out a room is it? You're providing a home for them." (KC127)

Following the professionalisation of mainstream foster care there is a perception that mainstream carers are financially motivated. This belief also reverberates down to the children who also show an understanding of the professional nature of foster care. Kinship carers, young people and social workers seem to believe that kinship care provides young people with a sense of being wanted and an emotional connection that is more challenging to replicate in mainstream care.

Stability

Carers also spoke about stability as a motivator for providing care. They seemed to feel that kinship care would be a more stable journey through the care system than mainstream foster care.

"It gives them more stability. In care it's a less stable environment isn't it?" (KC103)

This was a concept that social workers, both supervising and case workers, seemed to concur with. 
"Some foster carers are fantastic, I couldn't praise them enough, and those children in those placements get a lovely placement and I wouldn't see that different to kinship, but then there's others that aren't so fortunate and jump from one pillar to the other and obviously they're at a disadvantage aren't they?" (SW118)

One of the reasons attributed to this was the way in which carers identify. Whilst mainstream foster carers are encouraged to consider their role as a job, kinship carers are encouraged to think of the care they provide as a natural familial role. As such kinship carers do not necessarily consider the child's presence to be a foster placement that can come to an end if necessary but rather a permanent solution to the child's living arrangements.

"There's a lot of instability in terms of foster care, there's other children coming and going, that's not going to happen if you're living with grandmother, we're not going to place other children there, that is their home rather than their placement, they don't see it as a placement whereas the majority of children see, with foster carers, see that as a placement and as foster carers." (SW105)

This was an important distinction, particularly because it was echoed by the young people who felt secure in their placements. Rather than being in the care system and under threat of being moved, they simply regarded themselves as living in their new home with family. This also extended to contingency plans in case of carer infirmity or mortality.

"I feel a lot, as if I don't need to worry about whether I'm moving homes every six months or whether it's for a while and then out of nowhere I'm going. Hopefully, because I live with my family, if something happened to my parents [grandparent carers] now l'd go and live with my auntie or I'd have someone else to support me." (YP129) 
Stability: persistence through hardship

Overall there was a shared perception that kinship care provides a greater sense of stability for the young people. Carers and social workers discussed the underlying reasons. Social workers noted that kinship carers were more persistent in the face of challenging behaviour from the child.

"They're far less likely to give up on a child early on, whereas a professional mainstream carer has to think, no, it's my own health, you know, other placements, other children, my own family, and they're more likely not to ride the really rough parts, they're going to bail out and say, "I've done my best but this kid isn't able to cope with this placement," where a family placement is not going to do that" (Supervising social worker)

Carers themselves noted that the behaviour displayed by the child in their care would likely have caused a mainstream placement to break down. Even when encouraged to break the placement down by their own adult children, kinship carers showed a commitment to the child in their care. Whilst mainstream foster carers may consider another placement for the child, a lack of alternative family placement for the child seemed to be sufficient motivation to persuade carers to persist; as though mainstream foster care were a step too far.

"They might have just been in the care system going from home to home to home because, especially YP, I can't see that any family would have put up with what we've put up with for the last 12 years and that's honest to god. He's a handful. So I think he would have just gone..." (KC130)

"When they were coming here and seeing how he was behaving and how he was speaking to us, our children found it hard, 'mammy just send him back'. You know? But my attitude towards it was where's he gonna go? And social services have agreed that if he had gone from here...now even, there wouldn't be a place, a foster place, no foster parent would put up with the behaviour that what we've put up with." (KC116) 
Stability: attachment

However, it was not just the lack of alternatives that aided the maintenance of a stable placement. Many carers spoke about the attachment they have for the child and the love that they felt for them.

"If you're a family and friends carer then you've got that attachment to the child haven't you? And I don't know if that's a good thing or a bad thing but I think probably with foster carers, if it doesn't work out then move the children." (KC127)

This commitment was also recognised by social workers.

"[They] stick with them through thick and thin no matter what, you know, that's what I think these children need, you do get some... like the odd foster carers who do stick and some of the older ones do give a good go at it, but ultimately despite for the best intentions, however fond they are of them, it's not their... it's not a real member of the family, they don't have to put up with it, they feel like a victim in their own home, so they can just throw in a towel and it's that, it's not that easy for your own child, and that's the difference." (SW101)

In all kinship carers felt that a kinship care placement provides a more stable care journey, a feeling that was shared by social workers. Some carers reported that the desire to provide this stability for the children was a motivating factor in caring, particularly through more challenges times. Furthermore, stability seemed to be attributed to an attachment to the child often linked with the concept of family. Children in kinship care also reported feeling more secure in their placement than they would do in mainstream foster care despite acknowledging the declining health of their aging carers.

Kinship and duty

Whilst each carer had their own reasons for taking in a particular child, a common theme ran through all of the interviews. When asked what had motivated them to 
take on the young people in their care, most indicated a sense of duty or obligation to do so. For the most part this appeared to be an internalised sense representing their own concept of identity. In many cases it was also underpinned by the concept of family. Carers seemed to adopt the ideology that family takes care of one another and that failing to do so would be neglecting ones duty.

"If you had a child and you knew that he was your grandchild and you knew that he was in care, would you ignore your responsibility? We couldn't. (KC131)

"I felt we didn't have a choice. I could never have said no I'm not taking you, he's got to go and live with strangers. I could never have done that you know? ... It's because he's my nephew and I couldn't have lived with myself and slept at night." (KC130)

Social workers also noted that carers often felt that they had no choice in whether they provided care. There was the suggestion that whilst there was no legal or physical obligation to do so, social expectations dictated that kinship carers would adopt the role of carer.

"A professional mainstream carer has come into this role because that's something that they'd like to do, whereas a family and friends carer has had no other choice really in a lot of situations because it's meant that either the child goes with them or they end up in care." (SW115)

The notion of familial obligation extended beyond the carers themselves and impacted on their interactions with the wider community. Such interactions could suggest that the internalised sense of duty could have an external source.

"We went to a meeting up in the centre and it was foster carers and us as well right, and this man said in the room, you should have those children, they're your grandchildren, he said. I said well, you know, why should... he was really thing about it- you've got to do it." (KC114)

In the vast majority of cases, this sense of obligation was directed towards the young person in question. However, one carer stated that it was an obligation towards the child's birth mother that had driven her to provide care. 
"We done it for [my daughter], really speaking. For her to get her act together and not lose her children. But it didn't work that way in the end. I think that's when it became intense as well because you, you are stuck in the middle aren't you?" (KC103)

\section{Summary}

Kinship carers frequently discussed their motivations for providing care. These focussed primarily on the concepts of love, and family, and the desire to protect the wellbeing of both the young person and the family unit. Kinship carers tended to have a negative view of the factors that motivate mainstream foster carers. The majority expressed that whilst professional care was a necessity in society, mainstream foster carers could not provide the love and attachments that kinship care could offer. Both of these factors were deemed to be important in ensuring the wellbeing of the young people.

Stability was also frequently cited as a motivator, with stable placements and attachments commonly believed to be essential to the child's welfare. Once again, kinship carers and social workers expressed the belief that kinship care could offer greater stability to young people, particularly in the face of adverse behaviour and hardship. This had implications for the young people who in turn felt stable in their kinship placement, both in the immediate future and in the longterm. The stability of kinship care was attributed to the attachment between young people and their kinship carer, but also due to kinship carers' internalised perception of duty and obligation, underpinned by the concept of kinship. Whilst an internalised motivator, there is some indication that external factors may interact to reinforce this obligation. 
7.3 Mixed advantages and disadvantages 
7.3: Mixed advantages and disadvantages

Introduction

A number of themes that carers, young people and social workers all discussed, seemed to simultaneously represent advantages and disadvantages of kinship care. Whether a factor was considered advantageous was often situationally dependent, however, in some placements factors were capable of being both advantageous and disadvantageous at the same time. This section will present the themes that were considered such.

Birth family contact was one area where all participant groups expressed some difficulties. In particular, all discussed the benefits of being geographically close to birth parents to facilitate contact, and the ability for carers to supervise and manage contact in a natural setting. However, many also discussed the challenges that this posed for them and the distress experienced by young people who may see their birth parents unexpectedly in the community.

An issue less frequently discussed by carers, although pertinent for those who did discuss it, was the fear of repeating patterns. This section will look at how a carer's experience of struggling with a child who suffered an addiction or illness meant that they were capable of identifying warning signs. Equally, this section will outline the difficulties that such fear has on the carers and their relationship with the young people in their care.

Finally, this section will look at the impact of kinship care on the wider family, recognising that the decision to provide care is often not taken in isolation from the wider family network. The results will present how the wider family, including the birth parent, can either be a strong source of support for the kinship placement, or a disruptive influence.

\section{Attachment: birth parent contact}

Carers and young people referred to birth parent contact outside of formal contact arrangements. This has been termed unarranged or informal contact. In some 
cases, unarranged contact was a positive factor in allowing a degree of normality to the way in which the young people interacted with their parent.

"Interviewer: and is it quite relaxed? She just comes to the house?

YP: yeah I'd normally be on my xbox and she'd come up to see me... it's just normal" (YP126)

In addition to normality, the informal nature of contact empowered young people and allowed them to exercise a degree of control over the contact.

"I just see them when I want to." (YP127)

But whilst having unarranged contact can be positive in some cases, it inevitably leads to problems in other placements. Carers and social workers in particular noted the issues surrounding geographical proximity and unsolicited contact. Where parents lived close to the kinship placement, unarranged contact was simply a hurdle to overcome. For the most part carers had been open to such contact, adapting to the needs of the young person in the situation.

"Sees his mother now and then. She lives at the top of the road see, so I see her on the street and he says "oh look da, there's mammy" I stop he has his two minutes and that's it." (KC111)

In others, unarranged contact seemed to undermine formal contact arrangements, which were ordinarily supervised. Doing so left the young people vulnerable to influence by the parents with social workers and carers unable to prevent such contact from taking place.

"There's contact going on outside of the allocated slots, especially with the... Mum lives in close proximity to the placement and obviously we don't have much control over where she chooses to live so it's a bit difficult, she knows where they live." (SW113)

Wellbeing of young people: unarranged and informal contact

For some young people, seeing their birth parents unexpectedly in the wider community is a worrying prospect. Speaking of an occasion where they saw their mother in a local shop one young person said: 
"I haven't seen them since I think I was in year seven or year eight at school and we'd seen them by the shops. But I didn't talk to her, I just ran away because I was scared and I didn't know what to do." (YP103)

This reaction was not uncommon amongst the young people. Whether through uncertainty over how they were supposed to act or through fear, a number of the young people had hidden when faced with unarranged contact.

“They've seen her in town and they've just hid. And l've just said no, no if she comes on to them and they're with me, I might say well you can speak to her, you're with me. Doesn't matter, the older one is just bitter I think." (KC114)

Other young people, particularly those who were older, showed great resilience in dealing with unarranged contact.

"She's totally sort of secure in her decision not to see mum, not to speak to her, and she's stuck by that decision, and it must be difficult for her because they still live in the same town, you know, and it's a small, little town, it's more of a village than a town. So she will see her now and again and she doesn't acknowledge her at all." (SW109)

It is not only unarranged contact that can cause difficulties in kinship care, but also informal contact. Where carers, for example grandparent carers, are torn between their own children and their grandchildren they may choose to disregard a formal contact plan. In some cases, the carers and birth parents were initiating contact outside of the contact arrangements.

"There's that possibility where families collude with their children, the parents of the child, you know, which doesn't help that child." (SW120)

"There was a period, Mum is not meant to be at the house when the children are there but I took YP out to do some direct work and I said about the contact after this incident and I said "Well, you know, if you told me what was worrying you then perhaps I could help, I might not be, but I'll try to help you", and she said "Well you said that before but mummy still comes to the house and she's not meant to". So I addressed that with the carer and she told the children obviously don't say that mummy's coming to the house." (SW105)

"Gran likes contacts whenever she wants, you know, we go in and we have these family meetings and we say, "Look, this is what contact is going to look like, this is what's best for the children," she goes, "Yeah yeah yeah," then posts on Facebook that mum has got the kids down Tesco's robbing and you're like, grrr." (SSW) 
"I've had carers who keep to all the arrangements and then, "For god's sake, it's Christmas, I can't leave my daughter on the doorstep and she's got to see them and give them presents," and there's no kind of thought about the kids." (SSW)

Whilst this represented a minority of cases, a number of social workers cited informal contact as a major concern in kinship cases. Whether this is due to a widespread problem of informal contact or simply due to the inherent risks that such contact may bring is unclear.

Whilst social workers were critical of kinship carers undermining the contact plan, many showed insight into the challenges faced by kinship carers. As one supervising social worker explained, kinship carers may be emotional exploited by the birth parents.

"The parents going, "Oh I know they said once a month but if I pop over for an hour I won't tell anyone," and it's just pressure, the emotional pressure on the carer is massive." (SSW)

This pressure on carers is further reinforced by the repercussions if they refuse informal contact. The negative effects can extend beyond their own relationship with the birth parent and create a rift in the extended family.

"They can't see past, "Well my mum's stopping me seeing my child when I want to," and it does, it causes arguments, and we get a lot of PPD1s then from police, so and so has turned up drunk knocking the door, I want to see my child, and they've got to call the police which then causes further problems 'cos they drag other family members in, "My mother phoned the police on me," and they've dragged them into it so then it becomes a massive family argument." (SSW)

The issues surrounding unarranged contact also seem to be exacerbated by social media. The widespread access of young people to social networking sites makes policing contact challenging. This was especially noticeable in households where the carers were older or less technologically aware.

"We just felt it was in the best interests if we put these sort of like boundaries in place, however mum and YP decided they weren't going to have this because of like you say modern technology they're able to communicate and YP being YP I suppose decided she would set her own agenda, and would tell her carer she was off to friends and mum would be waiting around the corner." (SW102) 
Social workers did, however, show an awareness of the effect of social media on contact. This reflected in the way in which contact was managed and the extent to which they expected to control or supervise contact.

"I've come into the case about three, four years ago and they'd already established that kind of phone and social networking contact. They're teenagers as well, they will have access to the internet and it's difficult for the grandparents to supervise that so it's about more supporting them around any issues that might come up rather than kind of putting a block on it I think." (SW113)

"In terms of what's being said between them, that's being said outside of contact anyway in terms of phone contact, Facebook contact or any other sites that they might use so I don't feel like I need to manage what's being said" (SW113)

Wellbeing: repeating patterns

Some kinship carers expressed concern that the young people in their care would follow a similar path to their birth parents. Often this route involved substance misuse. In one case, this fear had been realised by one of the young people they had previously cared for.

"He's got himself into trouble and on the same drugs scene and all the rest of it that the parents are on and I don't know. I mean, I still keep in touch with him and I still go and take food parcels up to him every now and again, take him for a McDonald's don't we?" (KC127)

The carers seemed keen to continue to provide support where they could, but were limited by the nature of the young person's habits and by the continued care of another child. In other cases, the fear of the young person repeating the parental pattern was a cause of anxiety. Having gone through the difficulties associated with their own child's addiction, carers noted the impact that going through it a second time could have.

"She's gone down that road where her mother went down the wrong road and she's sixteen now and she's doing something now, we keep saying to her... sixteen you know, he was more concerned about her because it's coming up to that age, what his daughter done at sixteen. And we were going down a slippery little slope with her at the time, last year... he was 
beside himself thinking she was going to go that way after all this time. But luckily she's saddled back up." (KC114)

As a consequence of such behaviour, carers were often quick to seek advice and intervention from social workers. They seemed happy to take on recommendations and sought to identify troublesome behaviour at an early stage. In some respects, this ability to recognise patterns of deviant behaviour through experience may have been a positive factor in successful intervention. However, experience is not always a positive factor, especially where there are elements of trauma linked to the past. In some cases the ability to recognise some behaviour as a gateway to more severe action could impact upon the carer's relationship with the young person.

One such case involved a grandmother who had herself been the victim of domestic violence (DV). As such, aggressive outbursts were not treated as a teenager getting out of control but as a behavioural trait passed down through genetics. As the social worker explained, this affected the young person's ability to form a positive identity and may reinforce the violent behaviour.

"Gran making this bloody stupid association between his family, it's not stupid for gran but gran was a victim from YP's granddad and from YP's mother, now gran is telling YP he's turning out the same way which is the worst bloody thing you could possibly do, but to gran she thinks it's genetics." (SW101)

"It does worry me he's going to go down a DV path here. Not because of bloody gran, not because of his mother or father... but just because of what gran is doing, she's conjuring up this negative image which I just don't think it helps." (SW101)

Whilst carers were concerned about the potential for previous patterns to repeat themselves, social workers seemed less concerned by the possibility. Aside from the support from social services, carers' own experience and the effect of time was seen as a protective factor.

"what have they learnt from parenting that hasn't played out with the mother, is that different and is it changed, and it is, just experience looking at that, 20 years' experience, so many years gone by will make a difference to your parenting." (SSW) 
Family: shared labour

One of the strategies used by carers to prevent the cycle of substance misuse was to involve the birth parents in the child's upbringing. Where the young person and carer had a positive relationship with the birth parents, their support could be useful in providing advice to the young person and as backing to the carer.

"To be able to text her or phone her or something like that is a good way of trying to solve a problem and not putting it all on ourselves and not putting it all on the social workers but getting a little bit from her to do the right thing." (KC113)

Not all of the support provided by birth parents was emotional; some remained involved in parenting on a practical level too.

"I mean it works well. We jointly do these sorts of work things driving back and forth and together, I don't drive. So if she needs to go somewhere, daddy takes her." (KC108)

In these cases, the labour of raising a child was shared and seemed to be an effective strategy. This was also true of wider family members who were often involved in caring for the child. This regularly entailed the provision of respite care and shared responsibility for the school run.

"My daughter helped me a lot when they were small, she'd have them from a Friday to a Sunday for me to have a break." (KC105)

Some carers also noted family friends who provided essential support to the carers, whether emotional and social, or practical assistance.

"We had good friends who came on board who obviously had to go through the whole gambit of being tried and tested but were brilliant and up for it." (KC117)

Whilst wider family could be a source of support, they could equally generate conflict for kinship carers. In particular, grandparent carers sometimes found that their own adult children were less tolerant of a young person's negative behaviour. This was often exacerbated when the carer was experiencing physical or emotional ill health as a result. This led to arguments in the family such as in the two cases below. 
"And my kids were saying last year, how many more chances mam are you going to give him, you know but I was trying to explain to them you know, that he can't help the way he is." (KC116)

"They can see what YP's done to me, and they can see now what sh-she's doing to their mother so... it's very tense" (KC107)

Social workers also explained the difficulties associated with keeping all family members involved in order to prevent conflict. As one social worker stated, information is fundamental in ensuring that the family work as a supportive network as opposed to a source of conflict.

"If you haven't pulled in all the family quite early on to support that placement they don't understand why the children are removed fully, they're not given all the facts and it causes difficulties between the family around to support the placement because they're not sure, why have you taken, why won't you let so and so see Harry today, why, you know, they're upset, why are you stopping them" (SSW)

\section{Family identity}

Aside from conflict, kinship care placements can affect the wider family in numerous ways. By virtue of the young people's looked after status, family activity can be restricted or delayed by legal checks. This can in turn impact upon the young person's experience of normality and serve to perpetuate the identity of 'looked after child' rather than ordinary family member.

"It impacts on the rest of your family. In that sense, you know like when they wanna do anything, do you know what I mean, they like... they gotta be checked and things like this. And.. stuff like, they family aren't they? You know, it all... er... like my sons have had to be checked for YP, to take, you know, they go to football" (KC103)

The intensive nature of caring for young children, particularly for elderly carers, can mean that kin feel excluded. A number of grandparent carers expressed guilt over being unable to spend as much time with other grandchildren and there was some evidence that young people also feel that is the case. 
"There was one comment from one grandchild because we'd always done things together. And there was one comment- we have told the social worker that it was... "oh we had more fun with gran and grandpa before you come to live with them" " (KC131)

Family identity: role duality

In a number of cases, the young person being looked after was not the only child in the home. Some lived with their cousins or step-cousins, others with their siblings.

One aunt, who took in three young people in crisis, described how the sudden introduction of three children into the home made normal life challenging for her own children. In this case, her two children had sacrificed social activities and were expected to share bedrooms in spite of having previously enjoyed their own space.

"at the moment the biggest thing is, I haven't really been able to have children over for my two or any of their friends because there's already enough of us going around and so we are still trying to get the house to a place that we can, because ultimately we've been firefighting towards a day that we could pre arrange it." (KC112)

The challenge of having other young people in the home was common, as was the sense of intrusion that these children felt when their parent became a kinship carer. The behaviours displayed by the new arrivals could cause reactions ranging from annoyance to acute distress as the children watched their parent verbally or physically assaulted by traumatised or neglected young people.

"After a few days my daughter was quite angry, he was putting boogies everywhere and of course spitting everywhere and things like that. And of course, the mess isn't it and my daughter was saying mammy just send him back." (KC116) 
Kinship carers' children could find themselves assisting in the caring role, especially if they were teenagers. With the sudden influx of sibling groups into a household comes an increase in household labour and carers' children were often expected to share that labour.

"I used to ask my son, look, go to the supermarket do me a shop and I'll meet you at the checkouts and that's what I used to do. So it changed his life substantially because he all of a sudden really had to grow up and do things that he wouldn't normally be asked to do." (KC127)

However, whilst most carers chose to focus on the challenges faced by the wider family, some noted the positive impact that their caring role had on their own children.

"It's been brilliant because he's kind of woken up my son and my son has calmed him down. They've got something to talk about." (KC112)

\section{Summary}

It seems clear that whilst some features of a kinship care placement can be advantageous for many, such as geographical proximity, the same features can also cause difficulties for all those involved in a placement. Whether it is social workers attempting to limit contact, children trying to avoid seeing their birth parents, or kinship carers experiencing anxiety when they recognise patterns of behaviour in the young person, it is evident that such factors challenge all of those involved.

Birth parent contact, and its often informal nature in kinship care, seemed in many cases to be positive for young people's identity and their attachment to birth parents. However, in a number of cases, informal or unarranged contact negatively influenced the wellbeing of the young people as they experienced fear and rejection. Kinship carers also worried for the children's wellbeing, particularly concerned that patterns of behaviour displayed by birth parents would be repeated in the young people. To mitigate this risk, strategies were put in place 
such as working with the LA and sharing the labour of caring with other family members including birth parents.

Kinship care also posed challenges for the wider family as each adjusted to their new identity as both kin and carer. Kinship carers reported the experiences of their own children and the challenges that they had faced as their parents became kinship carers. However, some also noted the positive benefits of providing care on the wellbeing of both their own children and the young people in placement. 
7.4 Challenges of kinship care 


\section{4: Challenges of kinship care}

\section{Introduction}

A prominent theme that ran through the interviews was discussion around the challenges of providing kinship care and of supervising placements. This chapter will address research aims and questions relating to kinship carer health and wellbeing, and its impact upon placement quality and stability. In particular, this chapter will present evidence in response to research question 18 which seeks to explore how kinship care affects the health and wellbeing of kinship carers.

Challenges that kinship carers often cited as being particularly problematic included the lack of preparation time for kinship carers leading to a feeling of being unprepared for the physical and emotional aspects of caring for a neglected or traumatised young person. Also of significance are lifestyle changes that impact upon the carer's wellbeing, from a reduced social circle, to the process of becoming a professional carer; even needing to purchase livestock to facilitate placement.

This section will also examine the complications of multiple caring responsibilities, the challenges that carers face with identity as they play the roles of both professional carer and of kin, and the worries that aging kinship carers have in providing care in the long-term.

\section{Kinship carer wellbeing: contact}

Carers often faced many difficulties as a result of becoming kinship carers. One such difficulty, broached upon in unplanned contact, was the unsolicited interaction with the child's birth parent. This could be distressing for both the child and the carer, although carers reported that they did their best to hide the extent of the trouble from the young people. On occasion the abuse became so severe that the carers were forced to contact the police to intervene.

"I mean he's still on drugs and... he tortured me for a long while to see the boys, you know, but he's not allowed to see them, he's not. Because he's got a drink problem and a drug problem and he was ringing me sometimes 
12, 1 o clock in the morning "I want to see my boys" you know. And I said you're not allowed to, if you want to see them, got through social services. Now in the end I had the police here." (KC126)

Some carers reported that contact extended beyond harassment and escalated to threats of physical violence. In one case, these threats were made openly in a public place.

"Load of abuse we had off them, they were standing across the road threatening, threatening to cut our throats and stuff." (KC116)

In this case the carers were so unnerved by the threats that they altered their behaviour and now travel a considerable distance to the next town to buy groceries. In doing so, they hope to avoid unarranged contact with the birth parents and consequently further conflict. Not all interaction with birth parents, however, was confrontational. A few carers discussed occasions where the birth parent had been emotionally provocative leading the carer to feel conflicted.

"Crying on the doorstep she was, "mammy, mammy" like a little girl. Oh you know my stomach, oh... I had to tell her to go away you see and she was standing on the doorstep saying "oh mammy, mammy, I loves you" tell you it's heart-wrenching.” (KC120)

\section{Kinship carer wellbeing: transition}

For some, the lack of preparation time had been a greater challenge for carers. In a couple of cases, the child's transition into a kinship placement was gradual via either intervention in the family home or a mainstream foster care placement. In such cases carers were given the opportunity to make preparations in their home and work life.

"We'd known what was going to happen potentially and it was something that we'd prepared for and things so it just seemed to quite naturally happen in a way. You know obviously there's a lot of, with any new parent, there's a lot of things that you just have to pick up along the way. Yeah but we kind of handled it ok." (KC124) 
For the majority of cases, however, the transition was rapid occurring over the space of a few hours. This meant that often carers were left feeling overwhelmed and underprepared for the child's arrival in their home.

"Ultimately when you go in for mainstream foster care you get the training beforehand, you've gone in for it, you've decided your house is ready, your life is ready for it. That wasn't the case so we kind of felt that we were firefighting, winging it." (KC112)

"As family carers, it wasn't something that we ever planned on doing. I think if you look to foster, you look into it, you have your training, you know basically what's coming. But for us, well it was overnight. Basically overnight wasn't it, so we didn't really have much time to think about it at all did we?" (KC130)

In addition to feeling unprepared to take the children, some carers reported a lack of practical support from social services.

"We had to buy a triple sleeper, we had to buy furniture to put all their things, we had to put seats in our van... but we weren't offered anything, you know, do you need beds or... just get on with it really." (KC122)

Carers found this particularly challenging as the majority of young people were in recovery from neglect or trauma. As a result, many of the young people displayed challenging or alarming behaviour, especially during the transitional period.

"He didn't like to feel left alone in a bedroom and that probably was from his first 18 months where he probably was left in the house on his own or in a room on his own. But he still doesn't like being left alone in a bedroom for too long." (KC130)

"It was hard going in the beginning, because I don't think in his mind... he didn't know what was happening, you know? He was... sometimes he used to cry for hours and knock his head against the bedroom wall, you know. I sat there 2 hours one night, it was so bad I nearly took him up to $A$ \& E, you know. His screaming and crying because he couldn't see his mother at all then. But he gradually settled in then." (KC126)

Some social workers acknowledged the challenges faced by kinship carers. One supervising social worker noted that carers were often expected to nurture through recovery from neglect without equal recognition to mainstream foster carers.

"I also think they're not given credit in the same way mainstream carers are given credit, it's viewed as well of course they're just looking after their 
grandson, not they're helping a child who's had a really traumatic neglectful childhood recovery, yeah, they're just of course they're just loving their grandson and they should want to do it, and for some reason people think they should want to do it for free, you know, because it's their grandson it would be much cheaper for them than it would be for anybody else and it's just not, it's really expensive, on top of what they already sacrificed." (SSW)

Despite this, carers were often successful in providing an environment in which the children could begin their recovery. One carer noted the change they had witnessed over the year-long placement.

"I have five well adapted, ultimately happy children that are getting their homework in on time, got more pride, got, you know, that can actually talk about their feelings. Because before they knew they would be upset but didn't really know why, they couldn't verbalise it." (KC112)

Kinship carers found that they had to made changes to their lifestyle in order to facilitate the children in their care. Some of these changes were of a more practical nature, such as one family living in a townhouse who resorted to buying livestock for the children.

"He was allergic to milk, so he had to go on special milk. And we nearly lost him at six weeks old. And, my husband bought a goat for her, to milk it, and give him milk because he couldn't tolerate milk." (KC105)

In most instances, however, the changes that were made were less material. Carers were forced to change their social habits, manage an increase in household labour, and alter the way in which they planned the immediate and long-term future.

"I wouldn't say we gave up everything but we've had to radically change our life because all of a sudden, instead of having children who've grown up and left the nest, we've become parents again and we were the parents of toddlers and teenagers and young children again." (KC127)

The ability to travel freely seemed to be a significant factor in carers concerns. Intensified by the legal status of the child, carers were no longer freely able to visit friends and family or travel abroad. 
"I can't just go off for a week and just leave her here to fend for herself or... lock the house up and etc. I can't do that sort of thing that I used to do before." (KC109)

"Obviously having these children affects your life. We couldn't, once the children left home, we couldn't live our own lives because we never had our own life. I mean it's always been around the grandchildren and weekends, you couldn't go away for the weekend because you had arranged contact. If I wanted to do something, if there was a contact that weekend, I couldn't do it. I mean we'd both have to swap shifts so that we'd always make sure somebody was here, although the children had all left home, the grandchildren were still here so our shift patterns, our life, our earnings all blown because of grandchildren." (KC127)

Not all of the lifestyle changes were negative. Some of the carers enjoyed the company that having children in the house brought. They took part in activities with the children such as one grandmother carer who abseiled with her grandson. However, the gains were balanced with a sense of loss.

“We've done some things together! l'm now known as super-gran in the family! There are positives and things to it, so it wasn't just changes for... you know, it wasn't just loss. Lots of gains. And... but.... Yeah. So I think you know, you have to think differently. You have to start thinking children again. You can't give them back, you've got them and you become parents again don't you? And that's hard when you're going through it the second time." (KC117)

\section{Kinship carer wellbeing: intrusion}

The vast majority of kinship carers also commented on the intrusive nature of caring for a looked after child. Whilst expressing an understanding of the need for social services checks, they were seen as disruptive to the household, particularly during the initial assessment period prior to panel.

"In the beginning it did have a big impact cos we could do, do things with our own daughter, then it came about that we couldn't because... you know we had these two. And you know, there was a lot of erm... er... social services back and forth, and this that and the other, but once it settled then it was great, it was... they more or less settled into family life and you get on with it." (KC103) 
"It is really intrusive, like twelve weeks of your life is for social services. They can pop in your house anytime they want, they can look in your cupboards, they can look in your fridge, they can check the microwave's clean. You know, it is intrusive in that way but it's got to be done." (KC120)

After the assessment period, regular contact with social services still created difficulties for carers. Some expressed concern that regular visits from workers prevented normal family life for both the carer and the young person.

"There's a lot of times when l've got to not meet my boyfriend because l've got visitors coming here, like meetings here. Sometimes I have four or five people here and... sometimes that's a bit intrusive. It's not like having a proper... you know at home with the family? You don't get people coming back and forth to check on your bedrooms and check in your cupboards to check if you've got weapons of mass destruction. I mean every place I've been to they've had to go in every bedroom and look around." (KC108)

Kinship carer wellbeing: sacrifice

A recurring theme with kinship carers was that of sacrifice. Carers regularly commented on what they had given up in order to provide care for the young people. Losing employment was common for carers who often struggled to balance paid work with their new caring responsibilities.

"I can't work full time because l've got two grandchildren to get to school and pick up and look after." (KC127)

"I had to give up my job. I was working part time, I had to give it up because I was working different hours see morning and then part of the week I was working afternoons see. So I had to give it up, cos I had to be here for the children." (KC113)

For many carers, their previous employment had not only provided a degree of financial security, but reinforced their identity and provided social interaction.

"I was working for a friend of mine down in the market. I gave that up... I used to love going down there three or four days a week but I gave that up and that was it." (KC131) 
In one case carers felt it necessary to sell their business in order to provide the time that the children needed.

"We always provided every help we could. We sold our business-packed our business in to look after our grandchild. I mean when YP and her cousin moved in with us, I went and packed my job in. I haven't worked since." (KC127)

The discretionary payment system for kinship carers meant that they were often not compensated for the earnings they lost when giving up employment. This sometimes meant that carers struggled financially to provide for the children in their care.

"They're not paid the same, they're not given any kind of wage to be carers, they're given an allowance for the child, they're not given any additional finances. And that's not the same money as a mainstream carer gets." (SSW)

"I gave my job up to look after YP... and you do get less money to look after them and they need so much. And the money doesn't stretch, especially now I find it hard because I'm on a pension and the money that we have to look after YP doesn't stretch far enough." (KC129)

The lack of payment, coupled with loss of employment, was creating financial instability in a number of cases. Furthermore, the financial position of kinship carers appeared to differ from mainstream carers at the offset. Speaking of the kinship cases in one local authority, a supervising social worker explained the challenges carers faced.

"They generally start lower down socially and economically anyway, they're more likely to have health problems themselves, they're more likely to have poor housing, they're more likely to not be working in the first place. Whereas mainstream carers, probably one of them is earning and but then they're getting paid, this is their second job or whatever, on top, they've already got the house sorted, they've already got the mortgage, they've already got that financial security." (SSW)

In contrast to their mainstream counterparts, kinship carers often have very little chance to prepare for the young people. As many young people come to reside in kinship care through crisis, the decision to provide a home for the child is often made quickly with little time to consider consequences. One carer described the 
large financial cost and the hardship that came about as a result of this swift transition.

"They turned round and said to me was if I don't leave the house, this was about half past two in the afternoon, they would pick him up from school and take him straight into care. So I left the house, I took him in you know what I mean? I was living with my daughter for two months... then [my expartner] was in the house then for over two years, didn't pay no bills on the house so I ended up then, lost the house cos I couldn't afford to keep two houses going like. I manage with money now like, but I think I lost about seventy-eighty thousand on the house." (KC111)

Whilst this case was extreme, financial loss and hardship was a common theme amongst kinship carers. Whilst some lost the income from paid employment, others used their savings to subsidise the costs of caring for the young people.

"To a certain degree it has really [put a financial strain on us] because we've had to come down in the world then, put it that way. In a way. Because giving up our jobs and things like that." (KC113)

Supervising social workers who were working directly with kinship carers appeared to resent the way in which the discretionary allowance was determined. When asked about discretionary payments in relation to hardship, one social worker commented:

"I think the way to put it is you can feel the family and friend's carers are short changed." (SSW)

Consequently, with no additional payments for extra-curricular activities, financial hardship affected the young people.

"Even like two quid a week for subs for Brownies... actually that could make a massive difference to a kid in recovery and there's been research recently by the NSPCC that says we're now really good at recognising neglect, we're not good at doing the recovery." (SSW)

Kinship carer wellbeing: identity

Whilst financial hardship was a key concern for kinship carers, they also made other sacrifices. A number of the carers had reached retirement age by the time they took over the role of primary carer for the children. For many, retirement had 
held the promise of geographical freedom and opportunity. The sudden transition from retired to full time carer for young children led, in many cases, to feelings of loss. One carer, aware that they would likely be caring for their grandchildren for another decade, described their loss as bereavement.

"I was looking forward to retirement and the whole thing was that we lost our retirement. That was the big thing. It didn't affect my husband like it affected me... But for me, I had plans, you know. We were going to do a bit of travelling and we were going to do a bit of this that and the other and all that had to... you know, it's better now, but I went through a lot of grief and loss and bereavement if you like I suppose, I went through all of that." (KC117)

This case was not unique and other carers seemed to grieve for the future that they had imagined and planned for.

"I wanted them but I was very resentful as well, because I had so many different plans on my retirement. But they've been a blessing." (KC101)

"I think it ruined our old age because we sort of can't go and do what we want to do." (KC126)

Finally, when asked whether they had made any sacrifices to become kinship carers, one carer summed up with:

"I lost everything... Nothing else I can lose now... I give up everything for him." (KC111)

Whilst many carers recognised that they were formally referred to as foster carers, they did not internalise the role. For most, the title of foster carer was not a part of their identity. Rather, they identified as family who were simply doing what family do.

"I mean, I don't look upon myself as a carer for him, it's just our grandson living with us." (KC131)

In some cases, the decision not to identify as a foster carer seemed to be a deliberate choice. Such carers seemed to prefer the role of family member to foster carer. 
"I wanna be a grandmother, not a... not a foster carer to YP." (KC110)

This duality in the roles that carers played was evident when asked why they had become carers. Even those who had previously referred to being registered as a foster carer for the young person spoke about the alternative placements. Such placements were referred to as "in-care".

"They would have gone into care wouldn't they? Into the care system and you now, I don't think they could have coped." (KC103)

In legal terms, the young people in this study were in the care system in that they were legally looked after and placed with registered foster carers. However, their kinship relation to the carer seemed to protect them from being seen as 'in-care' in the traditional sense. Despite this, some carers found it difficult to balance their roles of foster carer and family.

"I think you are more aware of outside people being involved when you're bringing up your grandchildren under kinship care. So there are certain things that are different. There's a code of conduct because agencies are involved around you and that can make you a little bit different to what you are as a grandparent. It definitely makes you a different grandparent." (KC127)

Some of the carers managed to balance the two roles well, adapting as the situation demanded.

"It's somebody else's child you're looking after at the end of the day. I treat her as my grandchild but sometimes social services, I do involve them saying, social services say you can't do this." (KC114)

On one occasion, however, a carer rejected the identity of foster carer so strongly that they refused to register as such.

"So are you not an approved foster carer? No. I didn't want to do the... foster my own grandchild." (KC110)

To this carer, it seemed bizarre that the legal system would require her to register in order to care for kin. Following from a long family tradition of caring for one another, the concept of taking on the role of anything but grandparent to the young person was less than appealing. 
Whilst there was an element of role confusion surrounding being both kin and a foster carer, it was compounded by a third dimension: parenthood. Grandparent carers tried to remain grandparents to the young people, in part through fear of creating conflict with birth parents. However, as primary carer for the young people they inevitably found their role to be one of parenthood. This provided challenges for the carers' own sense of identity.

"They know who their mother is and they love their mother and we'd never be a mother and father to them, we are granny and grandpa. But we feel as if we are parents at times... thing is you see, although they're our grandchildren, we're not in a way grandparents really. We're really taking on the parent's role in a way." (KC113)

"I think it's one area that kinship carers do struggle with and, you know, there's split loyalties and ambiguity about their role." (SW108)

Furthermore, the duality of their role affected the way that they could behave with other young people in the family such as other grandchildren.

"Sometimes being part of the family it poses a bit of a problem, more difficult because like in this case you've got grandparents who are taking on parents' role when they are grandparents to the children and if they've got other grandchildren coming over, the dynamics of the relationship with those grandchildren are different to the two that are placed there, I think it also puts pressure on the relationship between them as cousins because, you know, they are living with the grandparents full-time so it does have its challenges." (SW113)

When making decisions about areas such as contact, kinship carers must negotiate their multiple roles. Whilst they may be a grandparent to the young person, they may also be the birth parent's own mother or father. In addition they must consider their responsibilities as a foster carer and make decisions in the best interest of the child. Navigating the multiple roles can be challenging for kinship carers and makes it difficult to avoid bias in decision making.

"Because of the blurred roles really, it's hard for them to say, look, do you know what, every time you don't turn up this child is breaking his heart, so let's reduce it, see if you can manage it once a month instead, and that's really difficult from mum saying to their daughter, you can't see your child." (SSW) 
Kinship carer health: effect of age

Carers also felt that their ability to perform the role of parent was limited by their age. Whilst many were in good physical health, the generation gap between themselves and the young people meant that they often felt unable to keep up. As such, some carers felt that they were failing the young people with being unable to provide the style of parenting that they would have liked to offer.

"A parent should be closer age to their child. We are a step again, we're another generation away and when we don't, we're not up with their fashions, we're a step away, our health is not, our outlook on life is different to how their parents would be and I think that has an effect on children as well... The things a child should do with their parents, I mean like play football and things like that. Once the carer's in their seventies, they're not going to be able to do the same functions as a parent." (KC127)

The age gap also meant that carers were sometimes limited in their ability to manage the behaviour and technological habits of the young people in their care.

"I think it's very difficult for them, you've got the generation gap and they're trying to parent, you know, I think in this case they're not young grandparents and they're parenting teenagers who are, you know, living a different kind of lifestyle to what they were doing as teenagers and it is difficult to manage." (SW113)

However, in some cases, carers were being introduced to new technology and entertainment.

"It's opened up a new world to me. I'm watching films I wouldn't have watched before, finding out about things, I know all the groups and the music now." (KC108)

"Carer: She texts to my phone so he can see- they haven't got that contact yet. But we've just put him up on the facebook? no it's not facebook... it's online talking... facetime yeah that's it." (KC113) 
Kinship carer wellbeing: multiple caring roles

For many of the kinship carers, the young person in their care was not their only caring responsibility. Commonly they also provided care for their own adult children who were battling addiction. This care had often lasted for many years prior to placement and on occasion continued, sometimes causing conflicting loyalties between the carer's own child and the grandchild in their care. Some of the carers had lived with their adult children prior to the children becoming looked after. In this situation, they sought to provide care for both the birth parent and the young person in order to prevent the child from being removed.

"I lived with them for about a year, I didn't know how... to try and... get her back on track. It obviously didn't work." (KC107)

Others provided the resources to help the birth parent battle addiction and prevent a care order being created. They sometimes opened their homes to the birth parent and their children in order to provide a safe environment whilst they underwent treatment.

"[We] paid bonds for houses for her, like I was taking her to rehab and stuff. And I think I was dropping her off and she was going to the pub! Haha! I dunno, she did sort of try for a couple of weeks. She moved in here, with the four kids mind in a little bungalow like this, moved in with my mother." (KC120)

In many cases, contact with the birth parent was forced to cease when a care order was made. Whilst this was done in order to protect the young people, it meant that birth parents who had previously received the care and support of their parents were pushed aside as carers were forced to prioritise the young people. In some respects, kinship care under a care order may therefore be tantamount to surrendering the fate of the birth parent. Without the continued support of their parents, it begs the question whether birth parents are likely to recover from addiction. However, despite the challenges faced by carers in determining their split loyalties, social workers seemed confident that they would prioritise the young people in their care.

"I think that it is a very difficult situation inevitably if you've got a daughter that you're worrying about because of the life that she's leading but you've also got their children but I am really, really confident that they'll always 
put the children first and they will always prioritise them over, over it." (SW126)

With aging carers came aging spouses and, alongside, various health complaints. In some cases, these conditions were so severe that they became registered carers for their spouse. When added to the responsibility of caring for young people and, in some cases, an adult child with an addiction, carers could find themselves overwhelmed. One carer described how these challenges led to the young people being placed in mainstream care.

"My husband was in hospital, he'd had a big heart attack, a small heart attack. I was back and forth the hospital three or four times a day, erm... and I- it was hard and my husband was a bit annoyed. He said, you should have kept the children, but how-you know, it's awkward... they'd been with me mostly since they were born. And my husband had a heart attack and they were with me, and I couldn't work out, you know, who to have. And, they came and they said they had to go into foster care." (KC105)

It was not uncommon for carers to struggle in meeting the multiple caring demands placed upon them. Some social workers noted that placements had required a large amount of dedication on the carer's part to prevent breakdown.

"She was there looking after [her husband], looking after their other grandson, and then having to deal with the behavioural issues with YP, so I think she did reach her breaking point." (SW116)

In one unusual, although not unique, case the carer took on far more caring responsibility than they had anticipated. The carer in question was not well known to the young people or their family but during a crisis was approached to care for two of the young people. Within a short period the house had been overrun by three generations of the family with nowhere to live. In addition to depleting the carer's finances completely over a four month period, the labour associated with caring for so many individuals posed a challenge for the elderly carer.

"I don't know how she managed to do it but I know when they first came here it took me two weeks to delouse the grandmother and three weeks to delouse the youngest." (KC109) 
Kinship carer health: physical and emotional health

Of all the challenges that carers faced, physical health was one of the more visible. With many carers reaching retirement age or older, a decline in health was unsurprising. However, some carers attributed some health complains to the labour of caring for young children and the associated challenges. Speaking about the effect of wider family interference, one carer attributed her husband's ill health to the stress.

"About six months after, [my husband] had a heart attack. It was the stress through bothering with the family. Interference, you know." (KC114)

For others, the behaviour of the young people was so detrimental to the welfare of both the carer and other young people in the household that placement broke down.

"I think the first week of the holidays you know, she was so naughty! Oh she was just beyond, you know? And I said I'm sorry, I can't cope because it's making me ill, it just wasn't fair for the younger one." (KC107)

But whilst carers were suffering from ill health, some social workers noted that the issue was in part due to carers' failure to maintain appropriate self-care. This was due to conflicting appointment times and the carer's sacrificial attitude towards providing care for the child. If forced to choose between a health appointment for the child or themselves, the child seemed to always be prioritised.

"He suffers from emphysema and he was skipping his appointments to ensure that YP was meeting his appointments to see the therapist, and the other child, the other grandson in their care went to school, so they were doing all the running around, appointments for the children, they were prioritising the kids, but they were failing to attend their own medical appointments." (SW116)

Aside from being damaging to their own wellbeing, this could be considered a false economy as carer ill-health could compromise the placement. Social workers argued that facilities were in place to assist carers in ensuring that children were able to attend health appointments. However, some carers felt they had valid reasons for being reluctant to ask for assistance from social services in 
the face of illness. One carer disclosed a previous instance when the children in her care had been removed and placed for adoption following carer illness.

"So the stress of that, because it was only a year between them, I ended up having a mini stroke. So I asked the social services for help and they took them into care and I never seen them after that. They put them up for adoption." (KC129)

The carer suggested that they would be reluctant to seek assistance now due to personal experience and through fear of the repercussions. The consequence of this adverse disposition to requesting aid has potentially devastating consequences as the wellbeing of the carer and thus the stability of the placement may be compromised.

\section{Kinship carer health: mortality}

Carers and young people both expressed concern over the future. Whilst most stated that they worried little and felt in control, the prospect of aging or mortality whilst the child was in their care concerned them. A few carers worried about their ability to provide the appropriate care for the young people as they grew older.

"It sort of brought it home when I thought the younger two might be coming here because all of a sudden I thought... at the moment I can cope with them, but when the youngest is thirteen, l'm going to be seventy. So that's why it made us think, you can't be there. Because if you're going to commit to something it needs to be long term so that it's a steady progress of growing up and you know what's right and what's wrong and the regime is the same; it doesn't fluctuate terribly. And that's what makes you a steady person isn't it? You get a good foundation and you build on that foundation. Whereas if your foundation is moving all the time it's not so steady is it?" (KC127)

For others, the concern surrounded their mortality and ensuring that arrangements were made for the young people following their death. Rather than worry about their own future, they tended to be more concerned with how the children would fare, both emotionally and physically, without them. 
"I mean, I'm going on seventy now and if anything happened to me I- I worry about where they going to go and what they going to do... I'm not worried about me. I know I'm gonna die one day and that it's gonna happen and the kids are going to have to deal with it. And erm, it's going to be hard for them." (KC101)

As a result of these fears, carers often made preparations in case of death or incapacity. One carer commented on the early death of her husband and how that had motivated her to apply for a Special Guardianship Order. By doing so she ensured that the young person could be in the care of a family member without the risk of being placed in mainstream foster care.

"My husband passed away and so all that sort of thing got, got thrown into the background... and then one day I thought well, you know he was a young man and he went... what if something happened to me?" (KC103)

In some cases, carers' preparation involved strengthening the child's relationship with birth parents to ensure that a strong support network was in place.

"YP, you know, gets a bit upset sometimes, you know, and she says I'm not going to talk to mammy and stuff. I tell her, I'm not gonna live forever and when something happens, I would like that your mother's there for you. She's been there for you in the past, l'd like to know that she'd be there for them then." (KC105)

Others still focussed on financial security for the young people. Many made provisions for young people, particularly those who were older, to be recognised in their last will and testament. This would ensure that they were provided for financially and would be able to continue to live comfortably.

"I wouldn't say I worry, but I would like to think that, you know, they're old enough and see them right before I went. I do like to think that." (KC105)

It was not just the carers who seemed to worry. Young people also expressed concern about the risk of losing their primary carers. However, for the most part, such concerns were mediated by the open discussion within the family regarding alternative arrangements. Social workers were often involved in this discussion 
giving the young person further assurances that they would not be removed from the family in such instances.

"His parents, his grandparents are elderly and I know he does worry about that and he worries about, you know, when they get old what will happen to him but I know because I've spoken to family members that they would all care for him and he hasn't got to worry." (SW126)

However, the risks to elderly carers was not the only concern reported by young people. Many worried about their birth parents, especially in instances where contact was limited or infrequent, or where substance misuse was a factor. Worrying about the fate of their parents could be distressing for the young people.

"Sometimes like when I think like when I have nightmares or I think too deep about it then I end up crying because I think that something's going to happen." (YP123)

\section{Summary}

In summary, kinship carers in particular face a number of challenges when providing care for their kin. For many, the transition to becoming a kinship carer is sudden and stressful with resources such as financial savings stretched to breaking point. Coupled with loss of employment, a common outcome for kinship carers who must negotiate the provision of care that their previous employment cannot facilitate, financial hardship is a common theme. The theme of sacrifice also extended beyond the financial dimension to include a reduction in social network, poorer health due to prioritising the young person's needs, and the perception of loss around retirement. The risk that these factors pose to the health and wellbeing of both kinship carers and the young people in their care is worth noting and highly relevant to the aims of this project.

Further to these themes, carers also seemed to struggle with their own identity. Many found it challenging to lose employment or social engagement, a source of identity for many people, and cope with the duality of being both a professional 
carer and kin, or a grandparent and primary caregiver. In turn, they also felt this duality impacted upon the way they treat the young person. Combined with the multiple roles often being performed by a carer, these themes posed a great deal of difficulty for kinship carers and impacted upon their wellbeing. Consequently, their physical and psychological health was reported to suffer, particularly in aging carers who worried about the future and the effect of their own mortality on the young people.

The results also indicated that social workers, and particularly supervising social workers, were often aware that kinship carers faced a number of challenges. This also resonated with the young people who in turn verbalised concerns around the health and mortality of, not only their aging carers, but also their birth parents. Each of these factors should be considered in relation to the health and wellbeing of kinship carers, and the impact that poor carer wellbeing may have on the quality and stability of a kinship placement. 
7.5 Working with the local authority 


\section{5: Working with the Local Authority}

\section{Introduction}

The chapter so far has established some of the benefits that formal kinship care can bring to young people. Equally, a number of challenges have been explored, particularly in relation to kinship carers. Section 7.4 highlighted the importance of maintaining the health and wellbeing of kinship carers in order to maintain a stable placement for young people. Understanding the way in which kinship carers are supported and work with professionals in the social work system is therefore pertinent. This is particularly so when considering the negative impact that retaining looked after status can have on the young person's identity.

Many of the carers had experienced little or no contact with social services prior to providing a home to their kin. With Welsh law making registration as a foster carer compulsory in order to care for a looked after child, carers had to adapt to the rules and regulations of being a foster carer. This section will present reports from kinship carers regarding the assessment process and their perceived treatment relative to their mainstream counterparts. Of particular relevance to the study aims are reports on stability as a shared outcome objective, alongside fears that accessing support may jeopardise stability.

Once again, the role of the family comes the fore as an important theme. In particular, the direct and indirect pressure to become kinship carers, and the consequential impact on the wellbeing of carers is of particular interest. Furthermore, the way in which social workers and kinship carers co-operate in promoting the wellbeing of the young people, and the perceived deficiencies of the system, will be presented. 


\section{Support from social workers}

The majority of carers' contact with social services was in direct work with their social workers. As with all cases in England and Wales, two social workers were allocated to each case. The supervising social worker was in charge of the placement as a whole and would primarily be in contact with the carers, although the young people would also have infrequent contact. The young people themselves had a social worker allocated to their case. The vast majority of carers valued the support of two social workers assigned to them.

"Everything I ask her to do, or everything I think I need, she just does. She's just fantastic she just supports us completely." (KC102)

"From the social worker's point of view, we've had nothing but help and it's been good. If we've had a problem or if there's been any information we need we only need to ask and it's been done. So we've been well supported." (KC131)

The social workers were easy to contact, enabling carers to ask for advice or assistance via a direct telephone call.

"If I think there's anything that I need to ask I only gotta ring and they will either come out and see me or they'll give me advice over the phone or... yeah they're fab." (KC120)

But whilst the majority of carers hailed their social workers as allies, some found that interaction with their social worker had a negative impact on their ability to care for the young people. One family found that social workers were too prescriptive in the strategies for caring for the young people. This led to conflict as the carers felt stripped of their power to care for the young people independently. In this case the carers viewed themselves as children's' guardians despite having no legal basis for doing so.

"They can say what they want isn't it? We are the guardians, we look after him. It's alright for people to come here and say you should be doing this you should be doing that-we are the ones that are in control, right. They haven't got a say in it." (KC116)

For another carer, the interaction with social workers seemed one-sided. Rather than a co-operative working relationship, the carer described a feeling of obedience. This was underlined by a negative experience in the past where the 
children were removed as a precaution. The fear of history repeating itself seemed to be a factor in the way in which the carer interacted with social services.

"I work with them, but er... you still gotta listen to them." (KC110)

Whilst some carers were fearful in their interactions with social workers, others found the support they offered to be a source of comfort. Some likened the social workers' visits with that of a family friend. They felt they were there to offer advice and support rather than assessment and judgement.

"Our social worker we've had now for maybe three years or so. She's brilliant and she's more like a friend of the family rather than someone coming in and assessing you." (KC124)

Others still found social workers to be amiable but distant in their dealings with the family.

"I don't think you're allowed to build a relationship with the social worker, they don't like it I don't think. I really don't think they like it, they want that little bit of distance between you." (KC113)

It is clear that the way in which the carer related to the social worker differed in each case. Those who had suffered negatively as a result of social services interaction seemed to find it difficult to work harmoniously with social workers. In such cases, intervention from social workers was viewed as interference and a hindrance to normal family life. Meanwhile, others embraced the involvement of social workers and used them willingly as a source of support and advice.

\section{Stability: fear of asking for support}

However, regardless of their relationship with a social worker, all carers seemed to share a fear of discussing difficulties in placement. Whilst perhaps more pronounced in some placements than others, supervising social workers described this fear as a common theme in kinship care. Kinship carers seemed to worry that if they verbalised problems that the child was having then they may be at risk of being removed from the placement. This sometimes meant that carers were not receiving the support that they required to aid the child in recovery. 
"That's something they need help with, you know, if it's a need the child has got but they're worried about coming forward and saying, "I'm struggling with this, this behaviour," because they're worried because the children will be removed from them, but actually his behaviour has resulted in whatever and we have nothing to do with them it's just something else that actually they need some help with." (SSW)

"We're going to see that with the SGO carers 'cos a lot of them are quite fearful, I was talking to one the other day and she's actually a mainstream carer who's gone for SGO and... even with her professional experience she still fears coming and saying exactly what's going on in the house in case they came." (SSW)

One carer noted that this fear may be exacerbated by the frequent changes in allocated social worker. Whilst over time they felt they developed a rapport, they found they were more cautious about opening up to a social worker that they did not know well.

"I haven't liked the change because as soon as I- the children had one and I had one - as soon as I got used to them, you feel... you're afraid to say too much in case it goes against you. And you get used to this person and you think right I can trust her now and I can talk to her, and then all of a sudden somebody else comes in. And it...it is a bit upsetting." (KC105)

Stability: social worker turnover

Frequent changes of social worker seemed to be common to all placements, particularly changes in the child's social worker. Children referenced the frequency with which their social worker seemed to change.

"As we've gone by we've had about, I think it's eight social workers now and they've all changed, they've all been different." (YP103)

As a consequence, there seemed to be an element of confusion for the children as to who they could contact within social services.

"Once it gets into the LAC system it's a totally... different aspect. The kids don't know from one time to another who the social worker is." (KC103)

"Some of them we only seen them once like. One will come see him once, oh I'm so and so, take him out for half an hour, come back, you might not 
see them again. If they walked in here like he couldn't tell you who is who." (KC111)

This confusion also appeared during interview with a young person who was awaiting allocation to a new social worker. For a number of weeks they had not known who they should contact with concerns or questions.

“Interviewer: so who's your social worker?

YP: I dunno, I'm meant to be getting a new one" (YP126)

Whilst changing social workers can be challenging for carers and young people due to being unable to contact someone directly for the transition period, one carer identified a further challenge: stability. In the year that the children had been in their care, the carers had witnessed three separate children's social workers. The changes of social worker had impacted upon the children.

"The more consistent that can be the better because they did have three social workers in their time and that's not... you understand why it happens but it's not the best because they need as little change as possible with the amount of change that they're going through anyway." (KC112)

Family: social worker expectations of kin

Changing social workers is common to all types of placement as staff are promoted, transfer to new departments, or leave the field altogether. However, kinship carers did feel that their interaction with social services provision was different from their mainstream peers. When initially approached by social services, a number reported having felt pressured into taking the children in under threat of placing them for adoption elsewhere. Some commented that social services seemed to expect them to provide a placement for young people in a way that mainstream carers are not. They also felt that the support they received was lacking in comparison as social workers expected them to try to cope where mainstream carers would be supported more intensively.

"They're there at the drop of a hat, they're there in an emergency and it's something that they want to keep paying out. I dunno whether it's the fact that some of the social workers or some of the senior officers think, oh well it's family they should be doing it? You know, this was back when my father 
was born and when he was a child, there weren't things like social services to look after kids, family did do it and family would do it. And like my wife said, it was almost like blackmail." (KC130)

"I think they think well, you know, they're your grandchildren you should do it for them." (KC122)

It was not only social workers who seemed to hold this expectation over the kinship carers. Those who had attended training or mixed support groups with mainstream foster carers also reported feeling detached from their counterparts. The support group, designed to be a mixed environment in which both kinship and mainstream foster carers could unite to share the challenges of providing care, became divided.

"They're your flesh and blood, you shouldn't have any money... you shouldn't have anything, you know. I would do it for nothing if it was my grandson'... and the answer to that was obviously that you're not in that position, you are mainstream carers by choice. We are carers not by choice, but by desire. We want to do it not have to do it. And that was it, that was the answer. But there was that split, there was always that split between us..." (KC131)

In one local authority, steps had been taken to address the unique nature of kinship care placements. Kinship placements were supervised by a 'Family and Friends Fostering Team' who had both training and experience of working with kinship cases. This was seen favourably by kinship carers who felt that having a specialised social worker addressed their concerns and issues was beneficial.

"I think there's been. In their training, there's been a better understanding that... kinship carers in whatever form, whether it's' directly grandson or grandchild or whatever... yes they understand that and it's certainly helped. They've got a better approach to us on that basis." (KC131)

This worked well in promoting a positive working relationship between the kinship carers and social services. However, the financial disparity between the payments given to kinship carers and to mainstream foster carers remained a contentious issue. By attending mixed events, kinship carers were able to learn that they were paid less than their mainstream colleagues which could lead to conflict and hostility towards both the mainstream foster carers and the local authority. 
"We were asking why we didn't have the same rates of pay as them... because we found out how much they had and you know." (KC114)

Supervising social workers also noted this disparity and the tension that it could cause. Of particular concern to the supervising social worker was the reasoning behind the disparity in payment, particularly between different kinship placements.

"We've got, which I feel terrible about, you get a roomful of our carers together and some of them are being paid more than others. Now I think, yes, it should be on a needs basis, but what it really boils down to is whether they felt confident enough to dig their heels in and weren't worried that we were going to remove the kid and they made a fuss." (SSW)

Support: promoting the wellbeing of the child

Financial resources are not the only disparity evident. Access to training, whilst seeming to be a simple process for some, was reportedly not offered routinely to kinship carers.

"You see that's what we're saying, it's different when you're family, it's different, you don't get offered nothing... we're not offered the courses. We were offered that because of his behaviour... But no, we're not offered the courses." (KC116)

A number of the children suffered from some form of behavioural or psychiatric disorder which made caring for the young people challenging. In contrast to a child from the general population, the young people in this study were, more often than not, in recovery from a traumatic or neglectful past. When available, kinship carers seemed to find the courses informative and benefitted from the increased access to families in similar circumstances to themselves.

"I enjoyed every single course that I went on, because I done the living with teenagers which is like a 10 week course or whatever. And I done another one as well." (KC118)

Once again, specialisation seemed to be favoured by kinship carers who preferred to have training specific to their unique placement type.

"A lot of the ones now who are doing the training are the family and friends, people who have been foster liaison then and they have seen it so a lot of 
the training I get then is quite specific for kinship which is quite a difference. And you do, there is a huge difference and it does need to be quite specific really, yeah." (KC112)

Therefore, whilst not all kinship carers were receptive to the offer of training, many found the training sessions were worthwhile. Those who had not been aware of being able to access training felt as though they had been disadvantaged by failing to access the resource. Whether all carers were entitled to access training is unclear, however many felt that this was not the only information that the local authority had failed to provide them with. One carer stated:

"We feel sometimes that we're in the dark about everything." (KC113) When asked to elaborate further on a similar statement, carers sometimes perceived social services as being somewhat reserved in the information they provided.

"They never told you what you were entitled to. If you asked, if you were entitled you got it, but they would never come along and say you can have this, this, this and this. You never had a list of things, you would have to ask for them." (KC130)

One of the areas most keenly criticised by carers was information about financial support. It was often through conversations with their social worker that carers discovered they were entitled to support. Carers gave examples such as a fuel allowance that was not mentioned for the first three years of placement. Through passing comment about the cost of fuel and the cost of having to buy a new washing machine, the carers were informed by their social worker that they were entitled to claim for both.

"Other information, you know, they got day trips here and day trips there and you're doing this over the summer holiday, that comes via post like innit. So, with your emergency numbers and things like that. Where money is concerned it is definitely not forward." (KC113)

Carers were clear when discussing the topic of information that their own social workers were relatively forthcoming in providing appropriate information. They seemed to feel as though social services as an institution was the limiting factor and that their own social worker was advocating on behalf of the carers. 
Some of the issues seemed to be a lack of familiarity with the social work system. Most of the carers had never needed to interact with social workers in the past and were unaware of their rights and responsibilities; perhaps more so than mainstream counterparts who have the opportunity to research such queries ahead of applying and throughout the training process. Often receiving the child in placement ahead of any formal foster care application, kinship carers have limited freedom to explore and comprehend the structure and mechanisms of a complex bureaucratic institution such as social services.

"Of course not being aware of how the system works, you obviously accept what they tell you because you think they are in a position who know this. And we accepted that to begin with. We didn't want to, and of course as we progressed further along we realised that it was misinformation and it wasn't based on any truth at all." (KC131)

A supervising social worker postulated that kinship carers' inability to be involved at the centre of the legal process surrounding the young people often precluded them from understanding their rights to request support packages.

"They're not part of the procedure, they haven't listened to the case, they haven't been sitting in that environment, they've been sitting outside waiting for us to move in and out and tell them stuff, to then come to the Court and say to a judge, "Alright, actually I think I'm entitled to more money," it's frightening I don't think I could do it!" (SSW)

Support: the wellbeing of kinship carers and young people

Despite being less involved in the legal process, kinship carers are often involved in formal contact arrangements. Where contact with birth parents needs to be supervised, responsibility to do so often rests with the carer.

"Well often it'll be supervised by the supervised contact team while it's a Court case, or by the Social Worker, and then because Social Services is closed, especially if it's an SGO, it's an expectation that the family will manage that for themselves, which can be a real transition." (SSW)

Supervising social workers noted the challenges that this transition can pose for kinship carers as they take on the role of contact supervisor. 
"They're only just been approved for them, they've got a supervised contact worker nine times out of ten and then they suddenly assume that they can just take on that role without really having any training for it." (SSW)

The training aspect was key in discussions surrounding contact supervision. The skills required to supervise contact go beyond physically monitoring the child. There is also responsibility to protect the child emotionally and make decisions regarding the contact schedule. Supervising social workers tended to feel that this pressure was too great for kinship carers.

"It's actually a skill to supervise contact anyway, it's definitely a skill to make decisions about contact, you know, trying to think about what's the kids needs in all of that and what level we make that and what not, and then to have the confidence to try it and then if it doesn't work how do you pull it back, you know, you've said, "Oh it's okay mum to have contact every fortnight," it doesn't work, that upsets the kid all the time, you're then going back and saying, "No," putting it back to a month, those are really difficult things to do anyway, let alone when you're actually the mum's own mother or father, I think that's really tricky." (SSW)

The children's social workers were less inclined to discuss the challenges that kinship carers faced in supervising contact. Whilst discussing the common perceptions amongst colleagues, one social worker commented on the disparity that existed between expectations of family-managed contact and reality.

"You think from an outside perspective, if somebody said "You've got a child living with gran, contact should be much more natural and easier to manage", but then you've got family members trying to manage that contact and managing the risks and there's obviously huge conflict." (SW105)

However, the majority of children's social workers supported contact being supervised by kinship carers citing that contact could occur more naturally. Often contact could take place in the home or on a family outing rather than being restricted to the confines of a contact centre. Interaction could be less formal and the absence of an official contact supervisor meant that birth parents and young people could spend time together without feeling as though they were being assessed. 
"It just creates a more natural environment for the child and they're better able to identify with their family and friends and is able to make it more of a natural process rather than an outsider like myself or a professional person if they was to be sat there kind of taking notes or being very aware that we are very much supervising that, I think it just appears to be a lot more of a natural environment and therefore a nicer experience all around." (SW115)

This support for family-managed contact was often passionate as they witnessed the benefits of a more natural contact setting.

"On the whole I think it does work a damn site better than any god damn contact team in there. But yeah I think family is the best way and it's the best way to do it really." (SW101)

For some, carers being able to supervise natural contact was one of the factors that made kinship care advantageous. When compared to mainstream foster care, the ability to manage contact with both birth parents and wider family was viewed as a benefit.

"They can provide contact a lot more naturally, so seeing family members is not with a social worker present, it can be a family member supervising it." (SW111)

However, kinship carers were also encouraged to manage contact more commonly than their mainstream colleagues. Some even felt that it was expected of kinship carers to take over contact supervision.

"Family members are generally more willing to step in, and to be fair they're expected to step in, you know, and they should, but no, it's generally much easier to manage." (SW101)

That is not to say that mainstream carers are never involved in doing so. Social workers also mentioned long-term foster carers who had become more involved in managing contact, however the pressure for them to do so was generally reduced.

"I think it's probably a little bit more applicable to kinship carers and it's probably easier to encourage them to do that because they already have a pre-existing relationship with that family member, but no I wouldn't say it's just specific to those because they have current mainstream carers who I also actively encourage to be involved in contacts." (SW115) 
But whilst kinship carers may have been expected to supervise contact, some were also keen to do so. Where their relationship with the birth parents was positive, supervising contact was an opportunity to spend time as a family in a way that would not be possible in a contact centre or with a social worker present. When the child in their care was at risk of having contact reduced due to a lack of resources, one carer actively pursued the opportunity to manage contact at home with the birth mother.

"There are some reason why her contact was cut down in initial reason. And in a way it was a valid reason but there could still be another day a week I think. You know, I wouldn't mind having her mum here, I wouldn't mind at all." (KC108)

The result of carers managing contact themselves is that they seemed to forget that they were supervising. That is not to say that they forgot their responsibilities to protect the child, but simply that the environment that family-managed contact created was so natural that it seemed like a perfectly normal situation.

"Contact with her mum isn't supervised, well it's supervised by us..." (KC124)

Whilst the expectation that kinship carers would supervise contact marked them as different from mainstream foster carers, many social workers also perceived the assessment process to be less rigorous for kinship carers. The standards that they were expected to meet were deemed to be lower and, for many social workers, this justified the lower rates of pay that kinship carers received. During the focus group, the following exchange occurred between a student and one of the more experienced supervising social workers.

“There's more discretion though isn't there in terms of foster care... family and friends and foster carers in terms of the standards they have to meet, is not so high and rigorous as independent...?"

“There's only a very small margin for leniency to be honest 'cos you've still got to get it through panel... apart from that the standards aren't really high, they're just good enough or they're what would give an excellent childhood, so there can't be too much flexibility or we'll basically abandon what is a good childhood and what is good parenting and what is excellent parenting." (SSW) 
However, one area where leniency could be exercised was where kinship carers were smokers.

"Well the policy for [this local authority] is that if they're under five we wouldn't place a child with mainstream carer who smoked, we can only advise family carers of that... Some people always smoked. And what are we going to do, are we going to not place that kid who loves their granny because of that?" (SSW)

The ability for social workers and managers to be able to assess placements on a range of factors meant that relative risks could be weighed against the benefits to promote the best outcomes. This seemed to be important to the social workers who expressed concern over a 'tick-box' system that could undermine their professional judgement. Where factors such as smoking could be outweighed by the wishes of the young people and their attachment to the carer, supervising social workers placed a high value on their ability to be able to exercise discretion.

"The doctor's kind of saying, you know, either short-term or respite, then you've got three kids who are so traumatised, all they wanted was to be with this woman." (SSW)

\section{Summary}

The way in which kinship carers interacted with the local authority varied case by case. Overall, most seemed to have a positive relationship with their case worker who advocated on their behalf against a system that carers felt was often weighted against them. Some had a less positive relationship with their worker and viewed their interaction as an unnecessary intrusion into their family unit. Regardless of whether this relationship with social workers was positive or not, kinship carers seemed to be reluctant to discuss issues in placement with social workers, a factor that supervising social workers noted in particular. The main reason attributed to this was that kinship carers seemed to be perpetually fearful that challenges in placement would be attributed to their care and result in placement breakdown. For kinship carers, their attachment to the child resulted 
in their decision to protect the stability of the placement, despite the potential for adverse effects on their own wellbeing and that of the child.

The fearful mistrust of the social care system was compounded by the frequent change of social workers, which prevented a working relationship with a foundation of trust between carer and worker. There were also concerns that frequent changes of social worker presented challenges for young people in undermining their sense of stability, a key factor in promoting wellbeing, and limiting their access to support during periods of transition between workers.

Kinship carers also felt that the expectations and support from the local authority was entirely different from mainstream carers. The access to financial support and training courses was a frequently occurring theme, and one that was recognised by supervising social workers. The carers and social workers expressed concern that a lack of training and support could adversely affect the wellbeing of both kinship carers and young people as they attempt to recover from trauma or neglect. The need for effective working relationships between kinship carers and social workers, and the appropriate provision of support services to kinship placements were recognised by carers and workers alike. 


\section{6: Special Guardianship Orders}

\section{Introduction}

Since their introduction at the end of 2005, the use of Special Guardianship Orders (SGO) has risen steadily. There has been a recognition of the potential benefits to both carers and local authorities who are often equally keen to minimise the LAC population and provide permanency for young people.

An increased focus on permanency has meant that young people are often 'twintracked' for an SGO from the beginning of placement. The process involves running simultaneous assessments for the carers as both long-term foster carers and as special guardians. This is not necessarily a negative, however, it has led to some carers, already overwhelmed by the complexity of the social work system, being increasingly confused by the legal outcome and consequences.

"It wasn't really explained to us what it was. Everyone was like here are the steps you've gotta take, YP is going to live with you, you've got to go to panel for fostering... We didn't really know. So said, yeah we'll do it, we'll do it, we'll do it, not really knowing that we didn't have, that we have a lot more options rather than an SGO. So we could have a residency granted or we could have YP, keep her as a foster child and make her a Ward of court, just in case anything happens. So you know, but we weren't told, you know, about the options." (KC102)

With the local authorities in this study both actively seeking to reduce their LAC population, discussions around SGOs was inevitable. Amongst these conversations came accusations of bullying, feelings of mistrust and a sense that social workers were trapped between a rock and a hard place.

This section will address these issues, looking at the experiences of the permanency process from the carers and the social workers perspectives. It will examine the way in social workers as individuals and social services as an institution promote SGO applications and, crucially for the aims of this study, the factors that either motivate or deter kinship carers from doing so. Finally, carers' lived experience and perception of support provision to promote permanency after SGO will be discussed. 
Deterrents: perceptions of cost-saving

Almost all of the carers had heard of an SGO, normally through conversations with their social workers. For some, the SGO was an appealing option, which gave them the freedom from the department to behave as a family unit. For others, the prospect of having an SGO was viewed less favourably and many of the carers felt that the move to guardianship would benefit the local authority more than it would them.

“When I said I didn't want to do it anymore [they said] that they'd get their legal department to come out and speak to me just so that they could, you know, help. But that wouldn't have helped because that just felt like more pressure. I felt, and still do feel, that they just needed to have our case closed to push us to the side. And that's exactly how I feel an SGO is. It's just, we'll just do this now and that's one more case closed and you're off the books." (KC102)

Carers and social workers mentioned that, on occasion, an SGO had been described to the carer without due consideration to alternative permanency options. With the value of an SGO realised by local authorities, there was some indication that it was being used as a 'one-size fits all' solution.

"I think we've got to be realistic, there's got to be lots of different options and lots of different paths to follow, whereas we're trying to push everybody down the same path." (SSW)

Social workers perceived pressure from management teams to coerce carers towards making an SGO application where suitable. Most found this pressure from management to be intangible and often stated that they did not know why they felt that way. Others, however, were able to give clear examples of when pressure from senior colleagues directly affected the way in which they went about discussing an SGO with a family.

"When I was in the area teams, deputy manager, the Social Worker went up twice to these carers to try and bully them into SGOs [laughs] 'cos that's how it was, and when we went back to PO discussions and the Social Worker explained really clearly what the reasons were, their reaction was, "I'm not happy with it, I want you to go and speak to them as a manager," so then I had to go back there and speak to them, and by this time they were so hostile, they were so annoyed, and they just felt that we were... 
and that's the word they used, you're bullying us, you're trying to bully us... And I agree with them." (SSW)

This is a highly emotive example of the pressure felt by a social worker to promote SGOs. Both the social worker in this case and the carers felt resentful that permanency was being pursued via SGOs as a means of cost-reduction, rather than being in the best interests of the young person.

Whilst social workers tended to acknowledge that they were under pressure to encourage carers to apply for an SGO, the way that this translated to the carer was often felt to be subtle. Some social workers felt that whilst they were encouraged to discuss an SGO with carers on a regular basis, it was not in a way that pushed the carers.

"I think there's a push by senior managers in terms like a permanency for children, that with an SGO then that maybe they would feel that way and I think it's been suggested then that when we visit that we discuss that with carers." (SW113)

Certainly, for many, there was a firm belief that it would not be possible to coerce a carer into pursuing an SGO against their will. They saw the carer as an equal partner in the application process.

"It's all done in partnership with everybody involved so I don't think that's the case because at any point during that assessment they could just pull out and they've got that option all the way." (SW128)

As an SGO is an aspect of private family law, the application must originate with the carer. The local authority's role is to decide whether to support the application and to provide an assessment of the suitability of a permanent placement. Some of the social workers commented on this balance as evidence that carers cannot be pressurised into applying.

"You can't force anyone to take an SGO, it's purely their decision and they have to write to us to let us know that." (SW126)

The financial support package that is put in place for special guardians was another area that social workers believed would ensure that carers were making the decision freely. 
"Obviously in many aspects you're closing the door, but because they're having the same level of financial support, you know, I don't know how they'd be bullied into it, but mm." (SW118)

However, some other workers noted strategies that they had been made aware of. These, they claimed, were used to coerce kinship carers into taking out an SGO. This often involved playing on the carer's emotional connection to the child by threatening to remove the children from placement.

"Some of ours have been told, "If you don't do this we will remove the children" and the fact that it's constantly brought up in any LAC review, or any meetings about the children, whilst they're under family and friends fostering in $L A C$, any meeting or any discussion about them, permanence is there all the time." (SSW)

However, whilst this issue was most often reported in kinship cases, mainstream foster carers were also not immune to being emotionally manipulated.

"There's another case that I'm involved with at the moment where we're talking about moving a boy out of his placement because part of the picture is the foster carers won't go for an SGO... and I have difficulties with that." (SW108)

Deterrents: the need for formal support

Although permanency is seen as the best option for a young person in the LAC system, there are risks in giving permanency paramountcy. One social worker, who was keen not to be identified for fear of professional reprisals, discussed the relative benefits of remaining on a care plan.

"I think sometimes.... They would get more if they were still under a care order. Financial support and the added extras that sometimes they get. But are you sure that's not going to get back to...? I think once the SGO is kind of put through that's it and they're on their own. There's little scope for changes..." (SW111)

Carers' fear of being left to cope alone if they received special guardianship was very real. Many had consulted with friends and family and also discussed the matter with other carers who they had met through support groups. 
"They were pushing for us to have a residency order but I said no, we stuck with the care order because I just felt that once they pull out, even though they said they'd come back on board, you hear such stories." (KC130)

One carer had spoken with social workers who had privately agreed that a special guardianship would mean a reduction in support. As such, they felt unable to apply for an SGO through fear that they would not be supported enough in the future.

"Whilst they say that everything will be the same and they'll provide support, etcetera etcetera, I know quite a few social workers outside and inside the department who have advised me against it due to the fact that as soon as you get a special guardianship they do look to cut pretty much everything. Which you can imagine happening really." (KC124)

This was a common deterrent. In most cases the placements were settled and there were no issues that seemed likely to arise. However, the prospect of problems occurring as the child grew older was too much of a risk for many. This was combined with the common understanding that the loss of an allocated social worker meant that young people would be put to the back of the queue.

"At the end of the day you've put yourself in a situation that you don't know how to handle either and to have no support at all. Because once you get your SGO you're not with a fostering team or anything so you're not with anybody. So if anything does go wrong you have to go through the whole process of social services again." (KC102)

For some carers, the fear of losing support after an SGO is granted was based on first or second-hand experience. In one case, an aunt was dissuaded from taking out an SGO by her own mother who had done so.

"I know that happens cos it's happened to my mother so, you know. My mother's gone for YP's sister and since that day, and that was five, six years ago now, she hasn't seen one social worker." (KC102)

Another couple were already special guardians for two of their grandchildren. When asked to apply for an SGO for the other LAC children in their care, they refused due to dissatisfaction with the support they had previously received.

"No matter what they put in the report, because it was in $P$ and $K$ 's report that you know, we'll support you for twelve months, we'll do this, do that, in reality you're on your own." (KC122) 
For social workers, the concern about future support featured more frequently. The potential for change and the perceived inflexibility of SGO support plans was understood by social workers to be a barrier for carers.

"I suppose that's the barriers really is circumstances change, and once that support plan is in place that's what you've signed up to isn't it?" (SW118)

In particular, the loss of leaving care services as a young person reached eighteen was regarded as a deterrent for the carers of older young people. The benefits of remaining looked after during the transitional period towards adulthood seemed to outweigh the permanency of an SGO.

"At 16, it's pointless, and the trade-off of leaving care services is just not worth it, she could benefit that support... they'd lose all their care, their leaving care criteria, their rights, they'd lose the service, [leaving care services] support it's not worth it, it's really not, and gran needs some support, she does, she needs some help." (SW101)

With the introduction of the 'When I'm ready' scheme in Wales, social workers seemed even less inclined to promote SGOs for older looked after children. The potential for a young person to stay in placement until the age of twenty-one unless they chose otherwise was deemed sufficient in providing permanency for young people. By contrast, an SGO would only provide that legal guarantee until the age of eighteen at which point an SGO would lapse.

Deterrents: birth parent contact

Whilst a general lack of support was a concern for carers who were considering an SGO, some specific support elements stood out to them. One example was contact. Following an SGO, the kinship carer would be expected to play a greater role in facilitating contact until they would take over altogether. If their relationship with birth parents or extended family was strained, this could be an overwhelming prospect.

"I think that sometimes kinship carers are reluctant if they haven't got good relationships with birth parents... because it will fall to them to be the 
supervisors and the facilitators of contact... and also that their support is limited..." (SW115)

Equally, where the carer's relationship with birth parents was positive, an SGO could be perceived as a threat to that relationship. Many birth parents felt undermined by SGOs, particularly where the implications had not been sufficiently explained to them. Equally, birth parents often disliked the prospect of surrendering the lion's share of parental responsibility to their own relatives.

"Coming back to the SGO as well, the other reason was the Mum. Until she got accustomed to the decision, she didn't want the SGO to begin with either. Because she kind of got the impression that SGO meant adoption and didn't really want to give away her parental consent either." (KC112)

\section{Deterrents: supporting recovery and promoting wellbeing}

Meanwhile, for social workers, a common concern was that the review process was insufficient in helping a young person through recovery from neglect or trauma. The comparison between an SGO review and a looked after child (LAC) review were highlighted. This showed the multifaceted approach that the LAC process takes to monitor and support the young person's wellbeing. By contrast, the SGO review was perceived by social workers to be of little value.

"An SGO review doesn't even see the kids does it?"

"No, or any other professionals involved necessarily, you know, with the $L A C$ review at least you get a realistic view of how are they doing with school, are there any issues." (SSW)

This challenge was exacerbated by carer's reluctance to seek help for fear that the placement would be broken down by social services. This relates to the fear expressed in the previous section that stability may be undermined by a request for support. However, the following comment shows that this fear pervades even after an SGO has been granted and permanency established.

"Don't forget the SGO carers think uh oh here come social services to check you're okay, they want the review to pass without any hiccups." (SSW) 
But whilst the lack of ongoing support worried most social workers, one noted cases where support was deemed to be too high. They were concerned that SGOs were being issued inappropriately, used solely as a means of reducing the LAC population rather than providing the benefits of an SGO for a carer and young person.

"Seems to me an SGO is basically where Social Services don't get involved anymore, but there's been SGOs where the Social Services have still been on a year down the line, so what's the point in an SGO?" (SW121)

Motivators: independence and kinship identity

Arguably, there are numerous benefits for both the young person and carer in taking out an SGO. One such benefit is the independence from social services and the ability to raise the young person without the regulation that they provide.

"I just want them off my back... I still got them with me for twelve months. But that's the only way out." (KC110)

The ability to make decisions over factors such as haircuts and holidays is also seen to be beneficial. Whilst under local authority the carer would need permission for such things, the Parental Responsibility that is granted by an SGO provides carers the freedom to make such choices.

"I think it's just to have that... well, it's to have parental responsibility, so she doesn't have to be coming back and forth to the local authority for decisions. So ultimately, the fact that she would share parental responsibility would mean that, you know, that she would be their guardian, and that she would make decisions in their best interests." (SW112)

The prospect of being in control was an appealing one for some carers who found social services intervention to be over reaching.

"Knowing that there would be no more social workers and everything will be down to me. They were my decisions and that's it. And you know, mum can go and complain if she wants to, but if I say no, it's no." (KC118)

An SGO does not simply provide independence for the carer, but can also be beneficial for the young people. For most, social workers were gatekeepers to 
decisions that they felt their carers should be able to make independently. Whilst most had a good relationship with their social worker, many disliked the continual assessment and review process.

"I had seven cases, I've got four left, and two of them are SGOs now. But you know, from the child's perspective they just don't want the LAC reviews and the Social Workers coming." (SW118)

It was not only the restrictions from social services that motivated carers to apply for an SGO. Intervention by birth parents, whether through action or inaction, was sometimes found to be a driving factor for carers.

"Because we're giving the carers a little bit more power basically... [with an SGO] they don't have to keep asking mum or dad, we've got a disappeared mum sometimes, and they're stuck in that, you know, "I can't apply for a passport because mum's on a bad month and I can't find her, I don't know where she is." (SSW)

\section{Motivators: permanency}

The element of control with an SGO also extended beyond short-term plans. With many of the carers reaching retirement age or beyond, the possibility of mortality was often a concern. In particular, kinship carers were keen for the young people to remain in the family in the instance that the carer was incapacitated. An SGO provided carers with the opportunity to plan ahead by nominating a guardian in such circumstances.

"With the SGO I would feel more. Because if anything should happen to me, then I wouldn't want them to go into care. You know, erm.. they've been... and I want them to stay in this family unit. so... I'd feel more in control by doing it this way." (KC103)

Many of the advantages for carers were recognised by social workers, even those who felt that the way in which SGOs were being used was inappropriate. For many, the downfall of an SGO was a perceived or real lack of support for carers. When asked what they would put in place in terms of support, most provided vague responses and indicated uncertainty regarding the optimal way forward. However, one social worker had no such difficulty and had a clear understanding of the needs of special guardians. 
"Access to training, financial support, access to respite services... Maybe even a supervising Social Worker if that was felt appropriate. It's not always going to be the case, some are perfectly capable, they've got an established relationship with the child and I'm sure that they can just get on with it but I think in a lot of cases they're just left to fend for themselves and they need, you know, access to, often the kids that they're taking on have significant sort of attachment difficulties and these are not your average child, they don't have average needs, they have needs that are over and above, just because they're kind of related to these children doesn't mean that they're magically going to be better at parenting them or need less support than the foster carer would." (SW108)

\section{Summary}

In order to understand perceptions of permanency in kinship care, it is important to establish the factors that motivate and deter kinship carers from applying for an SGO. A number of deterrents were identified including the perception that an SGO is a cost-saving measure for LAs rather than a beneficial route for kinship carers and young people. Interestingly, this view was shared amongst a small group of kinship carers and social workers. The latter expressed concern that SGOs were sometimes being used inappropriately and resulted in the withdrawal of support from placements that would have benefitted from remaining in the LAC system.

The loss of support seemed to be a common deterrent for kinship carers, particularly where the child expressed behavioural or mental health concerns, or were deemed to be struggling academically. This was particularly notable when the child was older and nearing the point where they would soon have access to leaving care services and the relatively new 'When I'm Ready' scheme. Equally, where children were young, the perceived inflexibility of SGO support packages deterred carers who were concerned that the child may develop further needs in the future where support services could be beneficial. Furthermore, the carers also expressed concern at losing less intensive support, such as advice offered by social workers over the phone. Having a designated social worker who could be accessed should a problem arise was a source of comfort for many kinship carers. 
Furthermore, both positive and negative relationships with birth parents seemed to be a deterrent. Those who did not have a good relationship worried that they would be expected to facilitate contact and be left vulnerable to pressure by birth parents to increase contact. Others worried that rocking the boat would jeopardise their own relationship with the birth parents and lead to further complications in the family dynamic.

Some key benefits to an SGO were identified, including the ability to exercise Parental Responsibility over decisions such as haircuts and school trips. Equally, where birth parents were frequently absent, or where the relationship was unstable, carers were able to provide consent in areas such as passport applications without the concern of trying to contact the birth parent. Independence from the LA was also deemed a major benefit of kinship care, with carers relishing the lack of intrusion that an SGO could grant them. Finally, an SGO provided security and stability, and a normal family identity for carers and young people, particularly where carers were older and wishing to make plans in case of incapacity or mortality. The SGO gave them the right to appoint a guardian who could take over the child's care, which brought them some peace of mind.

The tables on the following pages present the primary findings for each of the research questions. 
Thesis objective: To examine the implications of a shift in the way that social work theory is a child-rescue model, to a kinship model.

\section{Table 36: Primary findings, research questions 1-7}

Aim

Research Question

RQ1: What is the initial post-care destination of 'early care leavers'?

The most comm leavers was retu

RQ2: How does final placement type relate to post-care destination for children and young people and does this differ for those in kinship care?

Children and you more likely to lea early from mains

RQ3: To what extent do Special Guardianship Orders (SGOs) provide permanency for young people?

All of the young their carers for th period

RQ4: What factors influence whether an application for a $\mathrm{SGO}$ is made?

Genetic relatedn Section 20 each with an SGO.

1. Exploring factors affecting stability within formal kinship care and postcare.

RQ5: What measures do local authorities take to support SGOs of early leavers and are they dependent on preleaving placement care order type?

RQ6: To what extent are 'care leavers' who age out already 'staying put'?

RQ7: How does pre-leaving care placement type relate to post-care destination for young people who 'age out' of care and does this differ for those aging out of kinship care?
All Special Guarc have received ot Guardians and th subject to an ICC supervision.

Almost a third of least 12 months

All of those aging carers for the du Comparatively, the same. 
Table 37: Primary findings, research questions 8-18

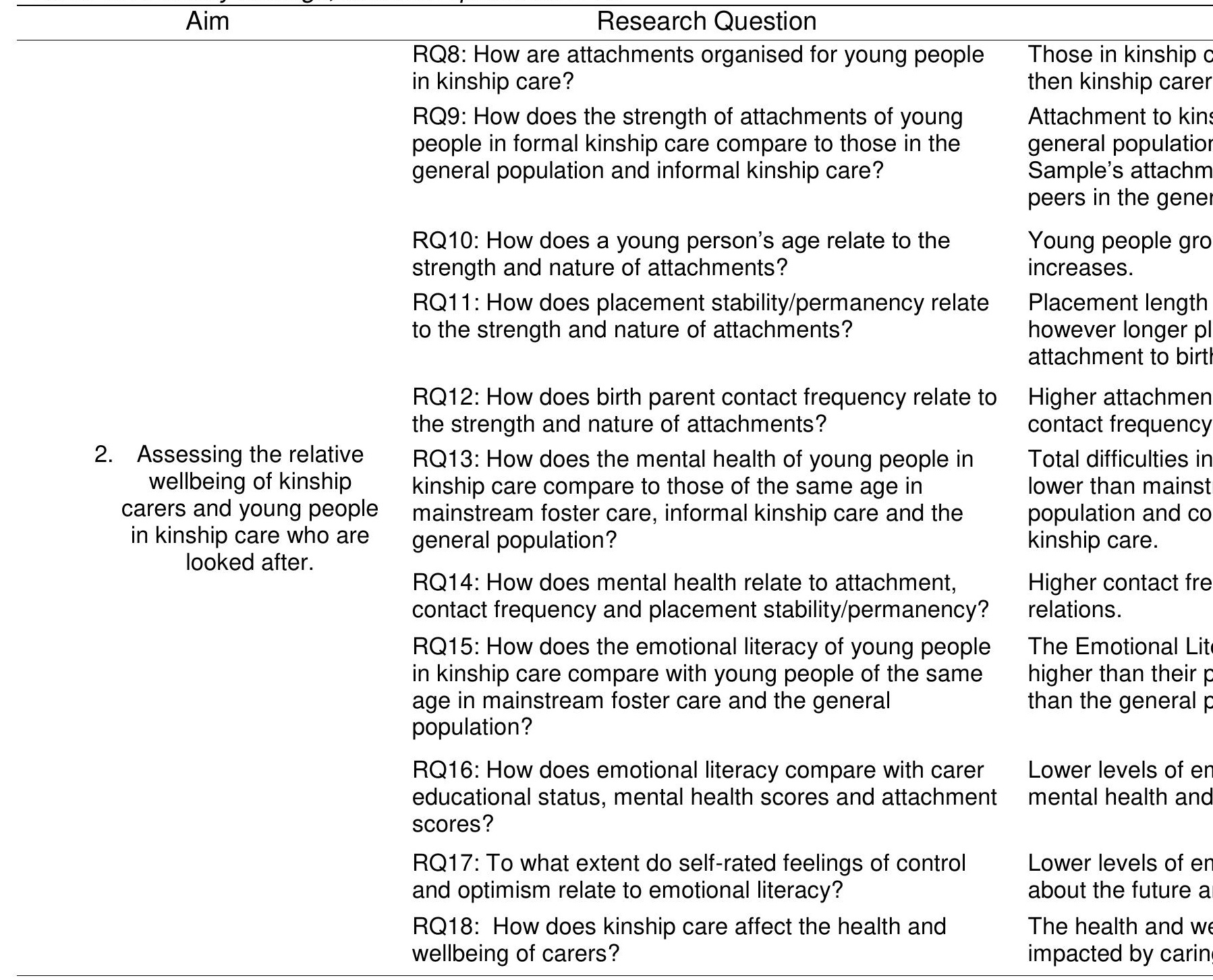


Table 38: Primary findings, research questions 19-21

Aim

Research Question

RQ19: What is the standard of literacy of young people in formal kinship care?

Literacy levels of you than average, howev expected based on $\mathrm{c}$

3. Assessing the educational achievement of looked after young people in kinship care.
RQ20: How does educational achievement in kinship care compare with other looked after children and the general population?

RQ21: Which placement objectives and characteristics are prioritised by social workers, young people in kinship care and their carers?
Achieving as predicte kinship sample than Literacy and numera than the general pop

Kinship carers, socia safety, feeling safe ar priorities of a placem 
Chapter 8: Discussion 


\section{Chapter 8: Discussion}

Chapter eight presents the discussion in four separate sections. The first three discuss the qualitative and quantitative results in relation to the focus of each of the three study aims; stability and permanency, wellbeing, and education. Tables 36, 37 and 38 on the previous pages outline the key findings in relation to each of the research questions and are used for reference within the discussion chapter.

The final section of this chapter addresses themes that emerged from the qualitative data, namely family, hardship, and the professionalisation of kinship care. Whilst not previously identified as areas for exploration, the inductive analysis of qualitative data led to the emergence of these key themes. Given their importance to participants within this study, it is essential that these areas are discussed.

Each of these sections are discussed in relation to kinship care theory and form the conceptual basis underpinning all of the study aims.

\subsection{Stability and permanency in kinship care}

The first aim of this study was to explore the stability and permanency of kinship care for looked after young people. This section will discuss four areas of stability and permanency. It begins with a discussion of the qualitative indicative factors affecting stability within formal kinship care. The discussion then moves on to explore both stability for early care leavers and permanency. Finally, the discussion focusses on the issue of placement stability for those aging out of care.

\subsubsection{Stability within care}

The literature review discussed the concept of stability in social work. It was identified as a positive factor in improving outcomes such as physical, psychological and behavioural wellbeing, attachment, and consistency in education (Harden, 2004; Rubin et al., 2007; Schofield, 2002; Simms et al., 2000). Furthermore, there was some evidence to suggest that kinship care 
placements tended to be more stable than their mainstream equivalent (Chamberlain et al., 2006; Farmer, 2009; Iglehart, 1994; Perry et al., 2012). Importantly, previous research had indicated that kinship carers may be more resilient in placements where children present challenging behaviour, something the qualitative findings from this study seem to support. Whilst not directly studied as a research question, emergent themes from interviews and focus groups provide evidence that aids in addressing the first aim of this project. For example, carers often noted that the challenging behaviour presented by the young people would likely have caused a mainstream placement to break down and that it was their kinship bond that preserved the stability of the placement.

The resilience of kinship carers was also noted as a factor by social workers who deemed the stability it yielded to be beneficial. However, where behaviour was extreme, the effect on carers could be detrimental. Some reported that negative behaviour could have an effect on their own physical or mental wellbeing. What is unclear is whether this influenced the wellbeing of the children in their care although in a couple of the reported cases there was some indication that it did. One case in which this was evident showed a kinship carer who was reminded of past trauma by the behaviour of the young person. Consequently, a negative identity was being imposed upon the young person which may lead to poorer emotional outcomes. Meanwhile, a few of the carers also spoke of historical caring responsibilities for grandchildren where behavioural issues had led to carer's poor physical health and, as a consequence, placement breakdown. The concern attributed to this pattern was the reluctance of such carers to seek further help where they were struggling for fear of the children being removed again. Being kept informed of long-term and contingency plans (for example, respite with other kin in case of sudden illness) was reassuring for carers, whilst a good relationship with both the supervising and children's' social worker may go some way to mitigating their worries.

Health was also reported as a factor affecting within-placement stability. The reports of poor physical health attributed to the stress of caring replicate, to an extent, findings from studies into informal kinship care suggesting that the support of the local authority is not a sufficient barrier to distress (Farmer, 2009; Selwyn et al., 2013). Although, while previous literature pointed to poor health leading to 
an increased need for respite services (Goodman, Potts, \& Pasztor, 2007; Selwyn et al., 2013), it seemed to be less of an issue in formal kinship care. This may be due to screening and registration of formal kinship carers which is not necessary for children who are not LAC. The assessment process may serve to ensure that formal kinship carers are fit to provide the care that young people provide. This did not prevent the caring responsibilities from taking their toll on carer's physical health. One explanation that was provided for their declining health, aside from the natural aging process, was the priority given to the children's health appointments. The demands of caring for a looked after child are high with persistent meetings, reviews and statutory health appointments for the young people. Where carers were offered medical appointments that conflicted with their caring responsibilities, there was a tendency to prioritise the young people. This meant that their own health needs were not being met which would then impact upon their ability to provide care.

The age of carers has been a concern in previous literature in terms of impact upon permanency (Selwyn et al., 2013). Whilst a kinship carer may be adequately healthy to care for a toddler when the placement commences, it is difficult to predict whether their health will remain adequate as the placement progresses. In some cases placements last until the age of eighteen meaning that carers are agreeing to almost two decades of commitment. However, whilst informal carers and the young people in their care regularly cite their concerns over their age and consequently declining health, it was less commonly noted by formal kinship carers. Where age was mentioned, it tended to be in relation to contingency plans, such as having another relative registered to take over care in case of illness or mortality, or in relation to the limitations that age imposed. The generation gap, for example, was a challenge that carers felt unable to overcome. Some felt that the age gap made it impossible to provide the same social interaction as a parent would such as playing sport or imposing boundaries with the young people. However, kinship carers felt overall that age did not have much of an impact on their ability to care, aided by the reassurance that having appropriate contingency plans in place could provide.

In turn, having a contingency plan was reassuring for the young people who knew what would happen if something were to happen to their carer. In contrast to the 
young people in informal kinship care in Selwyn, Farmer, Meakings and Vaisey (2013), the majority of the young people in this study were aware of the procedure should their carer become ill. This is likely part of the reason that young people were less concerned by the future than their informally cared-for counterparts. It should be noted that the inclusive nature of formal kinship care proceedings, which ensure the inclusion of the child to the level appropriate to their understanding, may have been a positive factor in this respect. Keeping children involved in the decision making and planning surrounding their care ensures that they are kept informed in a way that those in informal care are not. The perception of stability that this brings is likely just as important as actual stability as it allows young people the security to form attachments and settle in placement without fear of being uprooted. That said, neither total placement length nor perception of permanency in placement had a significant impact on the young peoples' strength and difficulties (SDQ) score. This may be again due to the planning process. As all of the young people will have been involved in the planning process to the level of their understanding, they may be more aware of plans than their peers in informal care. As a result they may be just as settled regardless of whether or not they are expecting to move on in the future, because they are aware of the plans in such instances.

Overall, kinship carers were keen to provide stability for the young people in their care, often citing stability as a motivator for providing care. The findings provide depth in understanding some of the factors affecting stability in formal kinship care. Interviews with carers, social workers and young people have also shown that stability is valued as a placement outcome by all parties, and its value in supporting wellbeing is recognised.

\subsubsection{Stability for early care leavers}

Whilst previous studies have focussed on young people who 'age out' of care, a large proportion leave care before the age of eighteen (StatsWales, 2016b). There is a dearth of research examining the destination of these 'early care leavers'. Consequently, the first two research questions sought to explore post- 
care destinations and any relationship these may have to final pre-leaving care placement type.

Overall, the most common post-care destination was return to birth parents with more than $40 \%$ being reunited upon early discharge from care. Furthermore, the results indicated that placement type pre-leaving care is related to post-care destination, with those in formal kinship care significantly more likely to leave via the issue of a SGO than their mainstream counterparts. By contrast, young people leaving mainstream foster care placements were significantly more likely to return to birth parents.

Whilst returning to birth parents was less common for young people leaving kinship care, with only $31 \%$ doing so, it may be less of a disturbance than for the mainstream foster care cohort. The nature of kinship care is such that any attachment formed during a kinship placement is not jeopardised by the child's reunification with birth parents. Rather a kinship carer is expected by social norms to remain a part of the child's ecological system in contrast with formal foster care. The co-operative nature of the theoretical kinship relationship means that reunification becomes a shift in the caring dynamic rather than a total displacement of the child from their ecology. This corresponds with findings from the second phase regarding attachment. Young people had formed multiple attachments, including strong relationships with kinship carers even where the young people aspired to return to their birth parent. This suggests that young people feel able to bond with kinship carers, with the relationship changing rather than being jeopardised by reunification.

This corresponds with the ecological systems theory discussed in chapter 3 which emphasises the need to look at the individual in the context of their wider ecology rather than as separate entities in themselves. Also discussed was the benefit of the preservation of the majority of a child's ecology provided by kinship care. It is not uncommon for young people to live within the same neighbourhood as they had previously, sometimes even the same street, and for their school and health providers to remain the same. The descriptive statistics presented at the start of Chapter 6 also support this, finding that a number of young people remained in the same street when they moved into placement. This means that there is less 
disruption to the wider elements of their ecological system and therefore increased consistency. This is equally true of the need for a stable placement. If a child is constantly moving from placement to placement then their system is in a constant state of adaptation, whilst a stable placement provides minimal disruption to their ecology. Furthermore, long-term contingency planning allows the family to plan ways to minimise disruption and young people to pre-emptively adjust to the change.

Previous studies have indicated that around a third of young people who return to their birth parents will re-enter care within five years (Mc Grath-Lone, Dearden, Harron, Nasim, \& Gilbert, 2017). The stability for these young people is therefore undermined by their repeated removal and return to the parental home. This may have implications for the wellbeing of young people, foremost in their ability to form meaningful attachments, but also in accessing physical and mental healthcare. It is therefore significant that the results have shown that differences in the rate of reunification exist between types of pre-leaving care placement. In particular, SGOs were more commonly granted to kinship carers as a permanency option, with social workers reporting that kinship carers were particularly encouraged to pursue a SGO. This will be addressed in the next section.

\subsubsection{Permanency for early care leavers}

Research questions 3-5 sought to explore the characteristics of special guardians, explore the stability and permanency of SGOs and establish how SGOs are supported by the LAs. As a relatively recent addition to family law, little is known about special guardians or the extent to which an SGO provides permanency for young people. Despite this, government statistics indicate a continuous rise in the number of young people leaving care via the issue of a SGO (StatsWales, 2016b). However, data collection strategies meant that previously, pre-leaving care placements for young people subject to a SGO could not be established. The results from this study indicate that young people in formal kinship care are significantly more likely to leave care early via the issue 
of a SGO than those in mainstream foster care. In some respects, this is unsurprising as many carers felt that the level of intrusion from the local authorities was disproportionate to the needs of a kinship placement. Without the identity of being professional carers, the statutory requirements seemed to present an unwelcome level of interruption and restriction on their family life. The prospect of no longer having that level of intrusion was appealing to many kinship carers and often motivated them to apply for an SGO. Some were overt in their explanations of this and how they intended to use an SGO to get out of a system that they disliked.

Perhaps more concerning is the mention of direct pressure to apply for an SGO from the local authority. Selwyn and colleagues (2013) discussed reports of informal carers being encouraged to take out an SGO, sometimes with the threat of adoption if they failed to do so. Interviews with carers and social workers in this study revealed that this phenomenon was not restricted to either informal carers, or historical reports. Rather, formal carers within the study reported feeling pushed into applying for an SGO by persistent social workers. Far from being a feeling unique to kinship carers, social workers themselves noted occasions where they were explicitly told that they should push a kinship carer towards an SGO. There was a feeling of being between a rock and a hard place as managers strove to reduce the number of LAC via the use of SGOs and social workers felt themselves pushed to promote them in cases where they deemed them to be inappropriate or where the carer was reluctant.

Special Guardianship Orders in themselves were seen as being a positive route. Where they were used appropriately they reduced the limitations on the carer whilst reducing time that social workers needed to dedicate to a case that they felt was safely self-sufficient. The worry raised by this study is that they may not always be used appropriately and that the desire to reduce the LAC population and provide permanency can dominate other factors. In such cases permanency is sought for permanency's sake without equal weighting being given to other outcome variables. Whilst a positive goal, it is only one factor to consider and pushing a family to independence from the LAC system too early may have consequences for the child, carers and their wider ecology. The social workers themselves noted that they were anticipating SGO breakdowns within the near 
future as a result of inappropriately supported SGOs. It would be impossible to infer that the placement would remain stable if the child had remained LAC, but social work professionals certainly felt that would be the case. For the duration of the eighteen-month follow-up period, however, none of the placements had broken down. This gave a novel insight into the stability of SGOs in kinship care, suggesting good stability in the medium term and supporting research conducted in the wider care population by Wade and colleagues (2014).

This study was also able to determine previously undocumented motivators and deterrents to applying for an SGO as a kinship carer. Aside from the desire for independence from local authorities, kinship carers felt a sense of duty and obligation to provide care. A unifying aspect was the social expectation and understanding of the function of the family unit. There was a common comprehension that family are supposed to step in and provide care for young people when their own parents cannot. This was echoed by social workers and, in the experience of kinship carers, by mainstream foster carers who had verbalised this expectation in the past. Whilst some of the carers did not volunteer, but waited to be asked to assume the role of carer, all felt that the child's rightful place was within the kinship unit. This was enhanced by negative perceptions of mainstream foster carers. Whilst most were respectful of mainstream carers, they expressed mistrust and queried their motivations. Many seemed to feel that their own motivations as kin were purer than those of mainstream counterparts, likely reinforced by social conditioning.

Interestingly, when related to permanency, being a single female carer did not deter kinship carers from applying for an SGO. By contrast, there were no single male applicants during the study period. The reasons behind this are impossible to determine without further examination, however some theories merit discussion. It may be that single male carers are less likely to be approached to assume caring responsibilities at the outset of the placement. This would mean that fewer were in a position from which they were able to make an application. Alternatively, it may be that single male carers were less willing or less pressured to apply for an SGO, encouraged instead to retain the support of the local authority. Both of these suggestions are based on theories of the gendering of caring roles. Historically domestic labour, including childcare, was performed by 
females (Warren, 2003). The engendering of labour has been diminished over the past century with the division of labour becoming more equalised (Sullivan, 2000). However, the extent of this equalisation is questionable and both external and internalised concepts of gendered labour are retained. This may mean that female carers are more inclined to adopt caring responsibilities than males. Equally, it may mean that structures such as local authorities may subconsciously promote a gendered approach to carer assessments.

Study participants also noted a number of deterrents to applying for an SGO, the most common being a fear of abandonment. For many, the support of the local authority had become so entrenched into their coping strategies that the prospect of jeopardising support seemed unwelcome. This was particularly prominent when the birth parents were deemed to be challenging or the young person displayed especially challenging behaviour. Where birth parents were forceful in demanding additional contact, the local authority could be used as the "bad guy" by carers. With an SGO, changes to contact would be at the carers' discretion and where contact was not deemed positive the carers felt that it would leave them vulnerable to manipulation. This factor was theorised in the literature review, although the extent to which it seems to influence carers' decision-making is perhaps surprising. Furthermore, financial disadvantage was cited in previous literature as a possible demotivating factor. Whilst this study supports that claim to an extent, kinship carers emphasised that the day-to-day advice and support of the local authority was a bigger driver. Remaining within the LAC system gave the young people and their carers access to specialised services, assistance with contact arrangements and carer training. Whilst there was some indication from local authorities that these services may still be offered on a discretionary basis, the individualised nature of SGO support packages made carers wary. Equally, the potential for support packages to change at annual review was too much of a gamble.

The results seemed to insinuate that if a guaranteed level of support was available then more would go for SGO. However this generated a more prominent question: how much support do special guardians actually need? On the one hand were carers and social workers who believed that an SGO was a means of respecting the capabilities of the carer and placing the responsibilities of 
guardianship entirely into the hands of the carer. On the other hand were carers and social workers expressing the need for further intervention, the justification for which being that the young people were still in recovery from abuse or neglect. Whilst providing stability and permanency in a kinship home would likely promote good outcomes, it would not necessarily be enough to facilitate recovery. This seemed to be recognised by local authorities who provided some form of support or supervision to more than half of Special Guardians in the sample. The reasoning behind the differing levels of support were impossible to determine using auditing methodology. However, it may be notable that the highest proportion of ongoing support was granted where interim care orders were being replaced by an SGO. Due to their temporary nature the difference may lie simply in the amount of time a placement has had to settle before moving to SGO; one might expect a Full Care Order to have been in place for a greater duration than an Interim order thus for conflicts surrounding contact to have subsided.

\subsubsection{Stability for young people 'aging out' of care}

Young people who age out of public care have previously been found to have difficulty in making the transition to adulthood (Reilly, 2003). However, the stability of post-care destinations and the extent to which young people remain with their carer, particularly in kinship care, is unexplored. Research questions 6 \& 7 sought to address this gap in the literature. The study results revealed that young people in kinship care were less likely to leave care at eighteen than their peers in mainstream foster care. This may be due, in part, to the higher rates of young people in kinship placements moving towards permanency via earlier routes such as SGO or Residency Orders. For those who had not achieved permanency via a legal order before their eighteenth birthday, the picture remains unclear. Despite auditing all care leavers from a 12-month period, only three young people "aged out" of kinship care during the study. This makes it impossible to generalise the findings to the wider kinship care population, although it is encouraging that all three participants remained with their carer for the 12-month follow-up period. Further research with a larger sample size is warranted, although it may imply that permanency may be achieved in kinship care without the need for a legally 
binding order such as an SGO. In some cases, the identity of family is a solid enough foundation to ensure permanency.

The findings highlighted regarding those "aging out" of care may have implications for the recent 'When I'm Ready' scheme (Social Services and Wellbeing (Wales) Act 2014) which grants the young person the right to remain in a foster placement until the age of twenty-one (or twenty-five if in full time education). In contrast to England's equivalent scheme, 'Staying Put' (Children and Families Act 2014), local authorities in Wales have not received an increase in funding to provide for these extended placements (Jarrett, 2016). The results of this study, looking at the period before the introduction of When I'm Ready, show that more than $28 \%$ of care leavers aging out already remain with carers for at least twelve months after they cease to be looked after. The proportion of those in foster care staying put was even higher accounting for $48 \%$. As such the results suggest that rather than pave the way for extended placements, schemes such as When I'm Ready are catching up with existing practice.

With regards to the first study aim which sought to explore stability and permanency in kinship care, the findings from this study support previous assertions that kinship care placements provide an enhanced perception of stability and permanency compared with alternative placement types. This perception is also reinforced by greater permanency for young people in kinship care via the issue of a SGO. This study also highlighted concerns from practitioners that the focus on permanency, and in particular the push for SGOs, may have reached the point that permanency has become an aim in itself rather than a route to achieving other positive outcomes. Supervising social workers in particular vocalised apprehensions in the way that permanency is becoming an objective for senior management under pressure to reduce the looked after population. 


\subsection{The relative wellbeing of young people in kinship care}

The second aim of this thesis was to assess the relative wellbeing of young people in kinship care. This section will discuss the results pertaining to wellbeing in three sub-sections: mental health, attachment and identity.

\subsubsection{Mental health}

The mental health of young people in the care system has been of notable concern in past literature. Previous evidence suggested that young people in the care system generally experienced a higher level of psychological and emotional challenges than their peers in the general population (Clausen et al., 1998). Likely a consequence of abuse or neglect prior to the start of placement, some researchers expressed concern that limitations of the care system, such as continuous placement changes and inconsistent access to psychological services, were exacerbating these issues (Holland, Faulkner, \& Perez-del-Aguila, 2005; Rubin et al., 2007). However, there was some indication that kinship care placements could mediate behavioural or emotional difficulties to a greater degree than mainstream foster care (Holtan, Rønning, et al., 2005). The results of this study tentatively support the assertion that kinship care promotes better mental health than mainstream foster care (chapter 6, RQs 13-17). In particular, the results regarding mental health as measured by the strength and difficulties questionnaire (SDQ) indicate that both average score and the number reaching clinically significant levels of difficulty are lower in kinship care (see Chapter 6 , $R Q s$ 13). Equally, carer-reported emotional literacy scores show significantly more of the young people in kinship care scored 'Well Below Average' (24.1\%) than the general population (10\%) and 'Well Above Average' (20.7\%) compared with a sample from mainstream foster care (1.6\%). By contrast self-reported emotional literacy was not significantly different from either their peers in mainstream foster or the general population; the reasons for this are unclear.

Whilst the results from this study indicate that young people in kinship care have more positive mental health than their looked after peers, it would seem that they are still lagging behind the general population. In some respects this is to be 
expected as the young people are looked after. In order to be within the care system a child must have suffered a serious degree of neglect, abuse, bereavement or rejection from parental caregivers, any of which are likely to have an impact on a child's emotional development. Certainly, these results support that theory suggesting that whilst kinship care may mediate the emotional impact, the young people's history still poses challenges for them throughout placement. Furthermore, comparison with an informal kinship care sample found that the results were consistent. This may have implications for future practice as it would imply that kinship care, rather than LAC status, may be the key variable in promoting mental health. Needless to say, future research would be warranted to investigate this concept further and to examine the elements of kinship care that are effective in promoting mental health. However, the results from this study serve to strengthen previous findings in support of kinship care (Holtan, Rønning, et al., 2005).

Two elements of kinship care that had been suggested in previous literature as playing a key role in mental health were attachment and contact with birth parents (McLaughlin, Zeanah, Fox, \& Nelson, 2012; McWey et al., 2010). Comparison between the results of the SDQ and attachment measures showed no significant relationship between the two factors. Of course, there are some limitations to using standardised measures to assess abstract concepts. The operationalisation of variables is a common yet contentious practice, and the extent to which attachment can be truly be understood in the context of a questionnaire is limited. The IPPA-r compounds this through the use of a single questionnaire which fails to account for reciprocity in interpersonal relationships. However, the IPPA-r shows good convergent validity with other measures suggesting that the concept is effectively operationalised. It is therefore interesting that in this sample attachment and mental health seemed to be unrelated.

Similarly, neither contact frequency nor the child's sense of being listened to were found to relate to SDQ score. The implications of these findings are two-fold. Firstly, it may be that no relationship exists between the variables, in which case it is crucial that we identify the factors of kinship care that promote mental health in order to ensure that they are identified in future carer assessments. 
Alternatively, it may be that the mechanism by which these factors have an impact has been oversimplified by the analysis. Each factor was compared directly with the outcome variable (SDQ score) without accounting for the effect of other variables. Whilst outside the realms of this exploratory study, a more complex analysis accounting for multiple variables may yield a relationship between attachment, contact and mental health.

Emotional literacy was found to relate to young people's feelings about the future with those feeling more positively about the future attaining higher emotional literacy. Conversely, those who worried about the future had lower levels of emotional literacy. This would indicate that good levels of emotional literacy mediate the extent to which young people worry about the future. The journey of a child through the care system is often unsteady with frequent placements changes. Whilst there is evidence that kinship care provides a relatively stable journey, it is complicated by factors such as carer age and health and the potential to be reunified with birth parents. These factors have the potential to generate anxiety for young people who may face an uncertain future. If a child's emotional literacy can impact upon their feelings about the future, and if emotional literacy can be improved, then it may offer an avenue to supporting young people in kinship care and improving mental health in the long-term. The implications also extend to other placement types, including mainstream foster care and provide some evidence to support the development and application of interventions promoting emotional literacy.

\subsubsection{Attachment}

Attachment Theory is an integral part of social work theory and, consequently, theories of kinship care. The importance of forming positive attachments to caregivers has been noted for decades, and yet attachment in formal kinship care, whilst hypothesised, has not been explored. This study sought to understand the way in which attachments are organised for young people in kinship care and how these attachments relate to other factors. The results showed that the primary attachment in the sample tended to be towards the 
kinship carer, followed by birth parent and then peer attachments (see Chapter 6, RQs 8-12). Interestingly the attachment to kinship carer was of a similar level to parental attachment in the general population. This may be an important finding as it supports the idea that kinship carers, when appropriately selected, become effective substitutes for parents not only in the practical aspects of care, but also the emotional aspects. By contrast, attachment to birth parent was lower than parental attachment in the general population. This may indicate that the young person is settled in placement and feels free to form attachments with kinship carers in place of "normal" parental attachments, safe in the knowledge that the attachment would not be in jeopardy. As such, the primary attachment is with the kinship carer, rather than the birth parent. This pattern of attachment was consistent across the age range of the sample.

The attachment scores were also analysed against a number of factors to explore their effect. Placement length was one such factor with results showing that length of placement had no notable relationship with attachment to kinship carer. This corresponds with kinship theories relating to the relevance of the pre-existing relationship between carer and child. Such theories would suggest that even if a child has only been in placement a short period, the role that a kinship carer had previously played in the child's upbringing would allow an attachment to be created. Whilst not always the case, as some carers had never met the child before they became their formal kinship carer, these results provide support to the notion that kinship care serves to promote previous attachments rather than attempt to create them. This is particularly relevant to the ecological systems theory of kinship care proposed in Chapter 3 . This theory posits that the strength of kinship care lies in its ability to realign existing relationships between the child and the various systems, rather than to replace them. In this respect, the child's pre-existing attachment to the kinship carer realigns from one of secondary attachment to one of primary caregiver attachment. Furthermore, attachment to birth parents was found to be negatively correlated with placement length, again showing this realignment of attachment rather than outright replacement. It may be that this process is easier for the young person than attempting to form a new attachment altogether. 
The study also explored correlations between contact frequency and birth parents and carer attachment. The findings showed that contact frequency and attachment to birth parent were moderately correlated to on another. This relationship was positive with attachment increasing as contact frequency increased. By contrast, contact frequency was not found to be correlated with carer attachment. This is an important finding as it indicates that, assuming it is appropriately managed, contact can have a beneficial impact on the child-parent attachment without undermining the child's attachment to the carer as their primary caregiver. It also provides further evidence to support the theory of multiple attachments that has previously been discussed (Haight et al., 2003). Meanwhile, attachment to peers was positively correlated with emotional literacy. A causational direction could not be established with regards to this factor, although it would provide an interesting basis for further exploration. Once again, if a causational relationship can be established, it would pave the way for interventions which target the improvement of emotional literacy with the potential for numerous positive effects.

Whilst efforts were made to find comparable data with which to compare the Inventory of Parent and Peer Attachment (IPPA-R) scores from this study to a mainstream sample, no comparable studies were found. Where the IPPA-R had been used with a mainstream sample, studies tended to feature small sample sizes vulnerable to bias (McSherry, Malet, \& Weatherall, 2016). As such, we cannot explore whether attachment to carer in kinship care is stronger than observed in mainstream foster care. However, with increased placement stability in kinship care, we might expect it to be so. Comparison with an informal kinship care sample found that attachment to carers was similar to that in formal kinship care. This suggests that the attachment challenges previously noted in mainstream foster care, in particular attachment to carers, may be more related to the placement itself rather than the LAC status of the young person. This lends weight to the theory that kinship care may nurture better child-carer attachments than mainstream placements. 


\subsubsection{Identity}

The final aspect of wellbeing to be discussed is the concept of identity. As defined by previous literature (Suh, 2002), identity is an important consideration in social work with implications for mental, emotional and developmental wellbeing. Thus, whilst not explored through a specific research question, qualitative data regarding identity from the study's second phase is useful in the context of the second research aim which sought to assess the relative wellbeing of young people in kinship care. For some time there has been concern that entering the care system can jeopardise a child's sense of identity. There was some previous evidence that kinship care preserves the identity of a young person and that young people value this preservation. The results of this study certainly support these notions with young people commenting on the value of knowing who they are and where they fit.

Identity is preserved in care through a number of routes, one of which is life story work. Whilst in mainstream foster care this work adopts a formal process whereby a social worker allocates time to work through a 'life story book' with the child, in kinship care the transmission of a child's life story tends to be more natural. Kinship carers described the benefits of having a basis of knowledge and being able to pass on family history anecdotally in a way that mainstream foster carers cannot. Equally, rather than allocate specific time to work on a child's identity, the transmission tended to be spontaneous and comparable to the way in which it is passed on in a natural family environment. In some cases the quality of life-story work reduced the quantity of formal work required, whilst in others it eradicated the need entirely. This was seen as universally beneficial as carers aimed to minimise the amount of intervention required from social workers and social workers in turn favoured the less formal approach.

There were some limitations to this natural approach to life-story work. In a small minority of cases there was the potential for less life story work as carers were too upset or traumatised by the actions of birth parents and others. This was not unduly concerning as the social workers were able to provide any necessary intervention in the same way that they would for a mainstream placement. In this respect, formal LA support services can be an important and necessary structure 
for young people looked after in kinship care. This may have implications for permanency planning, particularly where a LA seeks to withdraw support services following a court order such as a SGO. Perhaps more concerning was the potential of reinforcement of negative identity traits as carers struggled with past trauma. One example was noted in which a carer who had suffered domestic violence reinforced a negative identity on the young person. In this case, social workers were presented with additional challenges to promoting identity that would not be likely in mainstream placements. Consequently, it is impossible to conclude that kinship care is universally beneficial for promoting a child's identity. This poses challenges for social workers in assessing, balancing and managing carers' ability to facilitate life-story work and the promotion of identity.

In addition to promoting identity, kinship care also seemed to impact upon how a child perceived their own identity. In particular, the young people in the study did not identify themselves as looked after children, but simply as living with family. This was an important discovery as it may help to minimise the stigma that reportedly surrounds the care system. It also supports previous research, albeit in informal care, that kinship placements preserve family identity and diminish the impact of looked after status on identity (Selwyn et al., 2013). The identity of family was an important theme, and given the extent to which it is socially reinforced, it is not surprising. In addition to identifying as family, many carers commented on the importance of the family unit in providing emotional and social support and to reinforce their own sense of personal identity. Family identity was so important to some that they sacrificed paid employment, a source of personal identity for many, in order to care for their kin. This supports the theoretical basis of kinship care outlined in Chapter 3, particularly when understood through the epistemology of structural-functionalism. Whilst the nuclear family may be changing in favour of a wider kinship network, the concept of a family unit is still engrained in our fundamental concept of self.

Whilst the young people did not identify as LAC, the identity was being pushed upon them through statutory visits, particularly in school. Visiting the young people in school is an efficient way for social workers to speak with the young person without the interference of the carer and within an environment with which the child is familiar. It can also mean that social workers can combine visits, if 
there are multiple looked after children in a school, and save on time. However, previous research noted that children found having the choice of whether to disclose their status to their peers was important in preserving their identity and minimises stigma (Farmer et al., 2013; Selwyn et al., 2013). This study supports this, finding that students and carers disliked in-school visits from social workers for this reason. In some respects, when a child cannot choose whether to disclose personal information in this way, it may impact on their sense of agency. Agency can be an important aspect of promoting resilience, a protective factor against poor mental health. Consequently, the qualitative findings in this study are a key consideration for policymakers and social workers.

Given that preservation of identity has been found to relate to a person's overall wellbeing, it is clear to see why it plays a relatively prominent role in social work. Whilst the maintenance of a child's ecological system is an advantage in kinship care by promoting a positive identity, the intrusive nature of social work has the potential to undermine the benefits. Consideration should be given to the extent to which statutory requirements associated with being $L A C$, and the rigidity of the system within which these are enforced, impact upon the identity and thus the wellbeing of young people in formal kinship care.

\subsubsection{Health and wellbeing of kinship carers}

Research question 18 sought to explore the health and wellbeing of formal kinship carers following reports of poor outcomes from informal kinship care. The qualitative data collected indicated that a number of carers suffered from poor physical or emotional health, although the severity was less than previous studies have reported. For example, a quarter of informal carers interviewed by Selwyn and colleagues (2013) reported that they had difficulty climbing a flight of stairs, whilst a fifth struggled with basic tasks such as pushing a vacuum cleaner. By contrast, results from this study indicate that whilst some carers did sufferer from poor health, it did not interfere with kinship carers' ability to provide care. Some aspects of health and illness were attributed directly to providing formal kinship care for a young person. Carers reported suffering from strokes, depression and 
anxiety as a result of their involvement with the social care system. Others complained of health problems attributed to age that they worried would impact upon the wellbeing of the young person. The generation gap was of great concern to some carers who worried that their own poor health and age limited the opportunities of the young person. Equally, the loss of employment or retirement plans impacted upon the wellbeing of some kinship carers. However, some carers found that providing care for kin had benefitted their health and wellbeing by ensuring that they remained involved in social activities. One carer described abseiling with the young person, another described being connected to contemporary music and media in a way that they otherwise would not. For others, the formal support groups offered by the LA were a source of social networking, providing the opportunity to meet others with similar values as themselves.

Whether positive or negative, the way in which kinship care impacts upon the wellbeing of the carer is important. Primarily, the carer is required to be in reasonable health in order to fulfil the requirements of their role. Within the ecological system, the carer's role is often complicated. Many carers also provide support for other members of the kinship network, such as spouses, the child's birth parents, or other adult dependents. Furthermore, kinship care can be understood in Bronfenbrenner's ecological systems theory as a shift in the emphasis of responsibilities rather than replacement of the system. This, it is theorised, aids in fulfilling the functions of the family within a mutually strengthening model. Should the carer's health and wellbeing be adversely affected by the demands of providing kinship care, the system's structural integrity is threatened. Consequently, the findings from this study maintain previous research which proposes that LA support should be structured to the specific needs of kinship carers, and that their wellbeing should be considered alongside the needs of the child. 


\subsection{Educational achievement in kinship care}

Whilst generally considered an aspect of wellbeing, this study focussed on education as a separate aim. This was done in order to provide a deeper level of analysis via multiple research questions. As such, the final aim of this study sought to ascertain the level of educational achievement of young people in formal kinship care. The literature review outlined concerns surrounding the educational achievement of children and young people in the care system. Historically, young people in the care system have underachieved when compared to peers, although a relative dearth of evidence exists for those in kinship care. Where evidence did exist, it indicated that young people in kinship care faced many of the same challenges as their peers in mainstream foster care (Winokur et al., 2014). Having identified the methodological issues in measuring academic success, this study explored the attainment and then the achievement of young people in kinship care against their own cognitive baseline.

Research questions $19 \& 20$ examined the literacy attainment of young people in formal kinship care. The results indicated that attainment in both literacy and numeracy was lower for those in formal kinship care than the general population (see Table 33, page 201). In some respects, this result is expected. The kinship care population is one with a history of abuse, neglect, rejection or bereavement, all of which can impact upon a child's attendance and engagement with education. Consequently, developmental delay is more likely to be present than in the general population. However, when compared to their own cognitive baseline, the vast majority (85.7\%) of young people were found to be achieving as expected, with relatively few underachieving on word reading (14.3\%) and spelling $(9.5 \%)$. This rate of underachievement is significantly lower than in the wider care population where previous research has indicated that around two thirds underachieve in literacy (Rees, 2013).

These results indicate that whilst literacy attainment is indeed lower for those in kinship care than the general population, achievement is higher than previously thought. Furthermore, the differences highlighted between formal kinship care and mainstream foster care may suggest that some element of a kinship 
placement is uniquely beneficial to education. Given the emphasis on improving the educational performance of young people in care, this is an important finding.

There are some limitations to consider, namely the small sample size and nature of analysis. Whilst comparisons reveal a significant difference between the performance of the two groups, namely kinship care and mainstream foster care, analysis did not reveal causality. Thus it is not possible to infer whether differences are due to differences between the sample groups or due to the placement itself. It may be that the young people in mainstream foster care have suffered higher levels of abuse or neglect which affect their ability to attain highly in literacy. However, the results do indicate that formal kinship care does not have an adverse effect on educational attainment.

Interviews explored this effect further with some carers attributing academic success to the kinship placement. Some carers reported that, as family, the carers were more focussed on the child's success and consistently pushed them more than a mainstream carer necessarily would. Whilst a highly subjective explanation of the differences in attainment, it is one area that would be worthy of further exploration. Alternatively, some attributed the relative success of young people in education to the innate characteristics of a kinship placement. They emphasised that previously school had been a source of nurture for the young people. Now that the placement was able to provide a nurturing environment it enabled school to resume its primary role of education. The perception was that mainstream carers are not able to provide the same degree of nurture to the young people as they are restricted by regulations. Consequently, the consistent and nurturing environment provided by school could potentially impact upon a child's engagement with the educational aspects. Finally, the consistency of a kinship care placement allowed for consistency in schooling, which may have also given them an advantage over their mainstream peers.

Young people in kinship care placed an emphasis on the importance of education. The vast majority stated that they enjoyed school, with 'going to school' ranked $5^{\text {th }}$ out of 13 items on the task exploring priorities (see Chapter 6 , $R Q 21)$. The only factors that rated higher were love, being and feeling safe, and happiness. Meanwhile, comfort and being listened to were rated lower than 
education. Furthermore $72.2 \%$ of the young people were aspiring to careers that required either further or higher education. When compared with statistics reported in the literature, we can see that this is considerably higher than the $58 \%$ who had completed high school in a study from the USA (Benedict et al., 1996). Of course there are cultural limitations to such a comparison, not to mention the potential disparity between the aspirations of a young person and the actual progression of a young adult some years later. Regardless, these descriptive results tentatively suggest that the combination of a consistent kinship care placement and the intervention may promote progression to further or higher education for young people. 
8.4 Family, hardship and the professionalisation of kinship care

Many of the points discussed prior to this section have explored definitive concepts, however not all concepts in social work are so tangible. There are a number of abstract concepts that require discussion in order to understand the multi-dimensional nature of both social work and kinship care. The exploration and discussion of outcomes for young people in kinship care are naturally underpinned by wider theoretical debates surrounding concepts of family, the acceptance of hardship and the professionalisation of kinship care. Here, each of these concepts will be discussed in relation to the findings from this study and their connection with previous literature.

To a certain extent, the results presented in this section emerged from qualitative analysis. However, the role of each in understanding the context of kinship care and family, and in conceptualising kinship care, made their emergence inevitable.

\subsubsection{Family \& the acceptance of hardship}

Previous research has focussed on the identity of looked after children, although this study also found some evidence that kinship care also impacts upon the identity of the carer. As indicated by previous research (Backhouse \& Graham, 2012), and as predicted, carers often reported a degree of confusion over the roles that they fulfilled. The transition from grandparent, for example, to primary caregiver was challenging, particularly when birth parents were still heavily involved in the child's life. Added to this was the duality of being both family and a registered foster carer. Almost universally, the carers in this study stated that they were family first, however the role of a grandparent, parent and foster carer were not necessarily complimentary. The training, tending to be specified towards mainstream carers, was often impractical leading to much of it being ignored. Coupled with this was the expectation that they fulfil the requirements of the role of foster carer whilst not being paid to do so as professionals. This is despite a large number of kinship carers reporting that the additional caring responsibilities had left them with no choice but to resign from paid employment. In addition to financial hardship, this may also have impacted upon their internalised identity. 
Previous work has noted that paid employment, in addition to providing financial stability, also serves as a source of identity with loss of employment leading to loss of self-concept and depression (Kelvin, 1981).

Given the impact upon the carer themselves, it is perhaps strange that they would choose to become kinship carers. For them the answer was simple: because they are family and that is what family do. Indeed the results showed that kinship carers and young people do identify primarily as family before acknowledging their association with the social work system. Whilst the benefits of this kinship identity was discussed in 8.2, it may also bear relevance on the motivations of kinship carers. Primarily is the notion of group fitness and the seemingly biological urge to protect those with whom we feel a kinship connection. This seems to correspond with the feelings of obligation towards the young person as described by carers and their understanding of family. The second aspect of their reasoning, 'that is what families do', may be embedded more in the social construct of family and kinship. There seems to be a societal expectation upon kin that reinforces the internalised identity of family. This was not only evident in interviews with social workers who expressed that family should be expected to step in and provide care, but also in anecdotal evidence from kinship carers who described comments from mainstream foster carers. These included suggestions that kinship carers should not be paid for providing care to their own kin.

Of course the family unit, as discussed in Chapter 3 , is the foundation of structural functionalism and thus plays a critical role in the functioning of society. As such, it is not surprising that social expectations exist to reinforce it. As discussed in Chapter 3, however, the definition of kin seems to have extended beyond the realms of the nuclear family. The way that kinship carers identified kin seemed to vary. For some, having a blood tie to the young person was enough to define them as family, even if they had never met the young person. By contrast, others had no blood relation to the child and relied on a social comprehension of kin to justify their commitment. In either case, the carers were committed to providing long-term care for the young people and referred to them as kin. Where young people have never met the carers prior to placement, there may be implications for attachment. However, in terms of long-term stability, affection and dedication to the child, the degree of genetic relatedness did not seem to be a factor. 
Whilst the social ideology of family provided a level of commitment and motivation for carers, it could also provide challenges. The social expectations of family seem to differ from those of strangers. As such, the extent to which birth parents can pressure and intimidate kin may differ from the way in which they interact with mainstream carers. Consequently, carers may struggle to cope with the competing demands of their role as foster carer and their role as family. Many also described the challenges of having to choose between the young person and their birth parents, as some were forced to do. In such cases, the birth parents posed some kind of physical or psychological threat to the child and so carers were forced to prevent contact. The choice made by carers was always in the best interests of the young person. The reasons behind this are unclear, but two aspects were discussed that may indicate the reasoning. The first was that birth parents had often been supported and struggled, for example with an addiction, for a number of years before the placement began. By the time that the placement commenced and carers were asked to choose, a fatigue of sorts seemed to have set in which meant that carers felt that they had done all they could to support the birth parent and that further attempts would fail. Secondly was an ontological dissonance in the way that the young person and birth parents were perceived. Whilst the former was viewed as innocent and therefore deserving of help, the latter tended to be attributed blame for which the removal of support was a consequence.

Hardship was a common theme amongst kinship carers. Financial hardship, enforced adaptations to lifestyle, sacrifice pertaining to employment and retirement aspirations and the damaging effects of caring to physical and emotional health were far from rare and often led to a degree of distress with the carers. Whilst such tales of hardship might warrant an outcry for social justice in any other capacity, in reference to family such hardship is commended, perhaps even expected. Once again we also witness an ontological dissonance between the social rights of the child and those of the carer. It would seem that it is a social norm that the grandmother, for example, should make sacrifices for the young person. Again, this relates to the concepts of group selection and the function of family in which the role of older parts of the family unit is to promote the development of the young. Once again, this also seems to be reinforced by a 
social expectation that seems to have been internalised by the carers to form their own identity. Every time a carer mentioned something that they had given up, they qualified it with a comment such as "but they're worth it" or "but I wouldn't have it any other way". This behaviour suggests that, as a result of the social norms surrounding familial obligation, it is socially unacceptable for us to express loss when our kin have gained.

The concept of family was a positive factor in providing stability and permanency for young people, however it also led to a risk of poor quality placement as outlined by Farmer (2010). The sense of duty towards kin, and the emotional bond with the child, made carers fearful of asking for more help through fear of jeopardising the placement. As a result, young people may not be receiving the support that they require in order achieve to their abilities. Should intervention fail to be implemented in order to facilitate recovery from abuse or neglect, there is a risk that the cycle of neglect will continue to be perpetuated inter-generationally. Whilst kinship care has been promoted as a solution to this cycle, kinship networks are not necessarily enough to ensure that the young people are protected. Indigenous communities in Australia have a strong kinship identity and yet form a disproportionately high percentage of the care population (Tilbury, 2009). This leads to the conclusion that, certainly at this point in time, kinship networks are not enough, and that professional intervention is necessary to a degree. Now the question remains as to how we reach that balance. The strategy that has been used in the UK until now has been to increasingly professionalise kinship care, and in doing so integrating a high level of intervention. The next section will discuss the implications of this approach and propose alternative approaches supported by the theoretical model.

\subsubsection{Professionalisation of kinship care}

Whilst not an anticipated outcome of this research, an important finding from the qualitative elements was the impact of, and the discussion surrounding, the professionalisation of kinship care. In Wales, all carers of looked after children must register as formal carers regardless of kinship status (Care Planning, Placement and Case Review (Wales) Regulations 2015). This requires the same assessment process as a mainstream foster carer. There are no doubts that there 
are advantages to this strategy in respects to safeguarding vulnerable young people. However, as identified by carers, young people and social workers alike, this can challenge identity and normality and in doing so undermine some of the key benefits of kinship care.

In order to understand the impact of the professionalisation of kinship care, we need to refer back to the structure and function of social work. As outlined in chapter 3.1, social work can best be understood as a sub-unit of the family (Pratchett \& Rees, 2017). It exists to reinforce the functions of the family unit through reallocation of functional roles. Whether it has been adoption, fostering, boarding out or kinship care, the importance of the family structure has always been recognised by social work, albeit implicitly. Whilst the latent functions of social work have remained the same, to reinforce the family unit, the manifest functions have changed over time. Historically this has meant that social work has functioned in an interventionist pattern, removing children and replacing the family unit. More recently, a more holistic approach to the ecological system around the child has dominated and social work now, via kinship care, seeks to provide a more supportive role to the family unit. This involves altering the dynamic within a child's ecology rather than replacing it.

The challenge is that whilst a theoretical shift has begun, policy remains entrenched in the interventionist approach. Assessments, guidance and supervision are targeted at mainstream carers creating an element of redundancy with regards to kinship care. We see evidence of this in the reduced need for social workers to provide life-story work for identity, or with kinship carers' uncertainty or disregard of training guidelines. The result is that social work is now trying to fulfil both interventionist and supportive functions whilst adhering to an interventionist model. These contradictory mechanisms create challenges for all parties and generate a dissonance within which the family unit can be negatively affected.

The expanded understanding of kinship in which a family unit may include individuals with no relation by blood or marriage further complicates this. When an unrelated carer steps forward to provide care for a child, it can be difficult to determine the best mechanism through which to treat them. Should they be 
considered family due to the social and emotional connection they share with the child, or should social workers adhere strictly to government guidelines as they currently stand and treat them as mainstream carers? Given the importance of identity in social work, it seems that the former may provide a better solution. That is, if a child and carer self-identify as family, regardless of genetic relatedness, then they should be treated as such.

The shift from an interventionist to a supportive role is gradual, but we can see evidence of it in practice. Kinship carers report being treated differently from mainstream carers by social services. This is not necessarily a negative comment as, according to theory, social work should be supporting rather than regulating the family (Pratchett \& Rees, 2017). The way in which this is enacted, however, can be detrimental. The strict regulation of wider-family contact, the requirements for carers to document injuries and the persistent intrusion of social workers into family life make normality difficult to accomplish and threaten to undermine the benefits of a kinship placement. The answer to achieving balance has been to increasingly professionalise kinship care and in doing so to professionalise the family. Whilst this has been successful on some measures, as this study has shown there are limitations to this approach. An alternative is suggested, in line with the application of theory in kinship care.

Rather than seek to regulate the family, perhaps we need to focus more on supporting the family unit. This requires that we understand the key distinction between a professionalised foster care placement, in which the functions of family are fulfilled by a proxy for the State, and a kinship placement in which the family fulfils the functions with the support of the State. In doing so we need to treat professional and family-based placements as ontologically different.

In line with this understanding, we can consider the issue of payment for care labour. Payment is a contentious issue in kinship care, in part due to the hardship experienced by many kinship carers and the expectations currently placed upon them to behave and perform the function of a professional carer. The risk of providing payment for care services is that the role once again becomes professionalised and the carers become employees, bound by the restrictions and regulation of the employer. Equally, refusing to provide payment to carers 
can generate hardship, particularly given that many are forced to forgo employment in order to perform caring tasks. Once again, this discussion reverts to the difference between supporting the family unit and intervening by professionalising it. The allowance system currently employed by a number of local authorities, including one within this study, seems to achieve this balance to a degree. Such systems allocate an allowance for the needs of the child, but do not pay the carer for the tasks associated with caring. However, such systems do not take into account the loss of employment or income from such tasks and in doing so place the kinship unit at a disadvantage as a result of providing care. Perhaps accounting for the needs of the family, in particular needs that have come about as a result of placement, would be a more holistic approach to supporting the ecology of a child in a kinship placement.

There are inevitably challenges in deregulating kinship care, particularly the concern that by doing so, and by removing young people from the LAC system, they will not receive the services that they require. Some social workers in the study identified the access provided by LAC status to specialist services such as psychologists and leaving care services. It is also important to remember that the young people in kinship care may have experienced adverse life events that lead to a number of behavioural, emotional, social and developmental difficulties that are not experienced by their peers in the general population. The challenge in this regard is identifying and providing the services that a child may need in order to recover from abuse, neglect, rejection or bereavement whilst giving the family the freedom to operate in a natural way. However, when compared to an informal kinship care sample, the young people in this study performed at a similar level in spite of having been registered as looked after. Whilst this led to inferences that kinship care, rather than LAC services, is the key component in promoting recovery, it would also suggest that carers are able to provide or access services outside of the LAC system. Furthermore, the deregulation of kinship care is not synonymous with the withdrawal of care services. Rather, in accordance with the theoretical framework, services should be put in place to support the family unit, simply without the intrusion that professionalisation incurs.

In summary, the rise of kinship care represents a shift in the theoretical framework of social work from a professionalised interventionist model to a family-based 
supporting model. Whilst theory has shifted, practice and policy remain ingrained in the professionalised approach to fulfilling the functions of the family through replacement of a child's ecology. There are limitations to applying this approach to a kinship unit, which may undermine some of the benefits of a kinship placement. As a result, this thesis would support the deregulation of the family unit. 
Chapter 9: Conclusion 


\section{Chapter 9: Conclusion}

This chapter will present the thesis conclusion in five sections. Section 9.1 will present a summary of findings, noting the key results that this thesis has presented. This will address and summarise each research aim in turn. Section 9.2 will outline the thesis' contribution to knowledge. Sections 9.3 and 9.4 will discuss the study limitations and the implications of this thesis for further research. Finally, section 9.5 will present the implications for policy and practice, a key factor given the applied nature of this research.

\subsection{Summary of findings}

This thesis explored the implications of a shift in the way that social work theory is applied. This shift represents the transition from the historical child-rescue model, upon which mainstream foster care is based, to a family-based model. This objective was explored via three aims, each of which will be addressed in turn. The first aim sought to explore the patterns and perceptions of stability and permanency in kinship care. The results of this study conclude that the enhanced perception of stability and permanency in kinship care is, to a degree, supported by the empirical evidence. Phase one of the thesis explored permanency and stability through a case file audit and found that placement type had a significant effect on post-care destination for early care leavers. In particular, the results showed that kinship care is more commonly used as a permanency option, via an SGO, than mainstream foster care with the latter tending to return to live with their birth parents. Furthermore, this study provided novel evidence that SGOs are stable in the medium-term. Phase two of the study explored these trends further, highlighting concerns over how SGOs are being used by local authorities to reduce the LAC population. Supervising social workers in particular emphasised apprehensions in this regard. Despite this, the study identified novel trends in the increased use of SGOs, now the most common permanency order for kinship care. 
The thesis also explored factors affecting the perception of stability in kinship care, including the child's involvement in contingency planning, and stability in the wider ecology such as education and geographical location. Further explored, and of particular interest to practitioners, were the factors that either motivated or deterred kinship carers from pursuing an SGO. Factors such as independence from local authority supervision and ability to make decisions over matters such as haircuts and holidays were appealing to kinship carers. Meanwhile, the fear of being abandoned by the local authority and having support withdrawn, or the risk of disrupting the carer's relationship with birth parents, deterred many kinship carers from pursuing this route to permanency. This was despite a general feeling amongst carers that the placement would be long-term. This may have implications for the theoretical shift as the SGO represents a route of independence from the local authority and so allows the kinship unit to fulfil the four functions of family (Murdock, 1949) without interference. Equally, the support model provided by the local authority is more in keeping with a family-based model in which social work's role becomes one of supporting the family unit rather than replacing it.

The second aim of the thesis explored the relative wellbeing of young people in kinship care. Three areas were identified for comparison: mental health, attachment and identity. The study suggested that the mental health of young people in kinship care was better than their peers in mainstream foster care, but remaining less positive than the general population. Factors influencing this were discussed in relation to previous literature. The attachment of young people in kinship care to their carer was similar to parental attachment in the general population. Regardless of placement length, young people were attached to kinship carers as primary caregiver, which was found to be positive. Furthermore, carer attachment was at a level comparable with informal kinship carers, suggesting that the increasing professionalisation of kinship care did not directly affect attachment. Given the issue of informal, unplanned or negative contact with birth parents in kinship care, it was interesting to note that contact frequency with birth parents did not impact upon carer attachment scores. This would imply that contact was well managed and was not a risk factor in regards to stability. 
Identity of both young people and carers was examined and found to be more naturally preserved in a kinship environment. Social workers noted the reduced need for formal life story work and reduced stigma, whilst carers and young people focussed on the normalcy of their living arrangement. In contrast to mainstream foster care, they perceived kinship placements as a naturally organised environment and identified primarily as family. However, the results also suggested that the identity of being simply family was undermined to an extent by the intrusion of social services intervention. Despite identifying as a grandparent or aunt, carers were being treated as professional carers which created a duality in their role and conflict in their self-concept. Young people also felt stigmatised by the label of 'looked after child', and that practices such as inschool visits from social workers reinforced that stigma.

The third aim of this thesis was to assess the educational achievement of looked after young people in kinship care. The results were consistent with previous research, indicating that young people in kinship care attain lower levels of literacy than the general population. However, when compared with cognitive baseline, the majority of young people were performing as predicted. Furthermore, when compared with the mainstream care population, young people in kinship care were found to be achieving as expected with higher frequency than those in mainstream foster care. A number of factors that may contribute to this effect were identified and discussed, including consistency in ecology and educational establishment, the provision of a more nurturing environment in kinship care, and the perception from kinship carers that they were more invested in the child's future than mainstream carers. Furthermore, qualitative data indicated that kinship care may lead to better long-term educational aspirations. Whether this converts to actual educational participation was not in the remit of this thesis, although would be an interesting consideration for future research.

Some of the more abstract elements of kinship care were also explored via an inductive thematic analysis of interview data. Of note were the concepts of family and hardship; themes that ran consistently through all aspects of this thesis. These themes, whilst not directly targeted as aims in themselves, provide each research aim with a deeper level of understanding. This study found that many 
formal kinship carers suffered hardship that was similar to that documented by their informal counterparts. In this respect, it seemed that the status of formal carer did not protect them in the ways we might expect, such as financial security. By examining the concept of family and hardship, this thesis was able to gain insight into societal expectations of family. This included the expectation that an older kinship member should be willing to endure hardship in order to protect younger members of the kinship circle in a way that would not be expected for strangers. This was found manifest both internally, with kinship carers themselves expressing acceptance of hardship for family, and externally with mainstream foster carers and social workers sharing this view. These concepts are particularly important in understanding how stability and permanency (as in the first study aim) are achieved in kinship care despite the negative impact upon the carers.

\subsection{Contribution to knowledge}

This thesis sought to understand the outcomes of young people in kinship care and in doing so has contributed to the theoretical and practical knowledge of family and social work. Crucially, this thesis has identified an ongoing shift in social work practice from a child-rescue model to a kinship model, and explored some of the consequences of this shift. The results would indicate that kinship care has the potential to positively affect change with an abused or neglected young person in a range of domains from psychological wellbeing to educational achievement. Combined with the theoretical model, and alongside previous literature, this is an important finding and one that local authorities have been seeking to understand.

Interestingly, a number of measures used in this study found that kinship care can have a negative impact upon the family unit and in particular, the kinship carer. Whilst this tallies with the previous research, the prevalence of hardship within the formal kinship care environment is a novel finding. Furthermore, many of the hardships noted are a result of intervention from local authorities. This intervention jeopardises the natural sense of identity that a kinship placement can 
provide, by reinforcing the child's status as 'looked after'. It could be argued that the provision of a professionalised care service, alongside the regulation of care placements, is not an optimal means of providing services for a kinship unit. This is further reinforced by both the self-identity of kinship carers and young people, and the unequal provision of finances and services to kinship carers compared to their mainstream counterparts.

Undeniably, the policy and regulation is in place to protect vulnerable young people within the care system, however, in a placement where family is the critical element, the rigid policy is ineffective as a method of managing placement. In many cases, managers and social workers are satisfied that a placement is safe and stable, and yet statutory guidelines require a level intervention that both they and the families feel is disproportionate to the needs of the placement. As a result, care services are under excessive pressure to spread services and workers thinly, limiting the provision of services across the LA area. Practically this means that LAs are pushing for SGOs to reduce the care population where young people are deemed to be in a safe and stable placement. However, their removal from the LAC system may leave the young person and carer with insufficient levels of support to combat complex needs that may exist.

The thesis objective was to explore the implications of a shift in the way that social work theory is applied from a professionalised child-rescue model, to a familybased model. The theoretical shift has a positive impact in devolving power back to the family unit in order to fulfil the four functions of family. Equally, the shift towards a family-based model preserves the child's ecology by shifting the dynamics within the family rather than removing the child altogether. SGOs are a good example of this theory in practice and seem to show good outcomes in terms of providing autonomy for the family. However, the study has exposed a number of areas where social work policy straddles the two models of care and in doing so negatively impacts upon the family unit. Rather than following the theoretical model to allow social work to support the family unit, policy and regulations maintain the intervention of the child-rescue model. In doing so, kinship carers are receiving the short end of the metaphorical stick as they are encouraged to pursue autonomy without the support that they need, as it is only available to young people within the care system. 
The qualitative data in this thesis provides a novel insight into the impact that this discord between the two models is having on kinship placements. In particular, there seems to be an element of friction between the different actors involved in a placement. Kinship carers expressed a degree of mistrust, even those who spoke highly of their social worker. Many commented on their persistent wariness when talking to social workers. This would suggest that despite the supportive role that social work seeks to play, the regulatory, supervisory and, potentially, punitive powers held by the LA remain a barrier to a close working relationship.

Meanwhile, supervising social workers tended to speak fairly negatively about the way in which they felt permanency options were used by the local authorities. The severity of the language used serves to punctuate the heartfelt nature of these beliefs, with social workers accusing the system, and their own department, of 'bullying' kinship carers. Throughout the qualitative data, there is a sense that many feel stuck between a rock and a hard place as senior managers seek to increase uptake of SGOs in the face of kinship carers who seem adamant that they are not ready to leave the system. On many occasions, the kinship carers' beliefs were supported by the supervising social workers, yet they remained under pressure to decrease the care population by advocating permanency options. Whilst past literature has indicated that kinship carers can feel 'bullied', the data yielded in the course of this study is a unique opportunity to reveal the extent to which those beliefs are shared by those working within the system. The level of access granted by this thesis, along with the anonymity that was afforded to all participants, has provided a thorough and insightful look inside kinship placements and the social work structure that supports them.

\subsection{Study limitations}

Whilst these findings are a useful indication of the effectiveness of kinship care, an element of caution must be exercised in generalising the results. With regards to quantitative measures, the sample sizes can be considered to be relatively low. Whilst the sample sizes for this study are low for conclusive analysis of results, it is useful as an exploration of trends over a range of outcomes. A number of 
challenges were posed in recruitment of each group. Firstly, kinship carers often cited a lack of time as a reason for non-participation; a finding that replicates previous discussions around recruitment in this area. Secondly, carers were often nervous that participation had the potential to cause disruption to the placement and so were often reluctant to take part. Consequently, there is potential that the results are biased in favour of more settled placements. This is a common limitation of participatory research, particularly in this field where challenges around the risk of harm must be overcome. However, carers were not unanimously positive about their experiences of providing care or interacting with the local authority suggesting that if bias was introduced through recruitment, its effect was likely minimal and thus the findings may be considered reliable and valid.

Sample size was relatively low for the young people. This was due to a number of gatekeeping challenges, an unavoidable consequence of needing to approach the social worker first and then the carer to request access to the child. This was also compounded by a number of young people themselves declining to participate in the study. From an ethical perspective, the number of young people declining could be considered a strength in that they were each given the ability to exercise some power in deciding whether to participate. Equally, the rights of the child dictate that children must be heard and as such we should provide young people with the space to speak. Whilst as researchers it is inevitably more interesting if young people use this space to talk, perhaps being able to say nothing is giving the voice to the child by allowing them to be self-determining in participation.

Young people also seemed to be less engaged with the interview element of the research than either carers or social workers. This may have been due to order effects as young people became progressively fatigued, however, the length of session preceding interview did not seem to impact upon engagement. This included in cases where the testing was split across a number of sessions meaning that the interview was the sole purpose of that session. Alternatively, the lack of engagement may be rooted in sociological constructs. In society, young people are treated as inherently different to adults. They are subject to, sometimes arbitrary, boundaries such as age-restricted products, financial 
dependence and social restrictions on basic needs, for example asking to visit the bathroom during school hours. In this respect, young people are considered subordinate to adults. When we then ask a young person to ignore these constructs and to converse with us as equals, the process may seem alien and uncomfortable for the child.

In some respects, the subjectivity regarding measurement of identity is a limitation. As no standardised measure was used, it was impossible to ascertain whether any real difference exists in the formation and maintenance of identity between kinship and mainstream foster care. Whilst it would be interesting to explore such a question quantitatively, the operationalisation of such an abstract variable along with the limitations of a reductionist approach, would jeopardise the validity of such a measure. In this respect, the use of a qualitative approach was appropriate in providing a deeper understanding of how being looked-after affects identity in kinship care. Furthermore, the use of triangulation between three distinct groups limits the subjectivity somewhat and enables a useful examination of the concept of identity.

\subsection{Implications for future research}

As this thesis was exploratory in nature, it has exposed a number of interesting areas where further research would be warranted. One such area is attachment, where mainstream foster care data was unavailable. As such, it would be beneficial to create a meaningful comparison between mainstream foster care and kinship care to see whether any differences exist. Given the frequency with which those in mainstream foster care return to their parents, we might expect a lower level of attachment to carer compared with those in kinship care. Equally, since there is evidence that multiple attachments can be formed simultaneously, we may find that those in mainstream foster care are attached to their carer and birth parent.

Similarly, aspects of stability and permanency would be ideal candidates for further exploration. Due to the relative recent introduction of SGOs, exploring the permanence of placements was restricted in this study to an 18-month period. 
Given that an SGO can be granted after a six-month process, it could theoretically last as long as seventeen and a half years and so further examination of their stability would be beneficial. Similarly, the 'When I'm Ready' scheme in Wales (Social Services and Wellbeing (Wales) Act 2014) may impact upon how many young people remain with their carer after aging out of care at eighteen. With almost half of foster care leavers in this study still with their carer on their nineteenth birthday, it would be useful to establish whether policy has affected behaviour, or whether it simply enshrines in law that which already exists in practice.

On a more theoretical note, it would be beneficial to compare the trends and results of this study with international populations, particularly those employing a different system. Given the rather different theoretical basis of mainstream foster care and kinship care, it would be interesting to see whether similar difficulties are reported in systems already employing a family-based approach. The identification and study of such systems could be a key area for further exploration.

\subsection{Implications for policy and practice}

Whilst efforts are undoubtedly made to minimise the stigma attached to the LAC label, practitioners may need to consider the implications of current procedures. Furthermore, they may need to acknowledge the role of school-based visits in preventing a young person from moving away from the identity of being in care.

The implications may also be wider reaching. The challenges identified in this thesis in the simultaneously utilised models of family-based and professionalised care may prompt further exploration of the way in which the local authority interacts with kinship carers. Whether through further professionalisation and regulation of the family or, preferably, through a de-regulated, support-based approach, the results from this thesis may be the catalyst for change in the way in which the family is used to promote its function. 
Essentially, this thesis posits that local authorities and policy makers must find a strategy for supporting a placement whilst minimising disruption to the home in order to promote outcomes. With the increasing use of formal kinship care as a placement, it is crucial that the social work system adapts to incorporate the differing needs, qualification and expectations of kinship carers rather than attempting to shoehorn a family unit into a professionalised care model. There is no doubt that this is a challenging position to adopt, however the theoretical and empirical findings from this thesis suggest that it is an approach that needs to be clearly defined in order that kinship care becomes a viable and effective means of promoting recovery.

Essentially this thesis would support the development of a secondary route for looked after children. The first route would retain the child-rescue model and is characterised by the professionalisation of carers, mandatory registration of carers, monitoring of placements and high levels of social work intervention. This model follows the policy currently used to regulate mainstream foster care and into which kinship care placements are currently being shoehorned. The second route could incorporate the key elements contributing to the success of kinship placements which require a family-based placement characterised by a natural and familiar environment, a caring relationship based on emotional attachment rather than professionalisation, and local authority support rather than intervention. Crucially, whilst registration of kinship carers did not seem to impact upon attachments, the duality of identity for the carers proved challenging and impacted upon the way that carers interacted with young people. Both qualitative and quantitative results would indicate that a single system is unable to incorporate the unique nature of each placement type. Consequently, this thesis would support the recognition of formal kinship care as a unique placement type, and for policy to be developed in line with a differing theoretical basis to mainstream foster care. 
Appendices 
Interview questions - Children and young people in kinship care

1) Where do you think you will be living when you are 17 ?

a. How often do you talk about the future?

b. Who to you talk about it to?

c. How do you feel about the future?

d. How much do you feel you can affect decisions made about your future?

2) How often do you see your mum/dad [delete as appropriate]?

a. Have you always seen them that often?

b. How do you see them?

c. How has your contact changed?

d. Why has it changed?

e. Who decides if it changes?

3) How much of a say do you think you have in your life?

a. Who listens to you?

b. Who listens the most?

4) When you were asked about how important school was to you, you said

a. Is that what you would say now?

b. Why did you say that?

5) When you leave school, what do you think you will do?

a. Who do you talk to about you plans?

b. What do you have to do to get that job?

6) The law says that social workers and families should do what is best for you but it is sometimes hard to know what the best thing is.

a. What do you think is the most important thing they should think about?

b. Do you think that they also think it is important? 
1) Does _ [name] _ have contact with their Mum/Dad [delete as appropriate]?
a. Have they always had contact?
b. What form does this contact take?
c. How has their contact changed?
d. Why has it changed?
e. Who decided that it would change?

2) What led to you taking in?
a. How supported did you feel?
b. Has that support changed?

3) Where do you think _ _ [name] _ will be living when they are 17?
a. How often do you talk about the future with _ [ [name]_?
b. How do you feel about the future?
c. How do you think _ [ [name] _ feels about the future?
d. How much of an influence do you feel you have on the care planning?
e. To what extent do you feel in control of the future?

4) Social workers often talk about 'optimising outcomes'.

a. What do you think is the most important outcome of caring for $?$

b. To what extent do you feel that social workers share that view?

c. To what extent do you feel that _ [ [name] _ shares that view?

5) When you were asked about how much priority was given to education you said

a. Is that what you would say now?

b. Why did you say that?

6) In an ideal world, what would you want _ _ [name] _ to do when they left school?
a. What do you think that they will do?
b. How often do you discuss this?
c. What are the barriers to that? 
Interview questions - Social workers

In the case of _ $[$ name $] \ldots \ldots$

1) Does _ [name] _ have contact with their birth parents?

a. Have they always had contact?

b. How has their contact changed? (frequency, format, supervised/ unsupervised)

c. What prompted the change?

d. Who decided that it would change?

e. Would you have chosen that contact schedule in this case?

2) Where do you think _ _ [name] _ will be living when they are 17 ?

a. How often do you talk about the future with _ _ [name $]$ ?

b. How does the carer feel about the future?

c. How does _ [name] _feel about the future?

d. What do you think an SGO could bring to this placement?

e. To what extent do you feel an SGO is suitable in this case?

3) What do you think _ [name] _ will do when they leave school?
a. How often do you discuss it with _ [name]_?
b. How often do you discuss it with the carer?
c. Does the carer have the same idea of the future?
d. What are the barriers to this goal?

Please think back to a recent SGO case.

4) How do you think SGOs have affected practice in kinship care?

a. To what extent do social workers influence application for SGOs?

b. What are the biggest barriers for kinship carers?

c. What are the biggest barriers for social workers?

5) In social work we often talk about 'optimising outcomes'.
a. What do you think is the most important outcome?
b. To what extent do you feel that carers share that view?
c. To what extent do you feel that children share that view? 


\section{Ethical Approval}

\section{Ethics Committee Use Only}

\begin{tabular}{|l|l|}
\hline $\begin{array}{l}\text { Principal } \\
\text { Investigator }\end{array}$ & Rebecca Pratchett \\
\hline $\begin{array}{l}\text { Title of Proposed } \\
\text { Research }\end{array}$ & $\begin{array}{l}\text { Exploring outcomes of children and young people in kinship care in } \\
\text { South Wales. }\end{array}$ \\
\hline
\end{tabular}

\begin{tabular}{|c|c|c|c|c|}
\hline Application approved & Yes & $\checkmark$ & No & \\
\hline Date & \multicolumn{4}{|c|}{ 20th January 2015} \\
\hline Name & \multicolumn{4}{|c|}{ Paul Willis } \\
\hline Signature & \multicolumn{4}{|c|}{$\square$} \\
\hline $\begin{array}{l}\text { Position } \\
\text { (please state if a member or Chair of } \\
\text { ethics committee and name of } \\
\text { committee) }\end{array}$ & \multicolumn{4}{|c|}{ Senior Lecturer in Social Work - Human Sciences. } \\
\hline
\end{tabular}

This application has been granted ethical approval in its current form. Please ensure that you take account of the comments and feedback provided below and prepare a revised submission: 


\section{Contact with birth parents}

(Please circle the number that best suits how you feel about each statement.)

I feel that the level of contact is appropriate

I feel that the child would benefit from more contact

I feel that the child would benefit from less contact

I am happy with how contact is managed

I would prefer to have more social services support for contact

I have a strong influence on changes to contact arrangements

Social workers have a strong influence on changes to contact arrangements

The birth parent has a strong influence on changes to contact arrangements

\begin{abstract}
1
strongly disagree
\end{abstract}

4
agree neutral disagree neutral

3

strongly disagree

$\stackrel{3}{\text { neutral }}$

4 agree strongly agree

1
strongly
disagree
2
disagr .

$$
\begin{array}{cc}
2 & 3 \\
\text { disagree } & \text { neutral }
\end{array}
$$

4

strongly disagree

1
strongly
disagree

$$
\stackrel{2}{\text { disagree }}
$$

3
neutral

4
agree 5 strongly

\begin{tabular}{|c|c|c|c|c|}
\hline $\begin{array}{c}1 \\
\text { strongly } \\
\text { disagree }\end{array}$ & $\begin{array}{c}2 \\
\text { disagree }\end{array}$ & $\begin{array}{c}3 \\
\text { neutral }\end{array}$ & $\begin{array}{c}4 \\
\text { agree }\end{array}$ & $\begin{array}{c}5 \\
\text { strongly } \\
\text { agree }\end{array}$ \\
\hline
\end{tabular}
agree 1
strongly
disagree $\stackrel{2}{\text { disagree }}$ 3
neutral 4 5

$\begin{array}{cc}2 & 3 \\ \text { disagree } & \text { neutral }\end{array}$

4 strongly disagree neutral agree strongly 5 disagree agree

The child has a strong influence on changes to contact arrangements

1 strongly disagree

\section{2} disagree
3

neutral

\section{4}

agree
5 trongly

agree

Please write, in order, the people with the most influence on any changes to contact arrangements. (You do not need to write on every line.)

1)

2)

3)

4)

5) 


\section{Thinking about the future}

(Please circle the number that best suits how you feel about each statement.)

I expect that the child will live with me until they are 18

I expect that the child will move back to live with their birth parent

I expect that another person will take over the care of the child

I often think about the future

I have made plans for the future

I often worry about the future

I discuss the future often with the child in my care

I have accessed information about Special Guardianship Orders

I have considered applying for a Special Guardianship Order

$$
\begin{gathered}
1 \\
\text { strongly } \\
\text { disagree }
\end{gathered}
$$

disagree

neutral

agree

5

1
strongly

disagr

disagree

3
neutral

4

agree

strongly

agree

1
strong

disagree

$$
\stackrel{2}{\text { disagree }}
$$

3

neutral

4
agree

5

rongly

agree

1
strongly
disagree

2

disagree

3

4

agree

5 disagree

1
strongly

2

disagree

3

neutral

4

disagree

1
strongly
disagree

$\stackrel{2}{2}$ disagree

3

4
agree

strongly

agree

1
strongly

2

disagree

3

neutral

$\stackrel{4}{\text { agre }}$

5 strongly agree

1
strongly

2
disagree

3

neutra

4 agree

5

strongly

agree

1
strongly
disagree

$\stackrel{2}{\text { disagree }}$
3
neutral

4

agree

5

strongly

agree

Please rate how likely you feel a Special Guardianship Order would be for you in the future

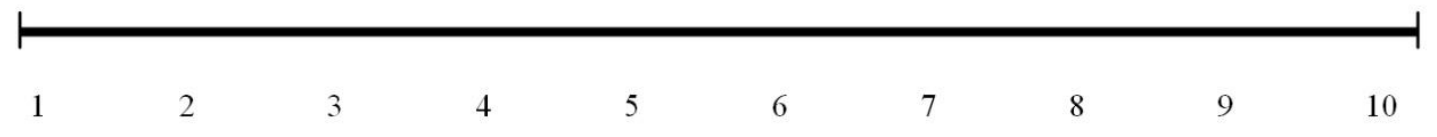

Not at all likely 


\section{Caring priorities}

(Please number the statements in order of how important you feel they are with 1 as the most important.)

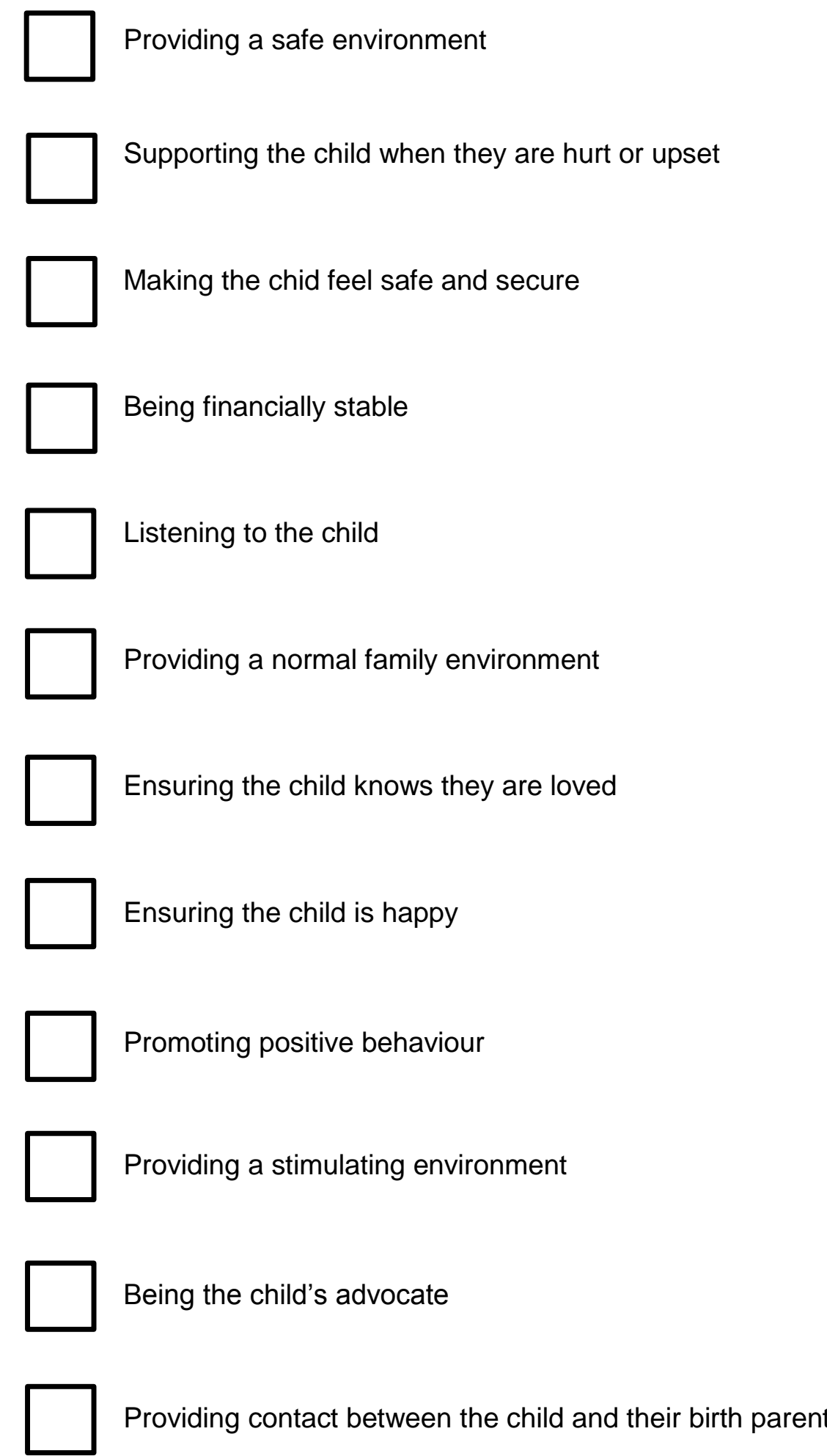


Please write down your three main priorities when providing care. You may include priorities not featured in the previous list.

1)

2)

3)

\section{Education and Employment}

(Please circle the number that best suits how you feel about each statement)

Education is the most important thing in our home

School attendance is extremely important in our home

There is a designated time for the child to do their homework

I always assist with homework

I enjoyed school when I was younger

$$
\begin{aligned}
& 1 \\
& \text { strongly }
\end{aligned}
$$$$
\text { disagree }
$$

$\stackrel{2}{\text { disagree }}$

$\stackrel{3}{\text { neutral }}$

4
agree

5

trongly

agree

$$
\begin{aligned}
& 1 \\
& \text { strongly } \\
& \text { disagree }
\end{aligned}
$$

$\stackrel{2}{\text { disagre }}$

3
neutra

4

agree

5

strongly agree
2
disagree

3

strongly disagree

1
strongly
disagree 2
disagree 3
neutral 4
agree
5 strongly agree

\section{5} strongly agree

When you imagine the educational future of the child in your care, what do you expect that they will do?

$\begin{array}{ccccc}1 & 2 & 3 & 4 & 5 \\ \text { strongly } & \text { disagree } & \text { neutral } & \text { agree } & \begin{array}{c}\text { strongly } \\ \text { agree }\end{array}\end{array}$

Have you discussed the future with the child? (Please circle)
Yes
No
Don't know 


\section{Basic information}

Age:

How long has the child lived with you?

Age of the child(ren) in your care:

Marital status (please circle):

single, married, civil partnership, separated, divorced, widowed

Annual household income:

(Please include any benefits you

may receive including foster care

allowance, child benefit or tax credits

if applicable)
$£ 4,745$ to $£ 6,000$
$£ 6,000$ to $£ 8000$
$£ 8,000$ to $£ 10,000$
$£ 10,000$ to $£ 12,000$
$£ 12,000$ to $£ 15,000$
$£ 15,000$ to $£ 20,000$
$£ 20,000$ to $£ 30,000$
$£ 30,000$ to $£ 50,000$
$£ 50,000$ to $£ 70,000$
$£ 70,000$ to $£ 100,000$
More than $£ 100,000$
Prefer not to say

Number of dependants:

(please include in this figure any adults for whom you provide care as their primary carer)

What is your profession? (If you had to leave work due to caring responsibilities, please indicate your previous profession)

What is your highest academic qualification?

How often does the child in your care have contact with their birth parent(s)?

What form does this contact usually take? 


\section{Contact with my birth parent}

(Circle the box that best suits how you feel about each statement.)

Totally disagree

Totally agree

I see my birth parent as much as I would like

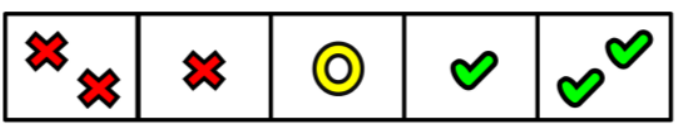

I can choose how much I see my birth parent

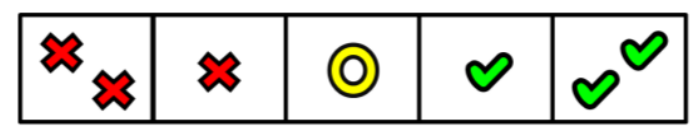

If I wanted to change how much I see my birth parent, I could speak to my carer

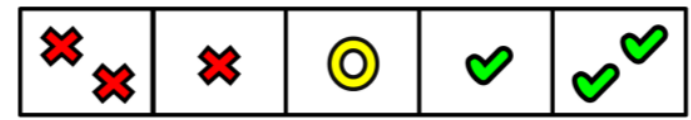

If I wanted to change how much I see my birth parent, I could speak to my social worker

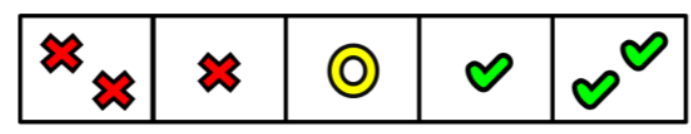

If I wanted to change how much I see my birth parent, I could speak to my birth parent

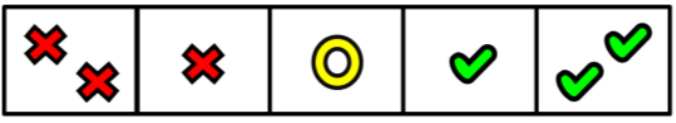

My social worker always listens to how I feel about seeing my parent

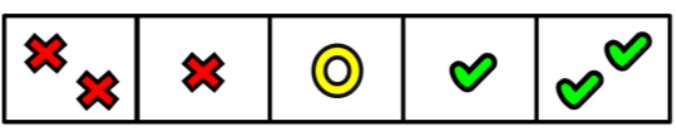

My carer worker always listens to how I feel about seeing my parent

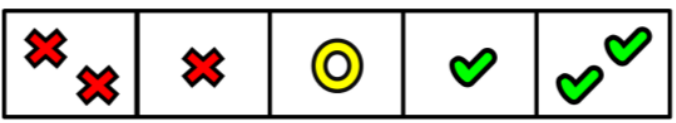

Who decides when you see your parent and how you see your parent?

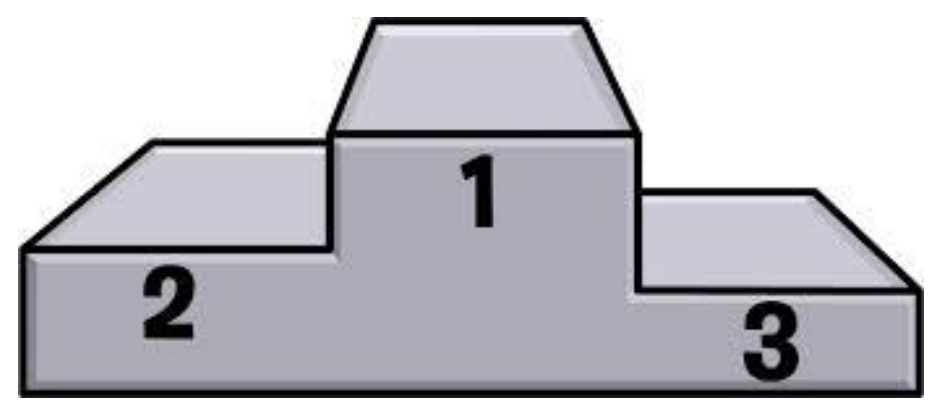

(Put the name of each person in order on top of the podium.) 


\section{Thinking about the future}

(Circle the box that best suits how you feel about each statement.)

Totally disagree

Totally agree

I think about the future a lot

\begin{tabular}{|l|l|l|l|l|}
\hline \multirow{2}{*}{} & $\varkappa$ & 0 & 0 & $0^{\infty}$ \\
\hline
\end{tabular}

I know where I will be living in the future

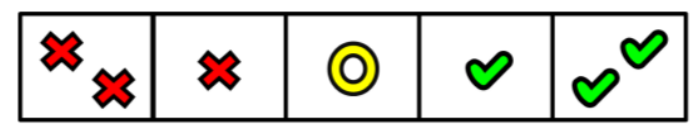

I think that I will stay with my carer

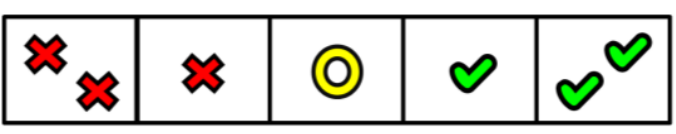

I think that I will move back to my parent's

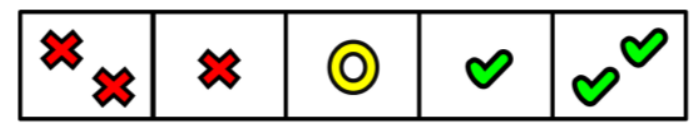

I think that I will go somewhere new

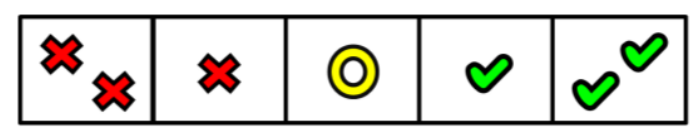

I talk about the future with my carer

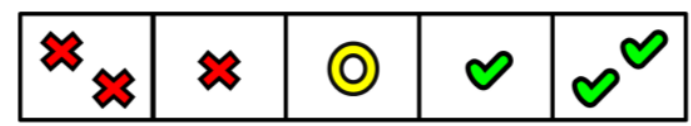

I talk about the future with my parent

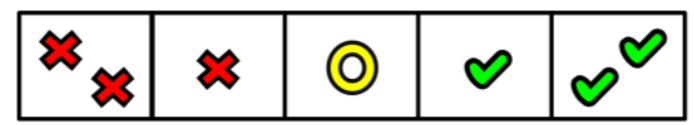

I talk about the future with my social worker

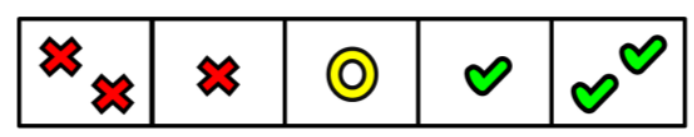

I talk about the future with my friends

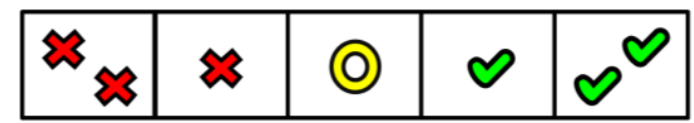

I feel good about the future

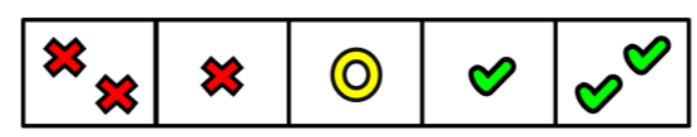

I sometimes worry about the future

\begin{tabular}{|l|l|l|l|l|}
\hline \multirow{2}{*}{} & $\approx$ & 0 & 0 & $0^{0}$ \\
\hline
\end{tabular}




\section{Being listened to}

(Circle the box that best suits how you feel about each statement.)

\begin{tabular}{|c|c|c|c|c|c|}
\hline \multirow[b]{2}{*}{ My social worker listens to how I feel } & \multicolumn{3}{|c|}{ Totally disagree } & \multicolumn{2}{|c|}{ Totally agree } \\
\hline & « & $\sqrt{2}$ & (2) & $\infty$ & $\infty^{\infty}$ \\
\hline My carer listens to how I feel & $\aleph_{\Sigma}$ & $\sqrt{2}$ & (2) & $\infty$ & $\infty$ \\
\hline My parent listens to how I feel & $\checkmark$ & $\sqrt{2}$ & (2) & $\infty$ & $\infty$ \\
\hline My teacher listens to how I feel & & $\sqrt{2}$ & (0) & $\infty$ & $\infty$ \\
\hline
\end{tabular}

Who listens the most? (You can put the names of anyone here)

1)

2)

3)

4)

5)

What is important to you?

1)

2)

3)

4)

5)

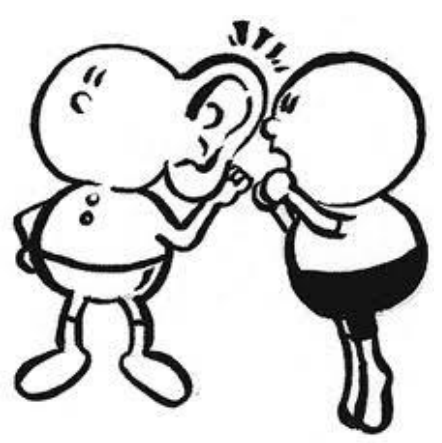




\section{School and work}

(Circle the box that best suits how you feel about each statement.)

Totally disagree

Totally agree

School is very important to me

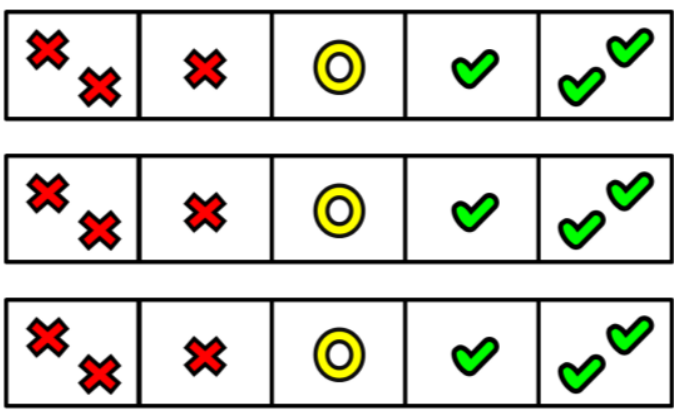

I have friends at school

\begin{tabular}{|l|l|l|l|l|}
\hline \multirow{2}{*}{} & $\approx$ & 0 & 0 & $0^{0}$ \\
\hline
\end{tabular}

Getting an education is important to me

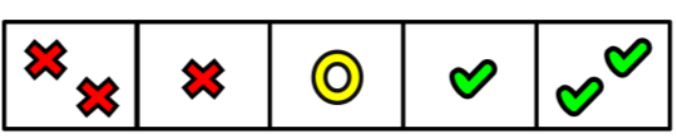

The teachers tell me that I do well

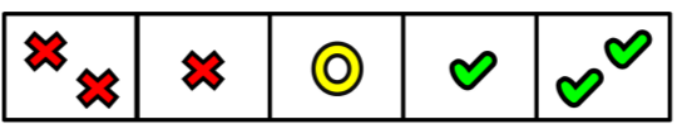

I am a good student

\begin{tabular}{|c|c|c|c|c|}
\hline $\mathbb{w}_{\mathbb{2}}$ & $\varepsilon$ & (2) & $\infty$ & $m^{\infty}$ \\
\hline
\end{tabular}

What do you like most about school?

What do you dislike most about school?

Totally agree

Totally disagree

I know what I want to do when I grow up

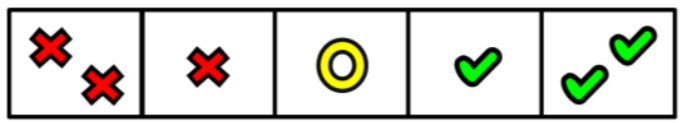

I know what I have to do to get there

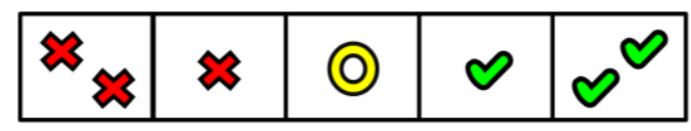

What do you want to be when you grow up? 


\section{Basic information}

Number of current kinship cases:

(Please give an estimate.)

Total number of kinship cases:

(Please give an estimate.)

Please think of one current case that you are working on. When answering the following questions, please refer to this case.

PARIS/ CareFirst number:

Child's date of birth:

Some of the analysis may require data to be triangulated between carer, social worker and child. In order to do so we require the information above. This will not be disclosed and the clients concerned will not be informed of your involvement. Authorisation to access sensitive information has been granted by the Heads of Service and with the awareness and consent of relevant Team Managers. 


\section{Birth family contact}

Does the child currently have contact with at least one birth parent?

Yes

No

Don't know

(Please circle the number that best suits how you feel about each statement.)

I feel that the level of contact is appropriate

I feel that the child would benefit from more contact

I feel that the child would benefit from less contact

I am happy with how contact is managed

I would prefer to have more involvement in contact

I have a strong influence on changes to contact arrangements

$\begin{array}{cccc}2 & 3 & 4 & 5 \\ \text { disagree } & \text { neutral } & \text { agree } & \begin{array}{c}5 \\ \text { strongly } \\ \text { agree }\end{array}\end{array}$

1
strongly
disagree

2

disagree

3
neutral

$\stackrel{4}{\text { agree }}$

5
strongly
agree

$\stackrel{1}{\text { strongly }}$

$\stackrel{2}{\text { disagree }}$

3

neutral

4
agree

5

disagree

1
strongly

disagree

$\stackrel{2}{\text { disagre }}$

3
neutral

4

agree

5

strongly agree

1
strongly

2

disagree

3

neutral

4

agree

5

strongly

agree

1
strongly

2
disagree

3
neutral

4
agree

5

strongly

agree

disagree

neutral

(n)

The birth parent has a strong influence on changes to contact arrangements
1
strongly
disagree

$\stackrel{2}{2}$ $\stackrel{3}{\text { neutral }}$

4

agree

5 strongly agree

The child has a strong influence on changes to contact arrangements

$$
\stackrel{2}{\text { disagree }}
$$

strongly disagree
5 strongly agree

Please write, in order, the people with the most influence on any changes to contact arrangements. (You do not need to write on every line.)

1)

2)

3)

4)

5) 


\section{Thinking about the future}

(Please circle the number that best suits how you feel about each statement.)

I expect that the child will live with their current carer until they are 18

I expect that the child will move back to live with their birth parent

I expect that another person will take over the care of the child

I discuss the future often with the child

I have discussed applying for a Special Guardianship Order with the carer

I believe this placement is stable

I would support the carer if they applied for a Special Guardianship Order

I believe that this placement is the best long-term option

The primary objective for any placement is permanency
1
strongly disagree

1
strongly disagree 1
strongly
disagree $\stackrel{3}{\text { neutral }}$ 4
agree 5

2
disagree

3
neutral

4 agree strongly agree

1
strongly disagree

$$
\stackrel{2}{\text { disagree }}
$$

neutral

4
agre

5 strongly agree

1
strongly disagree

$$
\stackrel{2}{\text { disagree }}
$$

3
neutral

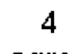

agree

5

strongly agree

1
strongly disagree

3
neutral

4 5

\begin{tabular}{|c|c|c|c|c|}
\hline $\begin{array}{c}1 \\
\text { trongly } \\
\text { isagree }\end{array}$ & $\begin{array}{c}2 \\
\text { disagree }\end{array}$ & $\begin{array}{c}3 \\
\text { neutral }\end{array}$ & $\begin{array}{c}4 \\
\text { agree }\end{array}$ & $\begin{array}{c}5 \\
\text { strongly } \\
\text { agree }\end{array}$ \\
\hline
\end{tabular}
trongly agree

1
strongly 2
disagre 3
neutral agre 5 disagree neutral strongly agree

$$
\begin{gathered}
1 \\
\text { strongly }
\end{gathered}
$$
$\stackrel{2}{\text { disagre }}$ disagree

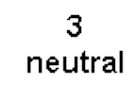

5 strongly agree

To what extent do you believe the carer in your case is likely to apply for a Special Guardianship Order? (Please circle)

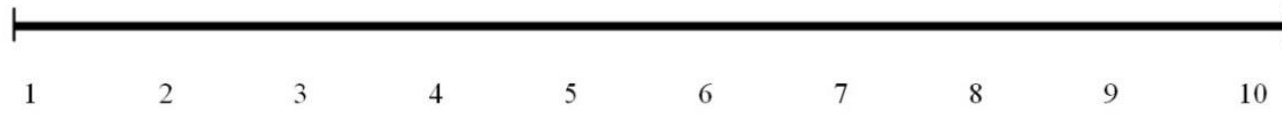

Not at all likely

Extremely likely 


\section{Priorities in care}

(Please number these statements in order of importance with 1 as the most important.)

Providing a safe environment

Supporting the child when they are hurt or upset

Making the chid feel safe and secure

Providing a financially stable environment

Listening to the child

Providing a normal family environment

Ensuring the child knows they are loved

Ensuring the child is happy

Promoting positive behaviour

Providing a stimulating environment

Acting on the child's wishes

Providing contact between the child and their birth parent 
Appendix 7

Please write down the three main objectives of a kinship placement. You may include priorities not featured in the previous list.

4)

5)

6) 
Appendix 8

Table 39: Results of literature database search

Databases searched

Search terms

PubMed Psycinfo WOS

Cochran Campbel

Kinship care

$474 \quad 106$

177

1

1

Formal Kinship Care

0

3

3

0

0

Informal kinship care

9

9

11

0

0

Kinship care AND looked after

0

1

0

0

0

Kinship care AND Reunification

14

6

4

0

0

Kinship care AND Kith

0

0

0

0

0

1


Appendix 9

Order of administration of assessment items (children and young people)

- Bespoke questionnaire

- $S D Q$

- IPPA-R (carer, parent and peer versions)

- Wechsler Intelligence Scale Abbreviated (WASI)

○ Block design

○ Vocabulary

- Matrix reasoning

- Similarities

- WIAT-II-A
○ Spelling
- Numerical Operations
○ Word Reading

- ELA

- Bespoke ranking task

- Semi-structured interview 
Appendix 10

Order of administration of assessment items (kinship carers)

- Bespoke questionnaire

- $S D Q$

- ELA

- Semi-structured interview

Order of administration (Kinship Carers) 
Appendix 11

Order of administration of assessment items (Social workers)

- Bespoke questionnaire

- Semi-structured interview

Order of administration (Social Workers) 
Appendix 12

\section{Qualitative Analysis}
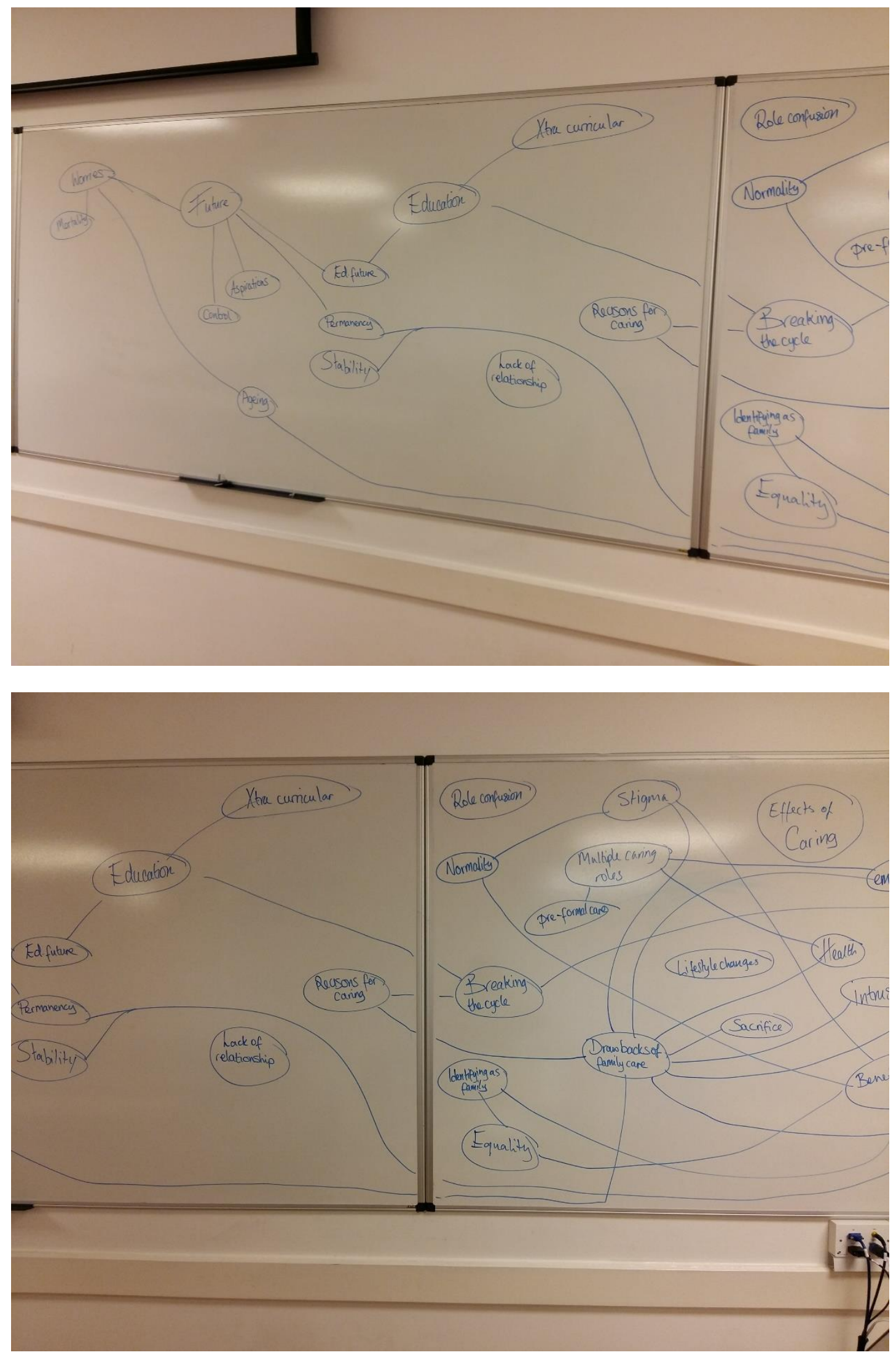
Appendix 13
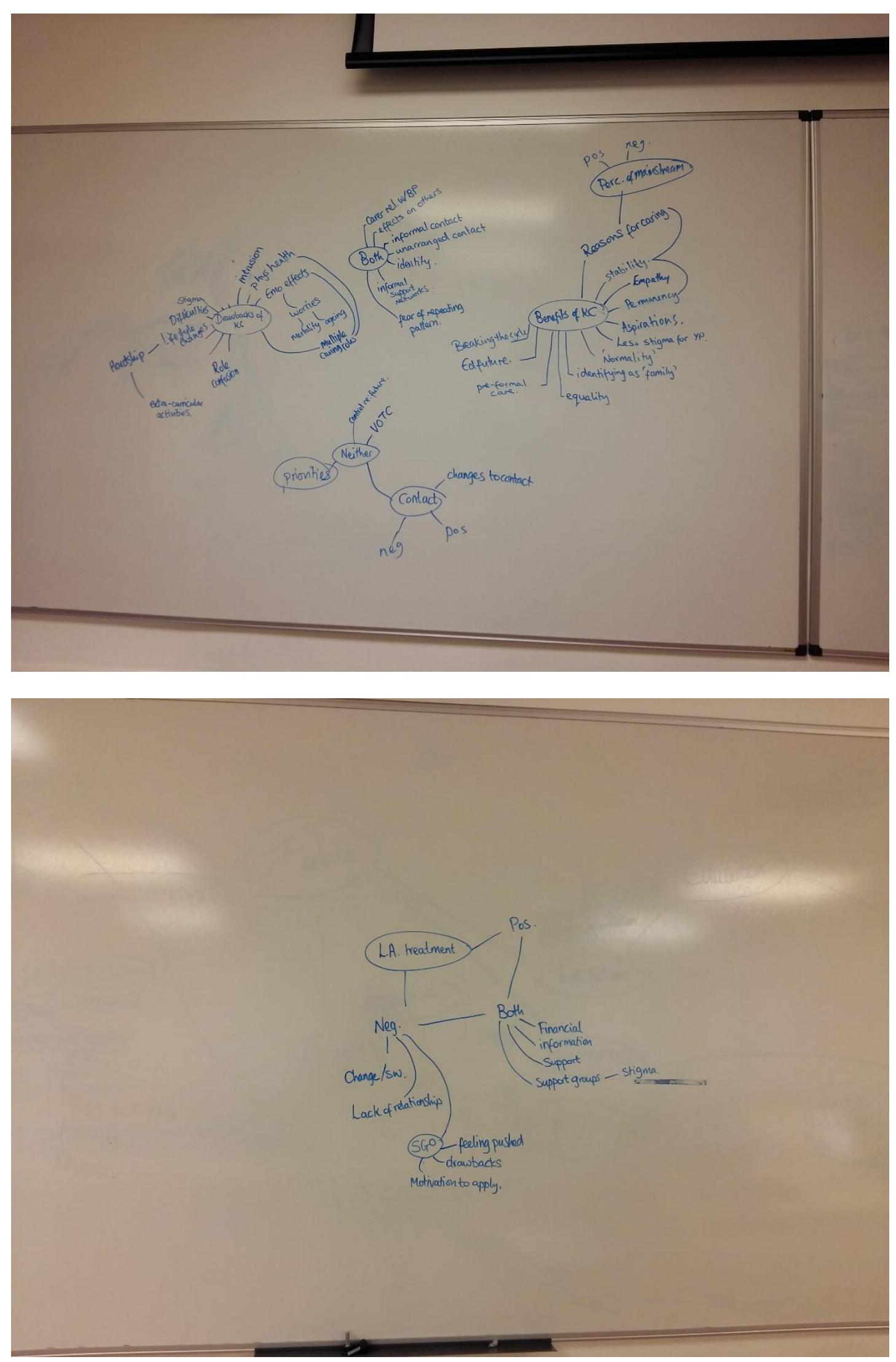


\begin{tabular}{|c|c|c|}
\hline Young people & & \\
\hline Name & $\begin{array}{l}\text { Number of } \\
\text { Sources }\end{array}$ & $\begin{array}{l}\text { Number of } \\
\text { references }\end{array}$ \\
\hline Afterschool activities & 2 & 3 \\
\hline Being listened to & 13 & 23 \\
\hline Involvement in decision making & 9 & 15 \\
\hline Benefits of KC over FC & 11 & 28 \\
\hline Shared understanding & 1 & 4 \\
\hline Change of Social Worker & 3 & 5 \\
\hline Contact & 14 & 39 \\
\hline Influences on contact & 12 & 17 \\
\hline Unarranged contact & 2 & 2 \\
\hline Education & 15 & 26 \\
\hline Future & 17 & 38 \\
\hline Identity & 7 & 13 \\
\hline Independence & 5 & 8 \\
\hline LAC label & 3 & 6 \\
\hline Peer relations & 11 & 23 \\
\hline Priorities & 17 & 18 \\
\hline Stability & 5 & 5 \\
\hline
\end{tabular}




\begin{tabular}{|l|l|l|}
\hline Kinship Carers & & \\
\hline Name & Sources & References \\
\hline Caring responsibilities & 0 & 0 \\
\hline Effects of caring & 9 & 18 \\
\hline Carer relationship with birth parent & 21 & 64 \\
\hline Difficulties & 10 & 26 \\
\hline Effects on others & 19 & 40 \\
\hline Emotional effects & 14 & 36 \\
\hline Fear of repeating pattern & 5 & 10 \\
\hline Health & 4 & 6 \\
\hline Intrusion & 14 & 34 \\
\hline Lifestyle changes & 20 & 56 \\
\hline Sacrifice & 11 & 21 \\
\hline Role confusion & 13 & 31 \\
\hline Stigma & 11 & 17 \\
\hline Multiple caring roles & 11 & 26 \\
\hline Pre-formal care & 14 & 22 \\
\hline Reasons for caring & 19 & 40 \\
\hline Contact & 13 & 24 \\
\hline Changes to contact & 18 & 62 \\
\hline Informal contact & 2 & 3 \\
\hline unarranged contact & 8 & 15 \\
\hline negative & 14 & 38 \\
\hline positive & 5 & 10 \\
\hline Education & 17 & 44 \\
\hline Breaking the cycle & 6 & 11 \\
\hline Educational future & 12 & 21 \\
\hline Extra-curricular & 4 & 6 \\
\hline Family & 21 & 44 \\
\hline Benefits of family care & 22 & 66 \\
\hline empathy & 5 & 6 \\
\hline Drawback of family care & 6 & 9 \\
\hline Identifying as family & 11 & 20 \\
\hline Lack of relationship & 5 & 8 \\
\hline Normality & 11 & 25 \\
\hline Equality & 4 & 5 \\
\hline Future & 1 & 1 \\
\hline Aspirations & 15 & 20 \\
\hline Control & 9 & 10 \\
\hline Permanency & 19 & 32 \\
\hline Placement stability & 10 & 19 \\
\hline Worries & 1 & 1 \\
\hline Ageing & 9 & 16 \\
\hline Mortality & 5 & 12 \\
\hline Hardship & 13 & 24 \\
\hline Identity & 7 & 16 \\
\hline Kinship vs Foster care & 22 & 68 \\
\hline LA treatment & 5 & 9 \\
\hline Perceptions of mainstream foster care & 2 & 2 \\
\hline Negative & 10 & 14 \\
\hline & & \\
\hline
\end{tabular}


Appendix 15

\begin{tabular}{|l|l|l|} 
Positive & 3 & 3 \\
\hline Priorities & 17 & 32 \\
\hline SGO & 3 & 3 \\
\hline Drawbacks & 9 & 20 \\
\hline Feeling pushed & 2 & 5 \\
\hline Motivation to apply & 4 & 8 \\
\hline Support & 0 & 0 \\
\hline Formal support & 22 & 76 \\
\hline Change of social worker & 14 & 22 \\
\hline Financial & 6 & 8 \\
\hline Information & 3 & 7 \\
\hline Lack of information & 14 & 31 \\
\hline Lack of support & 13 & 38 \\
\hline Support groups & 7 & 16 \\
\hline Informal support & 14 & 24 \\
\hline Hindrance & 1 & 1 \\
\hline Support from family members & 7 & 12 \\
\hline Voice of the child & 6 & 12 \\
\hline
\end{tabular}




\begin{tabular}{|c|c|c|}
\hline Social workers & & \\
\hline Name & Sources & References \\
\hline Age & 6 & 8 \\
\hline Benefits of kinship care & 1 & 1 \\
\hline Belonging & 9 & 11 \\
\hline Identity & 14 & 27 \\
\hline Normality & 6 & 7 \\
\hline Shared history & 8 & 13 \\
\hline Wider family contact & 9 & 12 \\
\hline Challenges for birth parents & 5 & 8 \\
\hline Challenges for carers & 0 & 0 \\
\hline Effect on carer of KC & 5 & 6 \\
\hline Emotional effects & 8 & 10 \\
\hline Fear of repeating cycles & 1 & 3 \\
\hline Finances & 1 & 2 \\
\hline Future & 1 & 1 \\
\hline Multiple caring roles & 5 & 8 \\
\hline Physical health & 2 & 5 \\
\hline Pre-existing relationship & 2 & 3 \\
\hline Relationship with birth parents & 12 & 29 \\
\hline Role confusion & 7 & 17 \\
\hline Sacrifice & 3 & 3 \\
\hline Challenges for SW & 5 & 7 \\
\hline Contact & 0 & 0 \\
\hline Changes to contact & 11 & 20 \\
\hline Effect of contact & 3 & 8 \\
\hline Contact promoting identity & 1 & 1 \\
\hline Influences on contact & 16 & 27 \\
\hline Negative contact & 10 & 12 \\
\hline Positive contact & 5 & 6 \\
\hline Supervising contact & 10 & 21 \\
\hline Supporting contact & 5 & 8 \\
\hline Unarranged contact & 12 & 23 \\
\hline Family & 16 & 32 \\
\hline Informal support & 5 & 11 \\
\hline Future & 6 & 10 \\
\hline Geographical proximity & 7 & 12 \\
\hline KC vs. MFC & 17 & 45 \\
\hline Commitment & 9 & 16 \\
\hline LA treatment & 1 & 1 \\
\hline Finances & 5 & 6 \\
\hline Formal support & 4 & 5 \\
\hline LA treatment of KC vs. MFC & 16 & 24 \\
\hline LAC label & 0 & 0 \\
\hline Benefits of LAC label & 5 & 7 \\
\hline Stigma of LAC label & 8 & 11 \\
\hline YP identifying as LAC & 3 & 3 \\
\hline Permanency & 18 & 30 \\
\hline Placement quality & 1 & 1 \\
\hline Priorities & 14 & 16 \\
\hline Repeating cycles & 3 & 4 \\
\hline SGO & 2 & 2 \\
\hline Benefits of SGO & 4 & 6 \\
\hline
\end{tabular}




\begin{tabular}{|l|l|l|}
\hline Belonging & 3 & 4 \\
\hline Normality & 7 & 11 \\
\hline Security and stability & 8 & 8 \\
\hline Concerns about SGO & 6 & 7 \\
\hline Deterrents to SGO app & 3 & 4 \\
\hline Financial & 9 & 12 \\
\hline Need of safety net & 14 & 27 \\
\hline Parents' concerns & 2 & 2 \\
\hline SGO causing role confusion & 2 & 2 \\
\hline Trauma & 1 & 2 \\
\hline Finances & 6 & 9 \\
\hline 'Misuse' of SGOs & 3 & 4 \\
\hline Motivators to SGO app & 5 & 6 \\
\hline Pushing for SGO & 17 & 35 \\
\hline Support after SGO & 9 & 19 \\
\hline SW influence on SGO apps & 13 & 14 \\
\hline Stability & 17 & 26 \\
\hline Voice of the child & 15 & 27 \\
\hline YP split loyalties & 1 & 1 \\
\hline
\end{tabular}




\section{Bibliography}

Aber, J. L., Bennett, N. G., Conley, D. C., \& Li, J. (1997). The effects of poverty on child health and development. Annual review of public health, 18(1), 463-483.

Abrams, D. E., \& Hogg, M. A. (1990). Social identity theory: Constructive and critical advances: Springer-Verlag Publishing.

Adaptation. (Ed.) (2011) Cambridge Dictionaries Online. Retrieved from http://dictionary.cambridge.org/dictionary/british/adaptation?q=adaptation

Ainsworth. (1979). Infant-mother attachment. American psychologist, 34(10), 932.

Ainsworth, M. D. S., \& Bell, S. M. (1970). Attachment, exploration, and separation: Illustrated by the behavior of one-year-olds in a strange situation. Child development, 49-67.

Ainsworth, M. S., \& Bowlby, J. (1991). An ethological approach to personality development. American psychologist, 46(4), 333.

Aldgate, J. (2009). Living in kinship care: A child-centred view. Adoption \& Fostering, 33(3), 51-63.

Aldgate, J., \& Mclntosh, M. (2006). Looking after the family: a study of children looked after in kinship care in Scotland: Social Work Inspection Agency Edinburgh.

Allen-Meares, P., \& Lane, B. A. (1990). Social work practice: Integrating qualitative and quantitative data collection techniques. Social Work, 35(5), 452-458.

Allen, M. (2003). Into the mainstream: Care leavers entering work, education and training.

Altruism [Def.2]. (2015). Oxford English Dictionary Online, Retrieved January 26, 2016 ,

from http://www.oed.com/view/Entry/5857?redirectedFrom=altruism\#eid.

Altshuler, S. J. (1997). A reveille for school social workers: Children in foster care need our help! Children \& Schools, 19(2), 121.

Angel, B. Ø., \& Blekesaune, M. (2017). Placement characteristics and stability: a longitudinal analysis of Norwegian children in foster homes. Child \& Family Social Work, 22(1), 236-245.

Antler, J., \& Antler, S. (1979). From child rescue to family protection: The evolution of the child protective movement in the United States. Children and Youth Services Review, 1(2), 177-204.

Armsden, G. C., \& Greenberg, M. T. (1987). The inventory of parent and peer attachment: Individual differences and their relationship to psychological well-being in adolescence. Journal of Youth and Adolescence, 16(5), 427454.

Arnon, S., \& Reichel, N. (2009). Closed and Open-Ended Question Tools in a Telephone Survey About "The Good Teacher" An Example of a Mixed Method Study. Journal of Mixed Methods Research, 3(2), 172-196. 
Ayre, P. (2001). Child protection and the media: Lessons from the last three decades. British Journal of Social Work, 31(6), 887-901.

Azuma, S. D., \& Chasnoff, I. J. (1993). Outcome of children prenatally exposed to cocaine and other drugs: A path analysis of three-year data. Pediatrics, 92(3), 396-402.

Backhouse, J., \& Graham, A. (2012). Grandparents raising grandchildren: negotiating the complexities of role-identity conflict. Child \& Family Social Work, 17(3), 306-315.

Bainham, A. (2007). Permanence for children: Special guardianship or adoption? The Cambridge Law Journal, 66(03), 520-523.

Bar-On, R. (1997). The BarOn Emotional Quotient Inventory (BarOn EQ-i). Toronto, ON: Multi-Health Systems Inc.

Barnett, D., \& Vondra, J. I. (1999). Chapter I. Atypical Patterns of Early Attachment: Theory, Research, and Current Directions. Monographs of the Society for Research in Child development, 64(3), 1-24.

Barrett, L., Dunbar, R., \& Lycett, J. (2002). Human evolutionary psychology: Princeton University Press.

Barth, R. P., \& Berry, M. (1988). Adoption and disruption: Rates, risks, and responses: Transaction Publishers.

Beckett, C., \& Horner, N. (2015). Essential theory for social work practice: Sage.

Benedict, M. I., Zuravin, S., \& Stallings, R. Y. (1996). Adult Functioning of Children Who Lived in Kin Versus Nonrelative Family Foster Homes. Child Welfare, 75(5), 529-549.

Bennett, L. A., Wolin, S. J., \& McAvity, K. J. (1988). Family identity, ritual, and myth: A cultural perspective on life cycle transitions. Family transitions: Continuity and change over the life cycle, 211-234.

Berrick, J. D. (1997). Assessing Quality of Care in Kinship and Foster Family Care. Family Relations: An Interdisciplinary Journal of Applied Family Studies, 46(3), 273-280.

Bhaskar, R. (2013). A realist theory of science: Routledge.

Biehal, N., Clayden, J., Stein, M., \& Wade, J. (1995). Moving on: Young people and leaving care schemes: HM Stationery Office.

Biehal, N., \& Wade, J. (1996). Looking back, looking forward: Care leavers, families and change. Children and Youth Services Review, 18(4-5), 425445.

Black, J. E., \& Greenough, W. T. (1986). Induction of pattern in neural structure by experience: Implications for cognitive development. Advances in developmental psychology, 4, 1-50.

Blehar, M. C., Lieberman, A. F., \& Ainsworth, M. D. S. (1977). Early face-to-face interaction and its relation to later infant-mother attachment. Child development, 182-194.

Boorse, C. (1977). Health as a theoretical concept. Philosophy of science, 542573.

Bowlby, J., Robertson, J., \& Rosenbluth, D. (1952). A two-year-old goes to the hospital. The Psychoanalytic Study of the Child.

Bradley, K., Logan, A., \& Shaw, S. (2009). Editorial: Youth and Crime: Centennial Reflections on the Children Act 1908. Crimes and Misdemeanours, 3(2), 1-17.

Braun, V., \& Clarke, V. (2006). Using thematic analysis in psychology. Qualitative research in psychology, 3(2), 77-101. 
Broad, B. (1998). Young people leaving care: Life after the Children Act 1989: Jessica Kingsley Publishers.

Broad, B. (2004). Kinship care for children in the UK: messages from research, lessons for policy and practice. European Journal of Social Work, 7(2), 211-227. doi:10.1080/1369145042000237463

Broad, B., Hayes, R., \& Rushforth, C. (2001). Kith and kin: Kinship care for vulnerable young people: NCB.

Bronfenbrenner, U. (1977). Toward an experimental ecology of human development. American psychologist, 32(7), 513.

Bronfenbrenner, U. (1979). The ecology of human development: Experiments by design and nature: Cambridge, MA: Harvard University Press.

Bronfenbrenner, U. (1992). Ecological systems theory: Jessica Kingsley Publishers.

Bronfenbrenner, U. (1994). Ecological models of human development. Readings on the development of children, 2, 37-43.

Brookover, W. B., Thomas, S., \& Paterson, A. (1964). Self-concept of ability and school achievement. Sociology of Education, 271-278.

Buchanan, A. (1998). Intergenerational Child Maltreatment. In Y. Danieli (Ed.), International Handbook of Multigenerational Legacies of Trauma (pp. 535552). Boston, MA: Springer US.

Burgess, C., Rossvoll, F., Wallace, B., \& Daniel, B. (2010). It's Just Like Another Home, Just Another Family, So It's Nae Different Children's Voices in Kinship Care: A Research Study About the Experience of Children in Kinship Care in Scotland. Child \& Family Social Work, 15(3), 297-306.

Burley, M., \& Halpern, M. (2001). Educational attainment of foster youth: Achievement and graduation outcomes for children in state care.

Buss, D. M. (2015). The Handbook of Evolutionary Psychology, Foundation (Vol. 1): John Wiley \& Sons.

Butler, I., \& Drakeford, M. (2003). Scandal Social Policy, Social Welfare and Scandal (pp. 1-5): Springer.

Calvin, E., Fenton, R., Lee, A., Pattison, B., Warner-King, K., \& Purbaugh, J. (2000). Make a difference in a child's life: A manual for helping children and youth get what they need in school. Team Child and Casey Family Programs, 1.

Carlson, E. A. (1998). A prospective longitudinal study of attachment disorganization/disorientation. Child development, 69(4), 1107-1128.

Carpenter, S. C., Clyman, R. B., Davidson, A. J., \& Steiner, J. F. (2001). The Association of Foster Care or Kinship Care with Adolescent Sexual Behavior and First Pregnancy. Pediatrics, 108(3).

Cassidy, J. (1994). Emotion regulation: Influences of attachment relationships. Monographs of the Society for Research in Child development, 59(2-3), 228-249.

Cavet, J., \& Sloper, P. (2004). The participation of children and young people in decisions about UK service development. Child Care Health Dev, 30(6), 613-621.

Chamberlain, P., Price, J. M., Reid, J. B., Landsverk, J., Fisher, P. A., \& Stoolmiller, M. (2006). Who disrupts from placement in foster and kinship care? Child Abuse Negl, 30(4), 409-424. doi:10.1016/j.chiabu.2005.11.004 
Chapman, M. V., Wall, A., \& Barth, R. P. (2004). Children's Voices: The Perceptions of Children in Foster Care. The American Journal of Orthopsychiatry, 74(3), 293-304.

Cheney, D. L., \& Seyfarth, R. M. (1992). How monkeys see the world: Inside the mind of another species: University of Chicago Press.

Chernoff, R., Combs-Orme, T., Risley-Curtiss, C., \& Heisler, A. (1994). Assessing the health status of children entering foster care. Pediatrics, 93(4), 594601.

Children Act, http://www.legislation.gov.uk/ukpga/1989/41/contents (1989).

Chopik, W. J., Edelstein, R. S., \& Fraley, R. C. (2013). From the cradle to the grave: Age differences in attachment from early adulthood to old age. Journal of personality, 81(2), 171-183.

Clausen, J. M., Landsverk, J., Ganger, W., Chadwick, D., \& Litrownik, A. (1998). Mental health problems of children in foster care. Journal of Child and Family Studies, 7(3), 283-296.

Cobb, S. (1976). Presidential Address-1976. Social support as a moderator of life stress. Psychosomatic medicine, 38(5), 300-314.

Coenjaerts, C., Ernst, C., Fortuny, M., Rei, D., \& Pilgrim, I. M. (2009). Youth employment. Promoting Pro-Poor Growth, 119.

Coleman, C. (2016). Foster care workers vote to form first ever trade union. http://www.bbc.com/news/uk-37411759.

Colman, A. M. (Ed.) (2003) Oxford Dictionary of Psychology. New York, United States: Oxford University Press Inc.

Colton, M. (2002). Factors associated with abuse in residential child care institutions. Children \& Society, 16(1), 33-44.

Colton, M., \& Heath, A. (1994). Attainment and behaviour of children in care and at home. Oxford Review of Education, 20(3), 317-327.

Cornell, T., \& Hamrin, V. (2008). Clinical interventions for children with attachment problems. Journal of Child and Adolescent Psychiatric Nursing, 21(1), 35-47.

Covington, M. V. (1989). Self-esteem and failure in school: Analysis and policy implications. The social importance of self-esteem, 72-124.

Creswell, J. W., \& Clark, V. L. P. (2007). Designing and conducting mixed methods research.

Cuddeback, G. S. (2004). Kinship Family Foster Care: A Methodological and Substantive Synthesis of Research. Children and Youth Services Review, 26(7), 623-639.

Daining, C., \& DePanfilis, D. (2007). Resilience of youth in transition from out-ofhome care to adulthood. Children and Youth Services Review, 29(9), 1158-1178.

Daly, M., \& Wilson, M. (1980). Discriminative parental solicitude: A biological perspective. Journal of Marriage and the Family, 277-288.

David, R., Blewitt, N., Johnston, E., \& Grazier, S. (2004). The Socio-Economic Characteristics of the South Wales Valleys in a Broader Context. Cardiff.

Dawda, D., \& Hart, S. D. (2000). Assessing emotional intelligence: Reliability and validity of the Bar-On Emotional Quotient Inventory (EQ-i) in university students. Personality and individual differences, 28(4), 797-812.

Dawkin, R. (1976). The selfish gene. Oxford University Press.

Deary, I. J., Strand, S., Smith, P., \& Fernandes, C. (2007). Intelligence and educational achievement. Intelligence, 35(1), 13-21. 
Department for Education. (2014). Statistical release: Children looked after in England (including adoption and care leavers) year ending 31 March 2014. . Available from: https://www.gov.uk/government/statistics/childrenlooked-after-in-england-including-adoption--2. Accessed [13/11/15].

Department for Education. (2016). Children looked after in England including adoption: 2015 to 2016. London.

DeVellis, R. F. (2012). Scale development: Theory and applications (Vol. 26): Sage publications.

DfE. (2017). What qualification levels mean - GOV.UK. Retrieved from https://www.gov.uk/what-different-qualification-levels-mean

DfES. (2003). Every Child Matters. Green Paper, Cm. 5860. London: The Stationary Office (TSO).

Dill, D. K. (2016). Evidence-Based Practice in Social Work: Development of a New Professional Culture, Haluk Soydan and Lawrence A. Palinkas: British Association of Social Workers.

Dollard, J., \& Miller, N. E. (1950). Personality and psychotherapy.

Donaldson, L. J., \& O'Brien, S. (1995). Press coverage of the Cleveland child sexual abuse enquiry: a source of public enlightenment? Journal of Public Health, 17(1), 70-76.

Dore, M. M., \& Kennedy, K. G. (1981). Two Decades of Turmoil: Child Welfare Services, 1960-1980. Child Welfare, 60(6).

Doyle Jr, J. J. (2007). Child protection and child outcomes: Measuring the effects of foster care. The American Economic Review, 97(5), 1583-1610.

Drakeford, M., \& Butler, I. (2007). Everyday tragedies: justice, scandal and young people in contemporary Britain. The Howard Journal of Criminal Justice, 46(3), 219-235.

Dubowitz, H., Feigelman, S., Zuravin, S., Tepper, V., Davidson, N., \& Lichenstein, R. (1992). The Physical Health of Children in Kinship Care. American Journal of Diseases of Children (1960), 146(5), 603-610.

Dubowitz, H., \& Sawyer, R. J. (1994). School Behavior of Children in Kinship Care Child Abuse Negl, 18(11), 899-911.

Dubowitz, H., Zuravin, S., Jr, S. R. H., Feigelman, S., \& Harrington, D. (1993). Behavior Problems of Children in Kinship Care. Journal of Developmental and Behavioral Pediatrics: JDBP, 14(6), 386-393.

Eberhard, M. J. W. (1975). The evolution of social behavior by kin selection. Quarterly Review of Biology, 1-33.

Education Act, (1996).

Egeland, B., \& Sroufe, L. A. (1981). Attachment and early maltreatment. Child development, 44-52.

Ehrle, J., \& Geen, R. (2002). Kin and Non-Kin Foster Care-Findings from a National Survey. Children and Youth Services Review, 24(1), 15-35.

Eichler, W. (2016). Foster care system in need of 'urgent attention', MPs say. http://www.localgov.co.uk/Foster-care-system-in-need-of-urgentattention-MPs-say/41806.

Elliott, M. (2017). "Looked-after" children in Wales: An analysis of the backgrounds of children entering public care. Cardiff University.

Emerson, R. (1960). From Empire to Nation. The Rise to Self-Assertion of Asian and African Peoples: Boston: Beacon Press. 
Ereshefsky, M. (2009). Defining 'health'and 'disease'. Studies in History and Philosophy of Science Part C: Studies in History and Philosophy of Biological and Biomedical Sciences, 40(3), 221-227.

ESRC. (2015). Framework for research ethics. http://www.esrc.ac.uk/aboutesrc/information/framework-for-research-ethics/.

Fanshel, D., \& Shinn, E. B. (1978). Children in foster care: A longitudinal investigation: Columbia University Press New York.

Farmer. (2010). What Factors Relate to Good Placement Outcomes in Kinship Care? British Journal of Social Work, 40(2), 426-444.

Farmer, \& Moyers. (2008). Kinship Care: Fostering effective family and friends placements: Jessica Kingsley Publishers.

Farmer, E. (2009). How Do Placements in Kinship Care Compare with Those in Non-kin Foster Care: Placement Patterns, Progress and Outcomes? Child \& Family Social Work, 14(3), 331-342.

Farmer, E., \& Moyers, S. (2005). Children placed with family and friends: placement patterns and outcomes. Executive Summary for the Department of Education and Skills, Bristol University, Bristol.

Farmer, E., Selwyn, J., \& Meakings, S. (2013). 'Other children say you're not normal because you don't live with your parents'. Children's views of living with informal kinship carers: social networks, stigma and attachment to carers. Child \& Family Social Work, 18(1), 25-34.

Faupel, A. (2003). Emotional Literacy: Assessment and Intervention. London: Nfer Nelson.

Fechter-Leggett, M. O., \& O'Brien, K. (2010). The Effects of Kinship Care on Adult Mental Health Outcomes of Alumni of Foster Care. Children and Youth Services Review, 32(2), 206-213.

Ferragina, E., Tomlinson, M., \& Walker, R. (2013). Poverty, Participation and Choice: The Legacy of Peter Townsend: Joseph Rowntree Foundation.

Fineman, M. A. (1998). What place for family privacy. Geo. Wash. L. Rev., 67, 1207.

Finzi, R., Ram, A., Har-Even, D., Shnit, D., \& Weizman, A. (2001). Attachment Styles and Aggression in Physically Abused and Neglected Children. Journal of Youth and Adolescence, 30(6), 769-786. doi:10.1023/a:1012237813771

Fischer, J. (1973). Is casework effective? A review. Social Work, 18(1), 5-20.

Fisher, C. R. (1979). Differences by age groups in health care spending. Health Care Financing Review, 1(4), 65-90.

Flynn, R. (2002). Kinship Foster Care. Child \& Family Social Work, 7(4), 311-322.

Font, S. A. (2014). Kinship and nonrelative foster care: The effect of placement type on child well-being. Child development, 85(5), 2074-2090.

Forrester, D., Goodman, K., Cocker, C., Binnie, C., \& Jensch, G. (2009). What is the impact of public care on children's welfare? A review of research findings from England and Wales and their policy implications. Journal of Social Policy, 38(03), 439-456.

Franklin, A., \& Sloper, P. (2006). Participation of disabled children and young people in decision making within social services departments: A survey of current and recent activities in England. British Journal of Social Work, 36(5), 723-741. 
Gambrill, E. (1999). Evidence-based practice: An alternative to authority-based practice. Families in Society: The Journal of Contemporary Social Services, 80(4), 341-350.

Garner, W. R., \& Hake, H. W. (1951). The amount of information in absolute judgments. Psychological Review, 58(6), 446.

Geen. (2004). The Evolution of Kinship Care Policy and Practice. The Future of Children / Center for the Future of Children, the David and Lucile Packard Foundation, 14(1), 130-149.

Giddens, A., Duneier, M., \& Appelbaum, R. P. (2003). Introduction to sociology: Norton.

Gilbertson, R., \& Barber, J. G. (2002). Obstacles to involving children and young people in foster care research. Child \& Family Social Work, 7(4), 253-258.

Goerge, R. M., Bilaver, L., Lee, B. J., Needell, B., Brookhart, A., \& Jackman, W. (2002). Employment outcomes for youth aging out of foster care. Chapin Hall Center for Children, University of Chicago.

Goodman, A., \& Goodman, R. (2012). Strengths and Difficulties Questionnaire scores and mental health in looked after children. The British Journal of Psychiatry, 200(5), 426-427.

Goodman, C. C., Potts, M. K., \& Pasztor, E. M. (2007). Caregiving grandmothers with vs. without child welfare system involvement: Effects of expressed need, formal services, and informal social support on caregiver burden. Children and Youth Services Review, 29(4), 428-441.

Goodman, R. (1997). The Strengths and Difficulties Questionnaire: a research note. Journal of Child Psychology and Psychiatry, 38(5), 581-586.

Goodman, R. (1999). The extended version of the Strengths and Difficulties Questionnaire as a guide to child psychiatric caseness and consequent burden. Journal of Child Psychology and Psychiatry, 40(05), 791-799.

Goodman, R. (2001). Psychometric properties of the strengths and difficulties questionnaire. Journal of the American Academy of Child \& Adolescent Psychiatry, 40(11), 1337-1345.

Goodman, R., Meltzer, H., \& Bailey, V. (1998). The Strengths and Difficulties Questionnaire: a pilot study on the validity of the self-report version. Eur Child Adolesc Psychiatry, 7(3), 125-130.

Goodman, R., \& Scott, S. (1999). Comparing the Strengths and Difficulties Questionnaire and the Child Behavior Checklist: is small beautiful? Journal of abnormal child psychology, 27(1), 17-24.

Gorrese, A., \& Ruggieri, R. (2012). Peer attachment: A meta-analytic review of gender and age differences and associations with parent attachment. Journal of Youth and Adolescence, 41(5), 650-672.

Government, W. (2014). Adoptions, Outcomes and Placements for Children Looked After by Local Authorities, Wales, 2012-13. Knowledge and Analytical Services, Welsh Government.

Gregg, P., \& Machin, S. (2000). The relationship between childhood experiences, subsequent educational attainment and adult labour market performance. Child Well Being in Modern Nations: What do we Know.

Grover, S. (2004). Why won't they listen to us? On giving power and voice to children participating in social research. Childhood, 11(1), 81-93.

Guilford, J. P. (1954). Psychometric methods. 
Gullone, E., \& Robinson, K. (2005). The Inventory of Parent and Peer Attachment-Revised (IPPA-R) for children: a psychometric investigation. Clinical Psychology \& Psychotherapy, 12(1), 67-79.

Haight, W. L., Kagle, J. D., \& Black, J. E. (2003). Understanding and Supporting Parent-Child Relationships during Foster Care Visits: Attachment Theory and Research. Soc Work, 48(2), 195-207.

Halfon, N., Mendonca, A., \& Berkowitz, G. (1995). Health status of children in foster care: The experience of the Center for the Vulnerable Child. Archives of Pediatrics \& Adolescent Medicine, 149(4), 386.

Hamilton, W. D. (1964a). The genetical evolution of social behaviour. I. Journal of Theoretical Biology, 7(1), 1-16.

Hamilton, W. D. (1964b). The genetical evolution of social behaviour. II. Journal of Theoretical Biology, 7(1), 17-52.

Haney, C., Banks, W., \& Zimbardo, P. (1973). Interpersonal dynamics in a simulated prison. International Journal of Criminology and Penology, 1, 69-97.

Hannon, C., Wood, C., \& Bazalgette, L. (2010). In Loco Parentis: "To deliver the best for looked after children, the state must be a confident parent . ...". London: Demos.

Harden, B. J. (2004). Safety and Stability for Foster Children: A Developmental Perspective. The Future of Children / Center for the Future of Children, the David and Lucile Packard Foundation, 14(1), 30-47.

Harlow, H. F., \& Zimmermann, R. R. (1958). The development of affectional responses in infant monkeys. Proceedings of the American Philosophical Society, 501-509.

Heineman, M. B. (1981). The obsolete scientific imperative in social work research. Social Service Review, 55(3), 371-397.

Heptinstall, E. (2000). Research note. Gaining access to looked after children for research purposes: lessons learned. British Journal of Social Work, 30(6), 867-872.

Herrick, M. A., \& Piccus, W. (2005). Sibling connections: The importance of nurturing sibling bonds in the foster care system. Children and Youth Services Review, 27(7), 845-861.

Higgins, J. R., Higgins, D., Bromfield, L., \& Richardson, N. (2007). Voices of Aboriginal and Torres Strait Islander children and young people in care: Australian Institute of Family Studies Melbourne.

Hill, C., \& Watkins, J. (2003). Statutory health assessments for looked-after children: what do they achieve? Child Care Health Dev, 29(1), 3-13.

Hill, M., \& Aldgate, J. (1996). Child welfare services: Developments in law, policy, practice, and research: Jessica Kingsley Publishers.

Hochstadt, N. J., Jaudes, P. K., Zimo, D. A., \& Schachter, J. (1987). The medical and psychosocial needs of children entering foster care. Child Abuse Negl, 11(1), 53-62.

Holland, S., Faulkner, A., \& Perez-del-Aguila, R. (2005). Promoting stability and continuity of care for looked after children: A survey and critical review. Child \& Family Social Work, 10(1), 29-41.

Holly, W. (1987). Self-esteem: Does it contribute to student's academic success. Eugene, OR: Oregon School Study Council, Univ. of Oregon.

Holtan, A. (2008). Family Types and Social Integration in Kinship Foster Care. Children and Youth Services Review, 30(9), 1022-1036. 
Holtan, A., Ronning, J. A., Handegard, B. H., \& Sourander, A. (2005). A Comparison of Mental Health Problems in Kinship and Nonkinship Foster Care. European Child \& Adolescent Psychiatry, 14(4), 200-207.

Holtan, A., Rønning, J. A., Handegård, B. H., \& Sourander, A. (2005). A Comparison of Mental Health Problems in Kinship and Nonkinship Foster Care. European Child \& Adolescent Psychiatry, 14(4), 200-207.

Home Office. (2011). Nature of Bicycle Theft. Crime Statistics, 20 October 2011. Howard, M. O., McMillen, C. J., \& Pollio, D. E. (2003). Teaching evidence-based practice: Toward a new paradigm for social work education. Research on Social Work Practice, 13(2), 234-259.

Howe, D., Kohli, R., Smith, M., Parkinson, C., McMahon, L., Solomon, R., . . . Fairtlough, A. (2018). Relationship-based social work: Getting to the heart of practice: Jessica Kingsley Publishers.

Hrabok, M., Brooks, B. L., Fay-McClymont, T. B., \& Sherman, E. M. (2014). Wechsler Intelligence Scale for Children-(WISC-IV) short-form validity: A comparison study in pediatric epilepsy. Child Neuropsychology, 20(1), 4959.

Hunt, J., Waterhouse, S., \& Lutman, E. (2008). Keeping them in the family: Outcomes for abused and neglected children placed with family or friends carers through care proceedings. Research Brief.

Hunt, J., Waterhouse, S., \& Lutman, E. (2010). Parental contact for children placed in kinship care through care proceedings. Child \& Fam. LQ, 22, 71.

Huskinson, T., Kostadintcheva, K., Greevy, H., Salmon, C., Dobie, S., Medien, K., . . SD'Souza, J. (2014). Childcare and early years survey of parents 2012-2013. Department for Education, SFR 06/2014.

Iglehart, A. P. (1994). Kinship Foster Care: Placement, Service, and Outcome Issues. Children and Youth Services Review, 16(1-2), 107-122.

Irby, S. M., \& Floyd, R. G. (2013). Test Review: Wechsler Abbreviated Scale of Intelligence. Canadian Journal of School Psychology, 28(3), 295-299.

Jacoby, J., \& Matell, M. S. (1971). Three-point Likert scales are good enough. Journal of Marketing Research, 495-500.

Jarrett, A. (2016). When I am ready policy and practice guidance. Report of the head of children and young people services. 7 April 2016. Retrieved from https://democracy.npt.gov.uk/ieListMeetings.aspx?Cld=132\&Year=2016:

Johnson-Garner, M. Y., \& Meyers, S. A. (2003). What Factors Contribute to the Resilience of African-American Children Within Kinship Care? Children \& Youth Care Forum, 32(5), 255-269.

Johnson, J. G., Cohen, P., Brown, J., Smailes, E. M., \& Bernstein, D. P. (1999). Childhood maltreatment increases risk for personality disorders during early adulthood. Archives of general psychiatry, 56(7), 600-606.

Jones, D. A., \& Peters, T. J. (1992). Caring for elderly dependants: effects on the carers' quality of life. Age Ageing, 21(6), 421-428.

Jones, O. (2012). Chavs: The demonization of the working class: Verso Books.

Kaler, S. R., \& Freeman, B. (1994). Analysis of environmental deprivation: Cognitive and social development in Romanian orphans. Journal of Child Psychology and Psychiatry, 35(4), 769-781.

Kelvin, P. (1981). Work as a source of identity: The implications of unemployment. British journal of guidance and counselling, 9(1), 2-11. 
Kerfoot, M., Panayiotopoulos, C., \& Harrington, R. (2004). Social services and CAMHS: A national survey. Child and Adolescent Mental Health, 9(4), 162-167.

Kinship [Def.1a]. (2015). Oxford English Dictionary Online, Retrieved January 26, 2016 , from http://www.oed.com/view/Entry/103585?redirectedFrom=kinship\&

Kinship [Def.1b]. (2015). Oxford English Dictionary Online, Retrieved January 26, 2016,

from http://www.oed.com/view/Entry/103585?redirectedFrom=kinship\&

Kiraly, M., \& Humphreys, C. (2013a). Family Contact for Children in Kinship Care: A Literature Review. Australian Social Work, 66(3), 358-374.

Kiraly, M., \& Humphreys, C. (2013b). Perspectives From Young People about Family Contact in Kinship Care:"Don't Push Us-Listen More". Australian Social Work, 66(3), 314-327.

Kiraly, M., \& Humphreys, C. (2016). 'It's about the whole family': family contact for children in kinship care. Child \& Family Social Work, 21(2), 228-239.

Kochanska, G. (1995). Children's temperament, mothers' discipline, and security of attachment: Multiple pathways to emerging internalization. Child development, 66(3), 597-615.

Kroll, B. (2007). A family affair? Kinship care and parental substance misuse: some dilemmas explored. Child \& Family Social Work, 12(1), 84-93.

Laerhoven, H. v., Zaag-Loonen, H. v. d., \& Derkx, B. (2004). A comparison of Likert scale and visual analogue scales as response options in children's questionnaires. Acta paediatrica, 93(6), 830-835.

Laird, J. (1979). An ecological approach to child welfare: Issues of family identity and continuity. Social work practice: People and environments, 174-209.

Laming, H. (2003). The Victoria climbie inquiry.

Lawrence, C. R., Carlson, E. A., \& Egeland, B. (2006). The impact of foster care on development. Development and Psychopathology, 18(01), 57-76.

Leathers, S. J. (2003). Parental Visiting, Conflicting Allegiances, and Emotional and Behavioral Problems among Foster Children. Family Relations, 52(1), 53-63.

Leslie, L. K., Gordon, J. N., Lambros, K., Premji, K., Peoples, J., \& Gist, K. (2005). Addressing the Developmental and Mental Health Needs of Young Children in Foster Care. J Dev Behav Pediatr, 26(2), 140-151.

Leslie, L. K., Gordon, J. N., Meneken, L., Premji, K., Michelmore, K. L., \& Ganger, W. (2005). The Physical, Developmental, and Mental Health Needs of Young Children in Child Welfare by Initial Placement Type. Journal of Developmental and Behavioral Pediatrics: JDBP, 26(3), 177-185.

Lewin, R. (1974). Accidental Career. New Scientist, 63(909), 325.

Lewis, M. (1998). Altering fate: Why the past does not predict the future. Psychological Inquiry, 9(2), 105-108.

Lichtenberger, E. O., \& Smith, D. R. (2005). Essentials Of Wiat-Il And Ktea-II Assessment (Vol. 48): John Wiley \& Sons.

Lindholm, B. W., \& Touliatos, J. (1980). Psychological adjustment of adopted and nonadopted children. Psychological Reports, 46(1), 307-310. 
Loopstra, R., Reeves, A., Taylor-Robinson, D., Barr, B., McKee, M., \& Stuckler, D. (2015). Austerity, sanctions, and the rise of food banks in the UK. BMJ (Clinical research ed), 350, h1775.

López López, M., del Valle, J. F., Montserrat, C., \& Bravo, A. (2011). Factors Affecting Foster Care Breakdown in Spain. Span J Psychol, 14(1), 111122.

Lyons-Ruth, K., Easterbrooks, M., \& Cibelli, C. D. (1997). Infant attachment strategies, infant mental lag, and maternal depressive symptoms: predictors of internalizing and externalizing problems at age 7 . Developmental psychology, 33(4), 681.

Lyons-Ruth, K., Alpern, L., \& Repacholi, B. (1993). Disorganized infant attachment classification and maternal psychosocial problems as predictors of hostile-aggressive behavior in the preschool classroom. Child development, 64(2), 572-585.

Macaskill, C. (2002). Safe Contact? Children in permanent placement and contact with their birth relatives. United Kingdom: Russell House Publishing Ltd.

Macionis, J., \& Plummer, K. (2009). Sociology: A global introduction.

Macleod, S., Hart, R., Jeffes, J., \& Wilkin, A. (2010). The Impact of the Baby Peter Case on Applications for Care Orders. Slough: NFER: the National Foundation for Educational Research.

Martins, C., \& Gaffan, E. A. (2000). Effects of early maternal depression on patterns of infant-mother attachment: A meta-analytic investigation. Journal of Child Psychology and Psychiatry, 41(6), 737-746.

Maxwell, J. A., \& Mittapalli, K. (2010). Realism as a stance for mixed methods research. Handbook of mixed methods in social \& behavioral research, 145-168.

Mc Grath-Lone, L., Dearden, L., Harron, K., Nasim, B., \& Gilbert, R. (2017). Factors associated with re-entry to out-of-home care among children in England. Child Abuse Negl, 63, 73-83.

McAuley, C., \& Young, C. (2006). The mental health of looked after children: challenges for CAMHS provision. Journal of Social Work Practice, 20(1), 91-103.

McCarthy, G., \& Taylor, A. (1999). Avoidant/ambivalent attachment style as a mediator between abusive childhood experiences and adult relationship difficulties. Journal of Child Psychology and Psychiatry, 40(3), 465-477.

McGuinness, F. (2015). Poverty in the UK: Statistics. House of Commons Library briefing paper(7096).

McLaughlin, K. A., Zeanah, C. H., Fox, N. A., \& Nelson, C. A. (2012). Attachment security as a mechanism linking foster care placement to improved mental health outcomes in previously institutionalized children. Journal of Child Psychology and Psychiatry, 53(1), 46-55.

McNeece, C. A., \& Thyer, B. A. (2004). Evidence-based practice and social work. Journal of Evidence-Based Social Work, 1(1), 7-25.

McSherry, D., Fargas, M., McLaughlin, K., Adams, C., O'Neill, N., Cole, J., \& Walsh, C. (2015). Mind Your Health: The Physical and Mental Health of Looked After Children and Young People in Northern Ireland. Queen's University Belfast, Office of the First Minister and Deputy First Minister. 
McSherry, D., Malet, M. F., \& Weatherall, K. (2016). Comparing long-term placements for young children in care: Does placement type really matter? Children and Youth Services Review, 69, 56-66.

McWey, L. M., Acock, A., \& Porter, B. (2010). The Impact of Continued Contact with Biological Parents upon the Mental Health of Children in Foster Care. Child Youth Serv Rev, 32(10), 1338-1345. doi:10.1016/j.childyouth.2010.05.003

Meltzer, H., Gatward, R., Goodman, R., \& Ford, T. (2003). Mental health of children and adolescents in Great Britain. International review of Psychiatry, 15(1-2), 185-187.

Merton, R. K. (1957). Manifest and latent functions.

Messing, J. T. (2006). From the Child's Perspective: A Qualitative Analysis of Kinship Care Placements. Children and Youth Services Review, 28(12), 1415-1434.

Metzger, J. (2008). Resiliency in Children and Youth in Kinship Care and Family Foster Care. Child Welfare, 87(6), 115-140.

Miller, N., \& Lewis, K. (2011). National Survey of Adult Skills in Wales 2010. $27 / 2011$.

Miller, W. R., \& Seligman, M. E. (1975). Depression and learned helplessness in man. Journal of abnormal psychology, 84(3), 228.

Minnis, H., Everett, K., Pelosi, A. J., Dunn, J., \& Knapp, M. (2006). Children in foster care: Mental health, service use and costs. Eur Child Adolesc Psychiatry, 15(2), 63-70.

Moffatt, S., Lawson, S., Patterson, R., Holding, E., Dennison, A., Sowden, S., \& Brown, J. (2015). A qualitative study of the impact of the UK 'bedroom tax'. Journal of Public Health, 38(2), 197-205.

Montgomery, S. M., Bartley, M. J., Cook, D. G., \& Wadsworth, M. E. (1996). Health and social precursors of unemployment in young men in Great Britain. J Epidemiol Community Health, 50(4), 415-422.

Montserrat, C. (2014). Kinship care in Spain: Messages from research. Child \& Family Social Work, 19(3), 367-376.

Mooney, A. (2009). Promoting the health of looked after children: a study to inform revision of the 2002 guidance.

Morgan, R. (2014). The children's views digest. Retrieved from Manchester:

Mount, J., Lister, A., \& Bennun, I. (2004). Identifying the mental health needs of looked after young people. Clin Child Psychol Psychiatry, 9(3), 363-382.

Mullen, E. J., \& Dumpson, J. R. (1972). Evaluation of social intervention: JosseyBass San Francisco.

Munby, J. (2016). 15th View from the President's Chambers: care cases: the looming crisis. Family law, 46(10), 1227-1231.

Murdock, G. P. (1949). Social structure.

Nandy, S., Selwyn, J., Farmer, E., \& Vaisey, P. (2011). Spotlight on kinship care. Using Census microdata to examine the extent and nature of kinship care in the UK. Final report. Bristol: University of Bristol.

National Foster Care Association. (1997). Foster Care in Crisis: A call to professionalise the forgotten service. London, NFCA.

Neil, E. C., \& Howe, D. (2004). Contact in adoption and permanent foster care: Research, theory and practice: British Association for Adoption and Fostering (BAAF). 
NHS.

(2013).

http://www.nhs.uk/Livewell/dentalhealth/Pages/Dentalcheckups.aspx.

Nowak, M. A., Tarnita, C. E., \& Wilson, E. O. (2010). The evolution of eusociality. Nature, 466(7310), 1057-1062.

NSPCC. (2014). Assessing Parenting Capacity: An NSPCC Factsheet https://www.nspcc.org.uk/globalassets/documents/informationservice/factsheet-assessing-parenting-capacity.pdf. Accessed 20/3/15.

O'Brien, V. (2012). The Benefits and Challenges of Kinship Care. Child Care in Practice, 18(2), 127-146.

O'Sullivan, A., \& Westerman, R. (2007). Closing the gap: investigating the barriers to educational achievement for looked after children. Adoption \& Fostering, 31(1), 13-20.

Obegi, J. H., Morrison, T. L., \& Shaver, P. R. (2004). Exploring intergenerational transmission of attachment style in young female adults and their mothers. Journal of Social and Personal Relationships, 21(5), 625-638.

Office for National Statistics. (2016). Compendium: Intimate personal violence and partner abuse. Available online: https://www.ons.gov.uk/peoplepopulationandcommunity/crimeandjustice/ compendium/focusonviolentcrimeandsexualoffences/yearendingmarch20 15/chapter4intimatepersonalviolenceandpartnerabuse\#reporting [Accessed 7.2.17].

Olsen, F. E. (1984). The myth of state intervention in the family. U. Mich. JL Reform, 18, 835.

Osterling, K. L., \& Hines, A. M. (2006). Mentoring adolescent foster youth: Promoting resilience during developmental transitions. Child \& Family Social Work, 11(3), 242-253.

Parrish, T., Dubois, J., Delano, C., Dixon, D., Webster, D., Berrick, J. D., \& Bolus, S. (2001). Education of foster group home children, whose responsibility is it. Study of the educational placement of children residing in group homes_Final report.

Parsons, T. (2013). Social system: Routledge.

Paxman, M. (2006). Outcomes for Children and Young People in Kinship Care: An Issues Paper: Centre for Parenting \& Research, Research Funding \& Business Analysis Division, NSW Department of Community Services.

Pecora, P. J., Kessler, R. C., O'Brien, K., White, C. R., Williams, J., Hiripi, E., . . . Herrick, M. A. (2006). Educational and employment outcomes of adults formerly placed in foster care: Results from the Northwest Foster Care Alumni Study. Children and Youth Services Review, 28(12), 1459-1481.

Peile, C. (1988). Research paradigms in social work: From stalemate to creative synthesis. The Social Service Review, 1-19.

Perry, G., Daly, M., \& Kotler, J. (2012). Placement Stability in Kinship and Nonkin Foster Care: A Canadian Study. Children and Youth Services Review, 34(2), 460-465.

Perry, J. (2002). Identity, personal identity, and the self: Hackett Publishing.

Pierson, J. (2011). Understanding Social Work: History And Context: History and Context: McGraw-Hill Education.

Pilowsky, D. (1995). Psychopathology among children placed in family foster care. Psychiatric services.

Pope, W. (1975). Durkheim as a Functionalist. Sociological Quarterly, 361-379. 
Pratchett, R. C., \& Rees, P. (2017). 3 Theories underpinning kinship care. Children, Young People and Care, 44.

Pratchett, R. C., \& Rees, P. (In Press). Exploring the educational attainment and achievement of looked after children in formal kinship care. In D. Mannay, A. Rees, \& L. Roberts (Eds.), Children and Young People 'Looked After'? Education, Intervention and the Everyday Culture of Care in Wales. Cardiff: University of Wales Press.

Qvortrup, J., Bardy, M., Sgritta, G., \& Wintersberger, H. (1994). Childhood matters: Social theory, practice and politics: Avebury.

Rebok, G., Riley, A., Forrest, C., Starfield, B., Green, B., Robertson, J., \& Tambor, E. (2001). Elementary school-aged children's reports of their health: a cognitive interviewing study. Quality of Life Research, 10(1), 5970.

Rees, P. (2010). State Dilemmas in the Provision of Alternative Care for Children: Relative Efficacy of Public Sector and Independent Sector Foster Placements. International Journal of Public Administration, 33(6), 325334.

Rees, P. (2013). The mental health, emotional literacy, cognitive ability, literacy attainment and 'resilience'of 'looked after children': A multidimensional, multiple-rater population based study. British Journal of Clinical Psychology, 52(2), 183-198.

Rees, P., \& Holding, M. (2013). The health literacy of children who are'looked after'by the state. Paper presented at the Nova Science Publishers, Inc.

Reilly, T. (2003). Transition from care: status and outcomes of youth who age out of foster care. Child Welfare: Journal of Policy, Practice, and Program.

Rink, E., \& Tricker, R. (2003). Resiliency-based research and adolescent health behaviors. Prevention Researcher, 10(1).

Roche, J. (1999). Children: Rights, participation and citizenship. Childhood, 6(4), 475-493.

Roffey, S. (2008). Emotional literacy and the ecology of school wellbeing. Educational and child psychology, 25(2), 29-39.

Rosenfeld, A. A., Pilowsky, D. J., Fine, P., Thorpe, M., Fein, E., Simms, M. D., .. . Saletsky, R. (1997). Foster care: An update. Journal of the American Academy of Child \& Adolescent Psychiatry, 36(4), 448-457.

Rubin, D. M., Alessandrini, E. A., Feudtner, C., Mandell, D. S., Localio, A. R., \& Hadley, T. (2004). Placement stability and mental health costs for children in foster care. Pediatrics, 113(5), 1336-1341.

Rubin, D. M., O'Reilly, A. L., Luan, X., \& Localio, A. R. (2007). The impact of placement stability on behavioral well-being for children in foster care. Pediatrics, 119(2), 336-344.

Ryan, J. P., \& Testa, M. F. (2005). Child maltreatment and juvenile delinquency: Investigating the role of placement and placement instability. Child Youth Serv Rev, 27(3), 227-249.

Sakai, C., Lin, H., \& Flores, G. (2011). Health Outcomes and Family Services in Kinship Care: Analysis of a National Sample of Children in the Child Welfare System. Archives of Pediatrics \& Adolescent Medicine, 165(2), 159-165. doi:10.1001/archpediatrics.2010.277

Sands, R. G., Goldberg-Glen, R. S., \& Shin, H. (2009). The voices of grandchildren of grandparent caregivers: a strengths-resilience perspective. Child Welfare, 88(2). 
Sawyer, R. J., \& Dubowitz, H. (1994). School Performance of Children in Kinship Care. Child Abuse Negl, 18(7), 587-597.

Scannapieco, M., \& Jackson, S. (1996). Kinship care: the African American response to family preservation. Soc Work, 41(2), 190-196.

Scheirer, M. A., \& Kraut, R. E. (1979). Increasing educational achievement via self concept change. Review of educational research, 49(1), 131-149.

Scherr, T. G. (2007). Educational Experiences of Children in Foster Care MetaAnalyses of Special Education, Retention and Discipline Rates. School Psychology International, 28(4), 419-436.

Schofield, G. (2002). The significance of a secure base: a psychosocial model of long-term foster care. Child \& Family Social Work, 7(4), 259-272.

Scott, D. (2006). Research Article 1: Towards a public health model of child protection in Australia. Communities, Children and Families Australia, 1(1), 9.

Scottish Government. (2015). Children's Social Work Statistics Scotland, 201314., Edinburgh: Scottish Government.

Scottish Government. (2016). National Guidance on Part 13 of the Children and Young People (Scotland) Act 2014: Support for Kinship Care

Secretary of State for Social Services. (1974). Report of the Committee of Inquiry into the Care and Supervision Provided in Relation to Maria Colwell. Retrieved from HMSO: London:

Seligman, M. E., \& Maier, S. F. (1967). Failure to escape traumatic shock. Journal of experimental psychology, 74(1), 1.

Sellgren, K. (2010). Baby Peter 'was failed by all agencies'. BBC News. Retrieved from http://www.bbc.co.uk/news/education-11621391

Sellick, C., Thoburn, J., \& Philpot, T. (2004). What works in adoption and foster care? : Barnardo's llford.

Selwyn, J. (2009). EP19 Kinship Care from NICE guideline PH28. Retrieved from https://www.nice.org.uk/guidance/ph28 on 17/2/16.:

Selwyn, J., Farmer, E., Meakings, S., \& Vaisey, P. (2013). The Poor Relations? Children and Informal Kinship Carers Speak Out. In U. o. B. School for Policy Studies (Ed.). Bristol: University of Bristol Print Services.

Selwyn, J., \& Masson, J. (2014). Adoption, special guardianship and residence orders: a comparison of disruption rates. Differences, 10(11), 12.

Selwyn, J., \& Nandy, S. (2012). Sibling Kinship Carers in England: Evidence from the 2001 UK Population Census. Children and Youth Services Review, 34(1), 194-199.

Selwyn, J., Wijedasa, D., \& Meakings, S. (2014). Beyond the Adoption Order: challenges, interventions and adoption disruption.

Sen, R., \& Broadhurst, K. (2011). Contact Between Children in Out-of-home Placements and Their Family and Friends Networks: A Research Review. Child \& Family Social Work, 16(3), 298-309.

Shannon-Baker, P. (2016). Making paradigms meaningful in mixed methods research. Journal of Mixed Methods Research, 10(4), 319-334.

Simms, M. D. (1989). The foster care clinic: a community program to identify treatment needs of children in foster care. Journal of Developmental \& Behavioral Pediatrics, 10(3), 121-128.

Simms, M. D., Dubowitz, H., \& Szilagyi, M. A. (2000). Health care needs of children in the foster care system. Pediatrics, 106(Supplement 3), 909918. 
Sinclair, R. (2004). Participation in practice: Making it meaningful, effective and sustainable. Children \& Society, 18(2), 106-118.

Smith, R. E., \& Smoll, F. L. (1990). Self-esteem and children's reactions to youth sport coaching behaviors: A field study of self-enhancement processes. Developmental psychology, 26(6), 987.

Social Services and Wellbeing Act, http://www.senedd.assemblywales.org/mglssueHistoryHome.aspx? Ild=5 $\underline{664}$ (2014).

Spencer, C., Sanders, C., \& DeBlois, D. (2002). Lilo and Stitch: Motion picture. USA: Walt Disney Pictures.

Spreen, O., \& Strauss, E. (1991). A Compendium of Neuropsychological Tests: Administration, Norms and Commentary. New York: Oxford University Press.

Stability. (2014). In Cambridge Dictionaries Online. Retrieved from http://dictionary.cambridge.org/dictionary/british/.

Statistics, O. f. N. (2010). Harmonised Concepts and Questions for Social Data Sources: Secondary standards. Version 3.1. In O. f. N. Statistics (Ed.).

StatsWales. (2016a). Children looked after by local authorities in foster placements, at 31 March 2016. Cardiff: Welsh Government. Retrieved from: $\quad$ https://statswales.gov.wales/Catalogue/Health-and-SocialCare/Social-Services/Childrens-Services/Children-Looked-

After/childrens-services-children-looked-afterchildrenlookedafterinfosterplacementsat31march-by-localauthorityplacementtype

StatsWales. (2016b). Episodes finishing for looked after children, by reason for finishing, year ending 31 March. Cardiff.

StatsWales. (2017a). Average (mean) gross weekly earnings by UK country English region and year $(£)$.

StatsWales. (2017b). Episodes finishing for children looked after during year to 31 March by local authority and reason for finishing 2016.

Stein, M. (2006). Research review: Young people leaving care. Child \& Family Social Work, 11(3), 273-279.

Stein, M., Wade, J., \& Britain, G. (2000). Helping care leavers: problems and strategic responses: Department of Health London.

Steiner, C. (1984). Emotional literacy. Transactional Analysis Journal, 14(3), 162173.

Stevenson, O. (1998). It was more difficult than we thought: a reflection on 50 years of child welfare practice. Child \& Family Social Work, 3(3), 153-161.

Stott, T., \& Gustavsson, N. (2010). Balancing permanency and stability for youth in foster care. Children and Youth Services Review, 32(4), 619-625.

Strijker, J., Zandberg, T., \& van der Meulen, B. F. (2003). Kinship foster care and foster care in the Netherlands. Children and Youth Services Review, 25(11), 843-862.

Strozier, A., \& et, a. (2005). Kinship care connection: a school-based intervention for kinship caregivers and the children in their care. Child Youth Serv Rev, 27(9), 1011-1029.

Suh, E. M. (2002). Culture, identity consistency, and subjective well-being. Journal of personality and social psychology, 83(6), 1378.

Sullivan, O. (2000). The division of domestic labour: twenty years of change? Sociology, 34(3), 437-456. 
Szilagyi, M. (1998). The pediatrician and the child in foster care. Pediatr Rev, 19, 39-50.

Tajfel, H., \& Billig, M. (1974). Familiarity and categorization in intergroup behavior. Journal of Experimental Social Psychology, 10(2), 159-170.

Tajfel, H., Billig, M. G., Bundy, R. P., \& Flament, C. (1971). Social categorization and intergroup behaviour. European journal of social psychology, 1(2), 149-178.

Tan, S. (2000). Friends and relative care: the neglected carers. Unpublished dissertation for the PQ Award in Social Work (London, Brunel University, 2000).

Tarren-Sweeney, M., \& Hazell, P. (2006). Mental Health of Children in Foster and Kinship Care in New South Wales, Australia. Journal of Paediatrics and Child Health, 42(3), 89-97.

Tashakkori, A., \& Teddlie, C. (2010). Sage handbook of mixed methods in social $\&$ behavioral research: Sage.

Taussig, H. N., \& Clyman, R. B. (2011). The Relationship Between Time Spent Living with Kin and Adolescent Functioning in Youth with a History of Outof-home Placement. Child Abuse \& Neglect, 35(1), 78-86. doi:10.1016/j.chiabu.2010.09.001

Teater, B., Devaney, J., Forrester, D., Scourfield, J., \& Carpenter, J. (2016). Quantitative Research Methods for Social Work: Making Social Work Count: Palgrave Macmillan.

Terling-Watt, T. (2001). Permanency in Kinship Care: An Exploration of Disruption Rates and Factors Associated with Placement Disruption. Children and Youth Services Review, 23(2), 111-126.

Ternay, M. R., Wilborn, B., \& Day, H. (1985). Perceived child-parent relationships and child adjustment in families with both adopted and natural children. The Journal of genetic psychology, 146(2), 261-272.

Testa, M. F. (2001). Kinship Care and Permanency. Journal of Social Service Research, 28(1), 25-43.

Testa, M. F., Shook, K. L., Cohen, L. S., \& Woods, M. G. (1996). Permanency planning options for children in formal kinship care. Child Welfare, 75(5), 451-470.

Teti, D. M., Gelfand, D. M., Messinger, D. S., \& Isabella, R. (1995). Maternal depression and the quality of early attachment: An examination of infants, preschoolers, and their mothers. Developmental psychology, 31(3), 364.

Tilbury, C. (2009). The over-representation of indigenous children in the Australian child welfare system. International Journal of Social Welfare, 18(1), 57-64.

Townsend, P. (1979). Poverty in the United Kingdom: a survey of household resources and standards of living: Univ of California Press.

Toyama, M. (2001). Adaptive advantages of matriphagy in the foliage spider, Chiracanthium japonicum (Araneae: Clubionidae). Journal of Ethology, 19(2), 69-74.

Trickett, P. K., \& McBride-Chang, C. (1995). The developmental impact of different forms of child abuse and neglect. Developmental Review, 15(3), 311-337.

Triseliotis, J. (1983). Identity and security in adoption and long-term fostering. Adoption \& Fostering, 7(1), 22-31. 
Triseliotis, J. (2002). Long-term foster care or adoption? The evidence examined. Child \& Family Social Work, 7(1), 23-33.

Triseliotis, J. (2010). Contact between looked after children and their parents: A level playing field? Adoption \& Fostering, 34(3), 59-66.

Tucker, D. J., Hurl, L. F., \& Ford, H. (1994). Applying organizational ecology to the family: The case of who persists in providing foster care. Journal of Marriage and the Family, 1005-1018.

Turiel, E. (1998). The development of morality. Handbook of child psychology.

Turnell, A. (1998). Aspiring to partnership; The Signs of Safety Approach to Child Protection or Reflections on the road toward a comprehensive partnership practice for child protection casework. Paper presented at the Twelfth International Congress on Child Abuse and Neglect in Auckland, September.

UNCRC, http://www.unicef.org/crc/ (1989).

Vanschoonlandt, F., Vanderfaeillie, J., Van Holen, F., De Maeyer, S., \& Andries, C. (2012). Kinship and non-kinship foster care: Differences in contact with parents and foster child's mental health problems. Children and Youth Services Review, 34(8), 1533-1539. doi:10.1016/j.childyouth.2012.04.010

Viner, R. M., \& Taylor, B. (2005). Adult health and social outcomes of children who have been in public care: population-based study. Pediatrics, 115(4), 894-899.

Wade, J., Sinclair, I. A. C., Stuttard, L., \& Simmonds, J. (2014). Investigating Special Guardianship: experiences, challenges and outcomes.

Wakefield, J. C. (1992). The concept of mental disorder: on the boundary between biological facts and social values. American Psychologist, 47(3), 373.

Walpole, M. (2003). Socioeconomic status and college: How SES affects college experiences and outcomes. The review of higher education, 27(1), 45-73.

Walz, G. R., \& Bleuer, J. C. (1992). Student Self-Esteem: A Vital Element of School Success. Volume 1: ERIC.

Warren, T. (2003). Classand gender-based working time? Time poverty and the division of domestic labour. Sociology, 37(4), 733-752.

Waterhouse. (2000). Report of the Tribunal of the Inquiry into the abuse of children in care in the former county council areas of Gwynedd and Clwyd since 1974, Lost in Care. Retrieved from

Waugh, I. (2014). Section three of Children's social care statistics Northern Ireland 2013/14, Belfast: Department of Health, Social Services and Public Safety.

Webb, S. A. (2001). Some considerations on the validity of evidence-based practice in social work. British Journal of Social Work, 31(1), 57-79.

Webster, D., Barth, R. P., \& Needell, B. (2000). Placement Stability for Children in Out-of-home Care: A Longitudinal Analysis. Child Welfare, 79(5), 614632.

Wechsler, D. (2005). Wechsler Individual Achievement Test (WIAT-II UK): Harcourt Assessment.

Weiss, E. L., Longhurst, J. G., \& Mazure, C. M. (1999). Childhood sexual abuse as a risk factor for depression in women: psychosocial and neurobiological correlates. American Journal of Psychiatry, 156(6), 816-828. 
Welsh Government. (2015). Children in need at 31 March by looked after status, category of need and disability, including unborn children., Cardiff: StatsWales.

Werner, E. E. (1984). Research in review: Resilient children. Young Children, 40, 68-72.

Westacott, J. (1988). Bridge to Calmer Waters: A Study of a Bridge Families Scheme: a Model of Specialist Fostering for the Middle Age Range Child Providing Preparation for a New Permanent Placement and Assessment After a Placement Disruption: Dr. Barnardo's, London Divisional Office.

WHO. (1948). Preamble to the Constitution of the World Health Organization as adopted by the International Health Conference, New York, 19-22 June, 1946; signed on 22 July 1946 by the representatives of 61 States (Official Records of the World Health Organization, no. 2, p. 100) and entered into force on 7 April 1948., 2.

Williams, G. C. (1966). Adaptation and Natural Selection: A Critique of Some Current Evolutionary Thought: Princeton University Press.

Willis, R., \& Holland, S. (2009). Life story work: Reflections on the experience by looked after young people. Adoption \& Fostering, 33(4), 44-52.

Winnicott, D. W. (1969). Transitional objects and transitional phenomena. A study of the first not-me possession. Psyche, 23(9), 666-682.

Winokur, M., Crawford, G., Longobardi, R., \& Valentine, D. (2008). Matched comparison of children in kinship care and foster care on child welfare outcomes. Families in Society: The Journal of Contemporary Social Services, 89(3), 338-346.

Winokur, M., Holtan, A., Batchelder, K. E., \& Winokur, M. (2014). Kinship Care for the Safety, Permanency, and Well-being of Children. Permanency, and Well-being of Children Removed from the Home for Maltreatment: A Systematic Review Campbell Systematic Reviews, 2.

York, W., \& Jones, J. (2017). Addressing the mental health needs of looked after children in foster care: the experiences of foster carers. Journal of Psychiatric and Mental Health Nursing, 24(2-3), 143-153.

Zayed, Y., \& Harker, R. (2015). Children in care in England: statistics. 